University of Louisville

ThinkIR: The University of Louisville's Institutional Repository

Electronic Theses and Dissertations

$5-2014$

\title{
Harbormaster command and control (HCCC) shelter : finite element model and structural analysis.
}

Justin Daniel Watson 1983-

University of Louisville

Follow this and additional works at: https://ir.library.louisville.edu/etd

\section{Recommended Citation}

Watson, Justin Daniel 1983-, "Harbormaster command and control (HCCC) shelter : finite element model and structural analysis." (2014). Electronic Theses and Dissertations. Paper 1537.

https://doi.org/10.18297/etd/1537

This Master's Thesis is brought to you for free and open access by ThinkIR: The University of Louisville's Institutional Repository. It has been accepted for inclusion in Electronic Theses and Dissertations by an authorized administrator of ThinkIR: The University of Louisville's Institutional Repository. This title appears here courtesy of the author, who has retained all other copyrights. For more information, please contact thinkir@louisville.edu. 
HARBORMASTER COMMAND AND CONTROL (HCCC) SHELTER: FINITE ELEMENT MODEL AND STRUCTURAL ANALYSIS

\author{
By \\ Justin Daniel Watson \\ B.S., University of Louisville, Kentucky, 2006
}

\begin{abstract}
A Thesis
Submitted to the Faculty of the

University of Louisville

J.B. Speed School of Engineering as Partial Fulfillment of the Requirements

for the Professional Degree
\end{abstract}

MASTER OF ENGINEERING

Department of Mechanical Engineering

May 2014 

HARBORMASTER COMMAND AND CONTROL (HCCC) SHELTER: FINITE ELEMENT MODEL AND STRUCTURAL ANALYSIS

\author{
Submitted by:
}

Justin Daniel Watson

A Thesis Approved on

(Date)

by the Following Reading and Examination Committee

Roger D. Bradshaw, Thesis Director

Thomas A. Berfield

Young Hoon Kim 


\section{DEDICATION}

This thesis is dedicated to my parents, Julie and Chester Watson, for all their love and support.

And also to my amazing wife, Erin.

Without you, I never would have finished this. 


\section{ACKNOWLEDGMENTS}

I am extremely grateful to Dr. Roger Bradshaw; I cannot thank him enough for granting me my research position and for his support and patience over the years. My thanks go out to my fellow research assistants, Kelley McCoy, Jon Mandt, Paul Long, and Jeff Borden; you guys were great to work with. I thank the U.S. Army for funding this project. I also thank the crew at Kentucky Trailers for their help throughout the project, especially Larry Hartog, Justin Tuscherer, Brooks Boughton, and Wally Wallace.

Lastly, I express my gratitude to Scott Cambron and Jeff Davis for talking me into staying in Speed School when I was struggling early on. You guys rock. 


\begin{abstract}
The Harbormaster Command and Control Center (HCCC) project provides mobile platforms intended to control harbor operations. The main component of the HCCC is a double-expandable shelter mounted on a 5 ton military flatbed truck. Kentucky Trailer Corporation manufactured a baseline shelter using standard materials (aluminum, steel, plywood, etc.) and also considered alternate designs using composite materials (carbon fiber laminates, glass fiber laminates, composite sandwich configurations, etc.).

Two faculty members and several graduate students in the Department of Mechanical Engineering at the University of Louisville participated in this effort, primarily in terms of material selection, structural analysis, and design approaches. This thesis presents one portion of that work. This consists of a finite element model (FEM) of the HCCC using standard materials. This model was constructed to match the design proposed and later built and delivered by Kentucky Trailer. The thesis also presents two structural analysis simulations performed using the HCCC FEM.

The HCCC FEM was built using ANSY Mechanical APDL. This software utilizes text-based "input files" to build, analyze and post-process the HCCC FEM entirely without user assistance. The author generated these input files to create the HCCC FEM
\end{abstract}


structure using 3D beam elements, layered shell elements, and point mass elements. This approach represented a simplification to eliminate the need for more computationally intensive 3D solid elements; it also provides a simpler approach for changing the model as design changes occur. For example, the thickness of an aluminum plate in the HCCC FEM model is represented as a number that can be easily changed; for a 3D solid element model, revisions would involve changing solid model entities such as volumes and areas followed by remeshing. This is feasible in a small model but impractical in a large complex model such as the HCCC FEM.

The HCCC FEM is constructed in a modular manner, with different models representing the roof, sides, rear and front, floor and both expandable sections. These various submodels are joined together using constraint equations to cause identical displacements and rotations along common boundaries between models. This also permitted scenarios such as analysis with the expandables retracted or expanded. Contact elements are used to simulate support of the HCCC FEM along is bottom by a rigid boundary simulating the truck bed carrying the HCCC. The HCCC FEM is a nonlinear model due to both the contact elements and the ability to solve in cases of arbitrarily large displacement needed for dynamic analysis.

Two analyses using the HCCC FEM are presented. The first is a static analysis under various constant inertial (acceleration) loads to demonstrate that the structure is worthy for air transport using a C-17 aircraft. The second is a dynamic analysis simulating the structural response during a rail impact; this occurs when the HCCC is mounted on a rail car which then collides with another rail car. Both analyses were beneficial in demonstrating that the HCCC design performs sufficiently well in service. 


\section{TABLE OF CONTENTS}

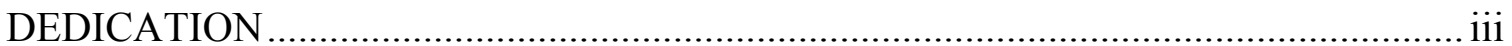

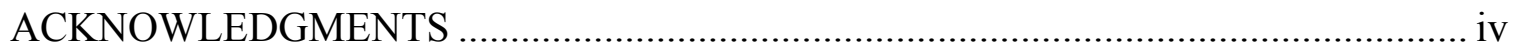

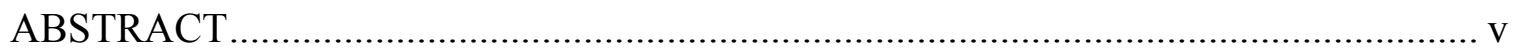

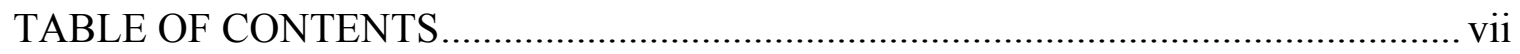

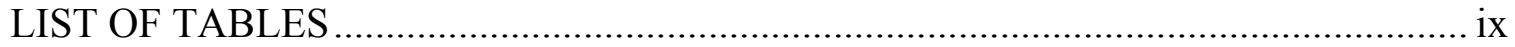

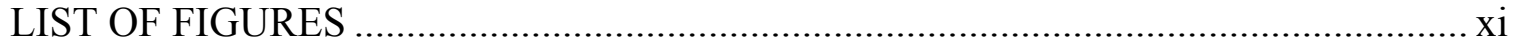

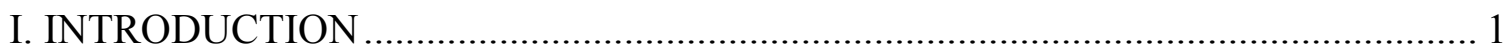

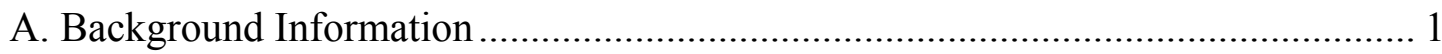

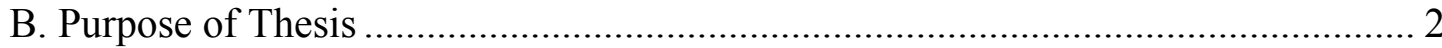

C. Collaborators, Reports and Funding .................................................................... 2

II. BASIC FEATURES OF HCCC FINITE ELEMENT MODEL (FEM) ……............... 4

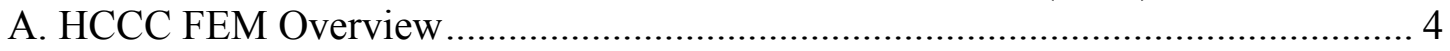

B. Converting AutoCAD / Inventor Models to ANSYS ........................................... 10

C. Overview of ANSYS Elements and Usage in HCCC FEM.................................... 13

D. Modular Construction of HCCC FEM Model .................................................... 14

E. ANSYS Input Files and Usage for HCCC FEM ………..................................... 17

F. Material Stiffness and Density Properties …………………………………….... 17

III. DETAILED DESCRIPTIONS OF EACH HCCC FEM SECTION............................ 19

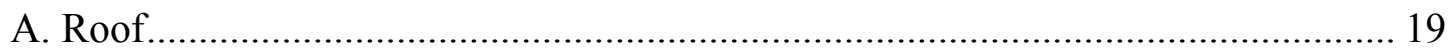

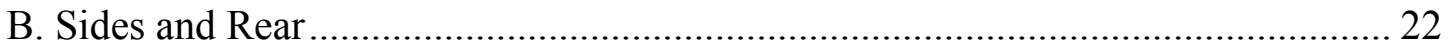

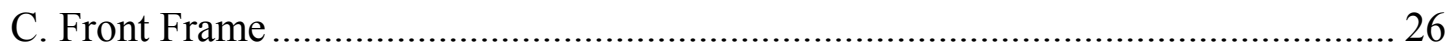

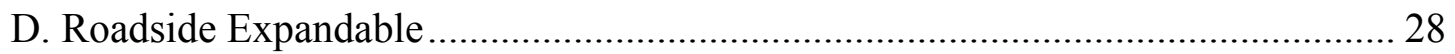

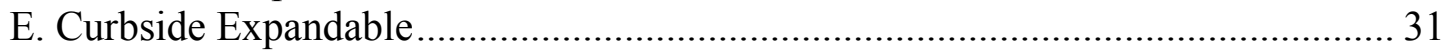

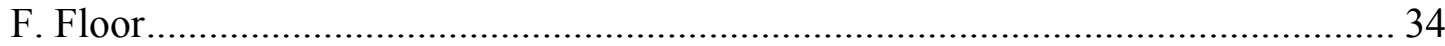

G. Attaching Non-Structural Masses to HCCC Model................................................ 38

IV. ADVANCED AND NONLINEAR FEATURES OF HCCC FEM .......................... 41

A. Common Features of Each Major Section Input File ……………………………..... 41

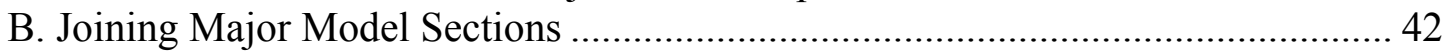

C. Joining Expandables to Main Shelter.................................................................. 44

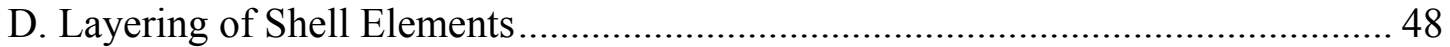

E. Contact between HCCC Floor and M1085 Truck Bed ........................................ 49

V. SOLUTION AND ANALYSIS OVERVIEW ……….............................................. 53 
A. Loading and Boundary Conditions ……………………..................................... 54

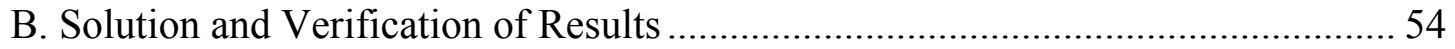

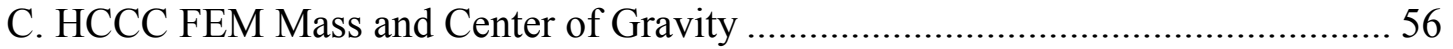

D. HCCC FEM Postprocessing Output …………................................................ 57

E. Material Strength and Margin of Safety (MS) ………….................................... 58

VI. HCCC FEM ANALYSIS - C-17 AIR CERTIFICATION …………………........... 62

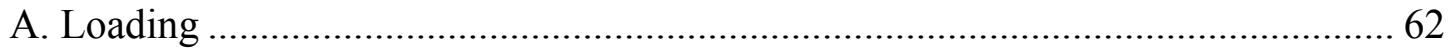

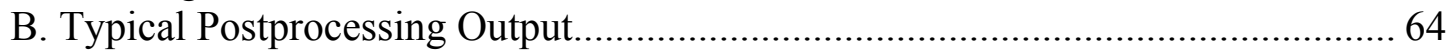

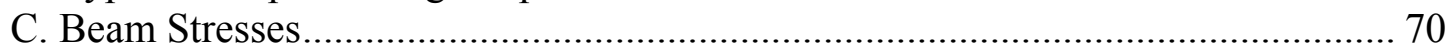

D. Exterior Aluminum Plate Stresses …………………...................................... 71

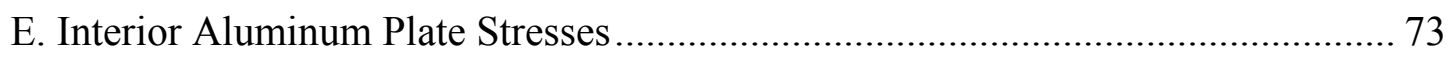

F. Lite-Ply Plywood Stresses .......................................................................... 75

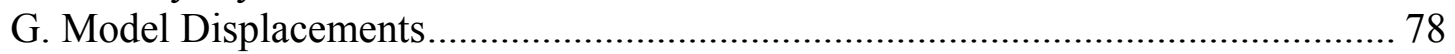

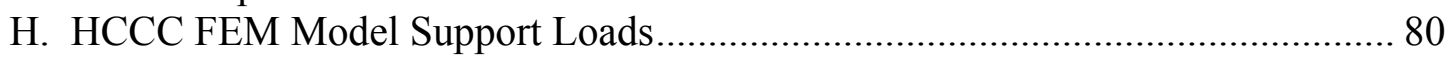

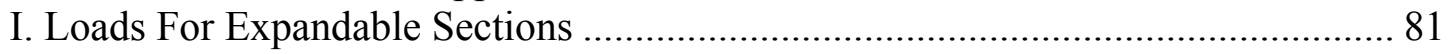

VII. HCCC FEM ANALYSIS - DYNAMIC SIMULATION ……………………....... 83

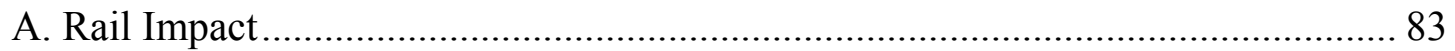

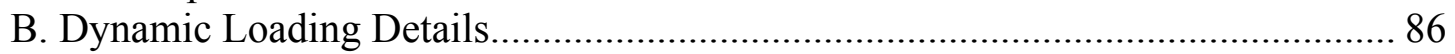

C. ANSYS Load Steps, Substeps and Solution Issues................................................ 89

D. Model Behavior At Peak Acceleration .................................................................. 92

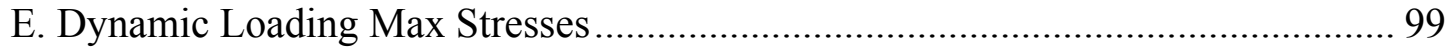

VIII. CONCLUSION ...................................................................................... 101

APPENDIX I. ANSYS ELEMENTS AND HCCC FEM DETAILS .............................. 103

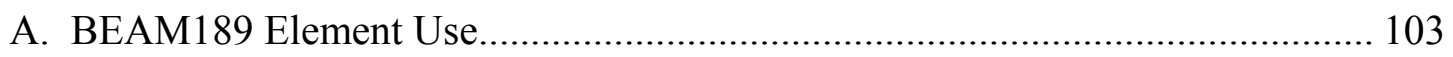

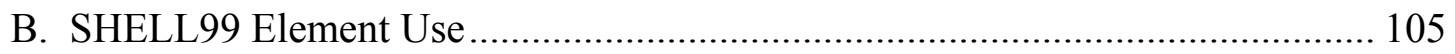

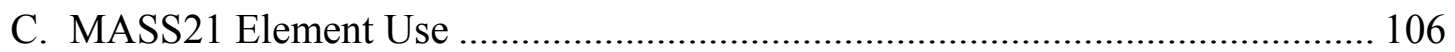

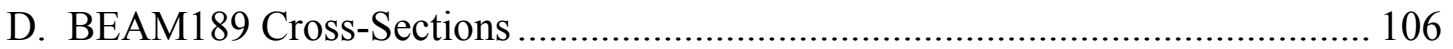

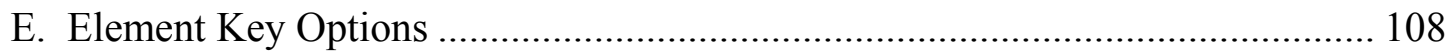

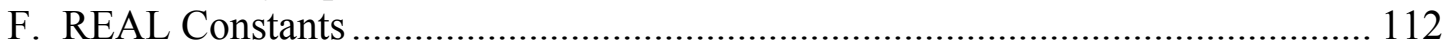

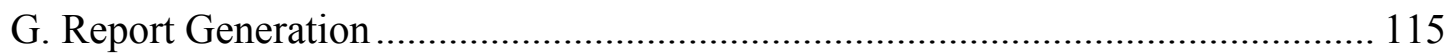

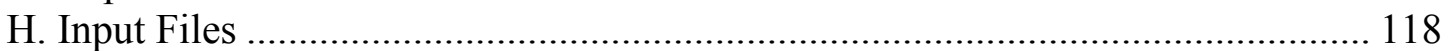

APPENDIX Ii. MATHCAD fILE - DISPLACEMENT POINT GENERATION ........ 121

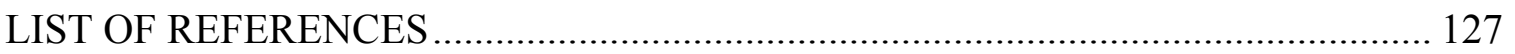

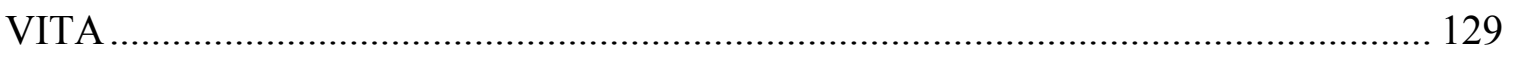




\section{LIST OF TABLES}

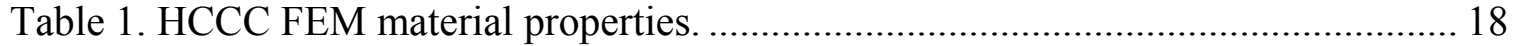

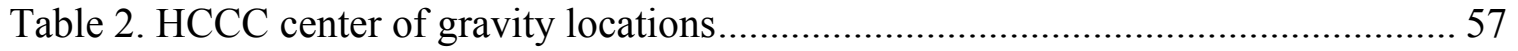

Table 3. Aluminum yield and ultimate strength values (typical) ................................. 58

Table 4. Yellow poplar proportional limit and ultimate strength for 5, 7 and 9 ply panels.

Table 5. C-17 air certification load factors (accelerations used for analysis)................... 64

Table 6. Maximum von Mises stress for HCCC beams from 5 load cases ...................... 70

Table 7. Margin of safety for HCCC beams from 5 load cases (assumed yield stress of 40 ksi for $6061-\mathrm{T} 6511$ alloy) ................................................................................. 71

Table 8. Maximum von Mises stress for HCCC exterior aluminum plates from 5 load cases

Table 9. Margin of safety for HCCC exterior aluminum plates from 5 load cases (assumed yield stress of $21 \mathrm{ksi}$ for 3003-H14 alloy)

Table 10. Maximum von Mises stress for HCCC interior aluminum plates from 5 load cases

Table 11. Margin of safety for HCCC interior aluminum plates from 5 load cases (assumed yield stress of $21 \mathrm{ksi}$ for 3003-H14 alloy)

Table 12. Maximum von Mises stress for HCCC interior aluminum plates from 5 load cases

Table 13. Margin of safety for HCCC interior aluminum plates from 5 load cases (assumed yield stress of $21 \mathrm{ksi}$ for 3003-H14 alloy)

Table 14. Maximum displacement for each region of the HCCC model from 5 load cases

Table 16. HCCC expandable support tube and top guide loads from 5 load cases ......... 82

Table 17. HCCC actuator loads from 5 load cases .......................................................... 82

Table 18. Nominal and actual speeds for multiple rail impact tests as listed in Table 2.5-

1. (ATC Rail Impact Facility, 2005 approx.)

Table 19. Max von Mises stress with corresponding margin of safety and load step for HCCC beams from rail impact case (assumed yield stress of $40 \mathrm{ksi}$ for 6061-T6511 alloy) 
Table 20. Max von Mises stress with corresponding margin of safety and load step for HCCC exterior aluminum facesheets from rail impact case (assumed yield stress of $21 \mathrm{ksi}$ for 3003-H14 alloy).

Table 21. Max von Mises stress with corresponding margin of safety and load step for HCCC Lite-Ply from rail impact case (assumed proportional limit stress of $2.931 \mathrm{ksi}$ for yellow poplar plywood) 100

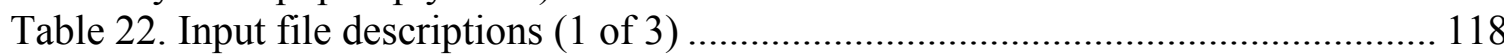

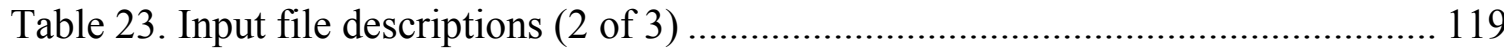

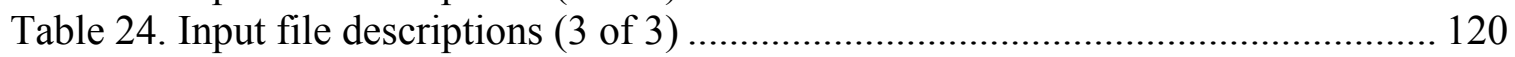




\section{LIST OF FIGURES}

Figure 1. Finite element model of HCCC (expandables shown extended beyond vehicle for clarity)

Figure 2. Finite element model of HCCC beams (expandables shown extended beyond

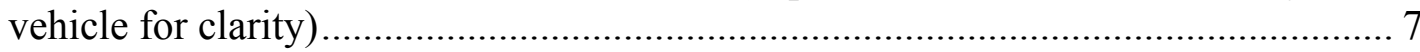

Figure 3. Finite element model of HCCC beams for main body only (note that corner ISO

block fittings are plate elements and do not show in this view) ............................ 8

Figure 4. Section view of HCCC body showing details of various layers (beams are

hidden in this view for clarity) ...................................................................... 9

Figure 5. HCCC model shown with coordinate system............................................ 12

Figure 6. HCCC with expandables separated and major sections identified.................. 15

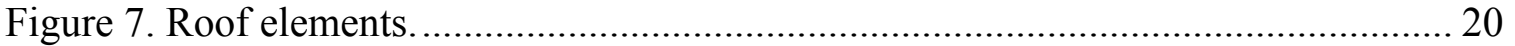

Figure 8. Roof elements - structural beams only. ..................................................... 20

Figure 9. Finite element model of the roof with structural members identified............... 21

Figure 10. Section view of HCCC roof showing various layers.................................... 22

Figure 11. Sides and rear structural with exterior aluminum...................................... 23

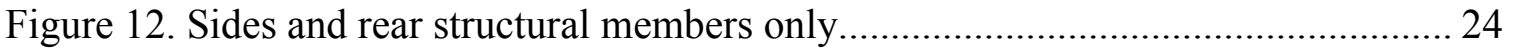

Figure 13. Sides and rear structural members only. Cross sections identified. ................ 24

Figure 14. Sides and rear - close-up of rear structural members ................................ 25

Figure 15. Demonstration of hinge and latch locations for rear access door................... 26

Figure 16. Front frame w/ext Al (left) and structural members only (right). .................. 27

Figure 17. Front frame only structural beams only with cross sections identified.......... 27

Figure 18. Front frame only structural beams as viewed from behind and underneath

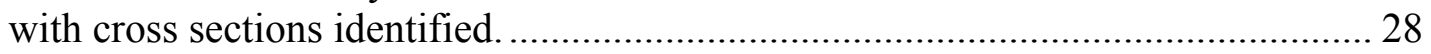

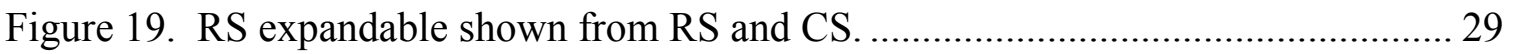

Figure 20. RS expandable without inside wall, viewed from RS................................ 29

Figure 21. RS expandable structural members only viewed from CS............................ 30

Figure 22. RS expandable structural members only viewed from RS............................ 30

Figure 23. Close up of expandable floor ply order. .................................................. 31

Figure 24. CS expandable shown from RS and CS with interior wall visible................. 32

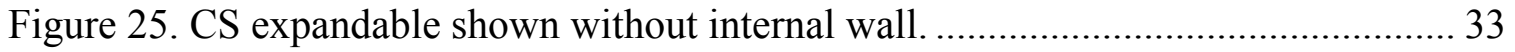

Figure 26. CS expandable with structural members identified...................................... 33 
Figure 27. Floor elements with structural members and floor panels............................ 35

Figure 28. Floor elements. Structural members and APU tunnel floor pan shown........ 35

Figure 29. Front floor elements. Structural members and APU tunnel floor pan shown. 36 Figure 30. Rear floor elements. Structural members and APU tunnel floor pan shown. 36 Figure 31. Floor elements. Structural members and APU floor pan shown from bottom.

Figure 32. Front floor elements. Structural members and APU tunnel floor pan shown from bottom.

Figure 33. Rear floor elements with structural members and APU tunnel floor pan

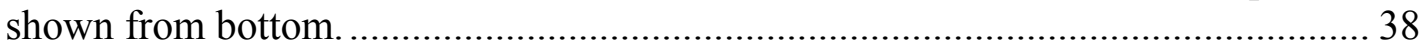

Figure 34. Masses attached to only the floor. ............................................................ 39

Figure 35. Masses attached to the front frame only (front view, left, and rear view, right).

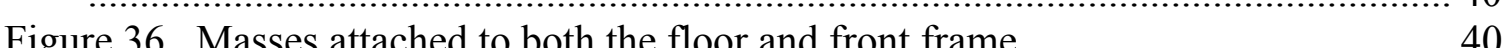

Figure 37. Roof and front frame constraint equations. .............................................. 44

Figure 38. Joining of the RS expandable and floor at the slide tubes........................... 45

Figure 39. Joining of the RS expandable and floor at the hydraulic cylinders............... 46

Figure 40. Joining of the RS expandable and roof at the expandable guide.................... 47

Figure 41. Internal and external SHELL99 elements. ............................................... 49

Figure 42. Elastic foundation and contact elements supporting the bottom of the HCCC

(separating distance is arbitrary; chosen to be 100" here to be simplify viewing) ... 52

Figure 43. Elastic foundation and contact elements supporting the bottom of the HCCC

(color contours denote pressure in psi; $1 \mathrm{~g}$ down gravity loading).......................... 52

Figure 44. HCCC beam and shell elements supported by contact elements simulating the

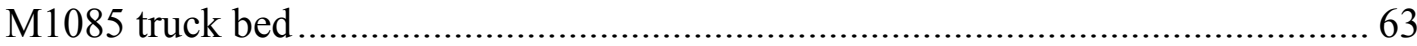

Figure 45. HCCC full model displacement vector plot (2.0 g upward load case; viewed

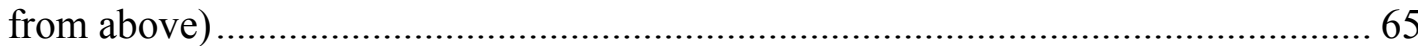

Figure 46. HCCC full model displacement magnitude contour plot (2.0 g upward load

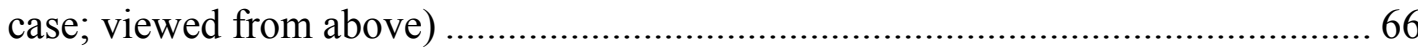

Figure 47. HCCC full model displacement magnitude contour plot (2.0 g upward load

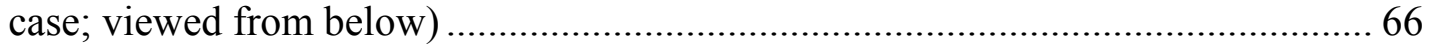

Figure 48. HCCC floor region displacement magnitude contour plot (2.0 g upward load case; viewed from above) .............................................................................. 67

Figure 49. HCCC floor beams von Mises stress ( $2.0 \mathrm{~g}$ upward load case; viewed from

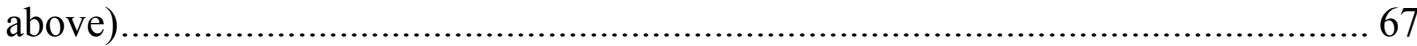

Figure 50. HCCC floor beams von Mises stress excluding actuator and expandable supports (2.0 g upward load case; viewed from above)....................................... 68

Figure 51. HCCC floor beams von Mises stress for only actuator and expandable supports

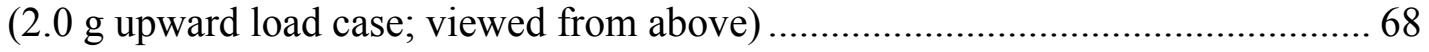

Figure 52. HCCC floor exterior aluminum plate von Mises stress (2.0 g upward load

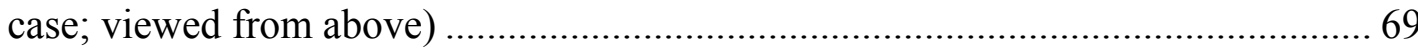

Figure 53. HCCC floor plywood von Mises stress (2.0 g upward load case; viewed from above)....

Figure 54. HCCC floor beams von Mises stress (1.5 g aft and lateral to curbside, viewed from below). 
Figure 55. HCCC floor exterior aluminum plate von Mises stress (4.5 g downward load

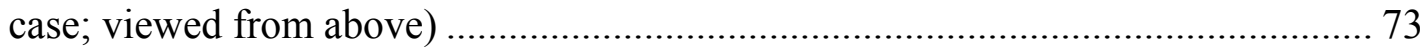

Figure 56. HCCC roof interior aluminum plate von Mises stress (1.5 g aft and lateral to roadside load case; viewed from above) ............................................................. 75

Figure 57. HCCC floor LitePly plywood plate von Mises stress (3.0 g forward load case;

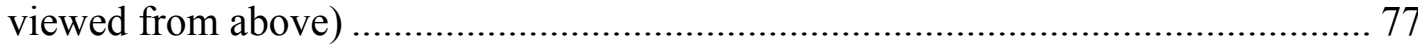

Figure 58. HCCC floor LitePly plywood plate von Mises stress (4.5 g downward load

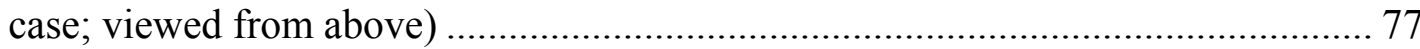

Figure 59. HCCC displacement vector plot (1.5 g aft and lateral to roadside load case;

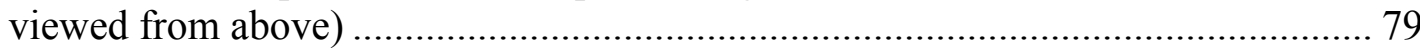

Figure 60. HCCC floor LitePly plywood plate von Mises stress (3 g forward load case;

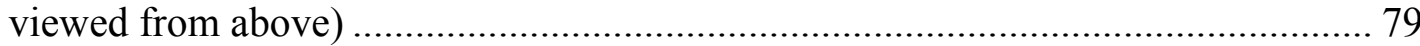

Figure 61. Rail impact test setup with HMMWV and rigid structure (ATC Rail Impact Facility, 2005 approx.) ......................................................................... 84

Figure 62. EDR mounting inside the rigid shelter (ATC Rail Impact Facility, 2005

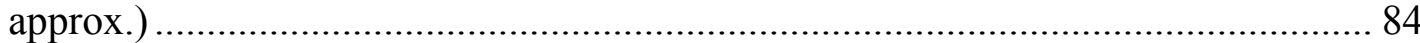

Figure 63. EDR acceleration data from reverse $8.3 \mathrm{mph}$ rail impact test. (ATC Rail

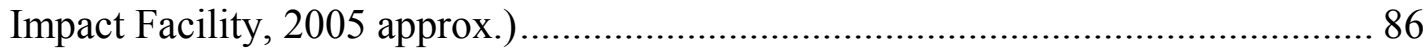

Figure 64. Simulated acceleration for HCCC FEM from reverse $8.3 \mathrm{mph}$ rail impact; inset shows portion of the original data from Figure 63 with time similarly offset. 87

Figure 65. Simulated velocity for HCCC FEM from reverse $8.3 \mathrm{mph}$ rail impact.......... 88 Figure 66. Simulated displacement for HCCC FEM from reverse $8.3 \mathrm{mph}$ rail impact. . 88 Figure 67. Demonstration of load steps and substeps in ANSYS.(ANSYS, 2008)......... 90 Figure 68. Displacement vector plot at load step $200\left(\mathrm{t}=0.1153 \mathrm{~s}, \mathrm{a}=3.995 \mathrm{in} / \mathrm{s}^{2}\right) \ldots \ldots .93$ Figure 69. Net displacement vector plot at load step $200\left(\mathrm{t}=0.1153 \mathrm{~s}, \mathrm{a}=3.995 \mathrm{in} / \mathrm{s}^{2}\right) .94$ Figure 70. Contour plot of net displacement magnitude at load step $200(\mathrm{t}=0.1153 \mathrm{~s}, \mathrm{a}=$ $\left.3.995 \mathrm{in} / \mathrm{s}^{2}\right)$ 95

Figure 71. Contour plot of von Mises stress in front frame beams at load step $200(\mathrm{t}=$ $0.1153 \mathrm{~s}, \mathrm{a}=3.995 \mathrm{in} / \mathrm{s}^{2}$ ) 96

Figure 72. Contour plot of von Mises stress in exterior aluminum skin of curbside

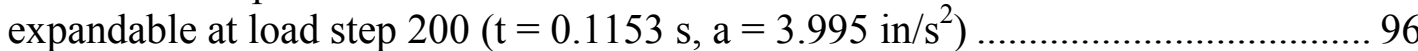

Figure 73. Net displacement of the 4 corner roof nodes over time in Y direction .......... 97 Figure 74. Net displacement of the 4 corner roof nodes over time in X direction ........... 98 Figure 75. Net displacement of the 4 corner roof nodes over time in $\mathrm{Z}$ direction............ 98

Figure 76. Beam orientation variations based on nodal offset.................................... 104 Figure 77. Beam orientation altered with orientation keypoint................................ 105 Figure 78. Depiction of SHELL99 elements with nodes offset to top (A), midsurface

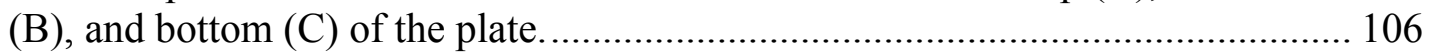
Figure 79. Depiction of beam cross-section 1 from ANSYS "beam section" tool........ 107 Figure 80. Depiction of beam cross-section 2 from ANSYS "beam section" tool........ 108 Figure 81. One page from a typical report following an HCCC FEM analysis. 117 


\section{INTRODUCTION}

\section{A. Background Information}

The U.S. Army is in the midst of a historic transformation that is refocusing the service's mission from a Cold War requirement to engage a ponderous, heavily armored enemy on a Central European battlefield with well-defined front lines, to a deployable, sustainable force that can respond to a full spectrum of threats anywhere on the globe. A critical element of combat effectiveness is the availability of appropriate command, control, communications, computers, and intelligence surveillance, and reconnaissance (C4ISR) systems to support the force decision makers. Accordingly, the Department of Defense has made a commitment to improve theater and tactical command and control (C2) systems. The U.S. Army Research Development Engineering Command's (RDECOM) Communications-Electronics Research Development Engineering Center (CERDEC) envisions a deployable command post (DCP) housing analysts, support specialists, and decision makers, along with the required electronics, computer, and communication systems as one possible approach to such improvements. Such shelters would be expandable to increase floorspace after transport and would also emphasize lightweight construction to facilitate transport by either air or road.(R.D. Bradshaw and G.P. Prater Jr., 2007)

Prior to this document's creation, the Harbormaster Command and Control Center (HCCC) was intended to be "a multi-vehicle array comprising a main command post platform (M-CPP) designed for harbormaster command and control (C2) of the harbor 
and littorals (inlet water ways) in conjunction with remote sensor platforms (RSP) over a distance of 50 km.” travel. (R.D. Bradshaw and G.P. Prater Jr., 2006)

\section{B. Purpose of Thesis}

The purpose of this thesis is to develop and verify a finite element model (FEM) that will accurately portray the HCCC in required testing scenarios. The FEM and tests performed were intended to verify the HCCC structure will not fail under standard test

loading scenarios. These tests include static loading (C-17 transport maneuvers) and dynamic loading (rail impact); the HCCC did not fail in static loading or dynamic loading.

\section{Collaborators, Reports and Funding}

While modeling, coding, and analysis were primarily performed by the author, three other graduate research assistants helped with specific portions of the project. Kelley McCoy worked primarily in detailed analysis of the HCCC's dowel mounts; Dr. Bradshaw produced a report based on this work, "Dowel Mount Analysis For Rail Impact Test: Harbormaster Command and Control Center (HCCC).” (R.D. Bradshaw and J.K. McCoy (uncredited), 2008) Jon Mandt and Jeff Borden focused on fiber-reinforced composite (FRC) material research to aid in material and modeling choices for a version of the HCCC using FRC materials. These efforts lead to the reports "Composite Materials Research Report: Harbormaster Command and Control Center (HCCC )” (J.E. Mandt and R.D. Bradshaw, 2008) and "Fiberglass Panel Materials Research Report: Harbormaster 
Command and Control Center." (R.D. Bradshaw and J.W. Borden (uncredited), 2009). A version of the HCCC FEM relying heavily on composite materials was modeled as part of this study but was not run through the same analyses as the conventionally-constructed version due to time constraints and lower priority. Paul Long was in charge of creating the original output creation input file, Create_Output.inp, that is run after an analysis is solved; it generates a report with a series of images and tables.

The two main reports that this thesis draws were written by the author and Dr. Bradshaw during the course of the project. The majority of the description of the HCCC FEM is detailed in a report entitled "Harbormaster Command and Control Center (HCCC): ANSYS Finite Element Model - Aluminum Shelter." (J.D. Watson and R.D. Bradshaw, 2009) The C-17 air transport analysis section is detailed in a report entitled "C-17 Certification Analysis: Harbormaster Command and Control Center (HCCC)" (R.D. Bradshaw and J.D. Watson (uncredited), 2008). The work on dynamic analysis of the HCCC FEM has been completed during a limited amount of time since 2009 when the author left the University of Louisville to accept an engineering position in industry.

Funding and oversight for this work were provided by Kentucky Trailer, the United States Army, and co-principal investigators Drs. Roger Bradshaw and Glen Prater, Jr. Dr. Bradshaw provided technical guidance and coding assistance with ANSYS throughout the project. 


\section{BASIC FEATURES OF HCCC FINITE ELEMENT MODEL (FEM)}

In this section, details of the HCCC finite element model (FEM) will be presented. This includes the construction and relationships of the FEM, and the tests simulated in ANSYS.

\section{A. HCCC FEM Overview}

The Harbormaster Command and Control Center (HCCC) shelter is mobile enclosure that is attached to an M1085 truck bed. The HCCC consists of a main body and two expandable units; the expandables are stowed for travel and expanded once the HCCC is located in the field. The total weight of the shelter when prepared for travel (i.e. closed, no personnel, etc.) is 10,100 lbs.

In order to study the behavior of the HCCC under various static and transient loading conditions, a detailed finite element model of the HCCC aluminum (baseline) configuration was created in ANSYS. Detailed 2D blueprints and 3D solid models were provided by Kentucky Trailers from which ANSYS models could be generated. These 2D prints and 3D models were provided in AutoCAD and Inventor, respectively. The FEM is made of mostly beam and shell elements; link elements for actuators and point masses for non-structural items were also used. The truck bed of the M1085, on which the HCCC shelter is secured, is modeled by contact elements.

Each expandable is supported by two lower tubes that nest inside support beams in the floor of the HCCC; the expandables are further supported by guides that attach at a 
point on their inside top surface that slide in matching rails in the HCCC roof. These supports provide forward and vertical restraints for the expandables. Lateral restraint is provided by four actuators (two per expandable) which run between floor pivot points and attachment points on the bottom inside edge of each expandable; these actuators are also used to expand the shelter in the field. In addition to the expandables themselves, there are several penetrations of the HCCC shelter. The curbside expandable has a window as indicated; this is represented as an open area in the model (assumes the window is non-structural). The rear of the HCCC has a door that is attached to the shelter at four points (three hinges on one side; one latch on other side). The environmental control units (ECUs) that provide heating and cooling to the HCCC also require two penetrations in the front as shown. 


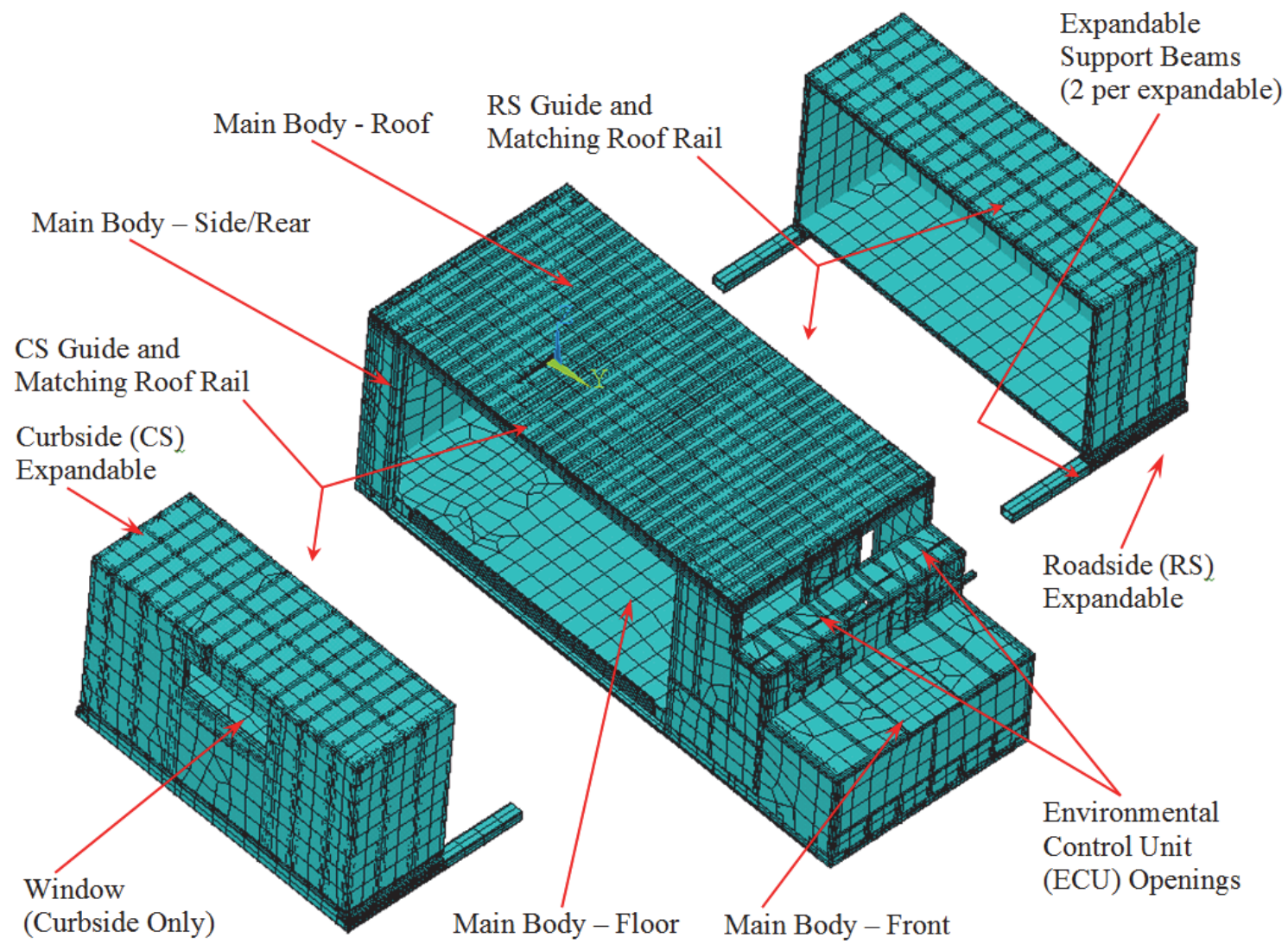

Figure 1. Finite element model of HCCC

(expandables shown extended beyond vehicle for clarity)

One part of the HCCC structure consists of a series of aluminum tubes and beams that are welded together. The various aluminum sheets, insulating foam and plywood layers are then attached to these beams to complete the structure. The beams of the entire HCCC model are shown with other elements hidden in Figure 2. It should be noted that the beams of the main body attach to four ISO blocks at the corners; these are plate elements in ANSYS and as a result are not visible in Figure 2. 


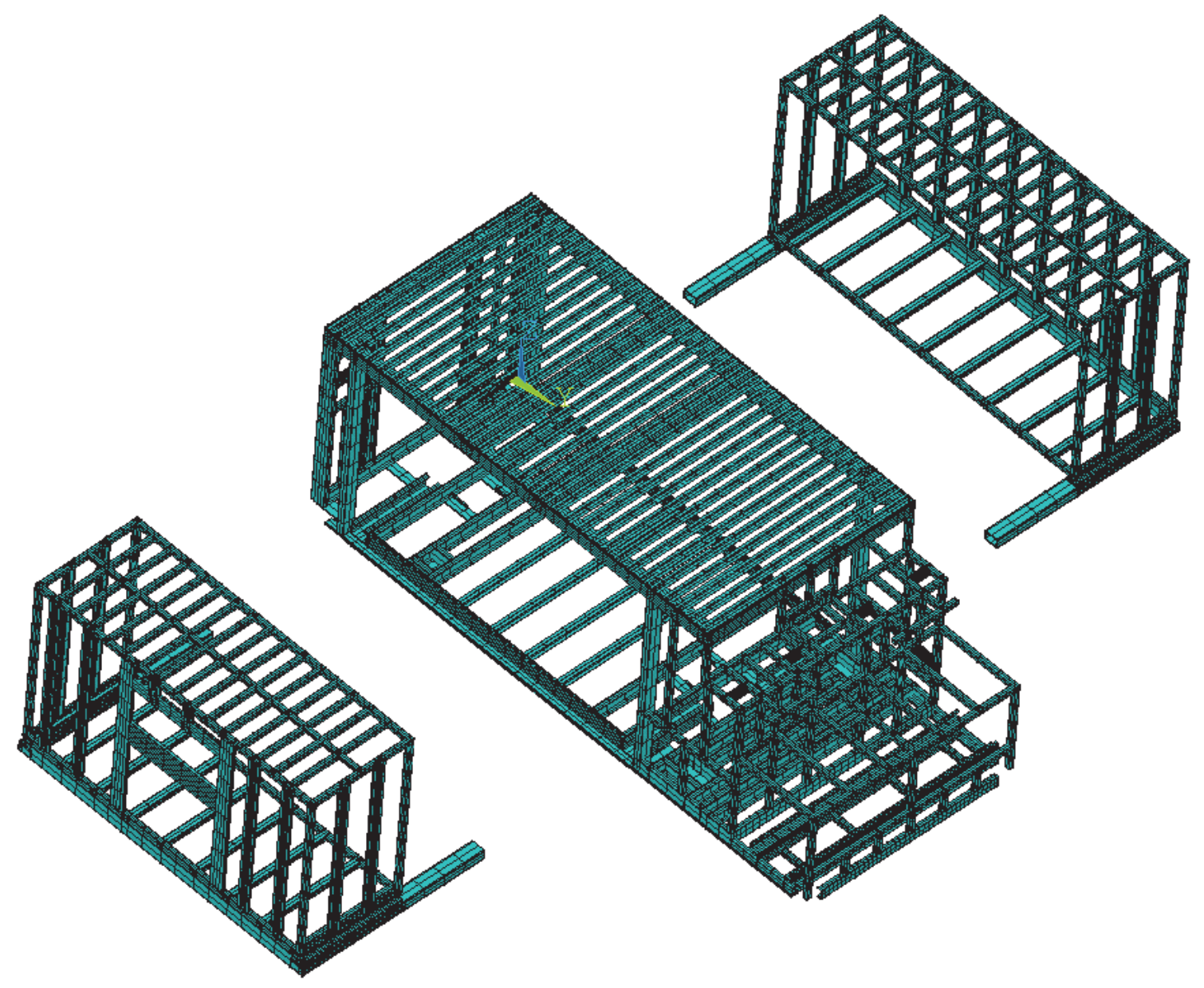

Figure 2. Finite element model of HCCC beams

(expandables shown extended beyond vehicle for clarity)

The model view consisting of beams alone is repeated in Figure 3 for the HCCC main body alone. In this image, the attachment between the HCCC and the M1085 truck are shown; these are referred to as the dowel mount supports and there are four total (forward CS, rear CS, forward RS, rear RS). The support beams in which the expandable support tubes nest are also evident in this view; there are four support beams (forward $\mathrm{CS}$, rear $\mathrm{CS}$, forward RS, rear RS). The support beams for the actuators are also indicated; again, there are two of these for each expandable for 4 total (forward CS, rear CS, forward RS, rear RS). The front of the HCCC main body houses the auxiliary power 
units (APUs); the tunnel that these are mounted in is noted. Finally, the frame for the rear door is indicated as well.

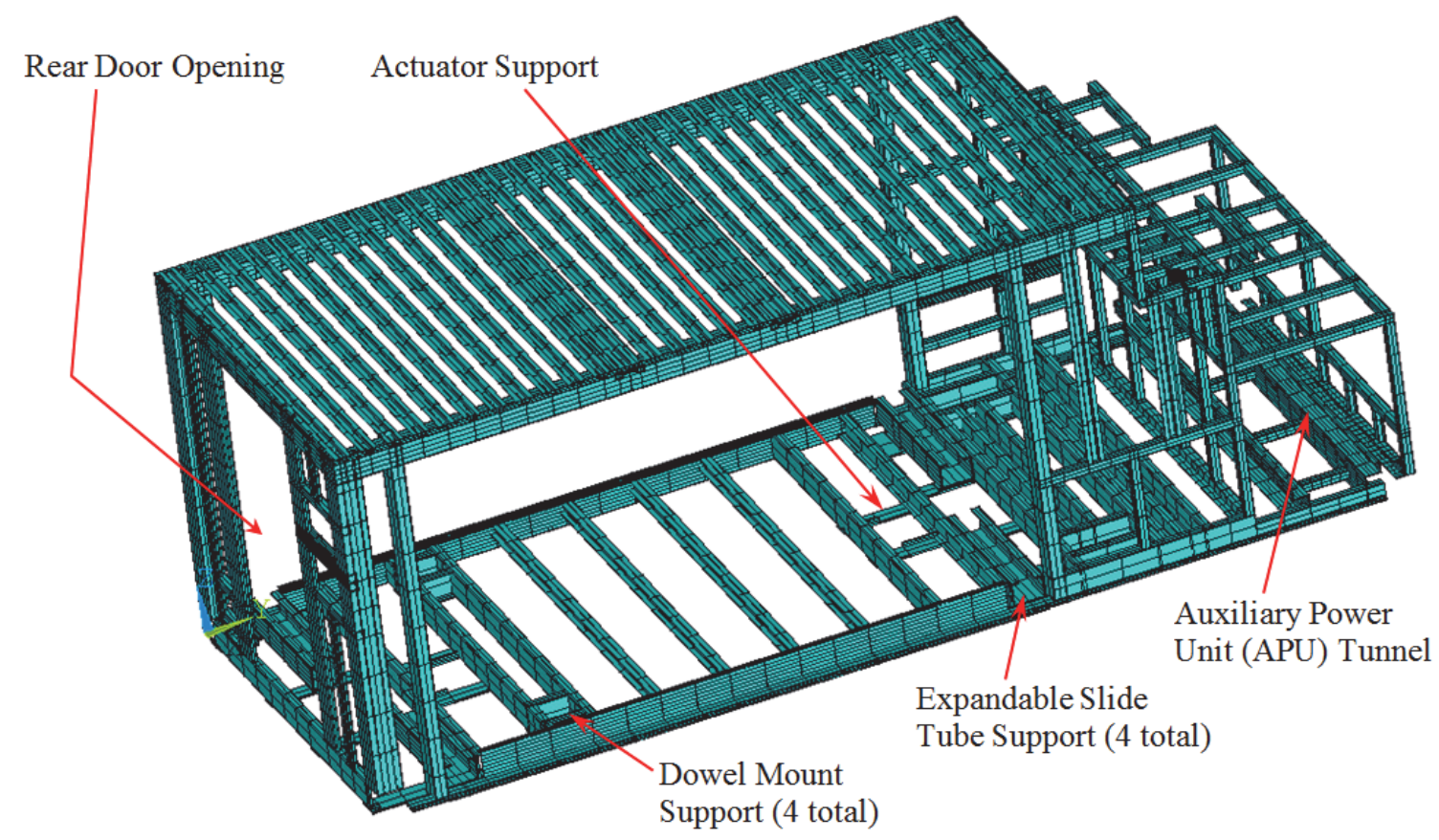

Figure 3. Finite element model of HCCC beams for main body only (note that corner ISO block fittings are plate elements and do not show in this view)

As noted previously, the remainder of the HCCC structure consists of aluminum sheets, wood sheets and polyurethane foam. A section view of the HCCC main body showing a cross-section of the roof and floor is provided in Figure 4.

The floor consists of three layers. The bottom layer is an aluminum sheet that is attached to the bottom of the various floor beams. The middle layer is polyurethane foam and fills the region to the top of the floor beams. The top layer is $3 / 4$ inch thick Lite-Ply poplar plywood that is attached to the top of the various floor beams. A surface layer suitable for walking is then placed on top of the plywood in the actual HCCC but this is 
not modeled here as it is non-structural. The floors of the expandables are identical to this configuration.

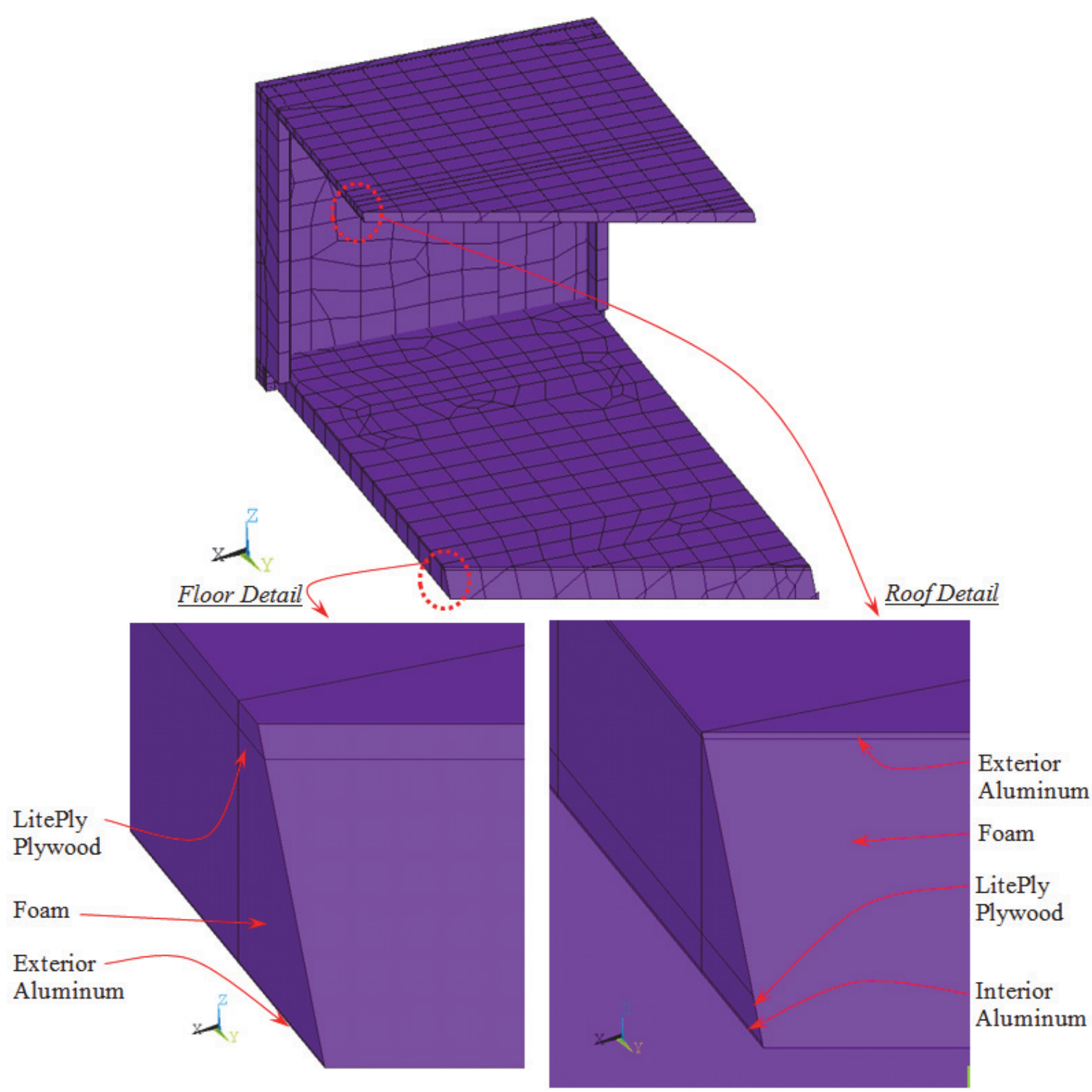

Figure 4. Section view of HCCC body showing details of various layers (beams are hidden in this view for clarity)

The roof consists of a total of four layers. The top layer is an aluminum plate attached to the roof beams. The second layer from the top is polyurethane foam that fills the region to the bottom of the roof beams. The third layer from the top is $3 / 8$ inch Lite- 
Ply plywood. Finally, the bottom layer is aluminum with a painted surface suitable for the vehicle interior.

Most other sections of the HCCC model that are not beams have a similar configuration as above - exterior aluminum, polyurethane foam, Lite-Ply plywood, and interior aluminum for non-walking HCCC interior surfaces. One exception is the APU support region, which is modeled primarily using plate elements representing gussets that stiffen the tracks on which the APU slides for maintenance. The model also consists of several point mass elements representing the following components:

1. APUs

2. ECUs

3. INMARSAT

4. Electronic equipment and racks (3)

5. Hydraulic pump

6. Power distribution panel

7. Safes (2)

These point masses are attached to appropriate locations using stiff beam elements (not shown in previous figures). It should be noted that this does not capture the actual structural stiffness of the components but it does allow the load to be distributed to the HCCC in a reasonable way.

\section{B. Converting AutoCAD / Inventor Models to ANSYS}

Designs for the Harbormaster Command and Control Center (HCCC) were completed by Kentucky Trailer Technology, KTT, in two-dimensional plans in 
Autodesk's AutoCAD and three-dimensional solid models in Autodesk's Inventor. Several steps were taken to transfer the data from AutoCAD and Inventor to a usable ANSYS model.

KTT AutoCAD drawing 3600-000-1 was used for most dimensioning as it includes nearly all of the details of the structure; it features structural beam locations as well as the placements of items attached to the inside and outside of the structure. A right hand coordinate system was used with the origin being placed at the rear roadside corner of the shelter. The global coordinate system of the shelter is shown in Figure 5. The X coordinates are measured laterally on the shelter going from roadside to curbside. The $\mathrm{Y}$ coordinates are measured longitudinally on the shelter going from the rear to the front. The $\mathrm{Z}$ coordinates are measured vertically upwards from the bottom to the top.

The finite element model in ANSYS is a meshed solid model. In this approach, a solid model is created consisting of the following entities:

Keypoints - individual points in space

Lines - join two (or more) keypoints together

Areas - consisting of several lines in a closed path

Volumes - a closed space comprised of several areas

The HCCC model in question consists primarily of beam elements, created by meshing suitable lines, and shell elements, created by meshing suitable areas. There are no volume elements in this model. 


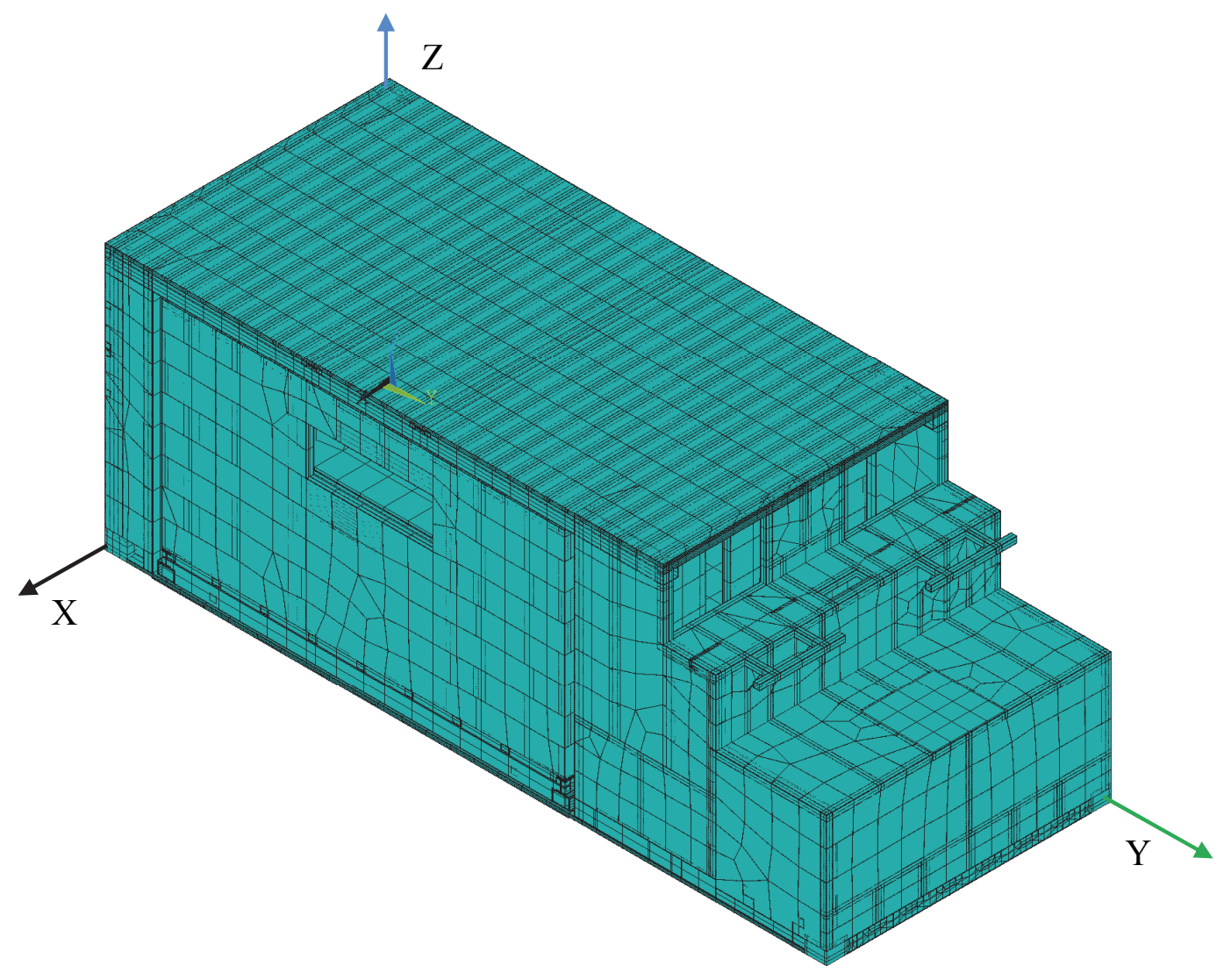

Figure 5. HCCC model shown with coordinate system.

In order to create the finite element model, AutoCAD was used to locate the endpoints of each structural beam in the global coordinate system. These were recorded into Excel and turned into keypoints in ANSYS for the construction of lines and areas. Initially, images of the HCCC's frame were taken from the solid models in Inventor, with each beam given a label consisting of letters starting alphabetically from A continuing past $\mathrm{Z}$ with multiple letters starting over at $\mathrm{AA}, \mathrm{BB}, \ldots, \mathrm{AAA}$, etc.; the beam label and its associated endpoints were then input into Excel for easy management. However, this approach was used throughout subsequent modifications and the formal spreadsheet was not updated past a certain point; instead, smaller spreadsheets were used to keep track of 
newer or updated keypoints and the formal naming convention was set aside. One motivating factor was the lack of updates to the Inventor models; as such, more focus was placed on the AutoCAD prints as certain aspects of the design changed multiple times.

\section{Overview of ANSYS Elements and Usage in HCCC FEM}

The structural beams of the shelter are modeled with BEAM189 elements. BEAM189 allows a user to place the node location to any spot in the plane of the beam's cross-section; this can be used to place a beam's cross-section in any position related to its associated line whether that places the line going through the cross-section or offset from it. Another desirable feature of the BEAM189 is the ability to use customgenerated cross-sections; this came into play heavily when beginning the investigation of a shelter using composite materials. A third key feature of the BEAM189 is the ability to rotate its cross-section around its associated line; rather than setting an orientation keypoint for every beam section, a set of "master orientation keypoints" are placed at 10 million $\left(10^{7}\right)$ inches from the center of the shelter model in each axis direction $( \pm \mathrm{X}, \pm \mathrm{Y}, \pm \mathrm{Z})$. This allows the largest angle of rotation for a beam, from normal, to be virtually 0 .

Aluminum skins, foam insulation, wood paneling, and most gussets were modeled with shell elements. SHELL99 elements are used to simplify the modeling and analysis of multiple material layers that are stacked on each other (i.e. insulating foam, wood paneling, and aluminum interior skin on most walls). SHELL99 elements can also have their nodes offset to the top, bottom, or midsurface; this allows for correct orientation of an element extruding from a respective surface. 


\section{Modular Construction of HCCC FEM Model}

While many FEA models consist of a single part (i.e. a baseball bat, spur gear, etc.), the HCCC is a very complex model with many features and components. To simplify making changes to different areas of the shelter, it was broken down into six different sections consisting of:

Floor

Roof

Front Frame

Side and rear walls

Roadside expandable

Curbside expandable

These sections are color coded and identified in Figure 6 with the expandables separated from the shelter for clarity.

The HCCC model is composed of multiple sections that are joined together via constraint equations. Building the model from multiple sections, each read from its own input file, makes it easier to display results and make alterations and corrections to individual sections. These sections, shown in Figure 1, are the floor (main body), roof (main body), sides and rear (main body, includes rear door), front (main body), curbside (CS) expandable, and roadside (RS) expandable. 


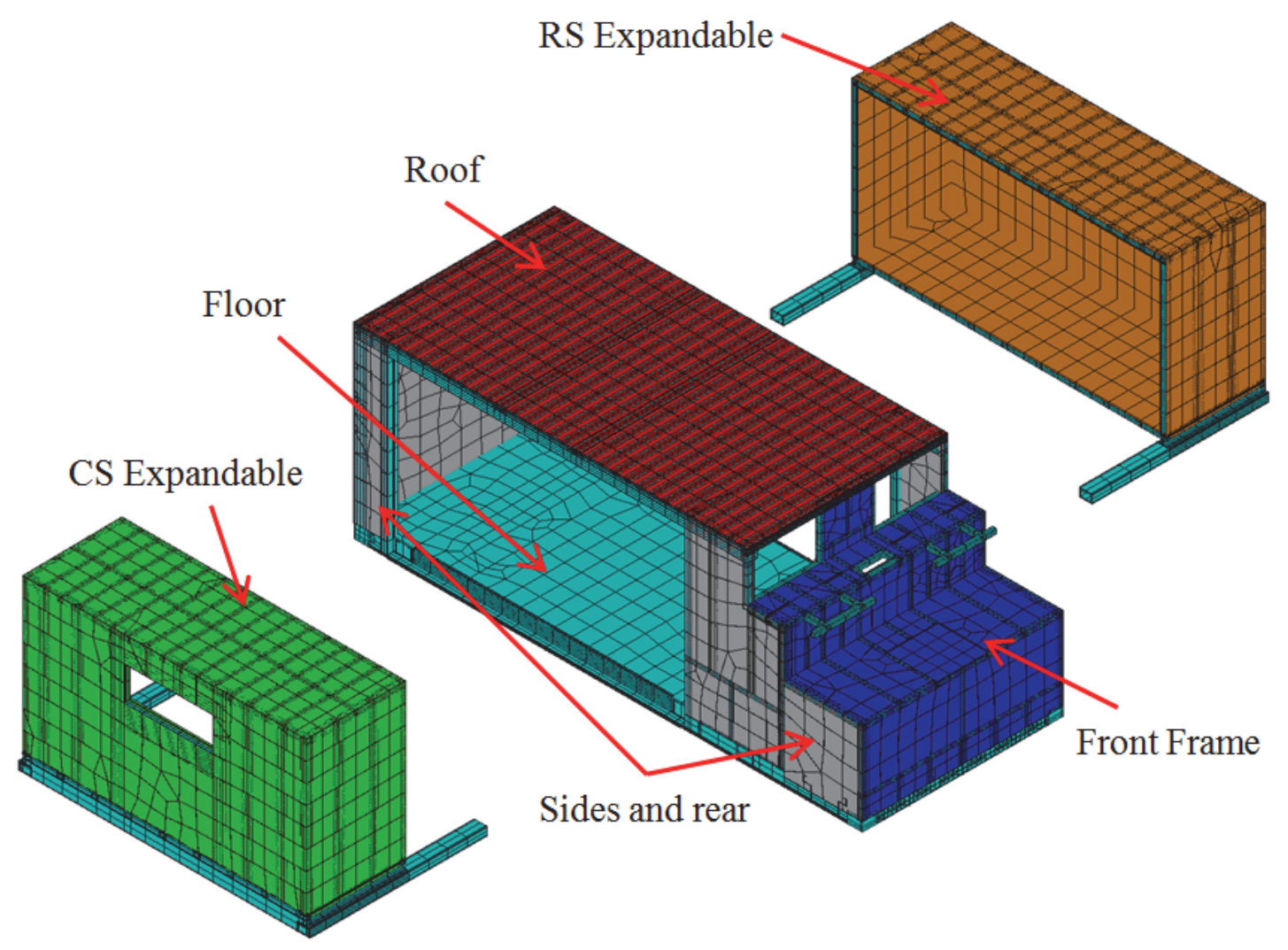

Figure 6. HCCC with expandables separated and major sections identified.

One approach to building a finite element model of a complex structure such as the HCCC would be to use solid, three dimensional finite elements - this would be bricks ( 8 node or 20 node) for regular shapes such as rectangular prisms or tetrahedra (10 node) for more complex shapes which are more difficult to mesh. However, such a model would be quite expensive from a computational perspective as many nodes and elements would be required. It would also be extraordinarily difficult to manage as ensuring proper mesh continuity across many volumes, areas, lines and keypoints would be challenging. Finally, such a model is not suitable for optimization as properties such as plate thickness cannot be easily modified; if a plate is modified as a volume of a certain thickness, significant alterations are required to the model in order to implement such changes. 
As such, assumptions are often made in a model, which then leads to simplifications such as using another type of element to reduce model complexity and fabrication / solution time., and it can be simplified by using another type of element or a combination of elements. As mentioned previously, this study uses a combination of beam and shell elements rather than 3D solid elements. Beams can essentially be thought of a 1D elements that lie along a path (straight or curved line) have a cross-section specified appropriately; the stiffness and behavior of this element is then defined using beam theory with relatively few degrees of freedom (nodal values such as displacement or rotation). Shells can be thought of as $2 \mathrm{D}$ elements that lie in a flat or curved surface that have thickness specified appropriately; the stiffness and behavior of this element is then defined using plate theory and again relatively few degrees of freedom describe the structural response. The reduction of the number of degrees of freedom compared to a comparable 3D solid model generally leads to a faster analysis time, requires less processing power, and requires less storage space. One other key benefit is that items such as beam cross-section and plate thickness can be easily changed without significantly altering the underlying model; for example, plate thickness is set as a single number (REAL constant) that can be modified without altering the mesh in any way. This beam/shell approach is used in the HCCC finite element model.

The main elements used in this model are described in Appendix I.A - I.C along with their associated options that govern their behavior. The real constants that govern the thickness of shell elements as well as other element behaviors are listed in Appendix I.F. The material properties used in the model are listed in Appendix I.E. Finally, a plot of two of the cross-sections used in defining the beam elements is provided 
in Appendix D; the full list of cross sections can be found elsewhere. (J.D. Watson and R.D. Bradshaw, 2009)

\section{E. ANSYS Input Files and Usage for HCCC FEM}

The HCCC is constructed, and analyzed, using multiple Input Files. Input files are simply text files with ANSYS commands; efficiency is improved with input files as a series of commands can be written in a text file, and edited for mistakes, quicker than entering the commands in the command bar or through the GUI. Larger efficiency gains come when running larger analysis and when running analysis multiple times.

While the HCCC model could be constructed using only one input file, it would be too large to manage effectively. The HCCC model and analysis start with running Build_HCCC.inp which establishes global properties (real constants, material properties, and etc.) and then proceeds to call upon other input files to construct the model, apply constraints, and then apply loading conditions before analysis. Each major component of the shelter (roof, floor, etc.) is generated from its own input file and thus easier to edit. Another benefit comes from being able to switch out entire input files to completely change the associated component, replacing the two aluminum-based expandables with expandables constructed from composite materials. The full list of input files used in the HCCC model and analysis are detailed in Appendix I.H.

\section{F. Material Stiffness and Density Properties}

A total of 5 material sets are used in the HCCC model. These consist of elastic properties ( $\mathrm{E}$ - modulus of elasticity and $v$ - Poisson's ratio) and density $\rho$ (important for 
inertial loading such as gravity and acceleration effects). The first three are HCCC materials - aluminum, LitePly plywood and polyurethane foam. The last two are fictitious materials - steel for to represent the actuators as 2 force members and aluminum to represent the base of the M1085 truck. The material properties are listed below in Table 1.

Two points should be clarified for this table. First, the weight of the HCCC model once completed was approximately $7,700 \mathrm{lbs}$, a value significantly lower than the operating weight of $10,100 \mathrm{lbs}$. The difference is that items many items such as wiring, tubing, fluids, furniture, etc. are incorporated into the structural model. In order to compensate for this discrepancy, the density of the aluminum (material 1) was increased until the $10,100 \mathrm{lb}$. target was reached. Second, material 5 belongs to the elastic foundation elements used to model the M1085 truck bed. These elements are only loaded by contact elements in the vertical $(Z)$ direction; the elements are supported out of plane (i.e. also in the $\mathrm{Z}$ direction) by a spring stiffness referred to as an elastic foundation. These elements are given nominal elastic properties to provide bending resistance to the plates; this is not critical to their behavior but avoids problems with convergence due to either low bending stiffness or the use of the element in membrane-only capacity. The elements are given 0 density to avoid any inertial loading.

\begin{tabular}{|c|c|c|c|c|}
\hline $\begin{array}{l}\text { Material } \\
\text { Number }\end{array}$ & Type & $\begin{array}{l}\text { E, Modulus } \\
\text { of } \quad \text { Elasticity } \\
\left(\mathrm{Msi}=10^{6} \mathrm{psi}\right)\end{array}$ & $\begin{array}{l}v, \\
\text { Poisson's Ratio } \\
\text { (unitless) }\end{array}$ & $\begin{array}{l}\rho, \\
\text { Density } \\
\left(1 \mathrm{lb} / \mathrm{in}^{3}\right)\end{array}$ \\
\hline 1 & Aluminum & $10.00 \mathrm{Msi}$ & 0.30 & 0.12920 \\
\hline 2 & LitePly Plywood & $0.725 \mathrm{Msi}$ & 0.30 & 0.01728 \\
\hline 3 & Polyurethane Foam & $1000 \mathrm{psi}$ & 0.25 & 0.001157 \\
\hline 4 & Steel - Actuators & $30.0 \mathrm{Msi}$ & 0.30 & 0.290 \\
\hline 5 & Aluminum - M1085 & 10.0 Msi & 0.30 & 0 \\
\hline
\end{tabular}

Table 1. HCCC FEM material properties. 


\section{DETAILED DESCRIPTIONS OF EACH HCCC FEM SECTION}

This section details the individual sections and how they are built. This is primarily completed using text and a limited number of images; a fuller understanding of the nature of the various sections is best achieved by directly inspecting the associated ANSYS model. In some images, the beam cross-section (Section ID) is indicated by a number; these are provided in further detail in Appendix 1.F. In addition to the 6 sections described above, this section also details the usage of MASS21 elements to represent non-structural weight components as well as the contact elements between the floor and the simulated bed of the HCCC.

\section{A. $\underline{\operatorname{Roof}}$}

The roof of the HCCC is the simplest of all the main pieces of the shelter. It contains 31 roof bows, four perimeter beams, two sets of the expandable guides, an exterior aluminum skin, insulating foam, an interior layer of Lite-Ply, and an interior aluminum skin. The roof bows, perimeter beams, and expandable guides are all beam elements modeled with BEAM189, a 3-D beam element. The aluminum, foam, and LitePly layers are all shell elements modeled with SHELL99 as described above. The roof is shown from above with the exterior aluminum in Figure 7 and with only the beam elements in Figure 8. 


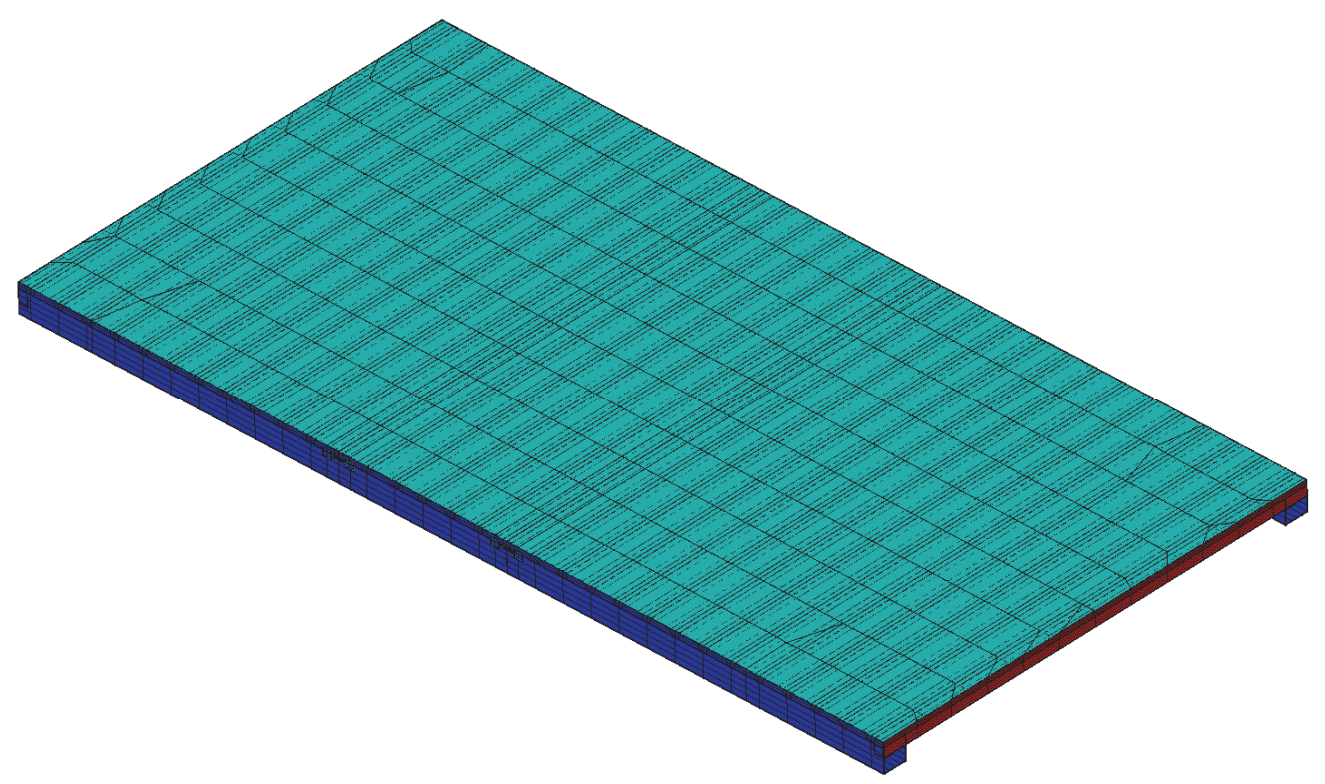

Figure 7. Roof elements.

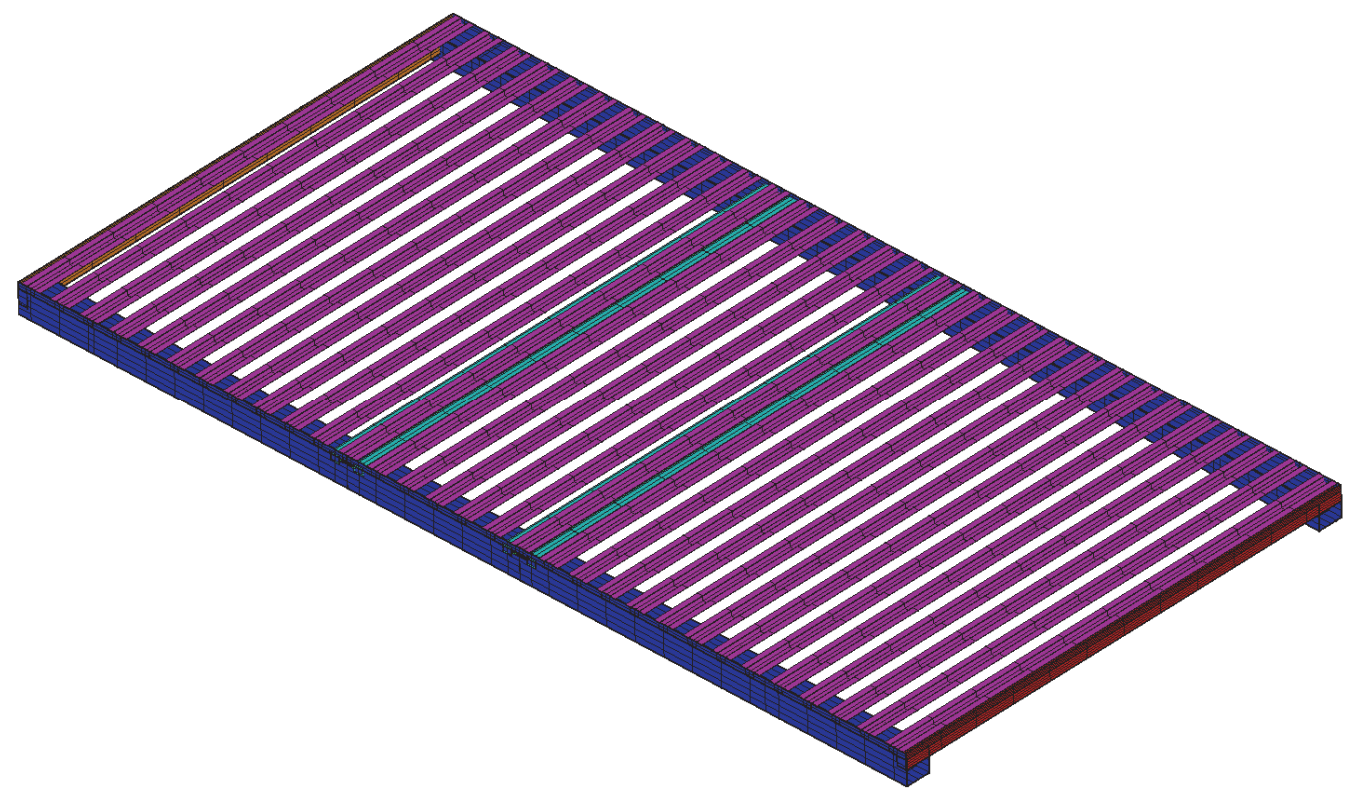

Figure 8. Roof elements - structural beams only.

All of the roof perimeter beams incorporate both a main box tube and the top rail beam (AutoCAD 3600-014-2 for roadside and curbside; 3600-022-2 for front and rear). The roadside and curbside roof perimeter beams are cross section ID 35 in ANSYS; the front and rear roof perimeter beams are section IDs 73 and 72, respectively. The roof bows are section ID 18, and the expandable guides use section ID 38 for the guide rails 
and section ID 37 for the supporting square tube on either side of the rails. All section IDs can be seen in detail in Appendix I. Figure 9 shows the roof beams with the curbside perimeter beam and some of the roof bows turned off to see the expandable guides and remaining perimeter beams more clearly. Each beam type is denoted with its respective section ID and is also color coded.

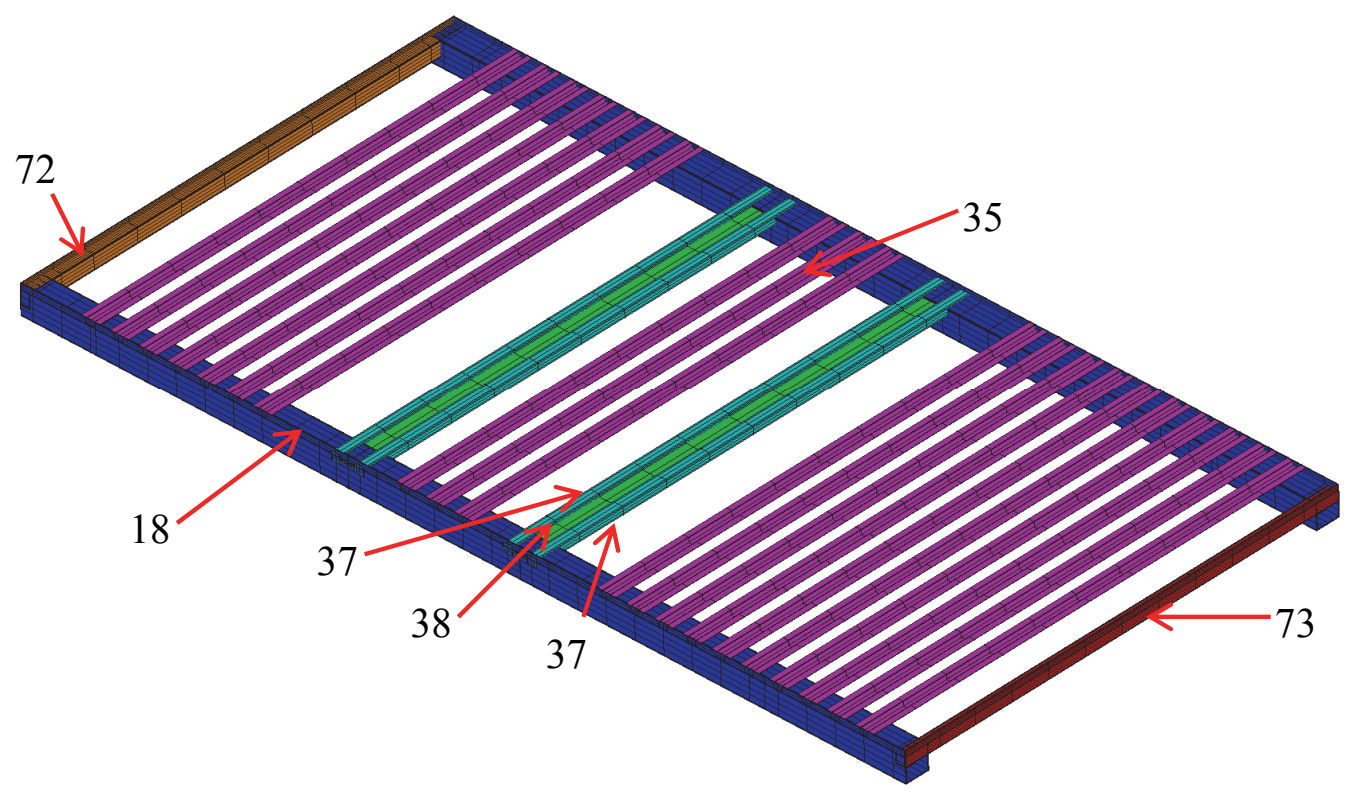

Figure 9. Finite element model of the roof with structural members identified.

The layered shells consist of two elements. The first is the exterior aluminum skin, which is meshed from the areas made on the roof; it uses Real Constant 1 and is a single layer shell element. The second section is an element that is composed of the insulating foam, Lite-Ply, and interior aluminum skin; it uses Real Constant 7 and is a three layer shell element. It is easy to distinguish between the two elements as the top layer is associated with an area and the bottom three layers are not. Figure 3 shows the roof layers in a cross section. 


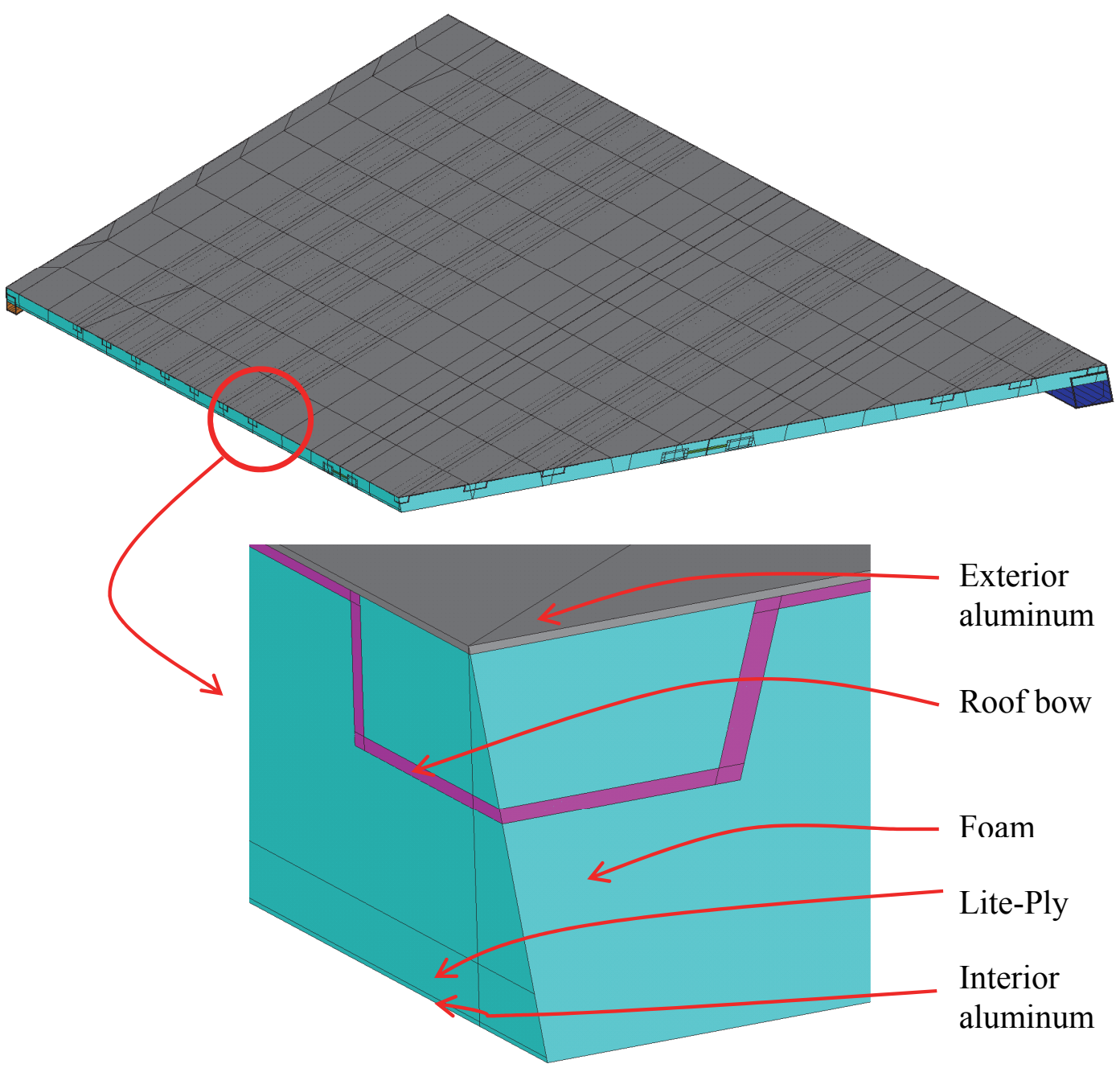

Figure 10. Section view of HCCC roof showing various layers.

\section{B. Sides and Rear}

The sides and rear are comprised of the beams and shells at the rear and sides of the model not associated with the other component structures. Two small sections are towards the front of the HCCC between the expandables and front frame; on larger section is comprised of the rear of the shelter behind the expandables and vertically between the floor and roof. This component contains four box tubes for the main vertical supports for the roof, box tube for top of the rear access door frame, custom bent sheet 
for the sides of the rear access door frame, box tube framing for various electronics panels, hat sections beams, and two corner posts for the shelter made of custom bent plate; these are all represented with BEAM189 elements. The exterior aluminum skin, insulating foam, Lite-Ply, and interior aluminum skin are represented with SHELL99 elements. The sides and rear are shown in Figure 11 with the structural members and exterior aluminum skin (foam and interior layers not shown for clarity), in Figure 12 with only the structural members, and in Figure 13 and Figure 14 with structural members identified.
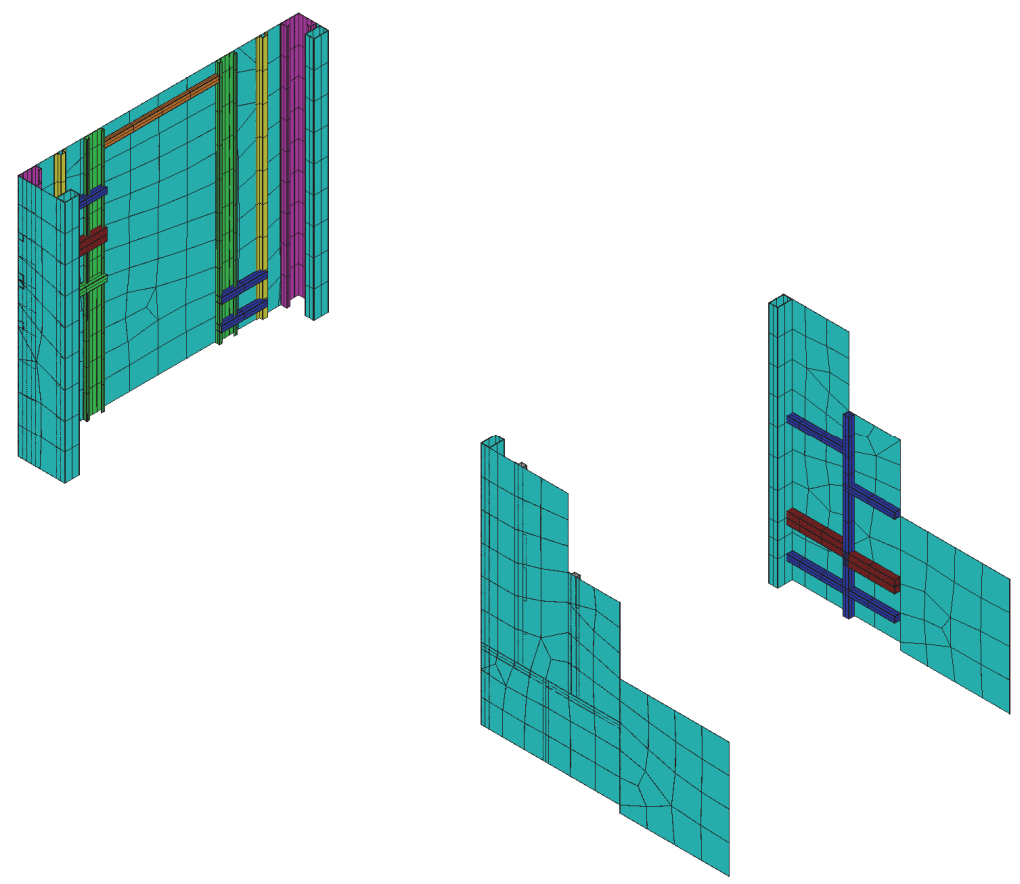

Figure 11. Sides and rear structural with exterior aluminum. 

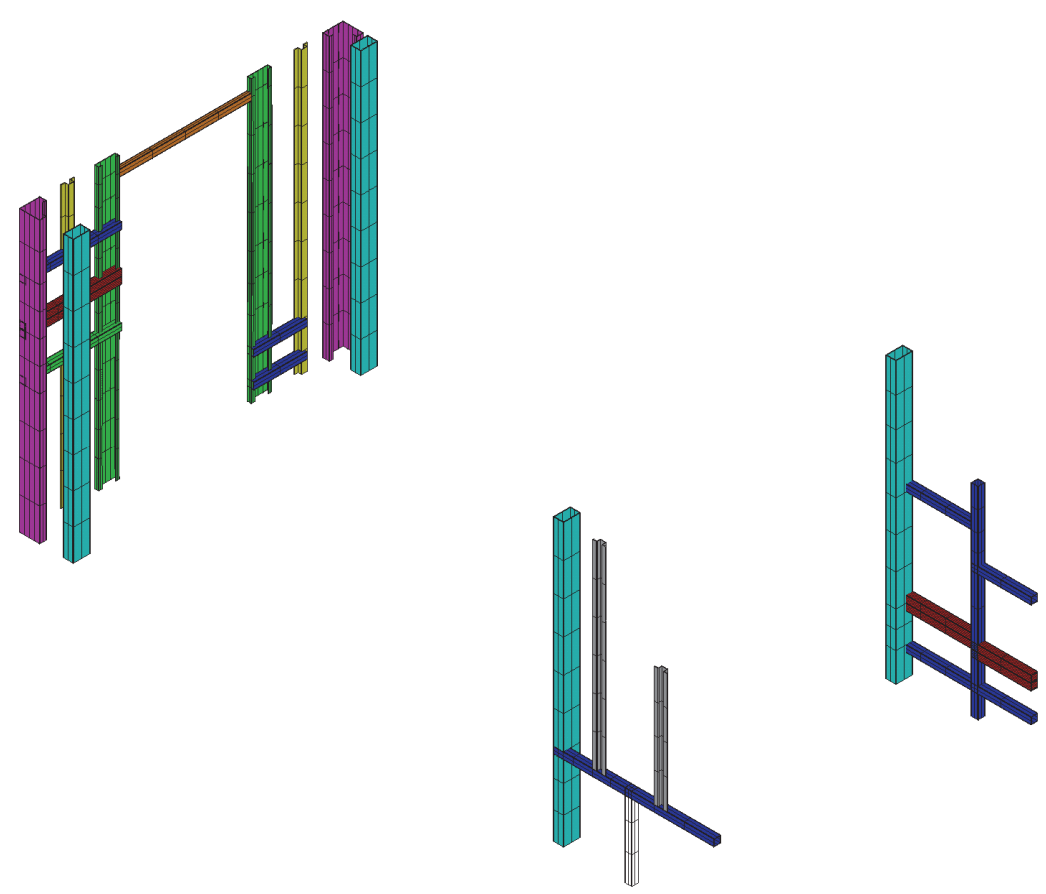

Figure 12. Sides and rear structural members only.
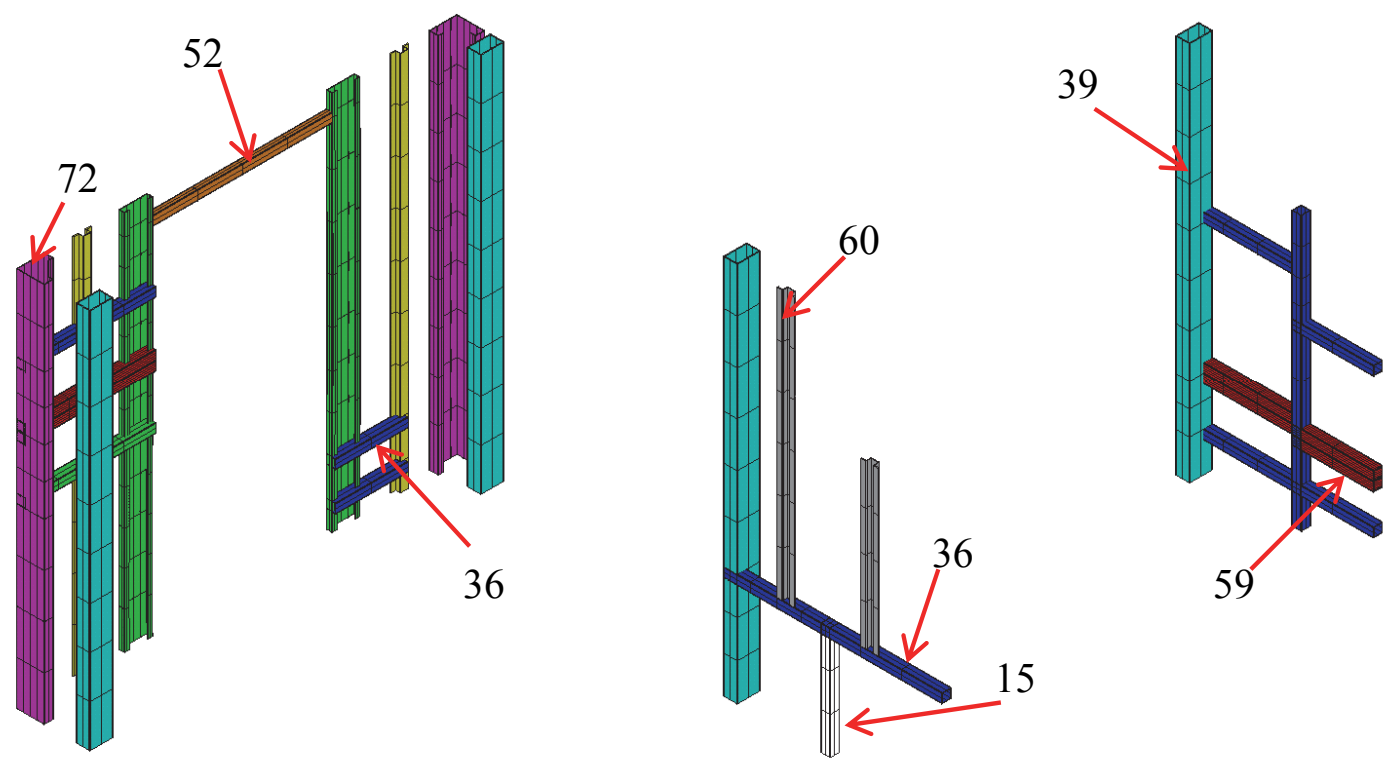

Figure 13. Sides and rear structural members only. Cross sections identified. 


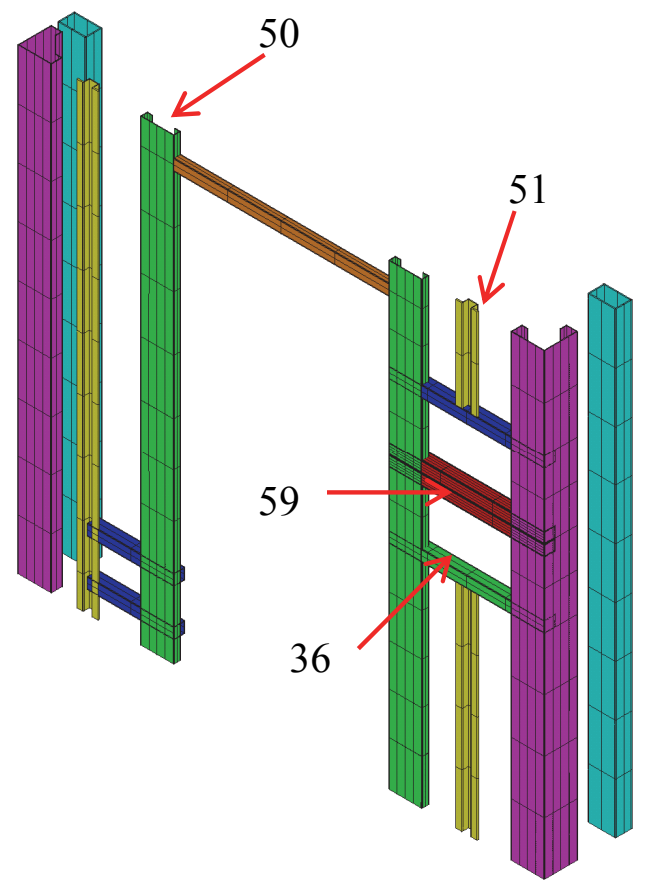

Figure 14. Sides and rear - close-up of rear structural members

The sides and rear component includes a door in the rear part of the shelter. It is hinged at three points on the curb side and has a latch on the road side; each of these points is recreated with keypoints shared between the area for the shell elements on the door and the lines for beam elements on the door frame. This keeps the door attached to the frame only at four points rather than being joined with the frame around their shared perimeter. These points are identified in Figure 15. The door was modeled the same way as the rest of the walls in the sides and rear were; it has an exterior aluminum skin of 0.050", insulating foam of 3", Lite-Ply of 0.375 ", and an interior aluminum skin of 0.030". This assumption was made as a makeup for the door was not provided. This and the rest of the walls in the sides and rear component are Real Constant 9. 


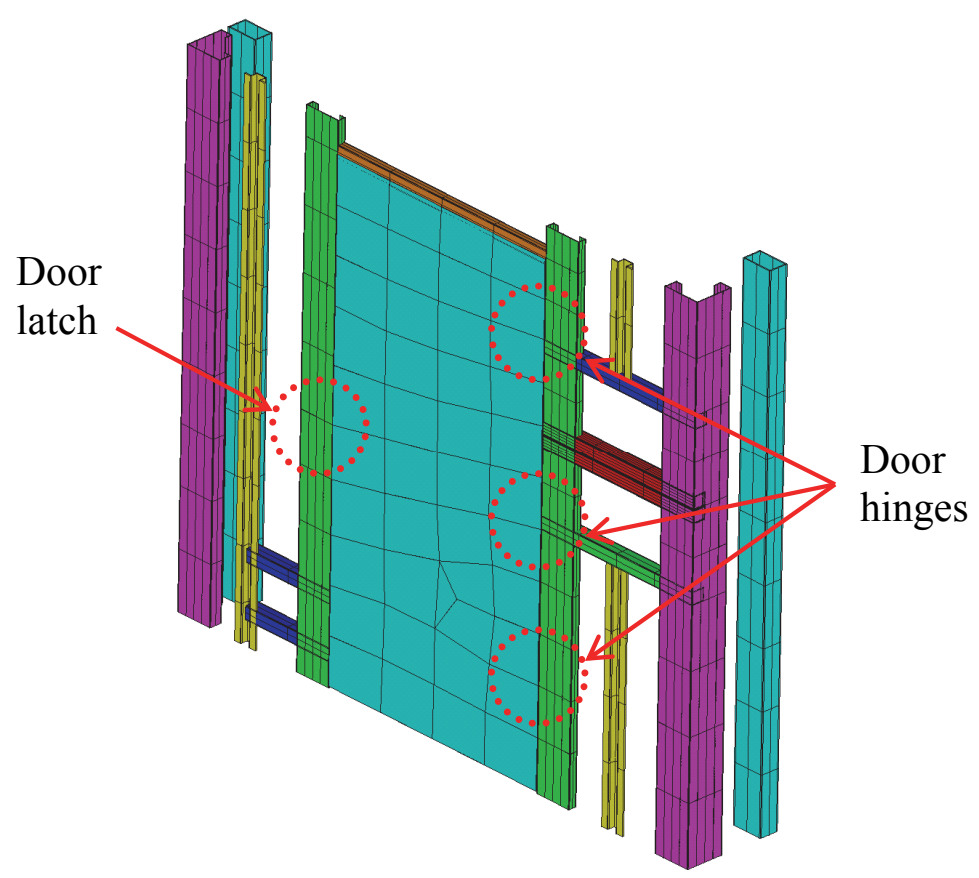

Figure 15. Demonstration of hinge and latch locations for rear access door

\section{Front Frame}

The front frame section of the HCCC consists of 53 structural 2"x2" box tubes, six hat section beams, four sections composed of two box tubes formed into an "L" shape underneath the environmental control units (ECUs) to enable a drain pipe to be used, two ECU supports each composed of three 2"x2" box tubes and two gussets, two plates for mounting the power distribution panel (PDP), two bars that act as the lateral supports for the communications racks, exterior aluminum skin, insulating foam, Lite-Ply, and interior aluminum. All beams were modeled with BEAM189 and the aluminum, foam, Lite-Ply, and gussets were modeled with SHELL99. The front frame is shown both with its exterior aluminum and with only its structural beams in Figure 4. 

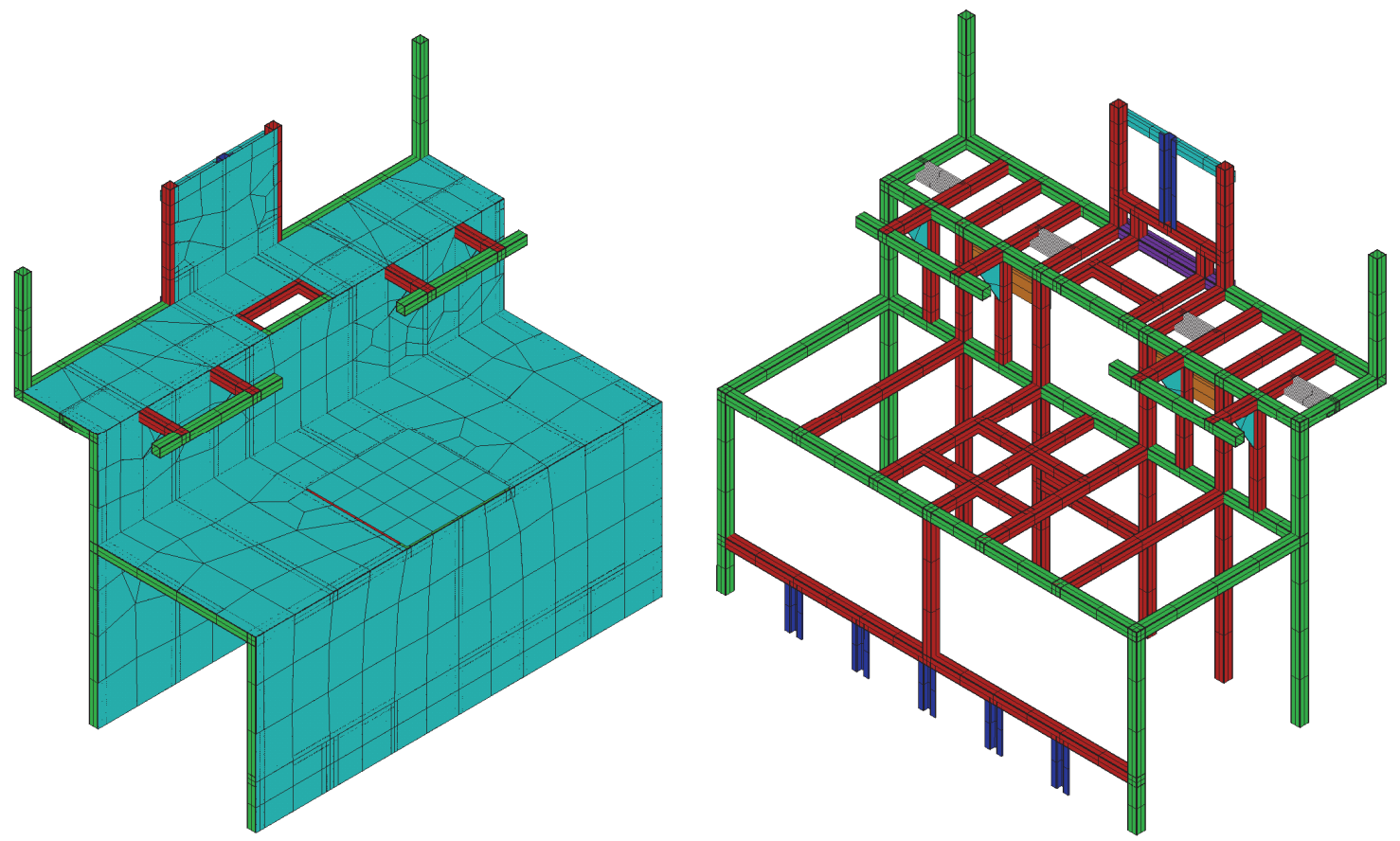

Figure 16. Front frame w/ext Al (left) and structural members only (right).

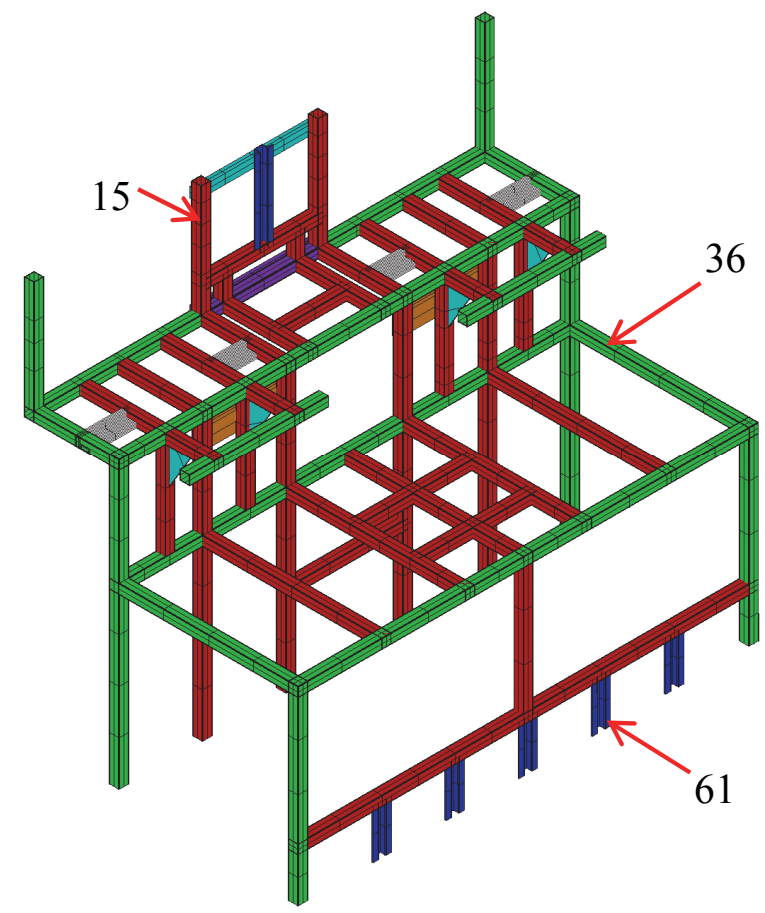

Figure 17. Front frame only structural beams only with cross sections identified. 


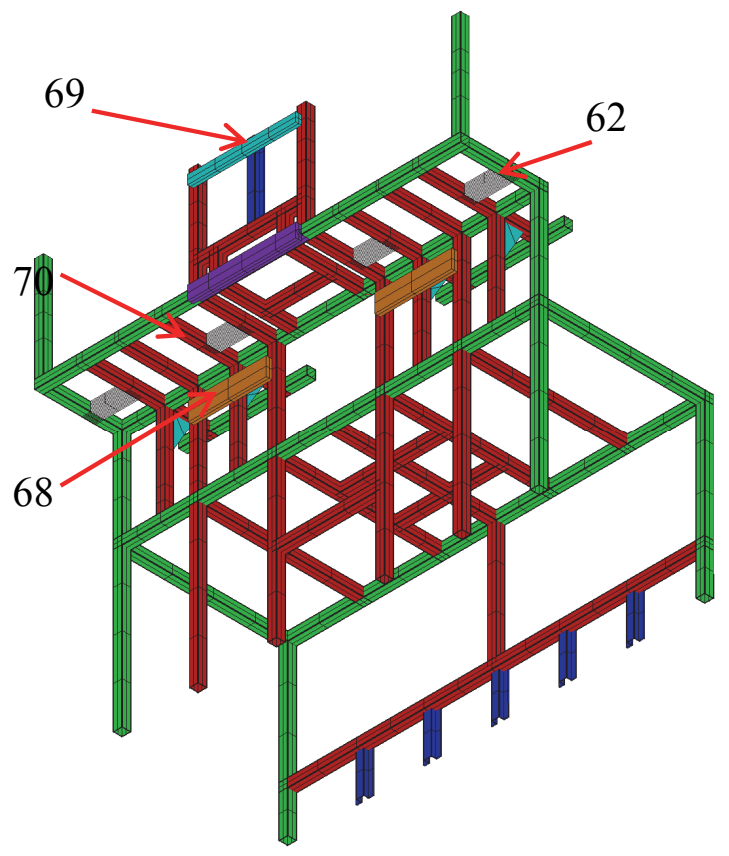

Figure 18. Front frame only structural beams as viewed from behind and underneath with cross sections identified.

\section{Roadside Expandable}

The roadside expandable contains 12 wall-stiffening hat section beams, 53 2"x"2 box tubes, two 4"x6" box tubes, one 2"x3" box tube, one 2"x6" box tube, and two wide flange beams. The wide flange and 4"x6" box tube are combined in the same cross section in ANSYS where applicable. The RS expandable is shown in Figure 19 and Figure 20. Cross section IDs 42, 43, 45, 46, and 48 are 2"x2" tubing. Section ID 41 is hat section. Section ID 44 is 4"x6" tubing, section ID 47 combines that with wide flange, and section ID 49 is 2"x6" tubing. Structural beams are identified in Figure 21 and Figure 22. It should be noted that the beam associated with Section 49 is not directly attached to the model; it is joined using constraint equations with the beam DOFs 
controlled by those along the bottom edge of the expandable (attached to the floor/side wall shell elements).
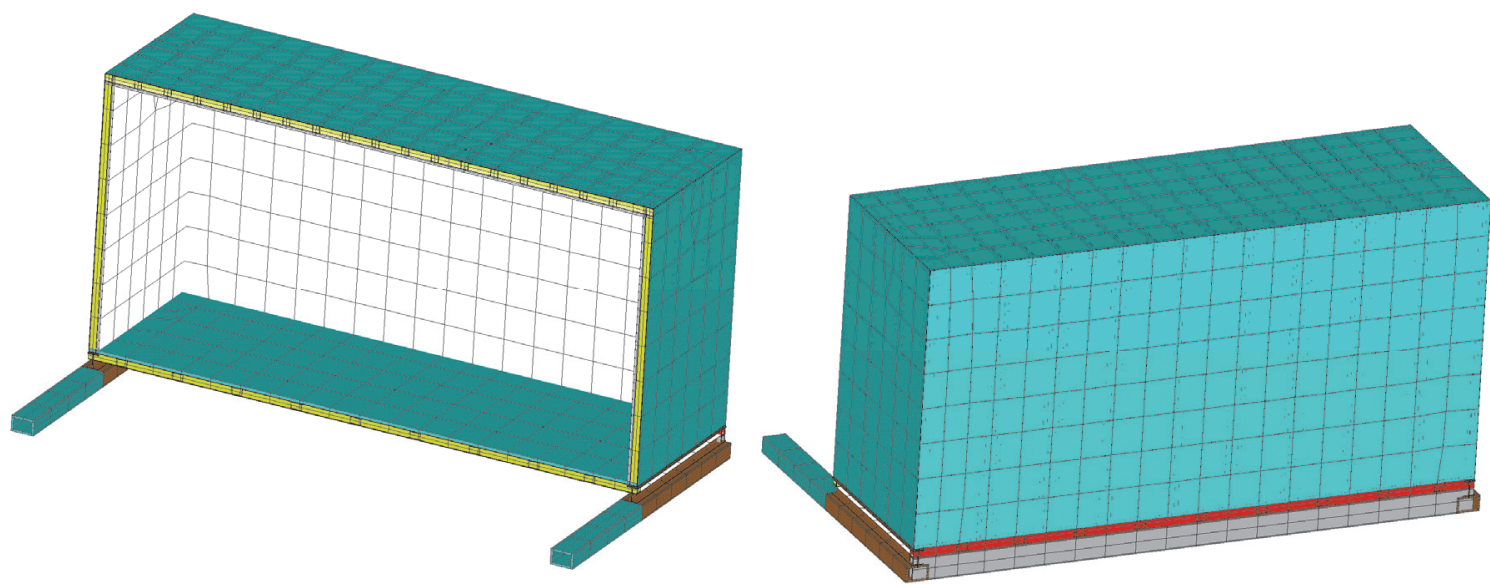

Figure 19. RS expandable shown from RS and CS.

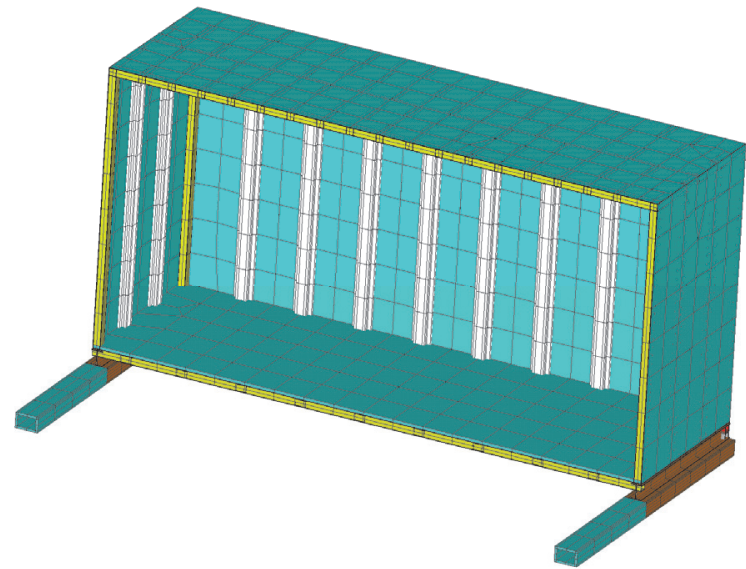

Figure 20. RS expandable without inside wall, viewed from RS. 


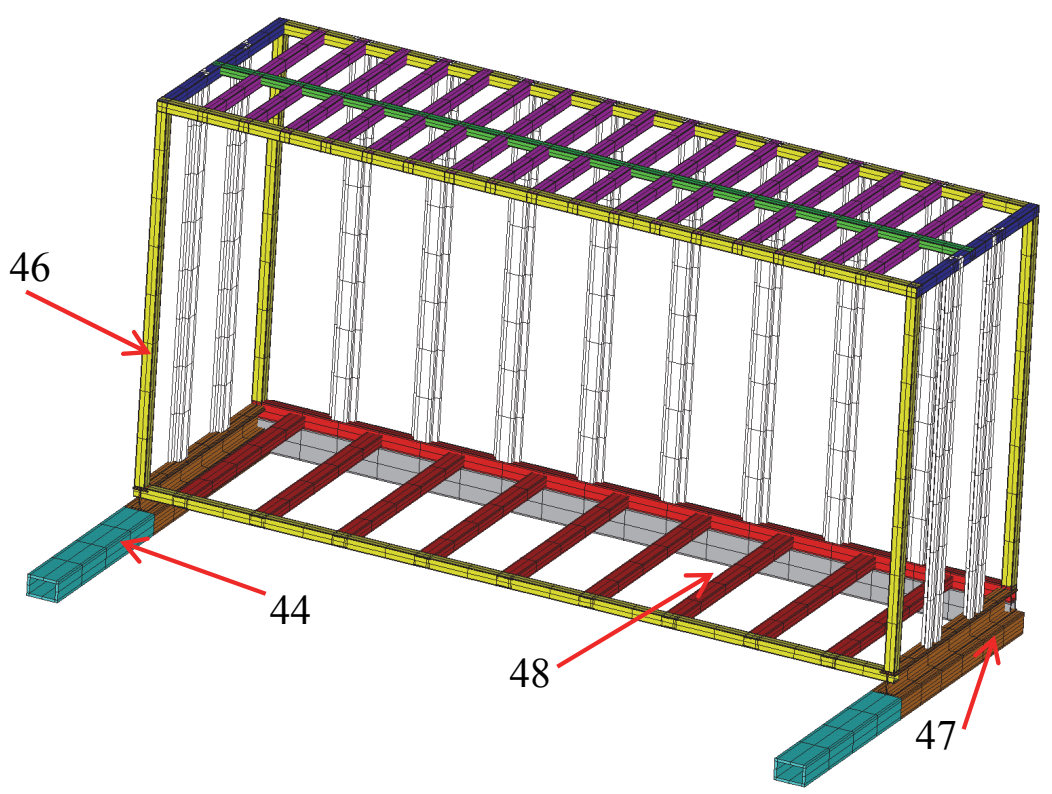

Figure 21. RS expandable structural members only viewed from CS.

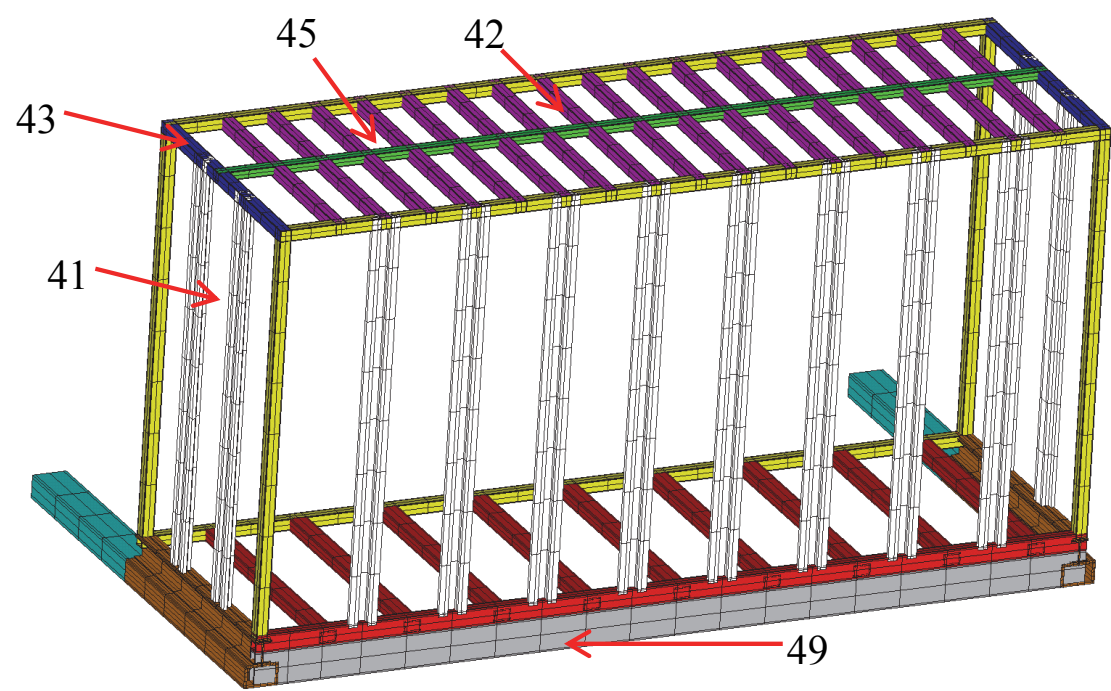

Figure 22. RS expandable structural members only viewed from RS.

The layered shells in the side walls and roof are built the same way as in the roof; one element is a single layer shell of aluminum, and the second element is a three layer shell of foam, Lite-Ply, and aluminum. The floor of the expandable is slightly different in that a thicker section of Lite-Ply is used as the single layer shell; the second element of 
the floor is a two layer shell composed of insulating foam and an exterior sheet of aluminum. A close up of the expandables floor layers is picture in Figure 23.

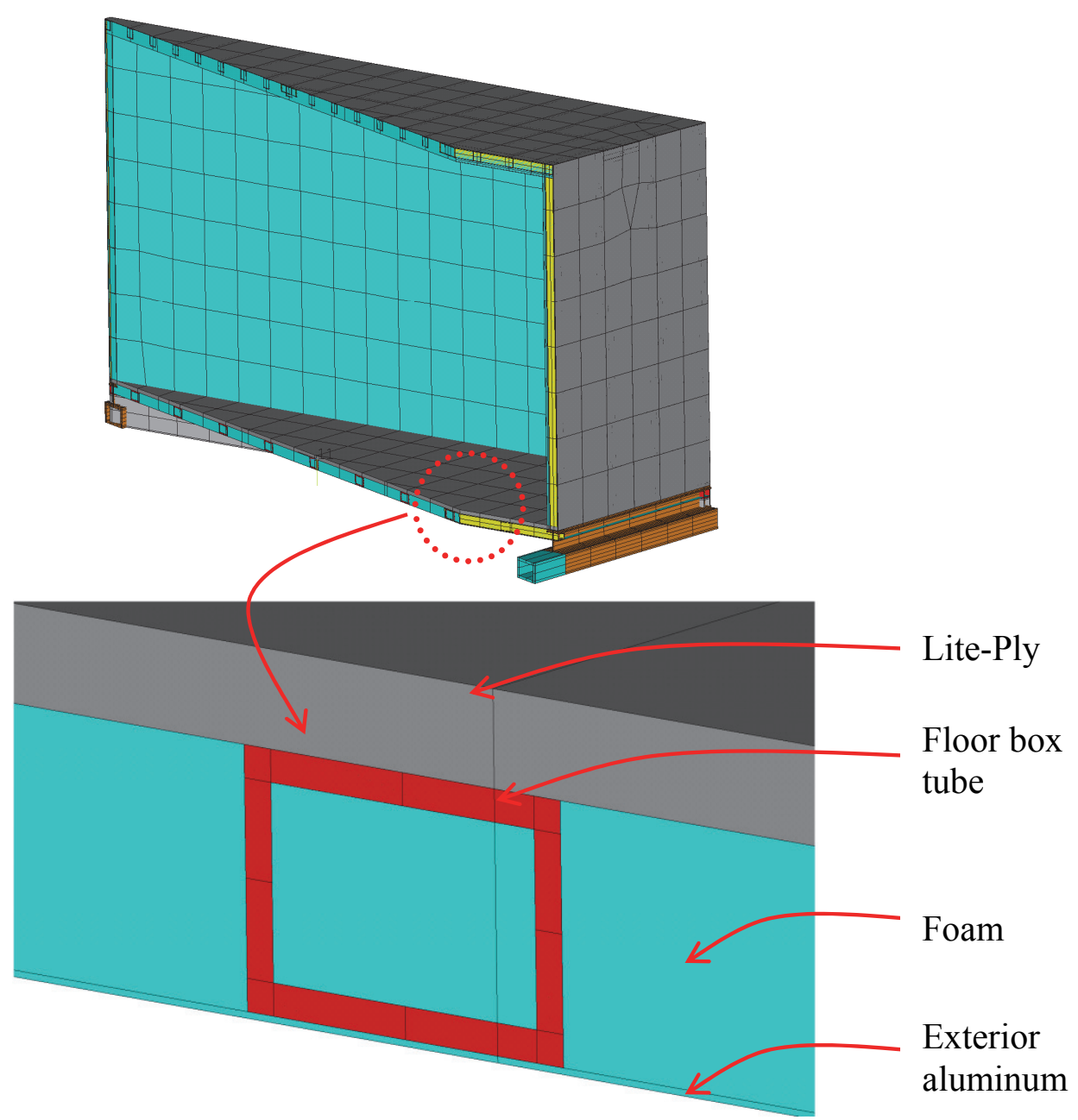

Figure 23. Close up of expandable floor ply order.

\section{E. Curbside Expandable}

The curbside expandable is similar to the roadside expandable; the differences include containing a window, emergency escape door, and being slightly shorter in width. It is comprised of 10 hat section beams, 49 2"x2" box tubes, two 4"x6" box tubes, two 
wide flange beams, one 2" $\mathrm{x} 6$ " box tube, one 2"x3" box tube, four custom bent sections of plate that create the window and escape hatch framing, an exterior aluminum skin, LitePly paneling, insulating foam, and an interior aluminum skin on the walls and ceiling. The expandable is shown from two angles and with the interior walls visible in Figure 24; it is shown without the interior walls in Figure 25. The curbside expandable shares section IDs 41, 42, 44, 45, 46, 47, 48, and 49 with the roadside expandable. Section IDs 50 and 63 are used to frame the window and emergency escape hatch located below the window. The structural member cross sections are identified in Figure 26. As with the roadside expandable, the beam associated with Section 49 is not directly attached to the model; it is joined using constraint equations with the beam DOFs controlled by those along the bottom edge of the expandable (attached to the floor/side wall shell elements).
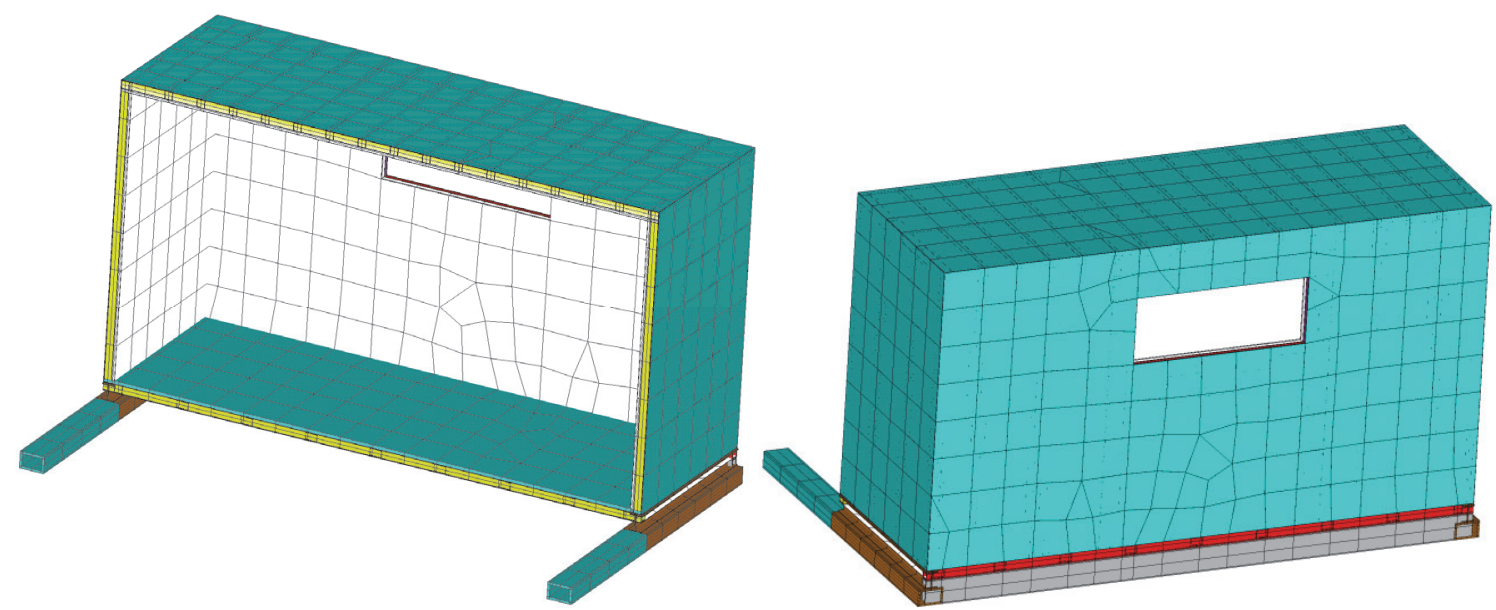

Figure 24. CS expandable shown from RS and CS with interior wall visible. 


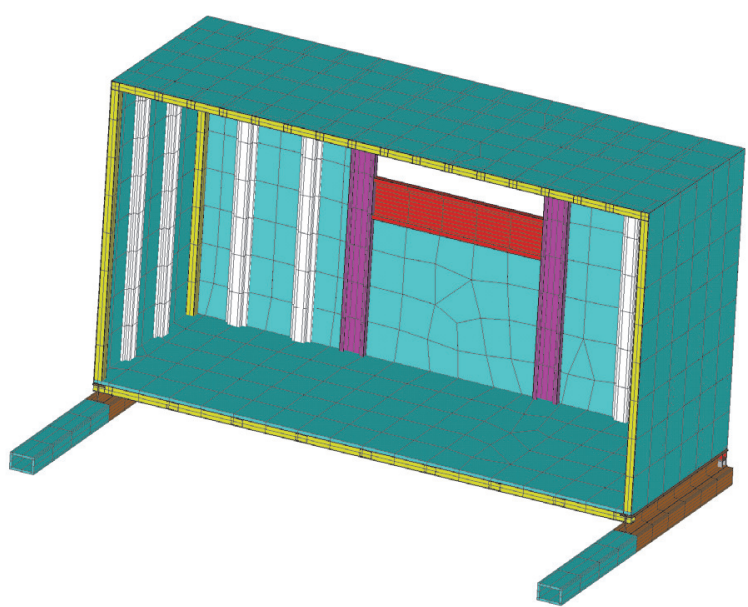

Figure 25. CS expandable shown without internal wall.

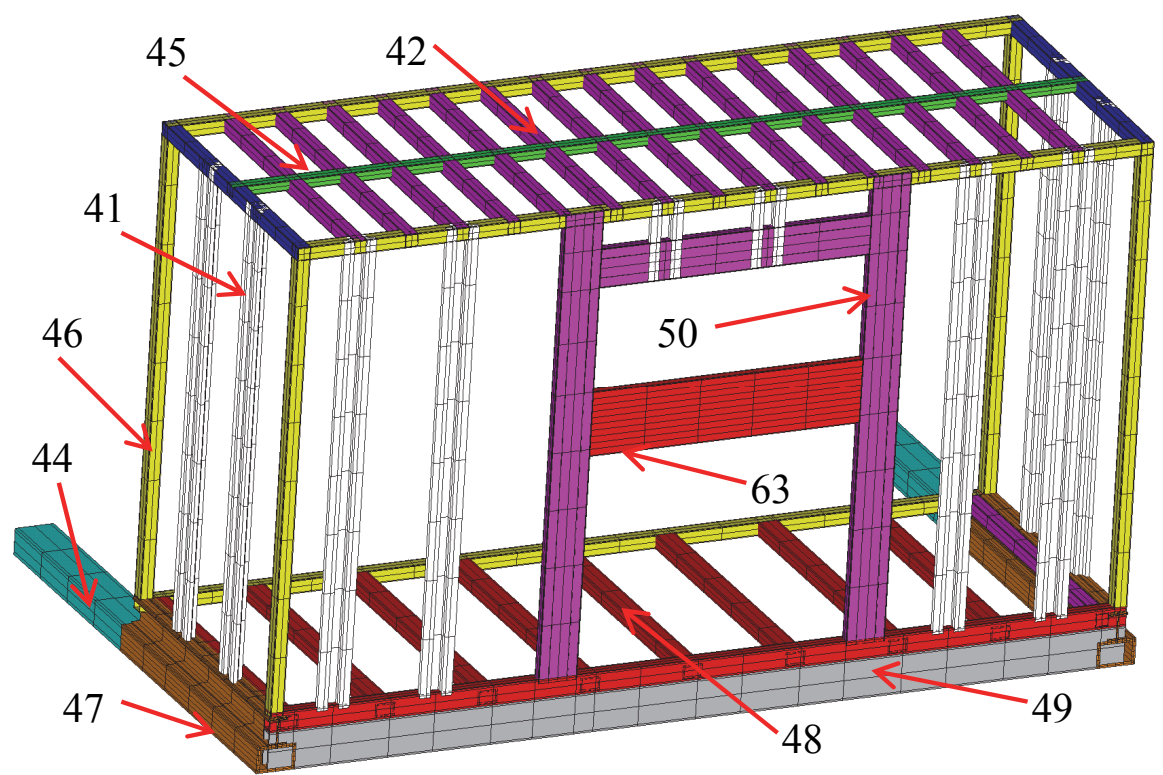

Figure 26. CS expandable with structural members identified.

The window, not being viewed as a structural component, was left as a void in the model. The emergency escape door was modeled in the same manner as the rest of the walls. Section IDs 48 and 49 are joined in the same manner as the bottom outside beams in the RS expandable. 


\section{F. Floor}

The floor section is composed of 62 structural beams, an underside aluminum skin, a Lite-Ply interior surface to walk on, and insulating foam underneath that. The structural beams include $\mathrm{C}$ channel, wide flange, box tube, bar stock, and custom cross sections for the side rails, slide tubes, and APU mounts. Gussets support the APU mounting rails. Additionally, one ISO block is located at each corner of the shelter; an additional ISO block was placed at midpoint on both the roadside and curbside of the shelter in production after the computer model was complete. Each ISO block is generated with single layer shell elements.

All of the floor elements are shown in Figure 27 while only the structural members are shown in Figure 28 (the aluminum skin underneath the APU tunnel is shown due to the nature in which it was created). Figure 29and Figure 30 go on to identify Section IDs in the floor seen from the top. The underside of the floor section is shown in Figure 31. Section IDs seen from the underside are identified in Figure 32 and Figure 33. As with the expandable sections, there are several beams that are not directly attached to the model but are instead joined via constraint equations; the side reinforcement beam (Section 55; see Figure 30) falls into this category. The forward section of the floor (i.e. in the region of the APU tunnel) is also built on a different elevation than the floor sections aft of this location. This is because the beam heights are different in this section and there was no simple way to do otherwise; again, constraint equations are used to join the model sections together appropriately. Finally, shell elements are used to represent the gussets reinforcing the lateral beams in the APU tunnel 
(see Figure 29 - the gusset plates connect sections labeled as 2 and 58 and 14 and the unlabeled section (also 58)).

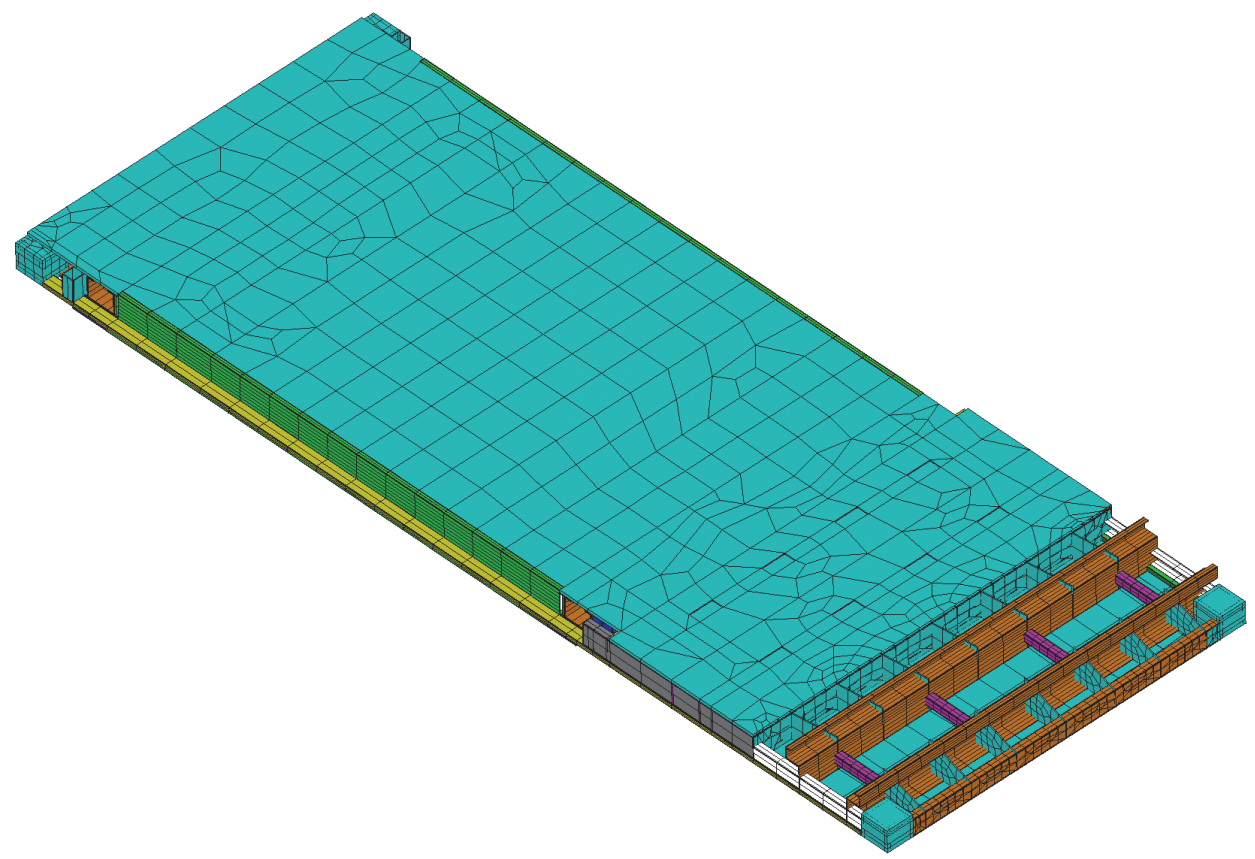

Figure 27. Floor elements with structural members and floor panels.

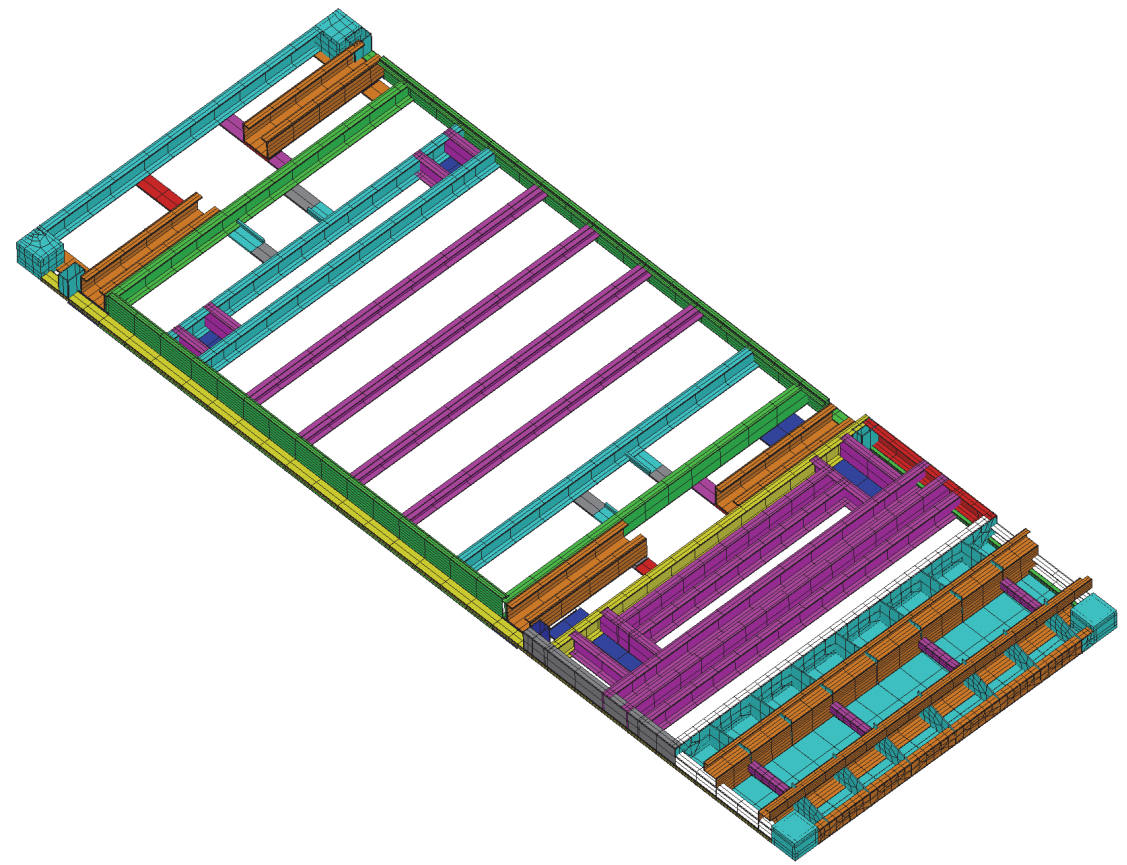

Figure 28. Floor elements. Structural members and APU tunnel floor pan shown. 


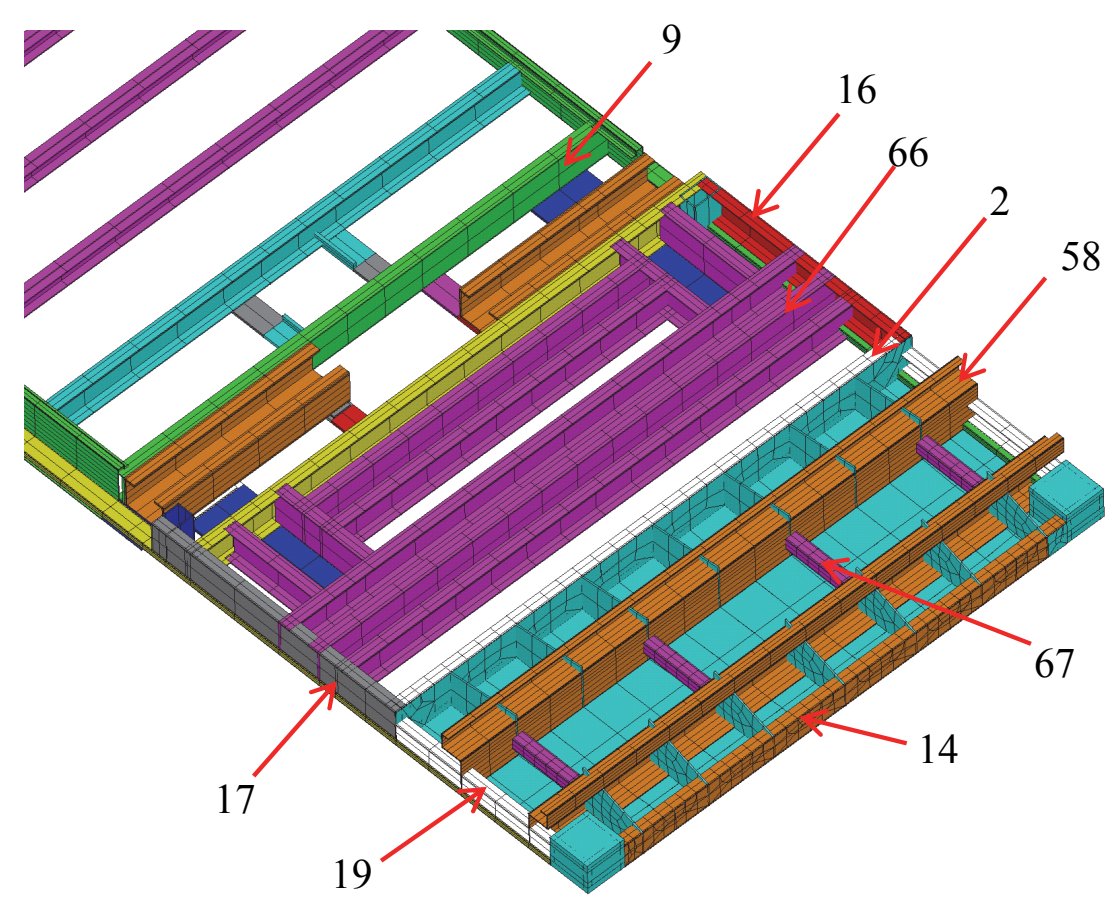

Figure 29. Front floor elements. Structural members and APU tunnel floor pan shown.

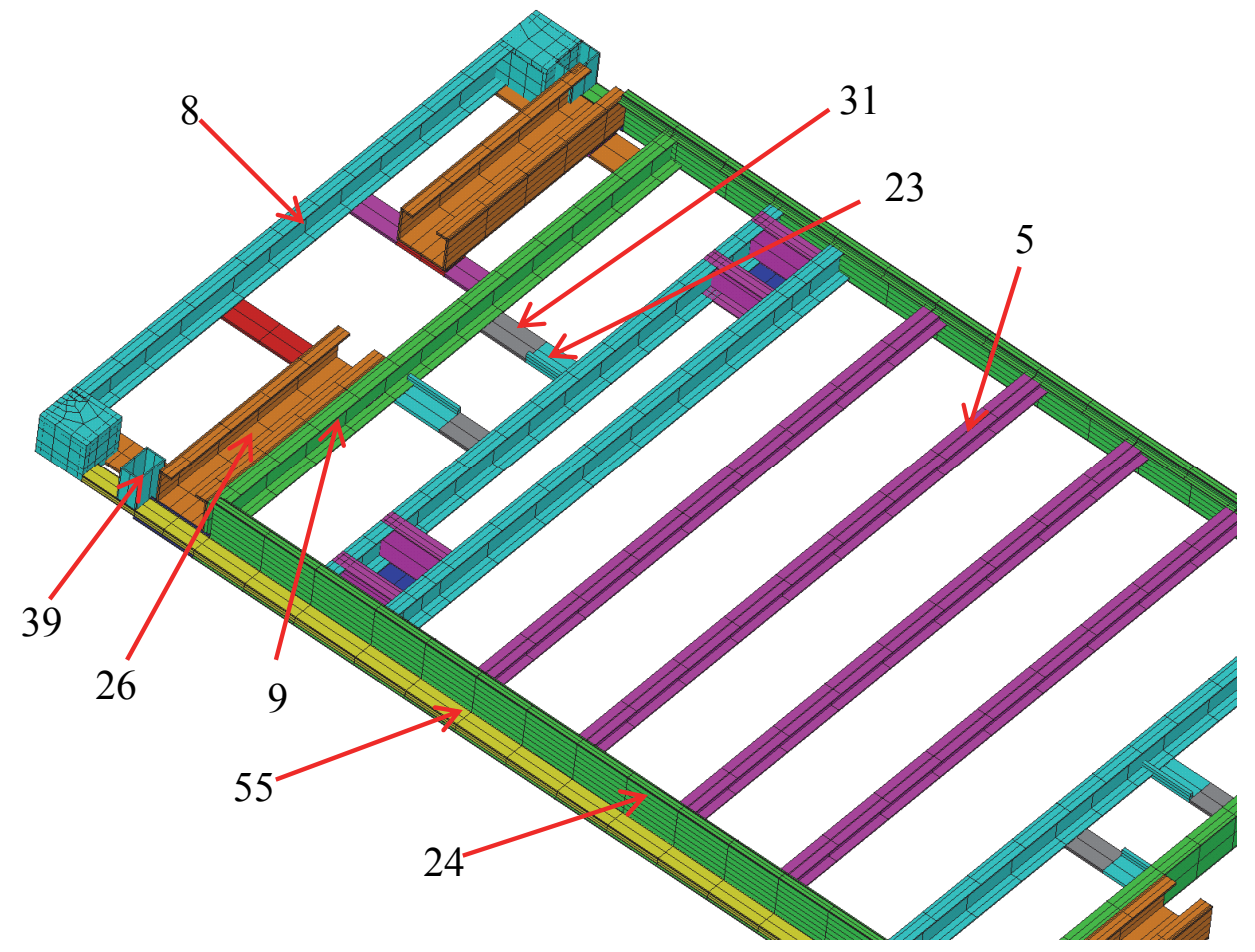

Figure 30. Rear floor elements. Structural members and APU tunnel floor pan shown. 


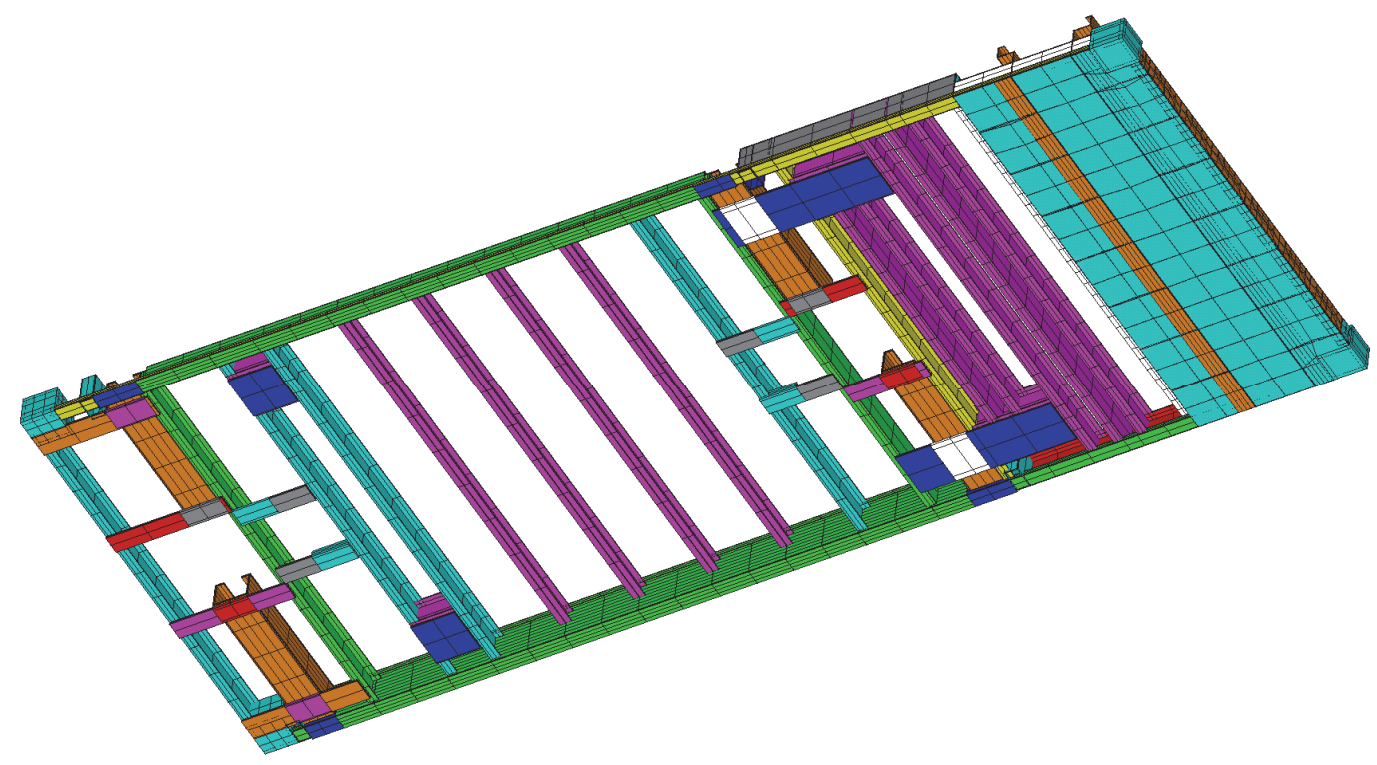

Figure 31. Floor elements. Structural members and APU floor pan shown from bottom.

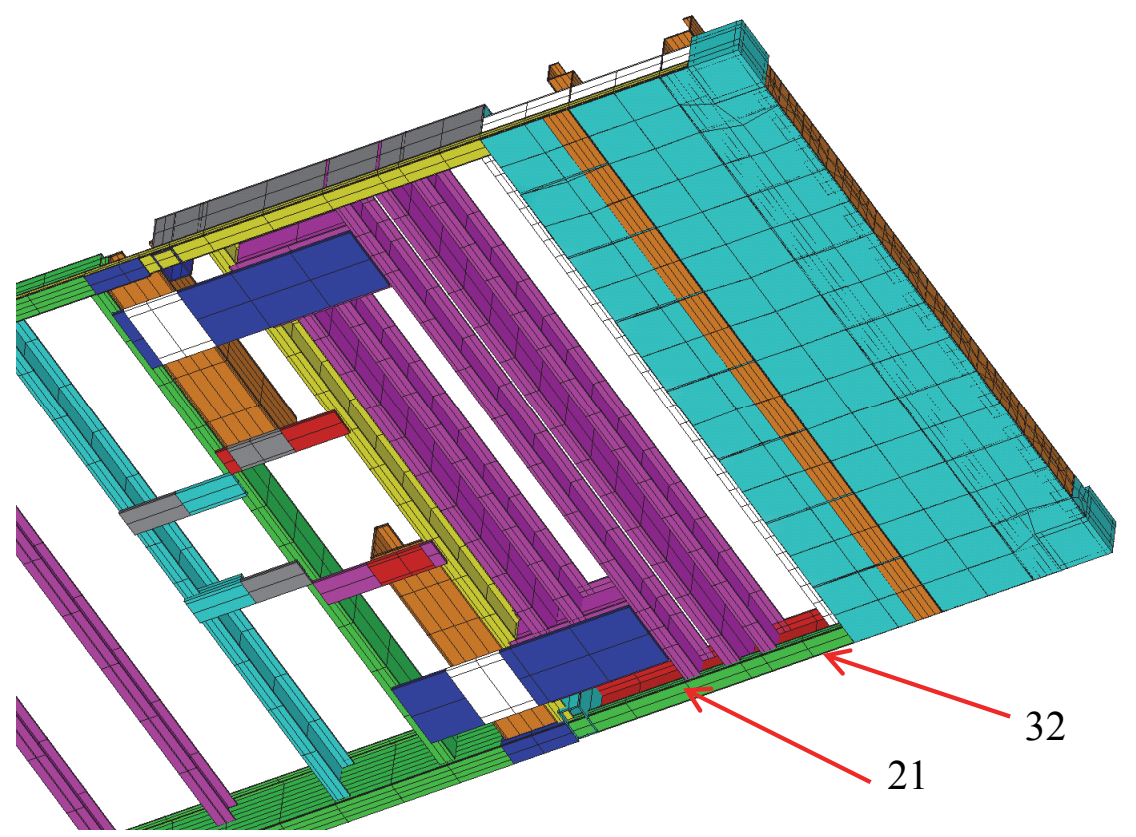

Figure 32. Front floor elements. Structural members and APU tunnel floor pan shown from bottom. 


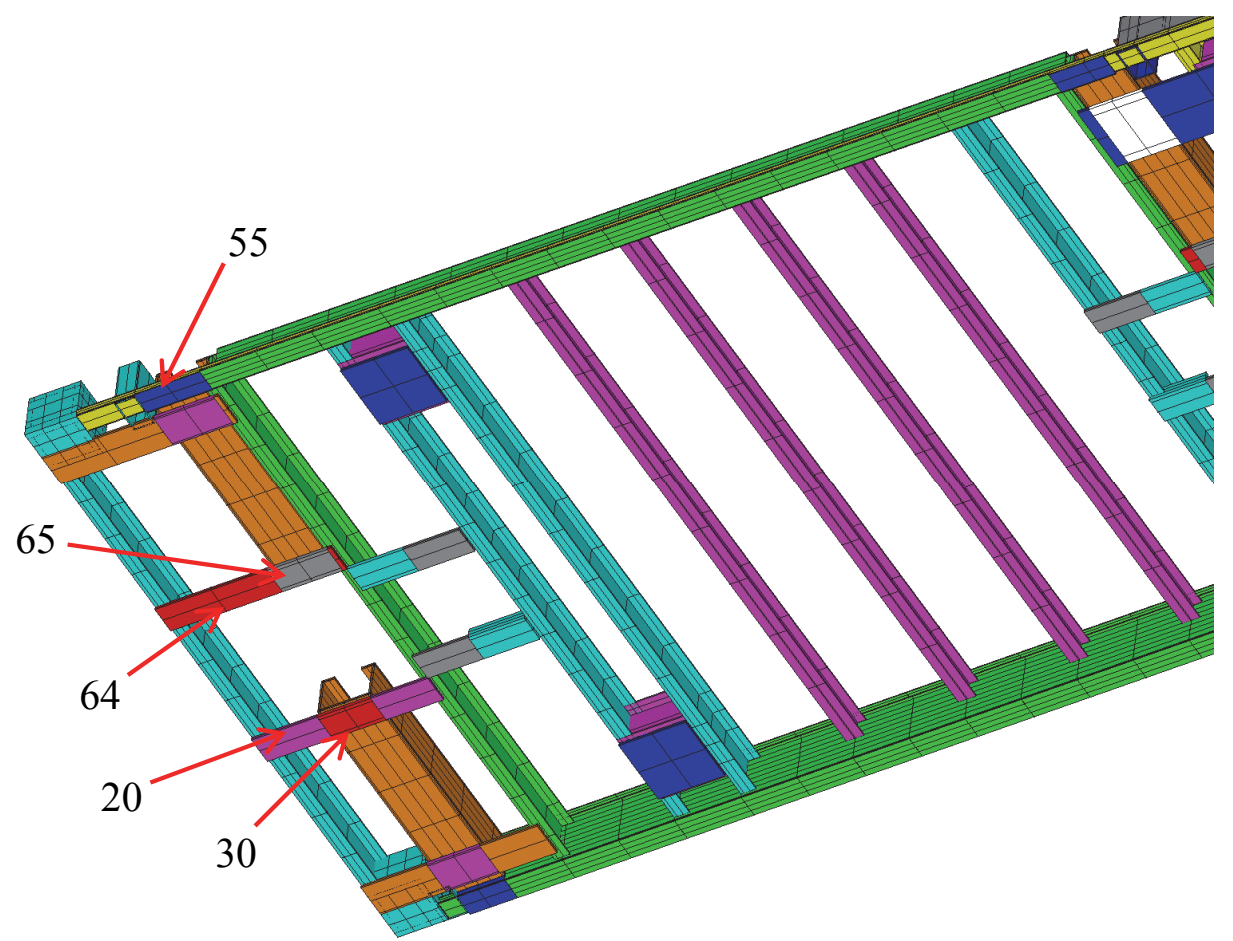

Figure 33. Rear floor elements with structural members and APU tunnel floor pan shown from bottom.

\section{G. Attaching Non-Structural Masses to HCCC Model}

Throughout the HCCC, there are several items that contribute a significant weight in a concentrated area. Such items include the environment control units on the front frame, hydraulic pump in the floor, and communications array on the front frame. Rather than model the items with respective geometry and materials, they were simplified with MASS21 elements. MASS21 elements represent point masses; they can represent masses in two dimensions or three dimensions and include or exclude rotational moments of inertia. The MASS21 elements used in the HCCC model are input for three dimensions and neglect rotational moments of inertia. The point masses were located at the centers of gravity for each item (as specified by Kentucky Trailer Technologies). These are attached to the appropriate model section with (nearly rigid) BEAM189 elements; this 
provided a way to both distribute the load to several attachment points but it does not correctly reflect the stiffness of the items that are being represented. There are 10 MASS21 elements used on the HCCC model. They are all attached to the floor, front frame, or both. The locations of the masses are shown in Figure 34, Figure 35, and Figure 36. Each mass is given its value with REAL constants 21-29; these are listed in Appendix II.

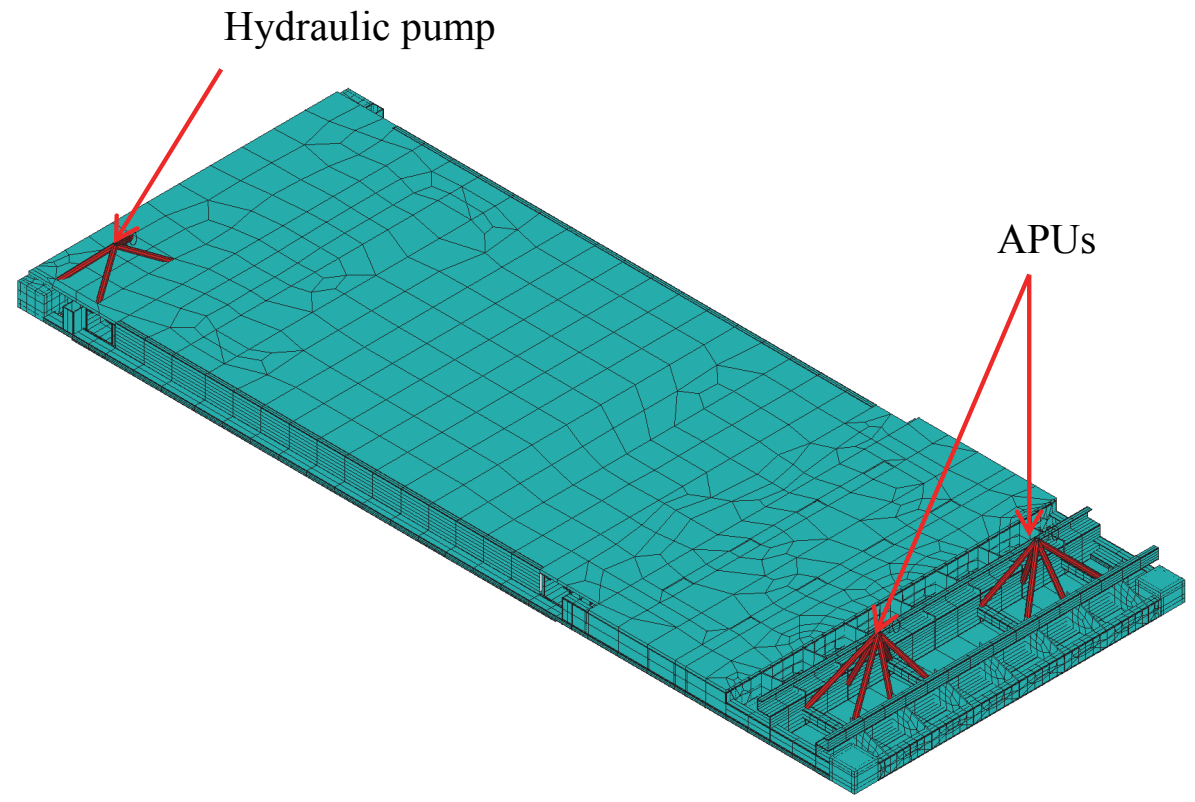

Figure 34. Masses attached to only the floor. 


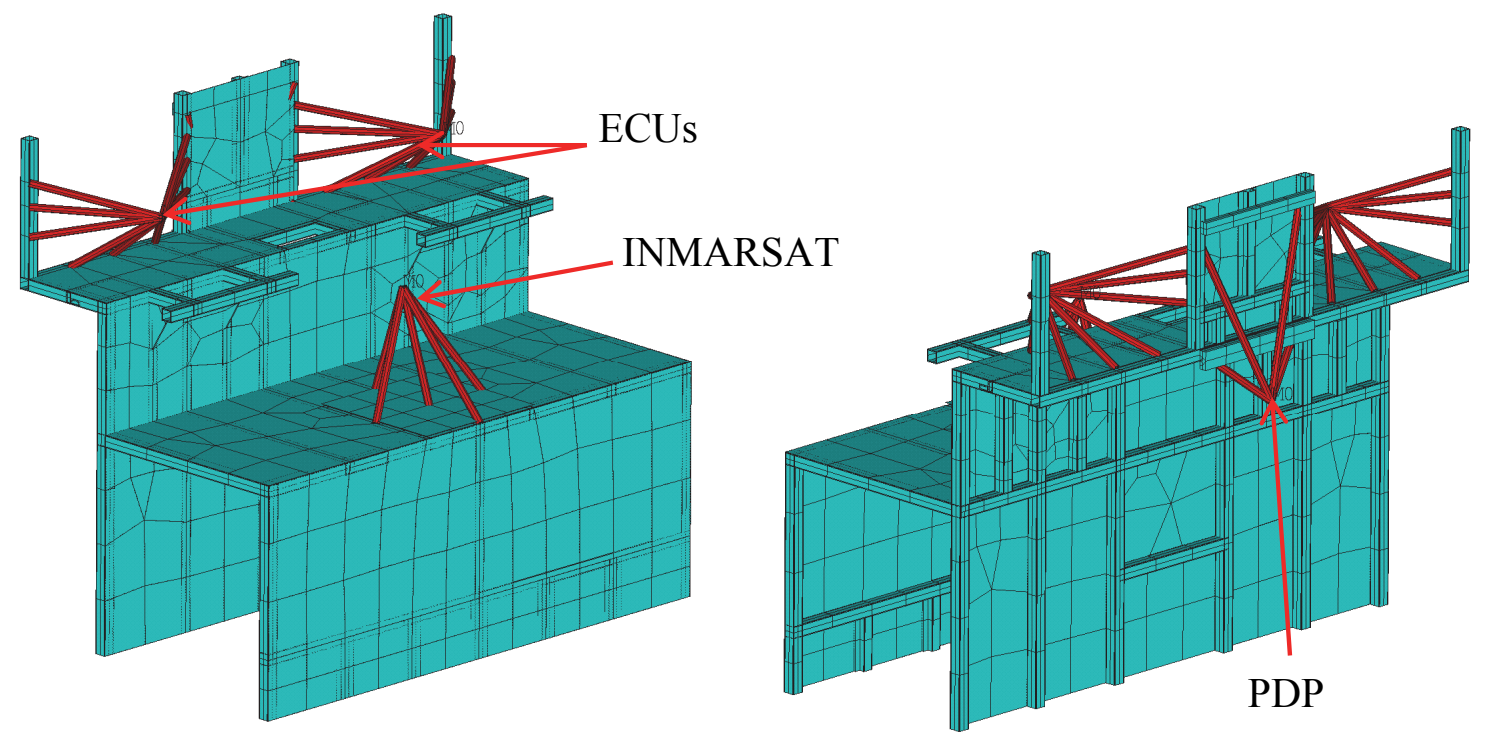

Figure 35. Masses attached to the front frame only (front view, left, and rear view, right).

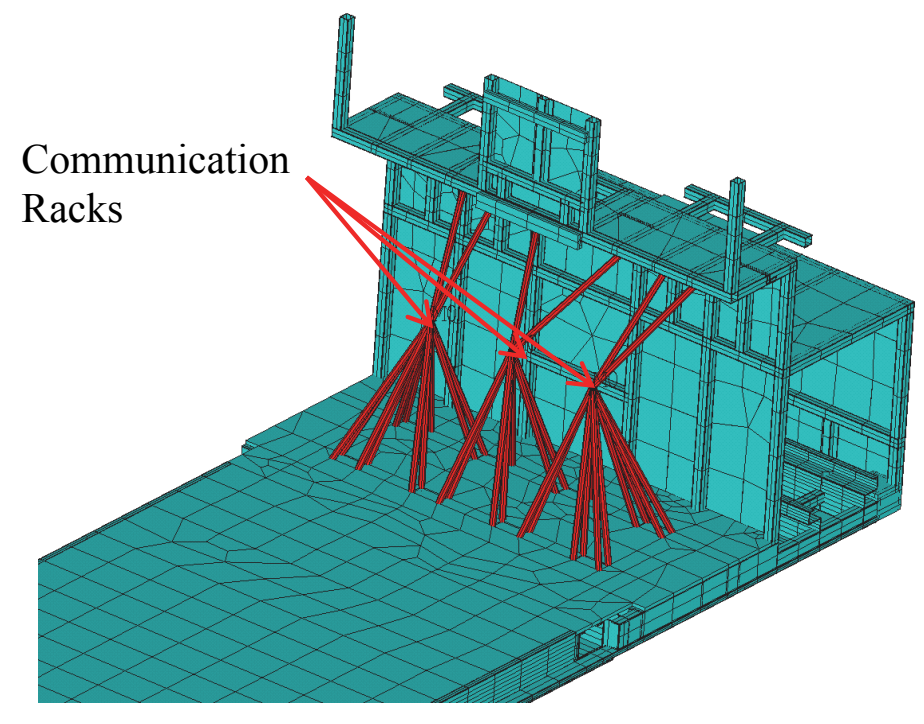

Figure 36. Masses attached to both the floor and front frame. 


\section{ADVANCED AND NONLINEAR FEATURES OF HCCC FEM}

The master input file "Build_HCCC.inp" fully creates the HCCC model. This file begins by creating the overall parameters for the model including the element types, real constants, material properties, model sections, other model properties, and loading parameters. Each section shown in Figure 6 is then created within its own input file called by Build_HCCC in order. Build_HCCC then joins the sections together suitably via coupling and constraint equations. Contact elements are also used to simulate the contact between the HCCC shelter base and the truck bed (assumed rigid for this analysis).

\section{A. Common Features of Each Major Section Input File}

The input files that create the sections shown in Figure 6 each follows the same format from start to finish. The basic order is keypoint generation, line generation, area generation, assigning attributes to lines and areas for element meshing, meshing lines and areas into elements, creation of individual components for later reference (e.g. structural beams only, shell elements only, combination of beams and shells, etc.), and generation of internal shell layers for walls, floors, and ceilings.

Each model section is initiated with the NUMSTR command which allows the user to define the numbering that model features start at such as keypoints, lines, and areas; each section was started in a different thousand series (1000, 2000, etc.) so as to keep certain aspects of the model creation easier as well as simplifying the identification between the sections. Certain sections were more complex than others and included geometry and model amendments that occur later in the input file. This typically resulted 
from changes to the HCCC fabrication relative to the original AutoCAD / Inventor models used to create the HCCC model. For example, the floor section input file has four parts in which keypoints, lines, areas, and elements are created to account for various changes during the project.

It should be emphasized that the finite element model is essentially a complex top-down code - changes to individual parts of any input file must be correctly treated to avoid having ramifications to the parts that follow. For example, the deletion of a line in one part can result in changing the line numbers of the lines that follow; areas constructed by referencing said line numbers must therefore change. A great deal of effort went into modifying and validating the HCCC finite element model; there were many such changes between the receipt of first drawings (approximately June, 2007) and the version that this report considered as final (approximately February, 2008). With the exception of minor corrections, the HCCC model was largely in a complete final form by June, 2008.

\section{B. Joining Major Model Sections}

Each model section is built separately to simplify its construction. An issue that arises with building the model sections separately comes in joining the sections together to form the shelter. Using this approach, the different regions do not share common nodes or elements and will behave independently of one another unless suitably joined. During creation of the model, lines were positioned and meshed in such a manner that element were formed where two sections met so that their nodes would be roughly collinear (i.e. all nodes lie on a common line even though they exist at different points along said line). 
The chosen method of joining the sections together was linear constraint equations. "Linear constraint equations provide a more general means of relating degree of freedom values than is possible with simple coupling." (ANSYS Help 12.4) In this approach, certain nodes are deemed as control (master) nodes; these nodes drive the remaining (slave) nodes via suitable geometric relationships. These constraint equations are automatically generated CEINTF command in ANSYS. The CEINTF command "can be used to 'tie' together two regions with dissimilar mesh patterns." (ANSYS Help) Figure 37 shows the roof and front frame sections with their constraint equations visible as pink triangles for each constrained direction; essentially, the nodes on the edge of one section (i.e. the roof) dictate the motion of the nodes on the other section (i.e. the front frame) using an appropriate interpolation of nodal degrees of freedom. These types of constraint equations exist between: 1) roof and front frame; 2) floor and front frame; 3) floor and sides and rear; and 4) between roof and sides and rear.

Constraint equations are also used in several sections to tie beams together that lie in different positions in space but that are joined in practice (i.e. when welded together). For example, the horizontal beam on the outside bottom surfaces of each expandable was modeled in this manner (discussed later). Finally, constraint equations are also used to attach the expandables to the main HCCC shelter; this is discussed in detail in the next section. 


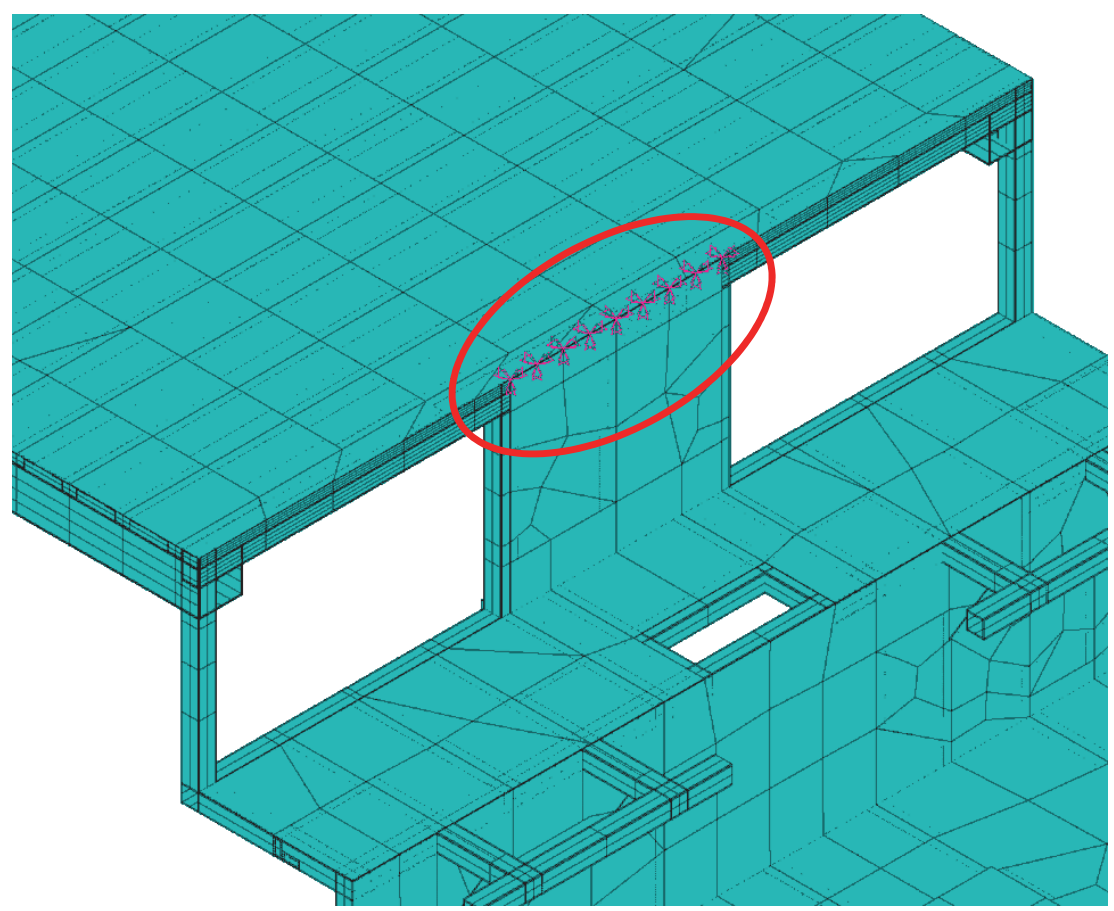

Figure 37. Roof and front frame constraint equations.

\section{Joining Expandables to Main Shelter}

The expandables are also distinct sections from the rest of the HCCC model. However, the model was created to allow analysis with the expandables in a variety of configurations (i.e. stowed as for transport or extended as when field deployed). As such, the CEINTF approach described above was not suitable. Constraint equations are still used but in a slightly different manner than the joining together of the other model sections. Each expandable has five connections with the main shelter. The expandables are primarily supported by two slide rails that slide into respective slide tubes in the floor; this is shown in Figure 38. Constraint equations connect the slide tubes and slide rails and constrain them in the vertical and longitudinal directions; specifically a node on the slide rail is specified to have the same motion as the neighboring nodes of the slide tubes 
(vial suitable linear interpolation). This required significant programming effort to complete but it does correctly provide for support of the expandables by the support tubes in any practical position.

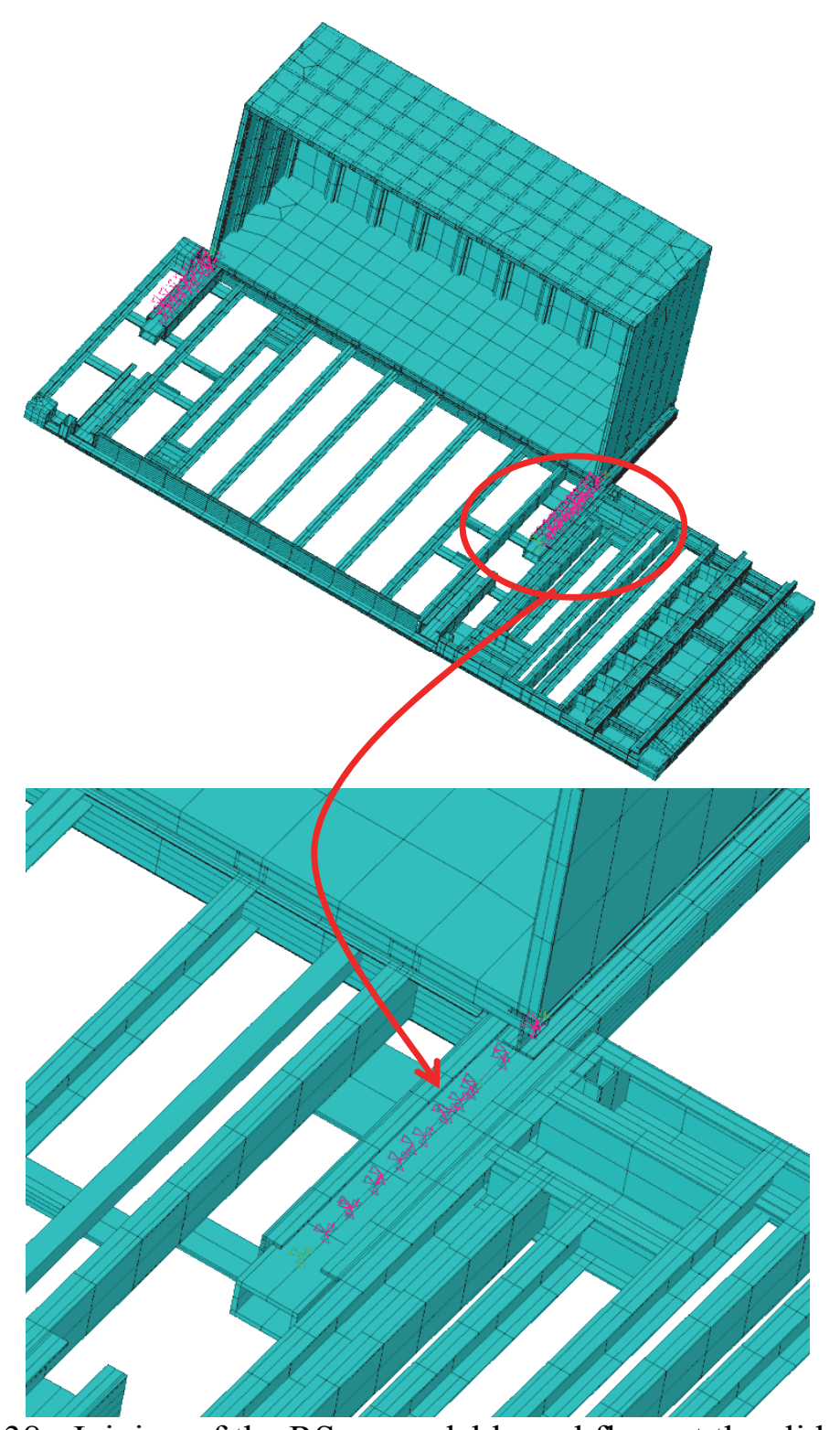

Figure 38. Joining of the RS expandable and floor at the slide tubes.

The expandables are held in place laterally via the hydraulic cylinders that open and close them. Each actuator is modeled as a (nearly) rigid 2 force member (via a 
LINK8 element). The ends of the actuator elements are attached to the floor and expandable by constraint equations as shown in Figure 39.

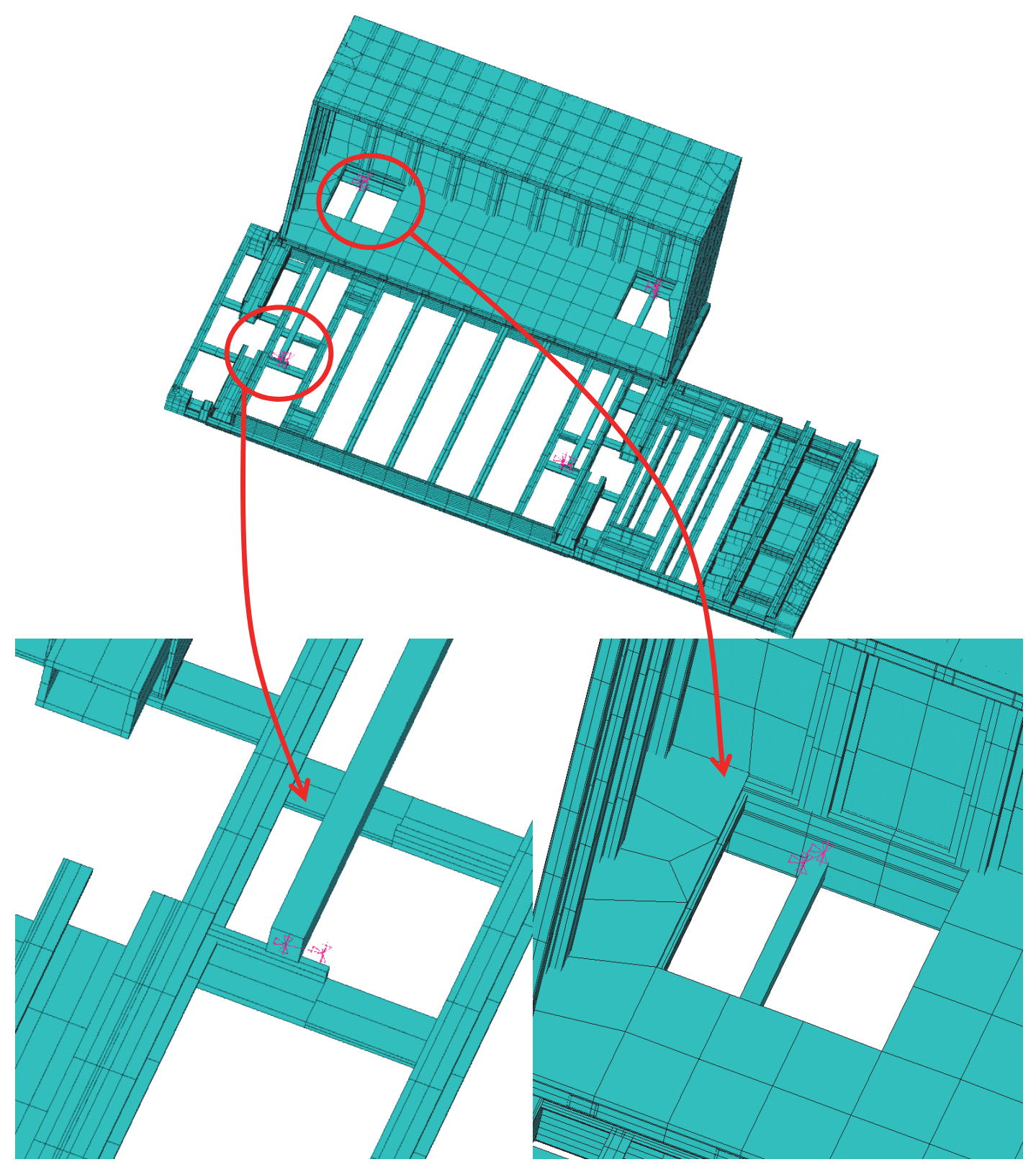

Figure 39. Joining of the RS expandable and floor at the hydraulic cylinders.

Finally, the top of each expandable is attached to the roof of the HCCC via an expandable guide that restricts movement in the vertical and longitudinal directions. This 
connection is shown in Figure 40; again, a suitable constraint equation is used. In this case, the proper node along the roof (representing the rail) constrains the motion of the guided point on the top of each expandable; this point is free to translate laterally but any vertical or forward motion requires a similar movement of the associated roof rail nodes.

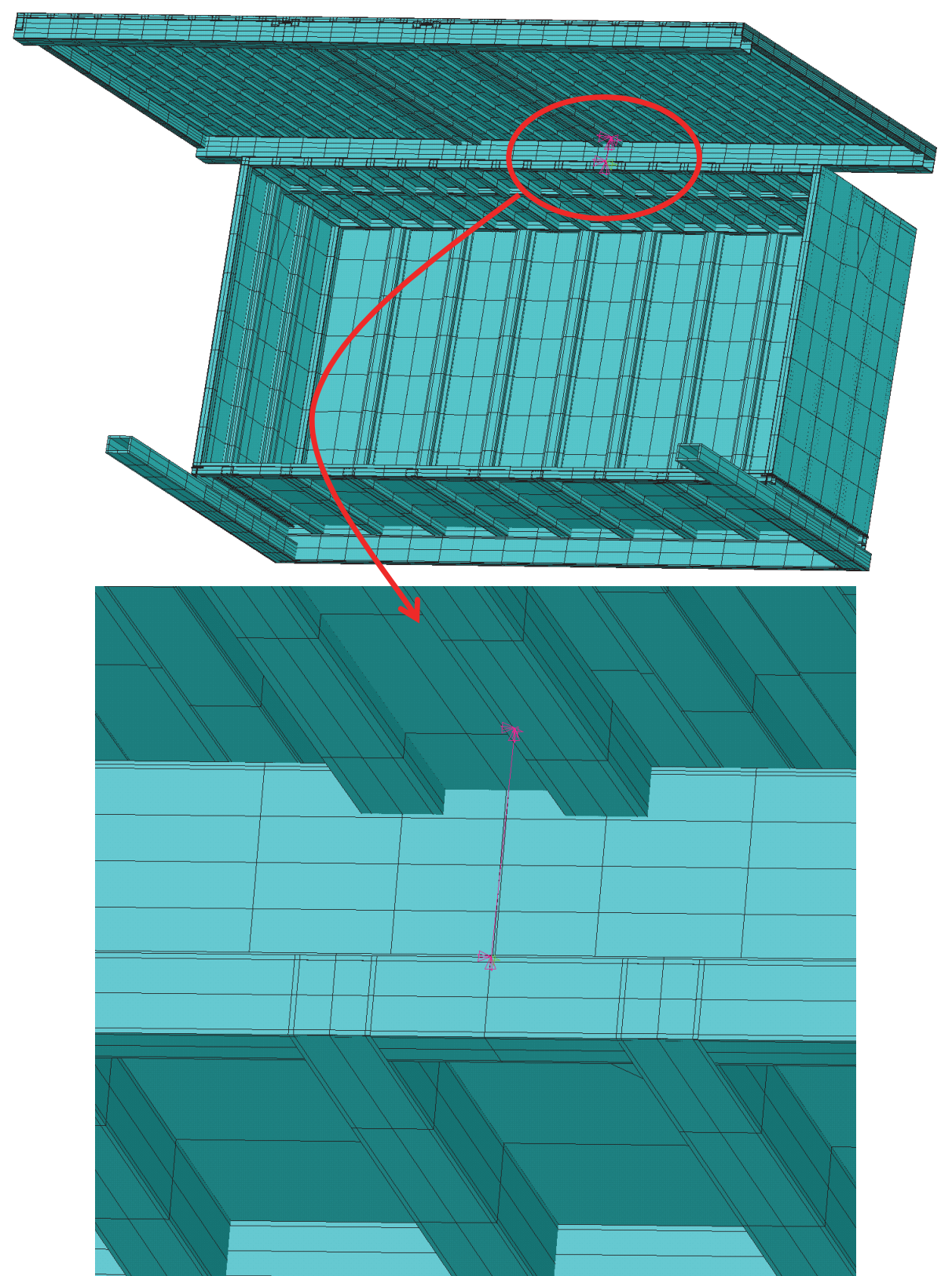

Figure 40. Joining of the RS expandable and roof at the expandable guide. 


\section{Layering of Shell Elements}

The composition of the walls, floors, and roof posed a unique challenge. Each area typically had an external (to the shelter) layer, a middle layer, and an internal (to the shelter) layer; for example, the external layer was often aluminum, the internal layer was often LitePly plywood, and the middle layer was polyurethane foam. The modeling challenge here came from the SHELL99 element. Each area can also only generate one shell element, whose nodes can be offset to the element top, middle, or bottom (see Figure 78). To keep these areas in the finite element model as close in resemblance to the actual shelter as possible, two different SHELL99 elements were used at each location. Specifically, one element was created via area meshing (walking surface for floors, external aluminum skin for the rest). These elements were then copied using the EGEN command with appropriate settings to generate the remaining layers. With this command, the newly generated element can have a different element type, real constant, material, and location in space than the original. In the HCCC model, properties were changed but the location in space was always identical to the element being copied.

The original SHELL99 elements had their nodes offset to the bottoms of their elements, so it was desirable to generate new elements with nodes offset to the top and so that the tops of the new elements were coincident with the bottoms of the original elements. This setup is illustrated in Figure 41 with a cross section of the roadside expandable's roadside wall. The exterior aluminum skin is shown in dark blue; this is the original set of elements. The interior layers (insulating foam, Lite-Ply, and interior aluminum) are shown in green; these are the copied elements. Finally, the cross-section 
of a roof-level perimeter box beam in shown in red for reference; the reason for the two element approach is evident in this image; by using this technique, the external aluminum sheet is aligned with the proper surface of the beam elements leading to properly idealized structure. Note that after copying, the new SHELL99 elements do not share nodes with the original elements; to correct this, the elements are then joined together by coupling all coincident nodes (i.e. different nodes but in the same location of the model). The CPINTF command automatically generates such coupled sets.

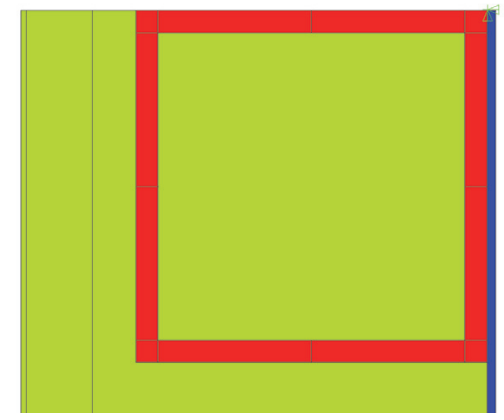

Figure 41. Internal and external SHELL99 elements.

\section{E. Contact between HCCC Floor and M1085 Truck Bed}

The HCCC is attached to 4 locations simulating the dowel mounts that connect the shelter to the M1085 truck. These attachment points provide capability to transfer both loads and moments in all 3 directions (X, Y, Z). However, it is clear that the HCCC is also supported by the M1085 truck bed as well. For example, imagine the HCCC hoisted in the air and then supported only at the 4 dowel mount locations; the results are quite different under self-weight than the same condition when it is setting on the truck bed. On the other hand, it is also not appropriate to constrain the bottom of the HCCC to not move in the vertical direction completely. Specifically, separation between the one part of the bottom of the HCCC and the truck bed leads to a loss of load path; a 
displacement constraint prevents such motion and introduces fictitious tension-type loads between the HCCC and the truck bed that do not exist absent an adhesive attachment.

In order to properly model this condition, contact elements were incorporated. The nodes on the bottom of the HCCC that are associated with beams that rest on the M1085 truck bed were selected. These nodes were copied an arbitrary distance below the HCCC floor (usually 100 inches to facilitate viewing). Node-to-node CONTACT12 elements in ANSYS were then employed to connect each of these nodes together. These elements were set to be initially in contact (i.e. any downward motion of the HCCC floor nodes leads to a contact force) but would separate upon an upward motion (i.e. no downward load occurs due to these elements if the HCCC floor nodes move up to open a gap). These elements were also given a normal (gap direction) stiffness; they essentially act as nonlinear springs with one spring stiffness in compression (contact) and a much smaller value in tension (no contact). The stiffness of the contact elements was specified in terms of the amount of deflection that the $1 \mathrm{~g}$ vertical self-weight would cause; this value is set as several parameters in the input file "Create_Floor_Contact.inp" and was commonly fixed such that a HCCC weight of $5000 \mathrm{lbs}$ (low) would lead to 0.001 " of vertical deflection of the HCCC floor into the M1085 truck bed.

The only negative associated with this approach is that it is not easy to visualize the pressure / loading on the HCCC bottom surface due to contact. This is because each of the elements reports its result as a force and different elements with similar contact displacements may have significantly different force values (for example, one contact element supporting a larger section than another neighboring element). To count this, a fictitious floor was created at the same elevation as the bottom of the contact element 
nodes. This floor was setup using SHELL63 elements that permit an elastic foundation option; in this approach, out-of-plane translation leads to a push-back pressure at a given spring stiffness (i.e. psi per inch of translation). The elastic foundation stiffness was set at a large value of $10^{6} \mathrm{psi} / \mathrm{in}$. The displacement of these elements can be scaled by $10^{6}$ in order to recover the out-of-plane pressure (i.e. 0.000100 inches of deflection would correspond to a pressure of $100 \mathrm{psi})$. The SHELL63 elements were created with a regular, rectangular grid pattern and constraint equations were used to join the SHELL63 elements to the bottom nodes of the contact elements. This provides a simple way to visualize the pressure between the HCCC bottom surface and the M1085 truck bed. An example of the elements is shown in Figure 42 and an example of the pressure between the floor and the truck bed is shown in Figure 43. 


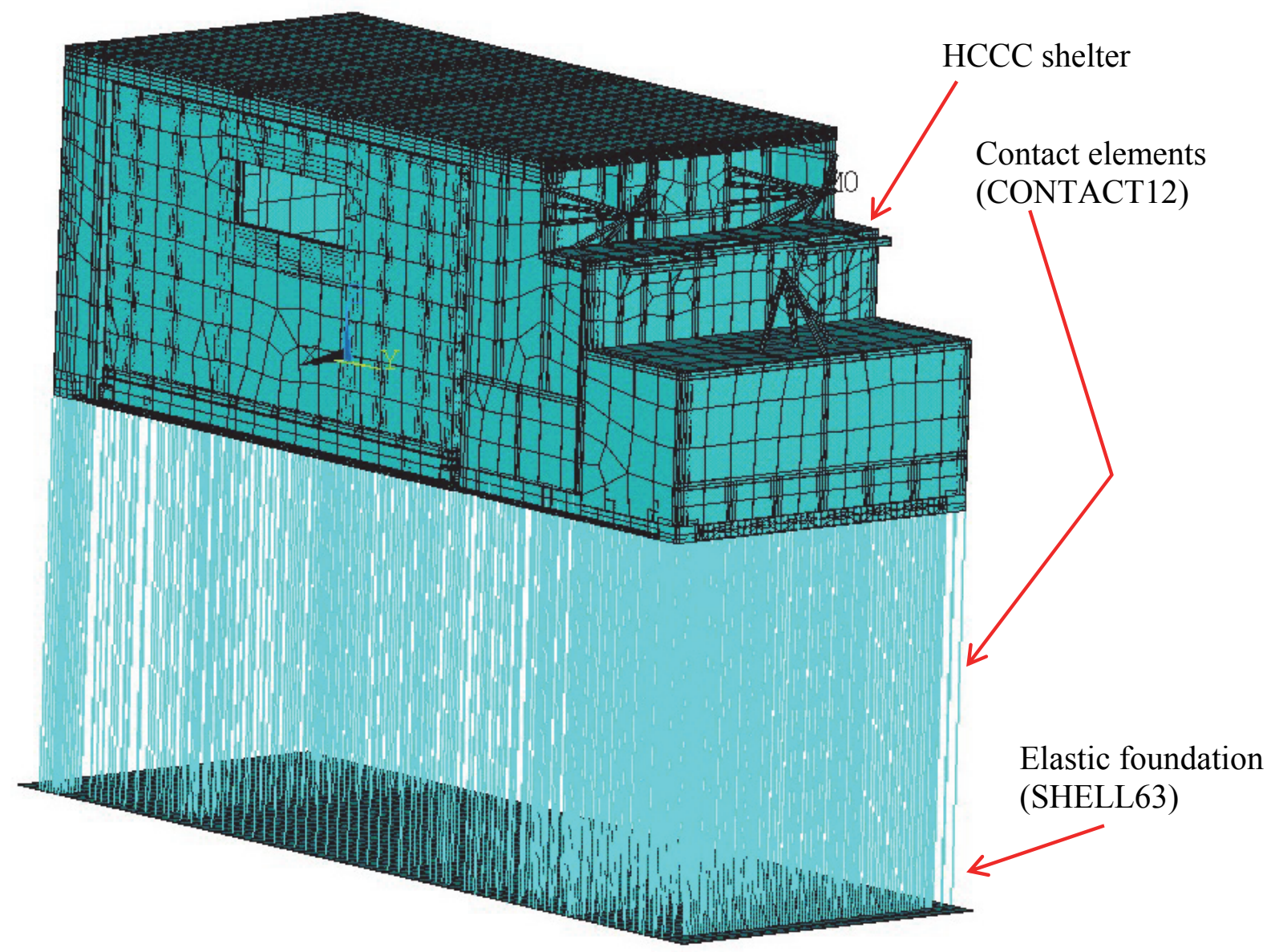

Figure 42. Elastic foundation and contact elements supporting the bottom of the HCCC (separating distance is arbitrary; chosen to be 100" here to be simplify viewing)
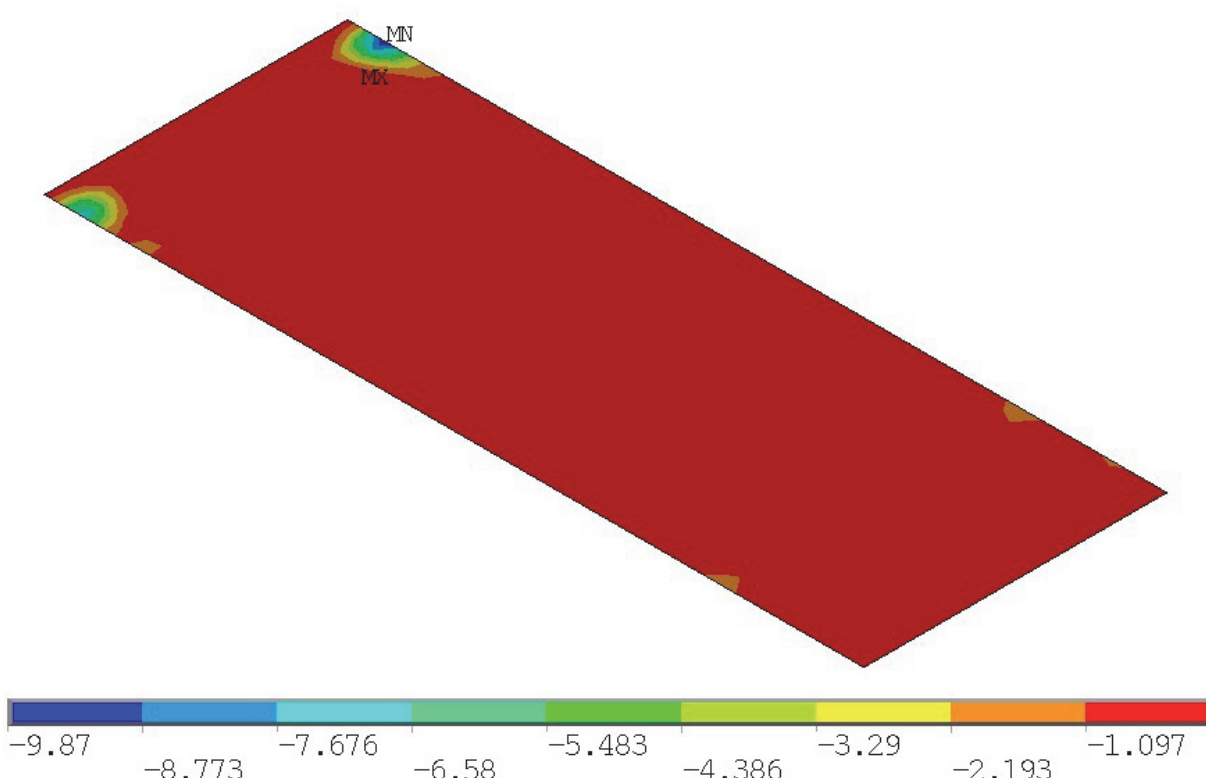

Figure 43. Elastic foundation and contact elements supporting the bottom of the HCCC (color contours denote pressure in $\mathrm{psi}$; $1 \mathrm{~g}$ down gravity loading) 


\section{SOLUTION AND ANALYSIS OVERVIEW}

This section describes briefly the various loading options that have been considered for this model, the solution algorithm used, and the verification efforts to ensure that the model is properly joined together.

One mode of transportation for the HCCC is via a $\mathrm{C} 17$ aircraft transport. Prior to such transport, an air transportability certification is required that states that the HCCC can meet certain specified loadings without a loss of serviceability.(Department of Defense, 1985) Specifically, these load cases are:
a. Downward acceleration of $4.5 \mathrm{~g}$
b. Upward acceleration of $2.0 \mathrm{~g}$
c. Forward acceleration of $3.0 \mathrm{~g}$
d. Aft acceleration of $1.5 \mathrm{~g}+$ lateral acceleration of $1.5 \mathrm{~g}$

A later chapter presents findings from the HCCC FEM to simulate structural response in support of this certification.

Anther condition of interest for the HCCC FEM is the response to dynamic impact. Simulation of rail impact, in which the HCCC is mounted on a rail car which impacts with another rail car, is discussed in a later chapter. Kentucky Trailer provided acceleration data obtained by testing done at the Aberdeen Proving Grounds of another vehicle mounted on a rail car and subjected to a rail impact test.(ATC Rail Impact Facility, 2005 approx.) This data was used to generate an acceleration profile that was anticipated to be consistent with that observed by the HCCC during a rail impact. 


\section{A. Loading and Boundary Conditions}

There are three primarily types of loads or boundary conditions applied to the HCCC model. The first type is the boundary conditions for the 4 dowel mount points; the associated degrees of freedom (DOFs) of those points are rigidly held for static analysis (such as the $\mathrm{C}-17$ air certification cases) or given a prescribed motion over time for dynamic analysis (such as a rail impact scenario).

The second type is global inertial loads. These are applicable for static analysis (such as $5 \mathrm{~g}$ forward in the $\mathrm{C}-17$ air certification case) and to simulate the effects of gravity in the dynamic analysis (i.e. $1 \mathrm{~g}$ downward).

Finally, surface pressure and point loads can be considered. The typical case for the HCCC FEM analysis has been snow load conditions applied to the roof of the main HCCC shelter (expandables retracted) or the roofs of both the main HCCC shelter and the expandables (expandables extended outwards). The model is setup to easily run with the expandables either retracted or extended any amount up to the physical limit of travel for the HCCC. Snow loading cases are not considered in this thesis; results for those cases can be obtained elsewhere from run-specific output reports generated following the analysis case.

\section{B. Solution and Verification of Results}

Without the contact elements, the ANSYS model of the HCCC is linear in nature and does not require an iterative solution. With contact elements to simulate the contact between the HCCC floor and the M1085 truck bed, a nonlinear solution is required. This is because the behavior of the contact elements (i.e. their stiffness) depends upon their 
displacement. In order to accomplish this solution, ANSYS compares the calculated forces (or moments) via the stiffness matrix (K) multiplied by the nodal degrees of freedom vector (d) to the applied forces (or moments) vector (r). These will be identical at the true solution to the problem; at iterative procedure is used to repeatedly solve the problem in an attempt to drive this quantity (often called the residual) to 0 . Once the residual is sufficiently small, the problem is considered solved.

Nonlinear solutions often require a number of steps to achieve the desired end result. Input files have been created to applied loads and setup proper solution parameters for static loading with inertia ("Loading_Contact.inp"), static loading with inertia and snow loads ("Loading_Snow.inp"), and transient analyses with either force or displacement applied at the dowel mounts to simulate the motion of the M1085 truck with the HCCC shelter attached to it. Ultimately, it required significant effort to have the HCCC finite element model successfully converge. The reason is that minor errors in position of the nodes can lead to force and moment imbalances due to constraint equations that cannot lead to a zero residual. Specifically, if the nodes along lines where two sections joined (i.e. roof and front frame) were not collinear, the problem would not converge. Once this was resolved, solutions are obtained without incident.

Once the solution is obtained, significant effort was spent reviewing model results attempting to discover discrepancies that cause errant results. The stresses and strains for each section were thoroughly reviewed to find regions where the models were not properly connected. Analysis was performed on the expandables in terms of the loads applied at the slide tubes to ensure that the loading was statically correct (i.e. there was not a net force or moment imbalance present in either expandable. The loading at the 
dowel mounts and at the truck bed - HCCC intersection were compared to inertial loads and verified (i.e. in a $5 \mathrm{~g}$ forward condition the total dowel mount / contact element load should be $5 \times 10,100 \mathrm{lbs}=50,500 \mathrm{lbs}$ in the forward direction and $0 \mathrm{lbs}$ in the lateral and vertical directions). A number of corrections were ultimately performed on the model; the current model appears to be correct in terms of results, connectivity, etc. The results of these analyses are described to some extent in the $\mathrm{C} 17$ certification report to demonstrate that the findings were consistent and reasonable.

\section{HCCC FEM Mass and Center of Gravity}

Using known densities of the various components, the HCCC weighs a total of 8695 lbs. The completed HCCC consists of many elements that are not currently included in the model, such as electrical wiring, hydraulic fluids, paint, etc. The first completed HCCC weighs approximately $10,100 \mathrm{lbs}$ when readied for travel. In order to simulate the missing weight, the density of the aluminum used for beam and plate elements was artificially increased from the known value of $0.098 \mathrm{lb} / \mathrm{in}^{3}$ to $0.1281 \mathrm{lb} / \mathrm{in}^{3}$. With this adjustment, the HCCC FEM weighs 10,097 lbs.

The center of gravity of the model is also noted by ANSYS. For location purposes, the origin of the ANSYS model and the HCCC construction drawings is at the bottom rear roadside corner, with $\mathrm{X}-\mathrm{Y}-\mathrm{Z}$ directions in the lateral (roadside-to-curbside), forward (rear-to-front) and vertical (up) directions, respectively. The value from ANSYS is compared to the value measured for the first completed HCCC shelter at Kentucky Trailer in Table 2. The values are quite similar; this provides a measure of confidence that the ANSYS model is accurately capturing the actual structure. 


\begin{tabular}{|l|l|l|l|}
\hline Source & $\begin{array}{l}\text { CG - X Direction } \\
\text { (Lateral), in }\end{array}$ & $\begin{array}{l}\text { CG - Y Direction } \\
\text { (Forward), in }\end{array}$ & $\begin{array}{l}\text { CG - Z Direction } \\
\text { (Vertical), in }\end{array}$ \\
\hline ANSYS Model & 47.30 & 125.34 & 36.78 \\
\hline First HCCC Shelter & 47.25 & 127.14 & 34.00 \\
\hline
\end{tabular}

Table 2. HCCC center of gravity locations

\section{HCCC FEM Postprocessing Output}

Upon the completion of the model solution, the post-processing portion of ANSYS is utilized to create a standard set of output images and tables for each case. These are separated into the 6 regions mentioned previously (floor, roof, side/rear, front, RS expandable, CS expandable). For each region, the displacement magnitude (vector sum of the displacement in the $\mathrm{X}-\mathrm{Y}-\mathrm{Z}$ directions) is plotted. The von Mises stress is also plotted for each component type (aluminum beams, exterior aluminum plate, Lite-Ply plywood, interior aluminum plate, polyurethane foam). The von Mises stress is a single scalar quantity that can be used to ascertain the likelihood of yielding in ductile metals; in this study, it is also assumed that it can be used to estimate the likelihood of sustaining permanent deformation in the Lite-Ply plywood components. The maximum value for each plot is noted and tabulated.

The reaction forces for the various components are also calculated and tabulated. These include the dowel mount forces, the total force in the $\mathrm{Y}$ and $\mathrm{Z}$ directions on each expandable slide tube and top guide points, and the actuator loads.

The collection of images and tables are automatically placed in a web page that can be viewed at a later date. This web page is also printed as a PDF document that can 
be transmitted for review; the PDF document of each case is provided in this document as an Appendix.

\section{E. Material Strength and Margin of Safety (MS)}

The strengths of the various materials in the HCCC are compared to the stress results from the HCCC FEM analysis to assess the effect of various types of loading. The aluminum structure of the HCCC primarily consists of 3 alloy types. The majority of larger structural beams are 6061-T6511; these are extruded shapes that are solution treated and aged followed by stretching to remove residual stresses with minor straightening permitted.(R. Ramsdale, 2006) The mechanical properties are identical to 6061-T651 (no straightening). There are a number of smaller beams (typically square tubing) that are 6063-T52; these are formed, stress relieved in compression and then artificially aged. The mechanical properties are identical to 6063-T5 (no residual stress relief). The remaining aluminum is in sheet form with alloy $3003-\mathrm{H} 14$; this material is strain hardened to a half-hard condition. The yield and ultimate strength values for these materials were obtained from Matweb (Matweb, 2006) and are presented in Table 3. It should be noted that these values are stated as typical and therefore do not contain any reduction for statistical variation.

\begin{tabular}{|l|l|l|l|}
\hline $\begin{array}{l}\text { HCCC } \\
\text { Material }\end{array}$ & $\begin{array}{l}\text { Matweb } \\
\text { Equivalent } \\
\text { Material }\end{array}$ & $\begin{array}{l}\text { Yield Strength } \\
(\mathrm{ksi})\end{array}$ & $\begin{array}{l}\text { Ultimate Strength } \\
(\mathrm{ksi})\end{array}$ \\
\hline $6061-\mathrm{T} 6511$ & $6061-\mathrm{T} 651$ & 40.0 & 45.0 \\
\hline $6063-\mathrm{T} 52$ & $6063-\mathrm{T} 5$ & 21.0 & 27.0 \\
\hline $3003-\mathrm{H} 14$ & Same & 21.0 & 22.0 \\
\hline
\end{tabular}

Table 3. Aluminum yield and ultimate strength values (typical). 
As noted previously, many of the interior panels consist of sheets of Lite-Ply plywood. This plywood is made from European poplar. Two HCCC panel thicknesses are used - the floor is $3 / 4$ inch thick (product listing of $18 \mathrm{~mm}$ with 11 plies) while the sides and roof are $3 / 8$ in thick (product listing of $9 \mathrm{~mm}$ with 5 plies). Several attempts were made to obtain definitive strength values for this material from the supplier without success; a search of historical archives lead to a very detailed study done by the US Forest Service on 3 types of plywood in bending (Sitka spruce, Douglas fir and yellow poplar) in 3, 5, 7 and 9 ply configurations.(Forest Products Laboratory, 1964) This document contains a detailed set of tables of both proportional limit strength (an indication of when permanent damage occurs; somewhat akin to the yield strength in metals) and ultimate strength. Each ply alternates direction by $90^{\circ}$ and the material was tested in two directions: 1) the outer ply parallel the span (the stronger direction, referred to as "outer-parallel"); and 2) the outer ply perpendicular to the span (the weaker direction, referred to as "outer-perpendicular"). The 5,7 and 9 ply panel tests provided 5 test results for both proportional limit stress and ultimate stress for each direction (outerparallel, outer-perpendicular). These were averaged and are presented in Table 4.

The strength of yellow poplar clearly has some directional dependence. An anisotropic failure criteria (maximum stress, Tsai-Wu, Tsai-Hill, etc.) coupled with the full stress field ( 3 normal stresses, 3 shear stresses) is likely necessary to most accurately assess the likelihood of failure of the plywood panel. In order to reduce the complexity of the analysis, the current study to simply uses the von Mises stress observed in the LitePly panel to characterize the stress state and compare this value to the average of the outer-parallel and outer-perpendicular strength results. If required, more complex 
anisotropic approaches can be considered later. These average values are also listed in Table 4.

\begin{tabular}{|c|c|c|}
\hline & \multicolumn{2}{|c|}{$\begin{array}{c}\text { Strength Values - Yellow Poplar Plywood } \\
\text { Proportional Limit, Ultimate Stress }\end{array}$} \\
\hline & Proportional Limit (F) & Ultimate Strength (S) \\
\hline Outer-Perpendicular & 3635 & 6800 \\
\hline Outer-Parallel & 2227 & 4042 \\
\hline Average Value (ksi) & 2.931 & 5.421 \\
\hline Average Value (MPa) & 20.2 & 37.4 \\
\hline
\end{tabular}

Table 4. Yellow poplar proportional limit and ultimate strength for 5, 7 and 9 ply panels.

In addition to strength data, the U.S. Forest Service study also provided the specific gravity of the samples. A total of 30 measurements for the 5, 7 and 9 ply panels were averaged to find the specific gravity to be 0.384 , which corresponds to a density of $0.01388 \mathrm{lb} / \mathrm{in}^{3}$ or $384.3 \mathrm{~kg} / \mathrm{m}^{3}$. The provider of the LitePly panels for the HCCC provided one summary data sheet that roughly corresponds to the material used in the HCCC. The density for two comparable panels $\left(410 \mathrm{~kg} / \mathrm{m}^{3}\right.$ for $8 \mathrm{~mm}=0.315 \mathrm{in} / 5 \mathrm{ply} ; 430 \mathrm{~kg} / \mathrm{m}^{3}$ for $15 \mathrm{~mm}=0.591$ in $/ 9$ ply) is quite similar to the U.S. Forest Service panels. This data sheet only provides ultimate strength, with the values being 31-38 MPa for the $8 \mathrm{~mm} / 5$ ply panel and 30-37 MPa for the $15 \mathrm{~mm} / 9$ ply panel. These values are certainly in the range of the average ultimate strength of $37.4 \mathrm{MPa}$ reported in Table 4 . This provides further evidence that the values from the U.S. Forest Service study are reasonable estimates of panel strength for the HCCC study.

In order to compare the obtained stresses from the HCCC finite element analysis to the strength values above, a margin of safety (MS) calculation is performed. This is defined as follows: 


$$
M S=\frac{F}{f}-1 \quad \rightarrow \quad F S=M S+1
$$

where $F$ is the strength quantity for the material in question and $f$ is the observed stress value from the analysis. A positive margin indicates that the strength quantity is not exceeded; the larger the margin, the lower the likelihood of failure. Although this work provides margin of safety values, these can be related to another common measure called the factor of safety (FS) by simply adding 1 to the margin of safety as shown above.

The present study evaluates the effects of various loading conditions for C17 air transport on the HCCC. The requirement for certification is that the HCCC can be exposed to the conditions of interest without a loss of serviceability. In this document, it is assumed that this condition would be satisfied if no yielding / permanent deformation occurs after loading; this can be demonstrated by a positive margin of safety compared to the yield strength (aluminum) or proportional limit stress (plywood). However, it should also be noted that loss of serviceability may not occur even if localized yielding does occur. One approach in such an event would be to incorporate a nonlinear material model that allows for plastic (permanent) deformation to occur to ascertain the degree of structural dimension change. In the present study, this is not pursued as all margins of safety remain positive against permanent deformation. 


\section{HCCC FEM ANALYSIS - C-17 AIR CERTIFICATION}

All of the loading scenarios considered using the HCCC FEM can be broken up into two classifications: 1) static analysis without time-varying inertial loads; and 2) dynamic analysis which incorporates the effect of acceleration without restriction on the type of motion that can occur. This section presents a static analysis used to certify the HCCC for air transport using a C-17 cargo aircraft; although the loading is entirely inertial, a static analysis is used by assuming the acceleration is constant and transient effects are not included.

\section{A. Loading}

The 4 dowel mount points attach the HCCC to the M1085 truck bed. These points are rigidly fixed in the $\mathrm{X}-\mathrm{Y}-\mathrm{Z}$ directions; this assumes that the truck bed is much stiffer than the HCCC. The dowel mount point rotational degrees of freedom are not constrained (i.e. the truck restraint points can provide forces but not moments).

The HCCC is also supported by the M1085 truck bed. The model assumes that those beams and ISO block plates along the bottom of the HCCC are in contact with the truck bed; these beams and plates are shown in Figure 44. Contact elements are then used to prevent vertical downward translation; upward vertical translation is permitted and there is no friction (i.e. displacement in the lateral and forward directions is not restrained). The model is set up to permit a specified gap between the truck bed and the HCCC; in the present study the gap is set to 0 . The nodes of the contact elements farthest away from the HCCC are supported by elastic foundation elements; this permits the contact to be visualized as a pressure along the entirety of the truck bed base. 


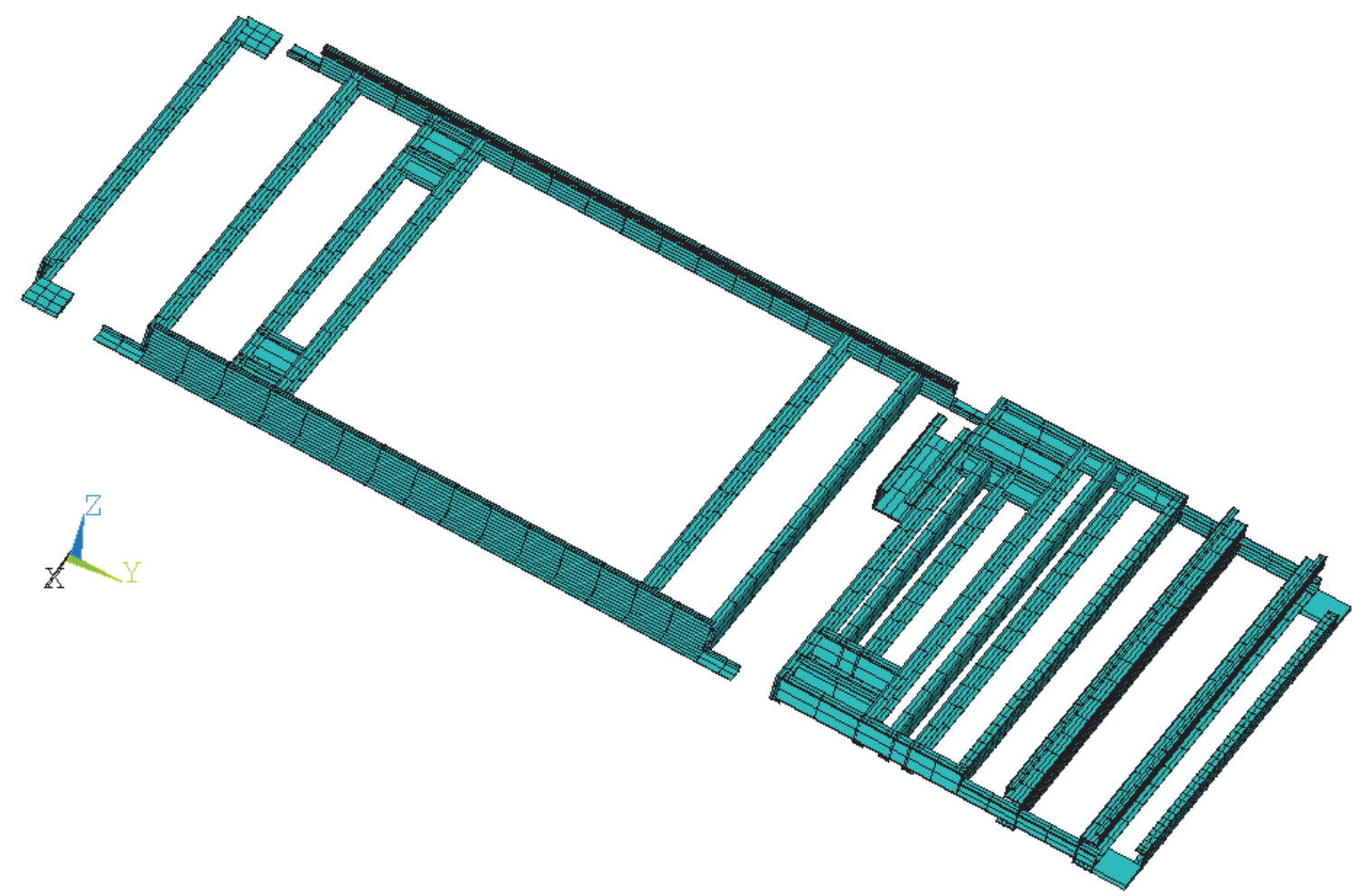

Figure 44. HCCC beam and shell elements supported by contact elements simulating the M1085 truck bed

The load cases for C-17 transportation are dictated in Department of Defense's MIL-HDBK-1791 (USAF). The shelter must pass these scenarios without loss of serviceability and without loss of structural integrity. These load cases are detailed in Table 5. The load factors below are specified in ANSYS as accelerations in the X, Y and $\mathrm{Z}$ directions. For densities provided in terms of $\mathrm{lb} / \mathrm{in}^{3}$, the accelerations are specified in g's (i.e. load factors in Table 5). This is suitable for static analyses such as those considered in this study. Dynamic analyses (considered in the next chapter) require conversion of the density to suitable mass units by dividing by the appropriate gravitational constant; for the HCCC FEM, this will be $386.4 \mathrm{in} / \mathrm{s}^{2}$ and accelerations are then specified in units of $\mathrm{in} / \mathrm{s}^{2}$. As the weight of the HCCC is known, the loading is 
verified by checking that the total reaction load in each direction sum to the associated acceleration multiplied by the HCCC weight

\begin{tabular}{|l|l|}
\hline Direction & Load Factor \\
\hline Up & $2.0 \mathrm{G}$ \\
\hline Down & $4.5 \mathrm{G}$ \\
\hline Forward & $3.0 \mathrm{G}$ \\
\hline Aft* & $1.5 \mathrm{G}$ \\
\hline Lateral $^{*}$ & $1.5 \mathrm{G}$ \\
\hline
\end{tabular}

Table 5. C-17 air certification load factors (accelerations used for analysis).

\section{B. Typical Postprocessing Output}

In order to provide further detail about the model solution, several images are presented for the $2.0 \mathrm{~g}$ upward load case. The full model displacements are shown in Figure 45 as a vector plot. The magnitude of the displacement for the full model is shown as a color contour plot from above and below in Figure 46 and Figure 47, respectively; for the solution output, most images are shown from above and below for completeness. The displacement contour for the floor region alone is shown in Figure 48; it is the maximum contour value on this chart that is reported for the floor maximum displacement for this load case. The von Mises stress for the floor beams is presented 3 ways: 1) for all beams in Figure 49;2) for all beams excluding those that support the actuators and the expandable slide tubes in Figure 50; and 3) for only the beams that support the actuators and the expandable slide tubes in Figure 51. This separation was made after high stresses were observed in the actuator and expandable support beams to facilitate changes during the design process to remedy them; in later sections, the maximum von Mises stresses for the floor is presented as those from Figure 50 and Figure 51. The von Mises stress in the exterior aluminum plate for the floor is presented 
in Figure 52; it should be noted that the plate region aft of the APU support region is shown elevated above its true position due to the manner in which ANSYS plots the results for the aluminum layer. Finally, the von Mises stress for the Lite-Ply plywood is shown in Figure 53. The stress plot for the foam is not shown as they are quite small (negligible for this study).

Similar results are obtained for the other regions of the HCCC. One difference is that other regions will have an interior aluminum layer results as well. A full set of output consists of a total of 84 images and 13 tables. As mentioned previously, these results are assembled into a single HTML file for ease of review. The tabulated values are presented later for all load cases.

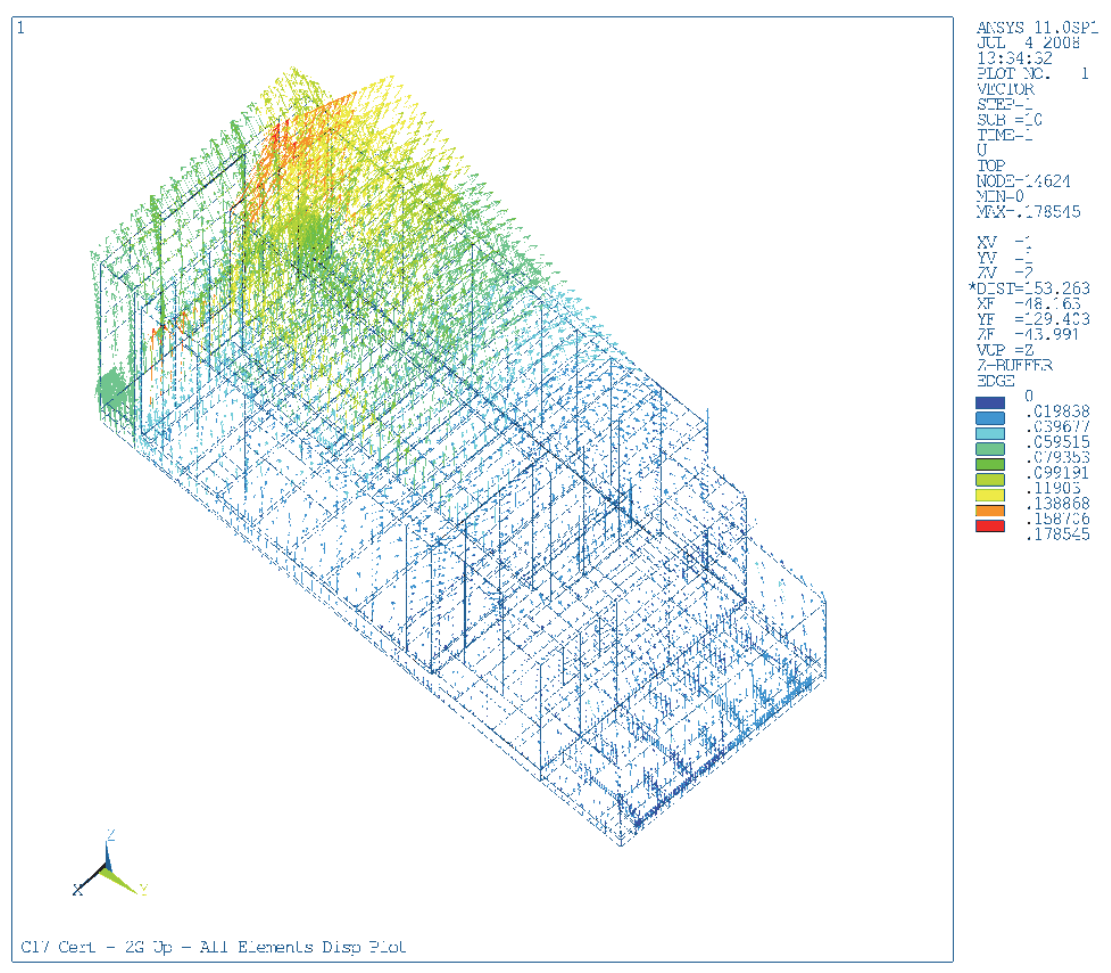

Figure 45. HCCC full model displacement vector plot (2.0 $\mathrm{g}$ upward load case; viewed from above) 


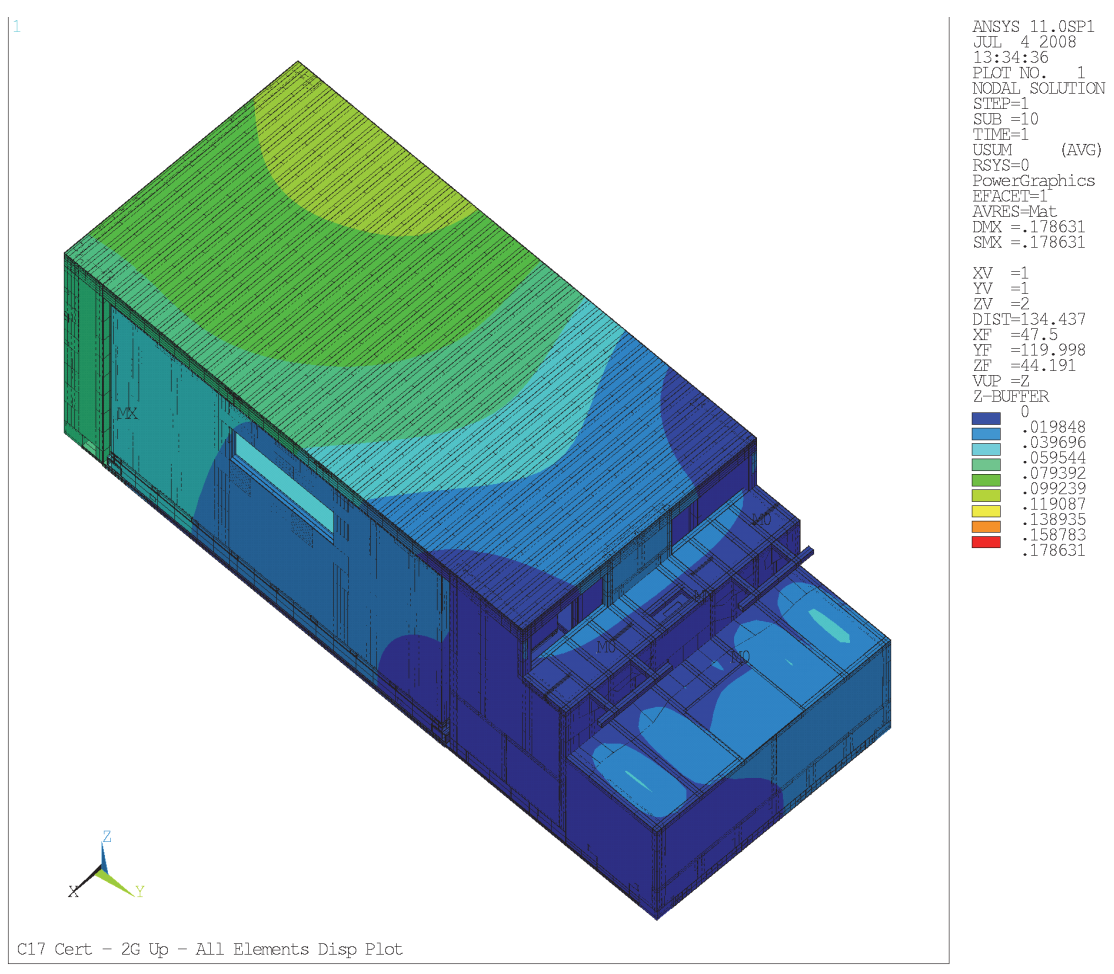

Figure 46. HCCC full model displacement magnitude contour plot (2.0 g upward load case; viewed from above)

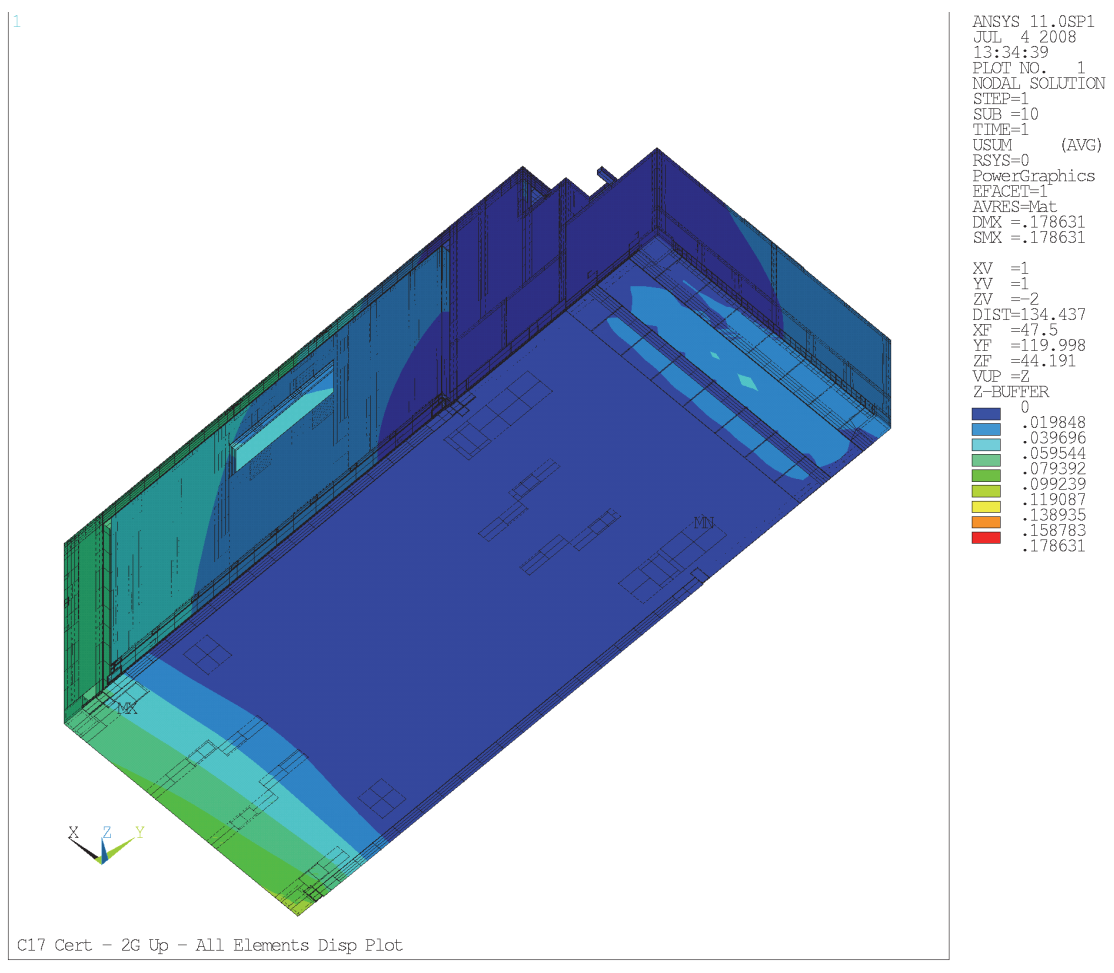

Figure 47. HCCC full model displacement magnitude contour plot (2.0 g upward load case; viewed from below) 


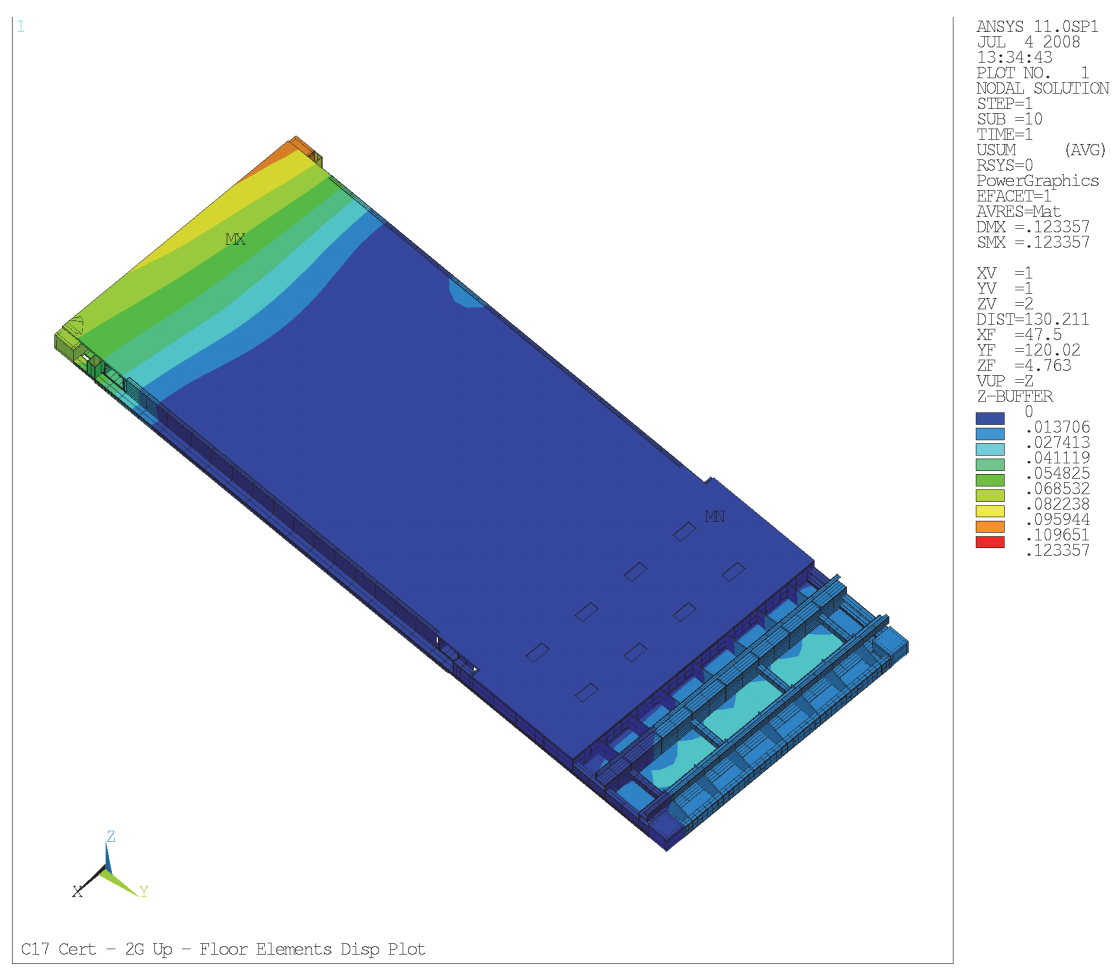

Figure 48. HCCC floor region displacement magnitude contour plot (2.0 g upward load case; viewed from above)

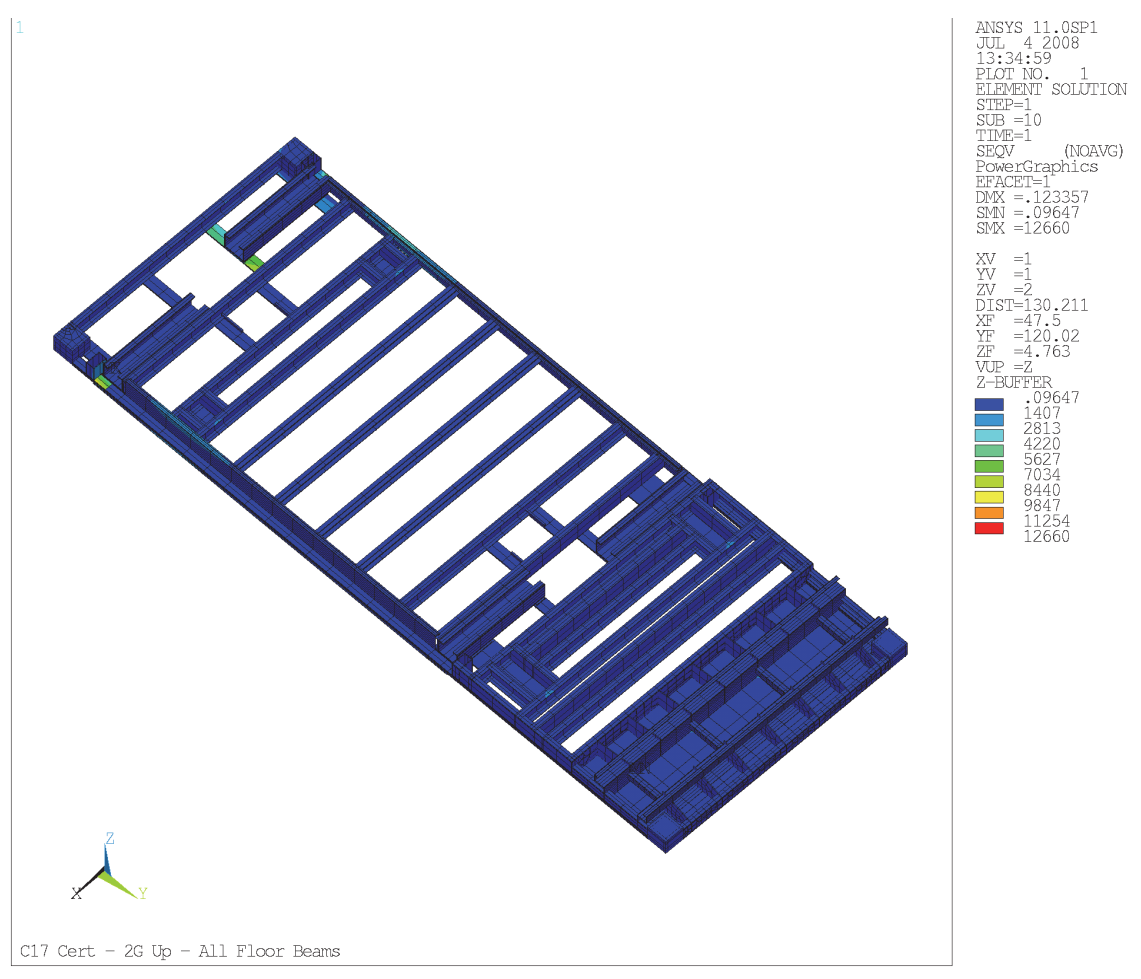

Figure 49. HCCC floor beams von Mises stress (2.0 g upward load case; viewed from above) 


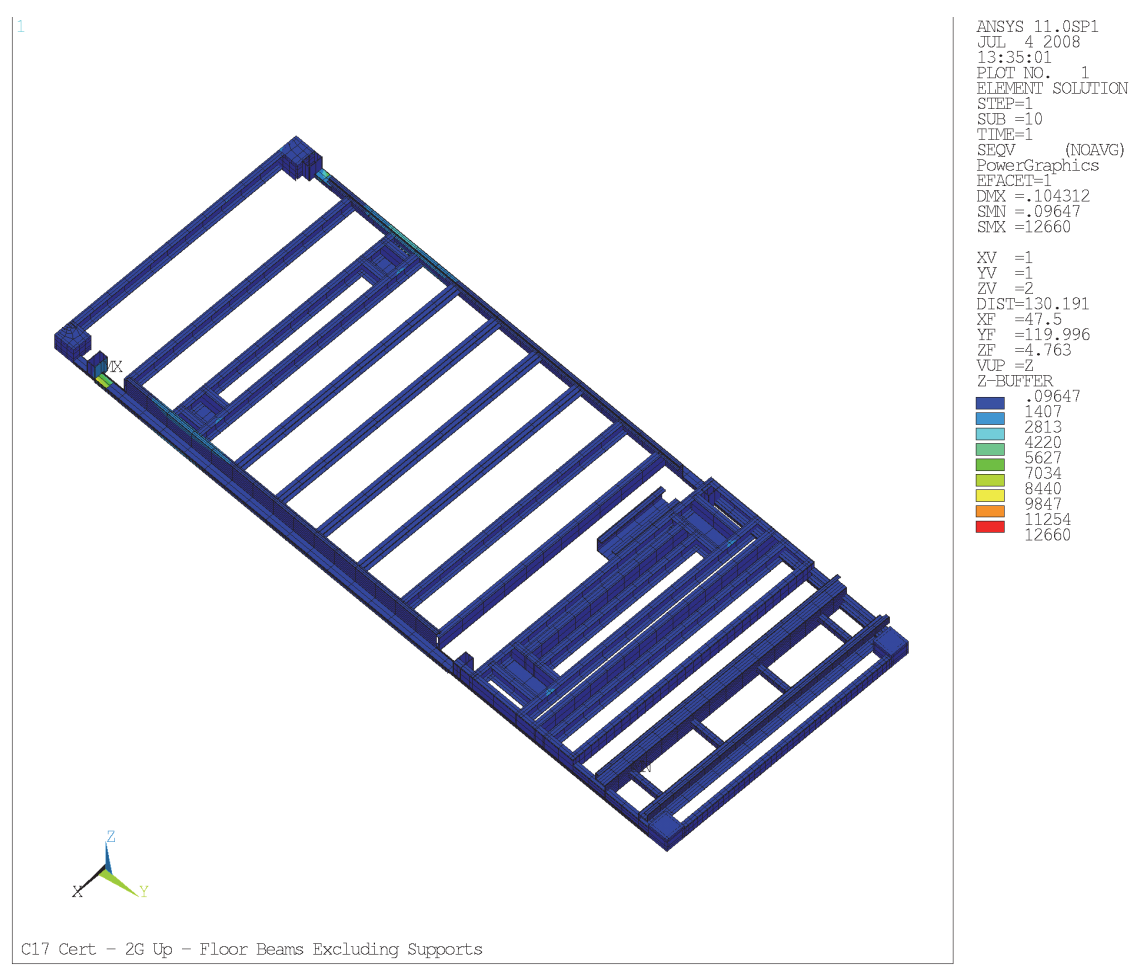

Figure 50. HCCC floor beams von Mises stress excluding actuator and expandable supports ( $2.0 \mathrm{~g}$ upward load case; viewed from above)

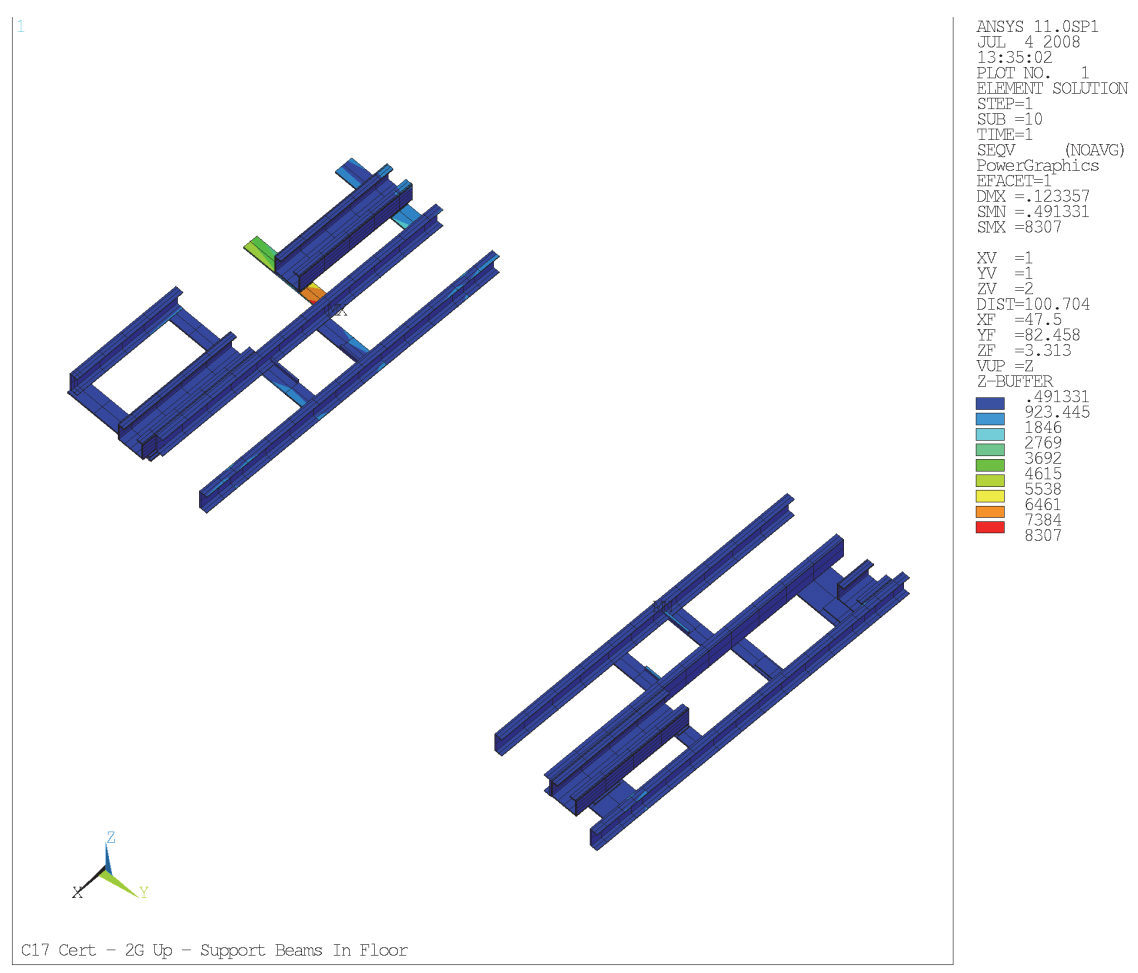

Figure 51. HCCC floor beams von Mises stress for only actuator and expandable supports ( $2.0 \mathrm{~g}$ upward load case; viewed from above) 


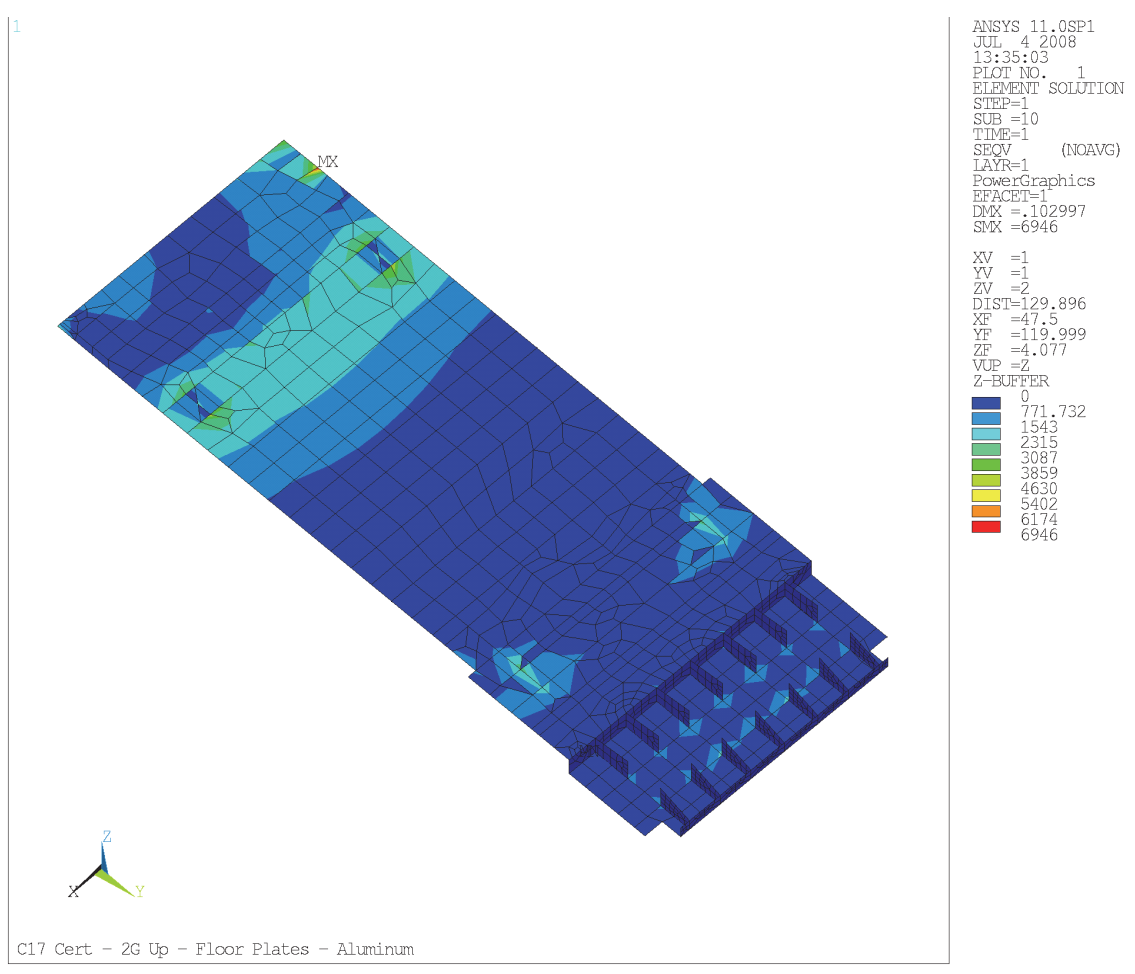

Figure 52. HCCC floor exterior aluminum plate von Mises stress (2.0 g upward load case; viewed from above)

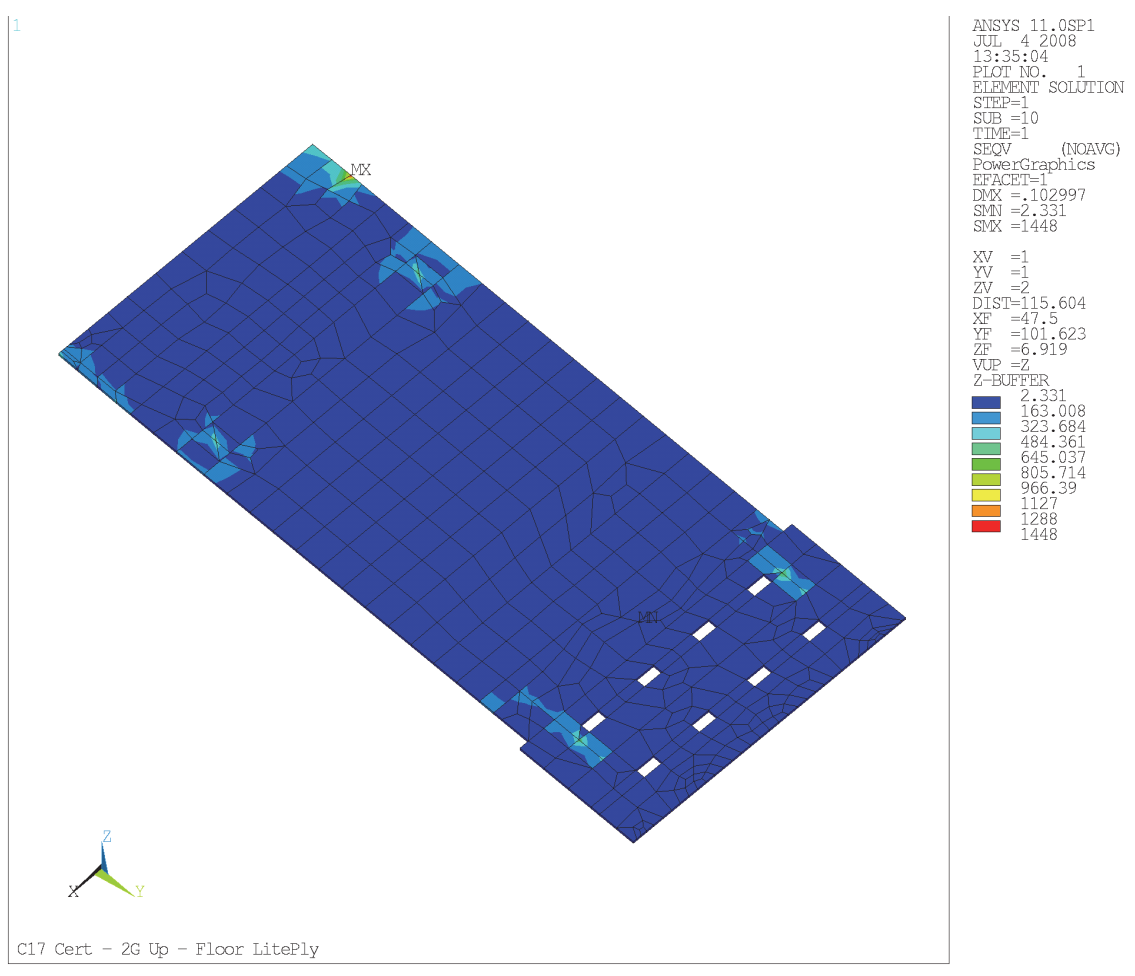

Figure 53. HCCC floor plywood von Mises stress (2.0 g upward load case; viewed from above) 


\section{Beam Stresses}

The stresses for all beams elements for the 5 certification load cases are presented in Table 6. The margins of safety for these beams are presented in Table 7; the yield stress of $40 \mathrm{ksi}$ for 6061-T651 was used for this calculation. To facilitate review, margins of $0-1,1-2$, and $2-3$ are shaded pink, yellow and green, respectively. The lowest margins are 0.74 and 0.94 in the aft/lateral $1.5 \mathrm{~g}$ cases. This is due to twisting of the actuator support beam by the actuator loads restraining the lateral acceleration of the expandables; in order to visualize this result, the von Mises stress in all floor beams is shown in Figure 54for the $1.5 \mathrm{~g}$ aft and lateral to curbside load case. All remaining cases have margins that exceed 2.

As noted previously, some of the HCCC aluminum beams are 6063-T52, which have a lower yield strength of $21 \mathrm{ksi}$. The beams with this material were selected and checked for maximum stress for all 5 load cases; the values ranged from 2.792 to 9.843 ksi, corresponding to margins of $1.13-6.52$. Based upon these results, the load cases under consideration will not lead to permanent deformation in the beams.

\begin{tabular}{|l|c|c|c|c|c|}
\cline { 2 - 6 } & \multicolumn{5}{|c|}{ Maximum von Mises Stress (ksi) } \\
\hline & & \multicolumn{4}{|c|}{ Aluminum Beam Elements } \\
Element & Down, $4.5 \mathrm{~g}$ & Up, $2.0 \mathrm{~g}$ & Forward, 3.0 g & $\begin{array}{c}\text { Aft, } 1.5 \mathrm{~g} \\
\text { Lat To CS, } 1.5 \mathrm{~g}\end{array}$ & $\begin{array}{c}\text { Aft, } 1.5 \mathrm{~g} \\
\text { Lat To RS, } 1.5 \mathrm{~g}\end{array}$ \\
\hline Floor, Excl. Supports & 7.642 & 12.66 & 3.225 & 7.391 & 8.782 \\
\hline Floor, Supports Only & 10.39 & 8.307 & 3.307 & 22.98 & 20.66 \\
\hline Roof & 2.29 & 1.751 & 0.883 & 2.772 & 2.988 \\
\hline Side and Rear & 2.454 & 1.357 & 1.251 & 1.019 & 1.46 \\
\hline Front & 6.22 & 2.305 & 2.167 & 1.968 & 1.955 \\
\hline Curbside (CS) Exp & 1.909 & 2.508 & 0.739 & 1.284 & 4.344 \\
\hline Roadside (RS) Exp & 1.409 & 0.978 & 0.866 & 2.863 & 1.177 \\
\hline
\end{tabular}

Table 6. Maximum von Mises stress for HCCC beams from 5 load cases 


\begin{tabular}{|l|c|c|c|c|c|}
\cline { 2 - 6 } & \multicolumn{5}{|c|}{ Margin of Safety versus Yield } \\
\hline & \multicolumn{5}{|c|}{ Aluminum Plate Elements } \\
\hline Element & Down, 4.5 g & Up, 2.0 g & Forward, 3.0 g & $\begin{array}{c}\text { Aft, 1.5 g } \\
\text { Lat To CS, 1.5 g }\end{array}$ & $\begin{array}{c}\text { Aft, } 1.5 \mathrm{~g} \\
\text { Lat To RS, } 1.5 \mathrm{~g}\end{array}$ \\
\hline Floor, Excl. Supports & 4.23 & 2.16 & 11.40 & 4.41 & 3.55 \\
\hline Floor, Supports Only & 2.85 & 3.82 & 11.10 & 0.74 & 0.94 \\
\hline Roof & 16.47 & 21.84 & 44.30 & 13.43 & 12.39 \\
\hline Side and Rear & 15.30 & 28.48 & 30.97 & 38.25 & 26.40 \\
\hline Front & 5.43 & 16.35 & 17.46 & 19.33 & 19.46 \\
\hline Curbside (CS) Exp & 19.95 & 14.95 & 53.13 & 30.15 & 8.21 \\
\hline Roadside (RS) Exp & 27.39 & 39.90 & 45.19 & 12.97 & 32.98 \\
\hline
\end{tabular}

Table 7. Margin of safety for HCCC beams from 5 load cases (assumed yield stress of $40 \mathrm{ksi}$ for 6061-T6511 alloy)

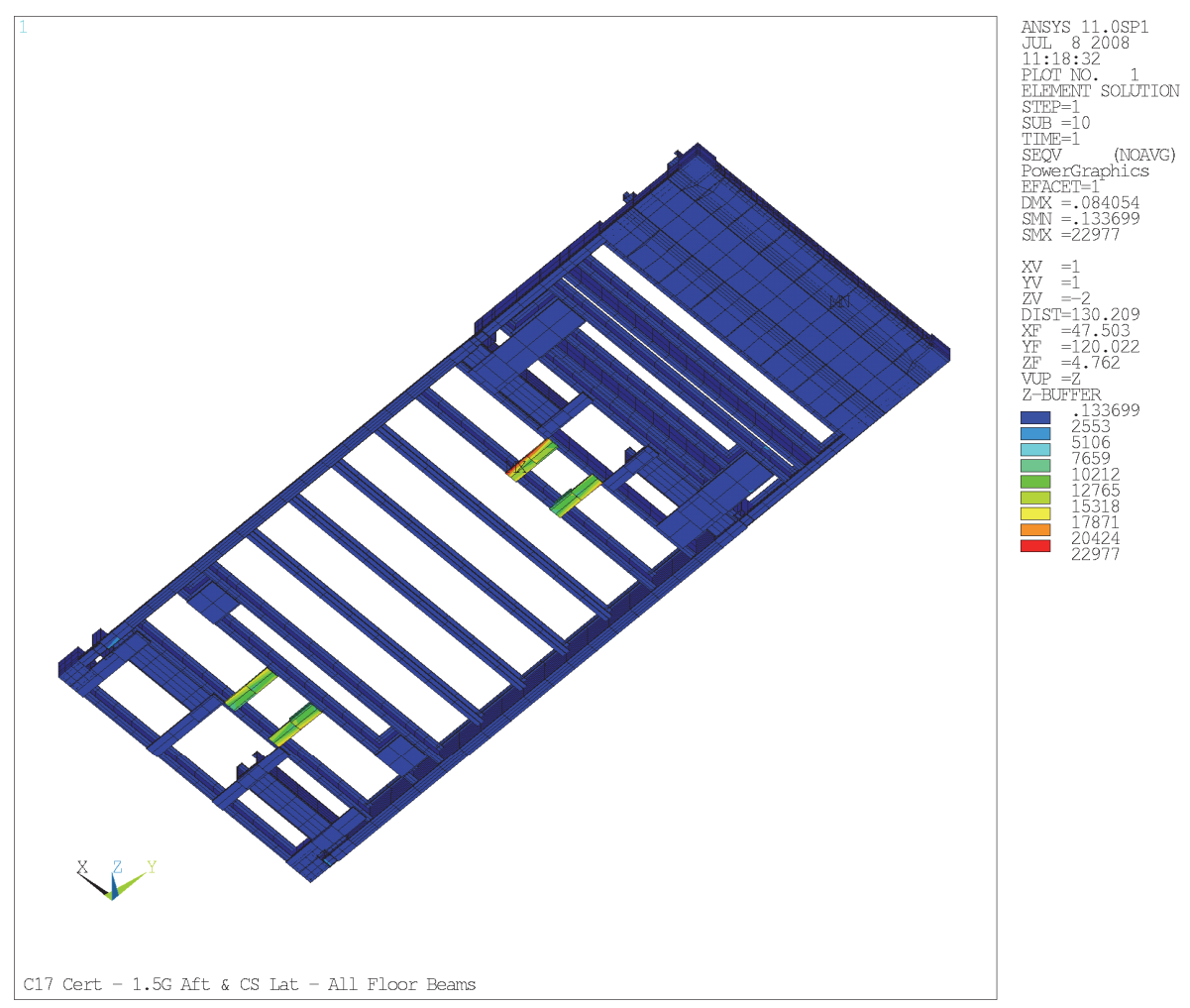

Figure 54. HCCC floor beams von Mises stress (1.5 $\mathrm{g}$ aft and lateral to curbside, viewed from below)

\section{Exterior Aluminum Plate Stresses}

The stresses for all exterior aluminum plate elements for the 5 certification load cases are presented in Table 8 . The margin of safety for these plates is presented in Table 
9; the yield stress of $21 \mathrm{ksi}$ for $3003-\mathrm{H} 14$ was used for this calculation. To facilitate review, margins of $0-1,1-2$, and $2-3$ are shaded pink, yellow and green, respectively. The lowest margin is 1.10 for the $4.5 \mathrm{~g}$ downward case. This is in the region of the cutout for the roadside expandable slide tube; in order to visualize this result, the von Mises stress for the exterior aluminum plate is shown in Figure 55 for the $4.5 \mathrm{~g}$ downward load case. Two other cases have margins less than 2 (1.56 for roof in $1.5 \mathrm{~g}$ aft and lateral to roadside case; 1.88 in side and rear for $2.0 \mathrm{~g}$ upward case) and all remaining cases have margins that exceed 2.

\begin{tabular}{|l|c|c|c|c|c|}
\cline { 2 - 6 } \multicolumn{1}{c|}{} & \multicolumn{5}{|c|}{ Maximum von Mises Stress (ksi) } \\
\hline & & \multicolumn{2}{c|}{ Exterior Aluminum Plate } \\
Element & Down, 4.5 g & Up, 2.0 g & Forward, 3.0 g & $\begin{array}{c}\text { Aft, 1.5 g } \\
\text { Lat To CS, } 1.5 \mathrm{~g}\end{array}$ & $\begin{array}{c}\text { Aft, } 1.5 \mathrm{~g} \\
\text { Lat To RS, } 1.5 \mathrm{~g}\end{array}$ \\
\hline Floor & 10.01 & 6.946 & 5.369 & 3.495 & 6.637 \\
\hline Roof & 3.514 & 3.16 & 1.73 & 7.746 & 8.21 \\
\hline Side and Rear & 3.509 & 7.297 & 6.327 & 3.335 & 2.571 \\
\hline Front & 3.924 & 1.736 & 2.529 & 1.919 & 1.901 \\
\hline Curbside (CS) Exp & 1.292 & 1.501 & 1.013 & 1.531 & 2.483 \\
\hline Roadside (RS) Exp & 1.785 & 0.863 & 1.102 & 2.851 & 2.406 \\
\hline
\end{tabular}

Table 8. Maximum von Mises stress for HCCC exterior aluminum plates from 5 load cases

\begin{tabular}{|l|c|c|c|c|c|}
\cline { 2 - 6 } \multicolumn{1}{c|}{} & \multicolumn{5}{c|}{ Margin of Safety versus Yield } \\
\hline & \multicolumn{5}{|c|}{ Exterior Aluminum Plate } \\
\hline Element & Down, 4.5 g & Up, 2.0 g & Forward, 3.0 g & $\begin{array}{c}\text { Aft, 1.5 g } \\
\text { Lat To CS, } 1.5 \mathrm{~g}\end{array}$ & $\begin{array}{c}\text { Aft, } 1.5 \mathrm{~g} \\
\text { Lat To RS, } 1.5 \mathrm{~g}\end{array}$ \\
\hline Floor & 1.10 & 2.02 & 2.91 & 5.01 & 2.16 \\
\hline Roof & 4.98 & 5.65 & 11.14 & 1.71 & 1.56 \\
\hline Side and Rear & 4.98 & 1.88 & 2.32 & 5.30 & 7.17 \\
\hline Front & 4.35 & 11.10 & 7.30 & 9.94 & 10.05 \\
\hline Curbside (CS) Exp & 15.25 & 12.99 & 19.73 & 12.72 & 7.46 \\
\hline Roadside (RS) Exp & 10.76 & 23.33 & 18.06 & 6.37 & 7.73 \\
\hline
\end{tabular}

Table 9. Margin of safety for HCCC exterior aluminum plates from 5 load cases (assumed yield stress of $21 \mathrm{ksi}$ for 3003-H14 alloy) 


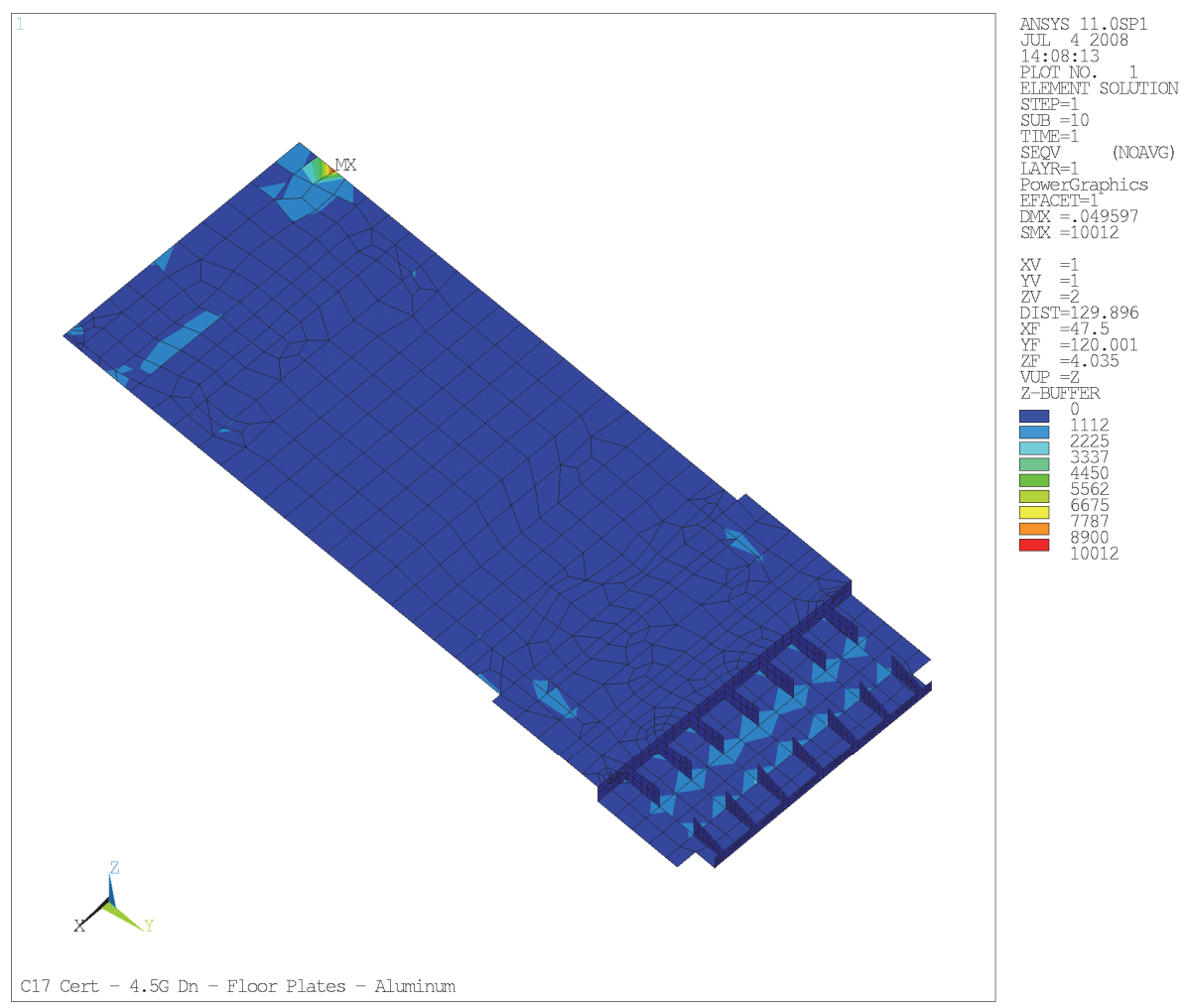

Figure 55. HCCC floor exterior aluminum plate von Mises stress (4.5 g downward load case; viewed from above)

\section{E. Interior Aluminum Plate Stresses}

The stresses for all interior aluminum plate elements for the 5 certification load cases are presented in Table 10; as noted previously, there is no interior aluminum for the floor. The margin of safety for these plates is presented in Table 11; the yield stress of 21 ksi for 3003-H14 was used for this calculation. To facilitate review, margins of $0-1,1-$ 2 , and $2-3$ are shaded pink, yellow and green, respectively. The lowest margin is 1.18 and 1.36 for the $1.5 \mathrm{~g}$ aft and lateral to roadside and curbside cases, respectively. These values are in the region where the top expandable guide attaches to the roof guide rail, indicating that significant load transfer is occurring at this point; in order to visualize this result, the von Mises stress for the interior aluminum plate is shown in Figure 56 for the 
$1.5 \mathrm{~g}$ aft and lateral to roadside load case. All remaining cases have margins of 2 or above.

\begin{tabular}{|l|c|c|c|c|c|}
\cline { 2 - 6 } \multicolumn{1}{c|}{} & \multicolumn{5}{|c|}{ Maximum von Mises Stress (ksi) } \\
\hline & & \multicolumn{5}{c|}{ Interior Aluminum Plate Elements } \\
\hline Element & Down, 4.5 g & Up, 2.0 g & Forward, 3.0 g & $\begin{array}{c}\text { Aft, 1.5 g } \\
\text { Lat To CS, 1.5 g }\end{array}$ & $\begin{array}{c}\text { Aft, } 1.5 \mathrm{~g} \\
\text { Lat To RS, } 1.5 \mathrm{~g}\end{array}$ \\
\hline Floor & - & - & - & - & - \\
\hline Roof & 3.933 & 3.24 & 2.025 & 8.915 & 9.642 \\
\hline Side and Rear & 2.169 & 4.097 & 5.54 & 2.485 & 3.217 \\
\hline Front & 4.858 & 1.392 & 2.444 & 2.264 & 2.311 \\
\hline Curbside (CS) Exp & 1.801 & 1.103 & 0.925 & 0.965 & 1.721 \\
\hline Roadside (RS) Exp & 1.536 & 0.904 & 1.03 & 1.8 & 1.345 \\
\hline
\end{tabular}

Table 10. Maximum von Mises stress for HCCC interior aluminum plates from 5 load cases

\begin{tabular}{|l|c|c|c|c|c|}
\cline { 2 - 6 } \multicolumn{1}{c|}{} & \multicolumn{5}{c|}{ Margin of Safety versus Yield } \\
\hline & & \multicolumn{5}{c|}{ Interior Aluminum Plate Elements } \\
\hline Element & Down, 4.5 g & Up, 2.0 g & Forward, 3.0 g & $\begin{array}{c}\text { Aft, 1.5 g } \\
\text { Lat To CS, 1.5 g }\end{array}$ & $\begin{array}{c}\text { Aft, } 1.5 \mathrm{~g} \\
\text { Lat To RS, } 1.5 \mathrm{~g}\end{array}$ \\
\hline Floor & - & - & - & - & - \\
\hline Roof & 4.34 & 5.48 & 9.37 & 1.36 & 1.18 \\
\hline Side and Rear & 8.68 & 4.13 & 2.79 & 7.45 & 5.53 \\
\hline Front & 3.32 & 14.09 & 7.59 & 8.28 & 8.09 \\
\hline Curbside (CS) Exp & 10.66 & 18.04 & 21.70 & 20.76 & 11.20 \\
\hline Roadside (RS) Exp & 12.67 & 22.23 & 19.39 & 10.67 & 14.61 \\
\hline
\end{tabular}

Table 11. Margin of safety for HCCC interior aluminum plates from 5 load cases (assumed yield stress of $21 \mathrm{ksi}$ for 3003-H14 alloy) 


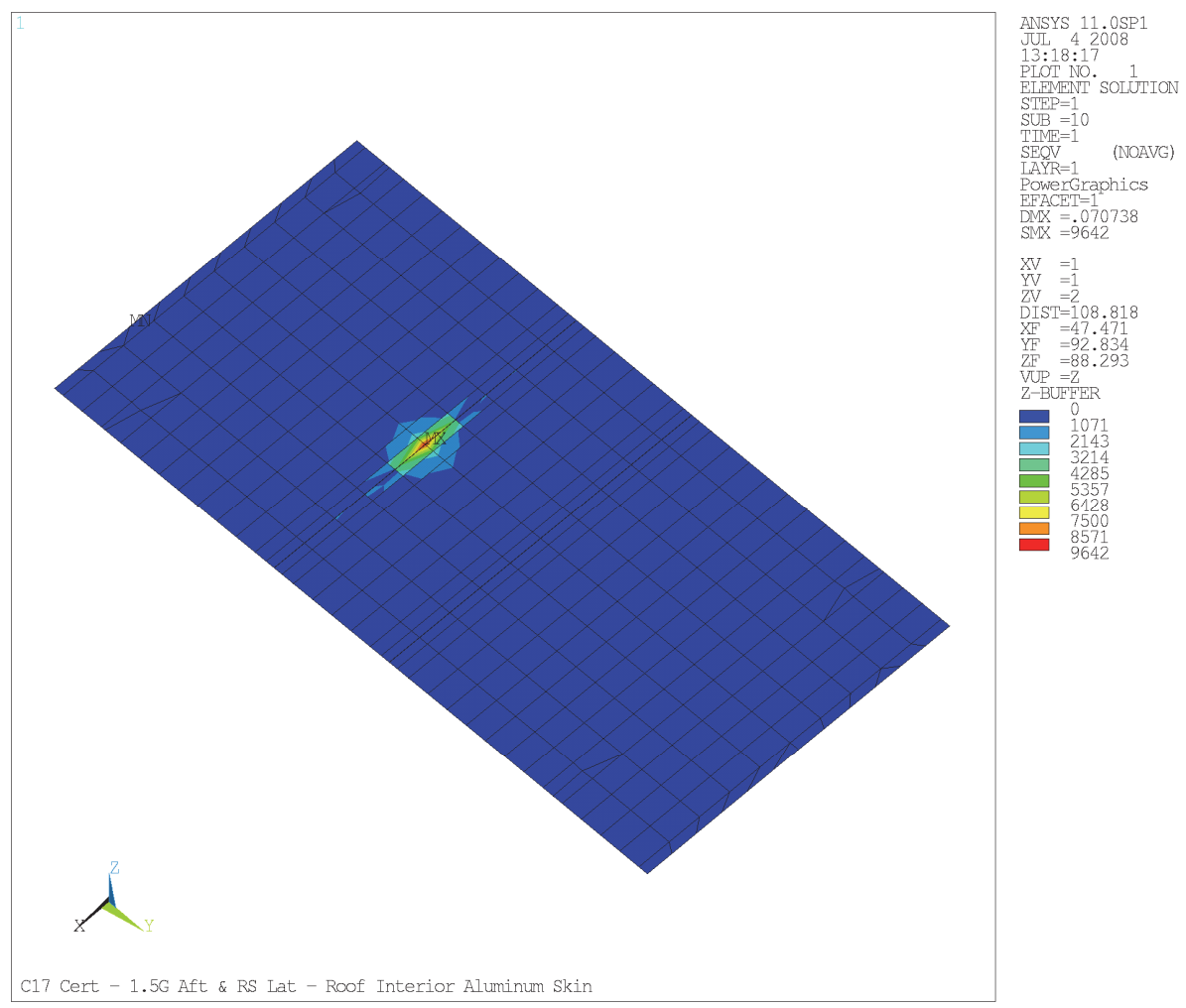

Figure 56. HCCC roof interior aluminum plate von Mises stress ( $1.5 \mathrm{~g}$ aft and lateral to roadside load case; viewed from above)

\section{F. Lite-Ply Plywood Stresses}

The stresses for all Lite-Ply plywood plate elements for the 5 certification load cases are presented in Table 12. The margin of safety for these plates is presented in Table 13; the proportional limit stress of 2.931 ksi for yellow poplar plywood was used for this calculation. To facilitate review, margins of $0-1,1-2$, and $2-3$ are shaded pink, yellow and green, respectively. All margins outside of the floor region are in excess of 3. The margins in the floor region are much lower, ranging from 0.13 for the $3.0 \mathrm{~g}$ forward load case to 1.02 for the $2.0 \mathrm{~g}$ upward load case. For the $3.0 \mathrm{~g}$ forward and $1.5 \mathrm{~g}$ aft/lateral cases, the region of high stress in the region where the electronic equipment racks bolt to the floor; in order to visualize this result, the von Mises stress for the Lite- 
Ply plywood in the floor is shown in Figure 57. It should be noted that the 8 white squares in Figure 57 indicate regions where aluminum plates are used to provide the rack attachment points; as such, it may be that the high stresses in the plywood are simply due to a stiffness mismatch that is not going to occur in practice (e.g. the plywood and the aluminum plates are not bonded/welded together). For the $4.5 \mathrm{~g}$ downward and $2.0 \mathrm{~g}$ upward load cases, the maximum stress occurs in the region of the rear roadside expandable slide tube support; this is shown in Figure 58 for the $4.5 \mathrm{~g}$ downward case. While several of these margins are low, all remain positive. It should be noted that all of these values have margin values in excess of 1 for ultimate strength $(5.421 \mathrm{ksi})$; hence, even if some permanent deformation occurs it should not lead to a complete fracture.

\begin{tabular}{|l|c|c|c|c|c|}
\cline { 2 - 6 } \multicolumn{1}{c|}{} & \multicolumn{5}{|c|}{ Maximum von Mises Stress (ksi) } \\
\hline & & \multicolumn{4}{c|}{ LitePly Plywood Elements } \\
Element & Down, $4.5 \mathrm{~g}$ & Up, $2.0 \mathrm{~g}$ & Forward, $3.0 \mathrm{~g}$ & $\begin{array}{c}\text { Aft } 1.5 \mathrm{~g} \\
\text { Lat To CS, } 1.5 \mathrm{~g}\end{array}$ & $\begin{array}{c}\text { Aft, } 1.5 \mathrm{~g} \\
\text { Lat To RS, } 1.5 \mathrm{~g}\end{array}$ \\
\hline Floor & 1.846 & 1.448 & 2.601 & 1.921 & 2.006 \\
\hline Roof & 0.279 & 0.230 & 0.144 & 0.632 & 0.684 \\
\hline Side and Rear & 0.157 & 0.295 & 0.408 & 0.179 & 0.232 \\
\hline Front & 0.346 & 0.100 & 0.149 & 0.162 & 0.165 \\
\hline Curbside (CS) Exp & 0.128 & 0.076 & 0.068 & 0.070 & 0.128 \\
\hline Roadside (RS) Exp & 0.140 & 0.081 & 0.106 & 0.133 & 0.102 \\
\hline
\end{tabular}

Table 12. Maximum von Mises stress for HCCC interior aluminum plates from 5 load cases

\begin{tabular}{|c|c|c|c|c|c|}
\hline & \multicolumn{5}{|c|}{ Margin of Safety versus Yield } \\
\hline & \multicolumn{5}{|c|}{ LitePly Plywood Elements } \\
\hline Element & Down, $4.5 \mathrm{~g}$ & Up, $2.0 \mathrm{~g}$ & Forward, $3.0 \mathrm{~g}$ & $\begin{array}{c}\text { Aft, } 1.5 \mathrm{~g} \\
\text { Lat To CS, } 1.5 \mathrm{~g}\end{array}$ & $\begin{array}{c}\text { Aft, } 1.5 \mathrm{~g} \\
\text { Lat To RS, } 1.5 \mathrm{~g}\end{array}$ \\
\hline Floor & 0.59 & 1.02 & 0.13 & 0.53 & 0.46 \\
\hline Roof & 9.51 & 11.74 & 19.35 & 3.64 & 3.29 \\
\hline Side and Rear & 17.67 & 8.94 & 6.18 & 15.37 & 11.63 \\
\hline Front & 7.47 & 28.31 & 18.67 & 17.09 & 16.76 \\
\hline Curbside (CS) Exp & 21.90 & 37.57 & 42.10 & 40.87 & 21.90 \\
\hline Roadside (RS) Exp & 19.94 & 35.19 & 26.65 & 21.04 & 27.74 \\
\hline
\end{tabular}

Table 13. Margin of safety for HCCC interior aluminum plates from 5 load cases (assumed yield stress of $21 \mathrm{ksi}$ for 3003-H14 alloy) 


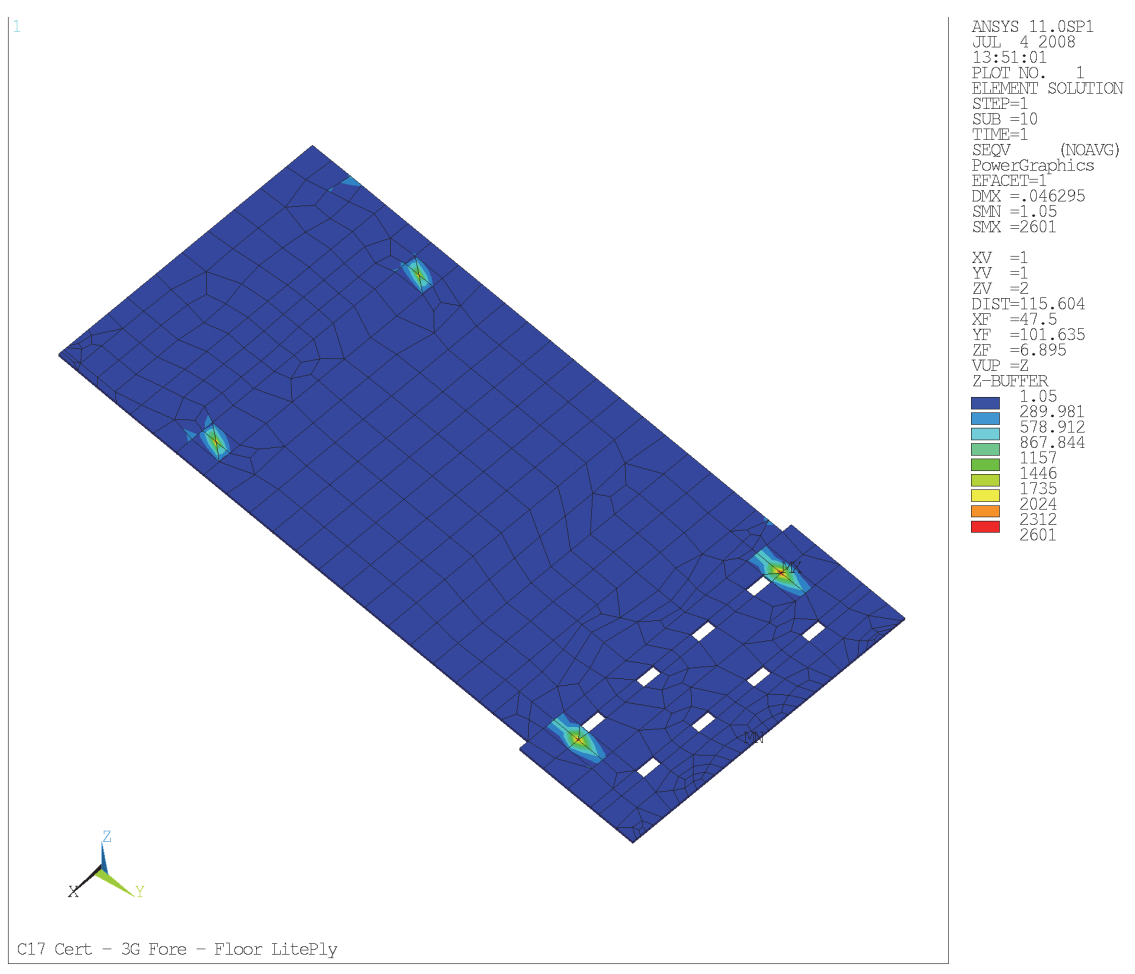

Figure 57. HCCC floor LitePly plywood plate von Mises stress (3.0 $\mathrm{g}$ forward load case; viewed from above)

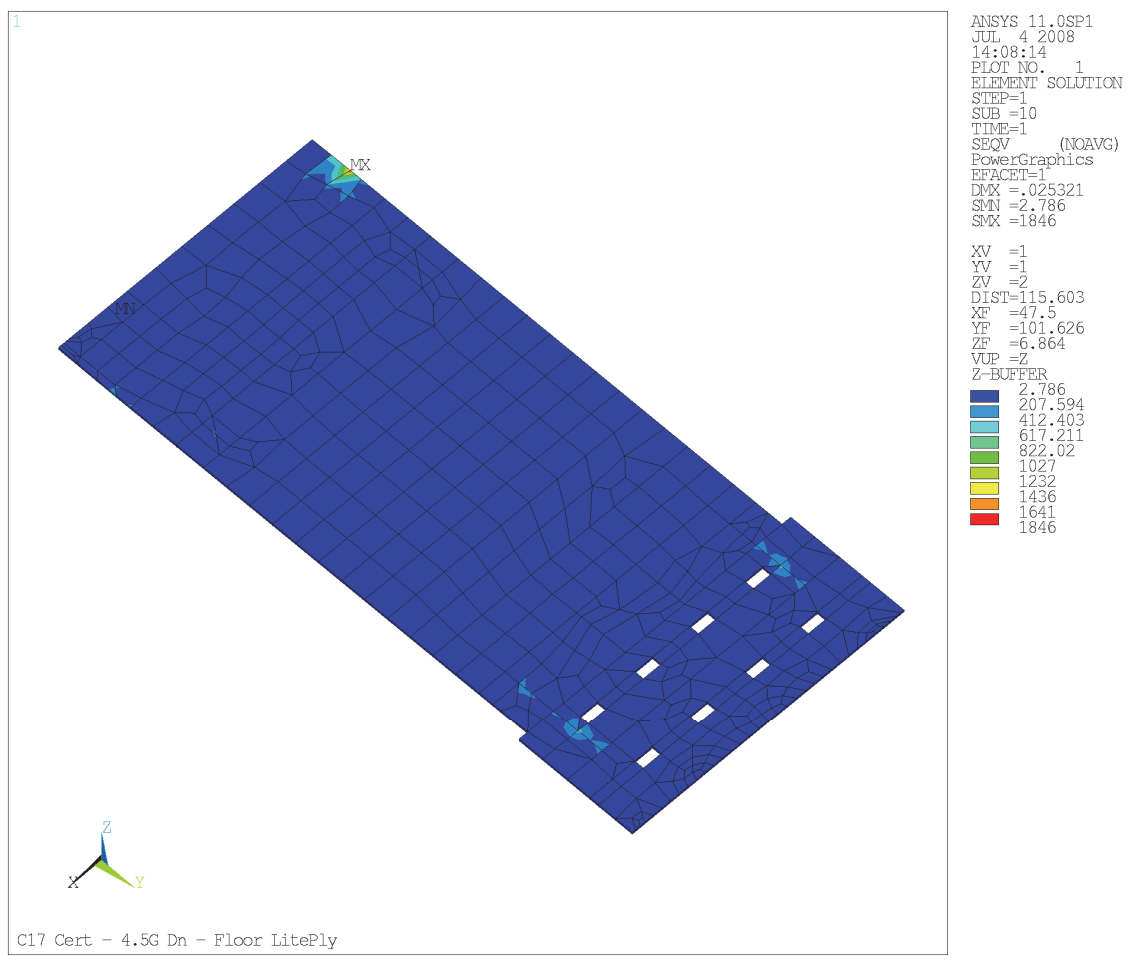

Figure 58. HCCC floor LitePly plywood plate von Mises stress (4.5 g downward load case; viewed from above) 


\section{G. Model Displacements}

The maximum displacement magnitude for each region for the 5 certification load cases along with the entire model maximum values are presented in Table 12. To facilitate comparison, the region with the largest displacement is highlighted green. The roadside expandable is the largest displacement in 4 of the 5 cases. One possible explanation for this is that the rear slide tube support is located approximately midway two floor rails while the other 3 are attached directly a floor rail (this is clearly shown in Figure 49); this renders the rear roadside less stiff than the others leading to greater displacements. This is demonstrated in Figure 59 for the $1.5 \mathrm{~g}$ aft and lateral to roadside load case; it is clear that the upper rear edge of the roadside expandable is the source of the largest displacement. The exception is the $3.0 \mathrm{~g}$ forward load case, in which the front has the largest displacement. This is in the region of several exterior aluminum sheets that are not stiffened with foam; this is shown in Figure 60. For all load cases considered, the maximum displacement is less than 5/16 inch. In the context of the size of the HCCC shelter, this certainly seems to be a reasonable value.

\begin{tabular}{|l|c|c|c|c|c|}
\cline { 2 - 6 } \multicolumn{1}{l|}{} & \multicolumn{5}{|c|}{ Maximum Displacement Magitudes (in) } \\
\hline & & & & Aflements \\
Element & Down, $4.5 \mathrm{~g}$ & Up, $2.0 \mathrm{~g}$ & Forward, 3.0 g & $\begin{array}{c}\text { Aft, } 1.5 \mathrm{~g} \\
\text { Lat To CS, } 1.5 \mathrm{~g}\end{array}$ \\
Lat To RS, $1.5 \mathrm{~g}$
\end{tabular}

Table 14. Maximum displacement for each region of the HCCC model from 5 load cases 


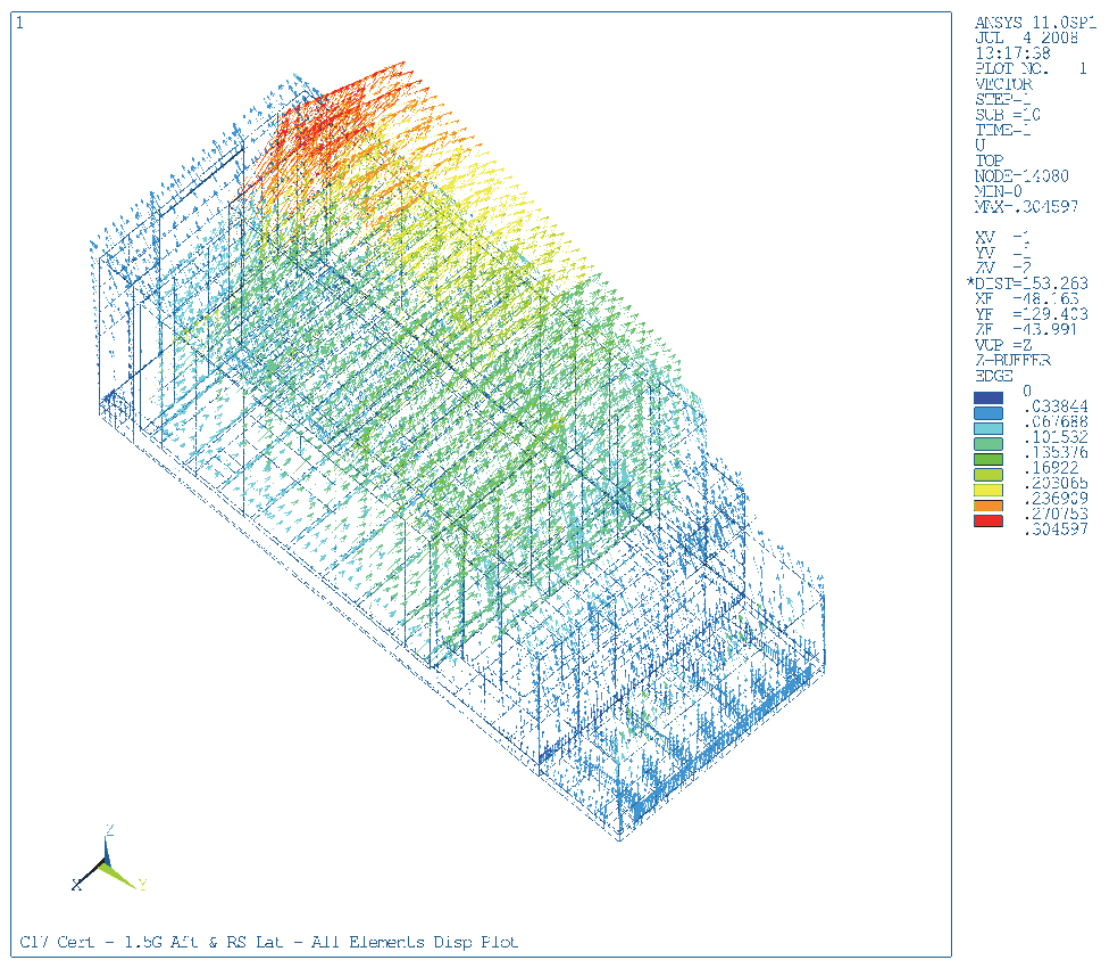

Figure 59. HCCC displacement vector plot (1.5 g aft and lateral to roadside load case; viewed from above)

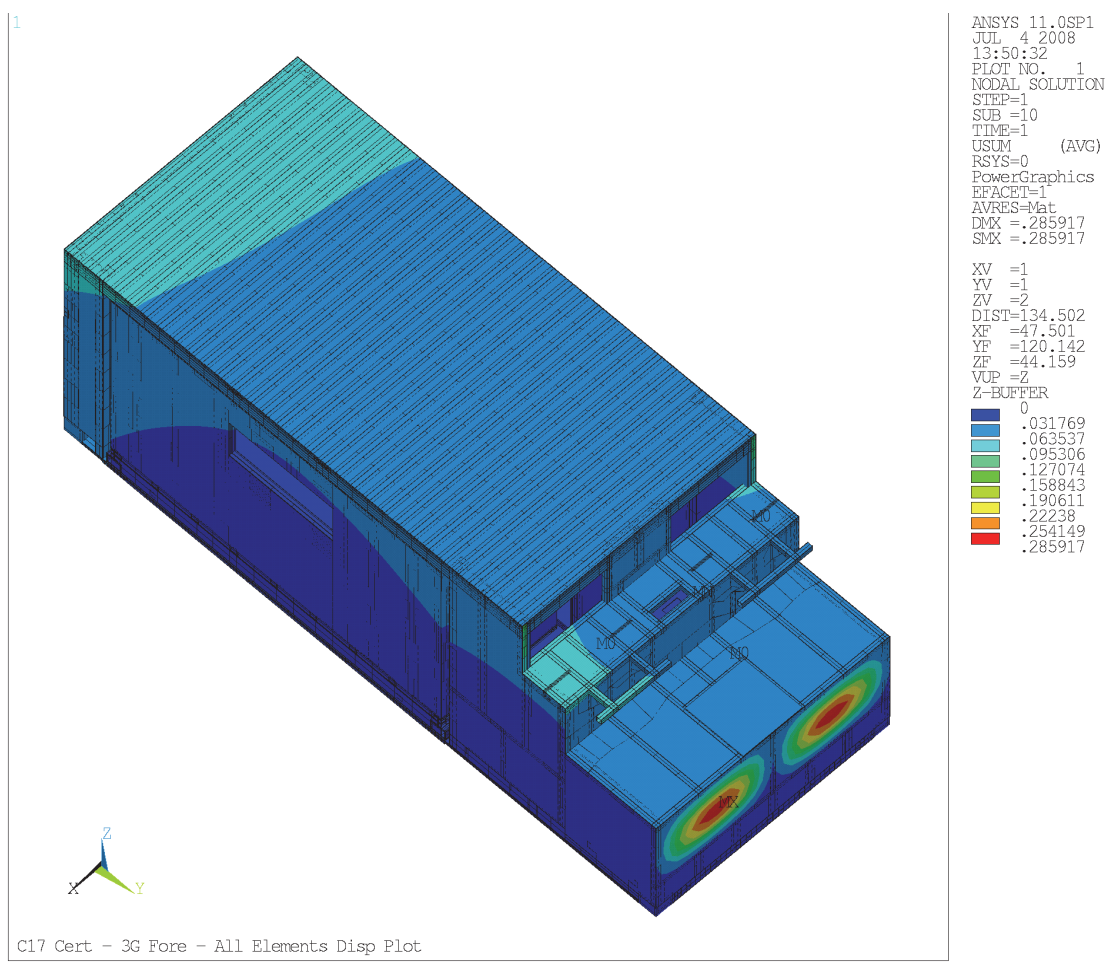

Figure 60. HCCC floor LitePly plywood plate von Mises stress ( $3 \mathrm{~g}$ forward load case; viewed from above) 


\section{H. HCCC FEM Model Support Loads}

As described previously, the HCCC is supported by 4 dowel mounts that attach it to the M1085 truck as well as vertical support from the M1085 truck bed. The loads in the X (lateral to curbside), Y (forward) and Z (vertical up) directions observed for the 5 certification load cases are presented in Table 15. To facilitate comparison, the loads in each case are summed and highlighted in green. These values clearly indicate that the correct load cases have been applied; for example, the $4.5 \mathrm{~g}$ downward load case leads to total loads of 0,0 , and 45.44 kips in the $\mathrm{X}, \mathrm{Y}$ and $\mathrm{Z}$ directions, which is consistent with the total mass of 10.100 kips multiplied by a $4.5 \mathrm{~g}$ downward acceleration (the M1085 must push upwards by 45.44 kips). The forces in the $\mathrm{X}-\mathrm{Y}$ direction are transmitted to the M1085 truck via the dowel mounts (in shear); the magnitude of these combined loads for each dowel mount are also provided in Table 15 for completeness. 


\begin{tabular}{|c|c|c|c|c|c|c|}
\hline & & \multicolumn{5}{|c|}{ Dowel Mount And Truck Bed Loads (kips) } \\
\hline Element & Element & Down, $4.5 \mathrm{~g}$ & Up, $2.0 \mathrm{~g}$ & Forward, $3.0 \mathrm{~g}$ & $\begin{array}{c}\text { Aft, } 1.5 \mathrm{~g} \\
\text { Lat To CS, } 1.5 \mathrm{~g}\end{array}$ & $\begin{array}{c}\text { Aft, } 1.5 \mathrm{~g} \\
\text { Lat To RS, } 1.5 \mathrm{~g}\end{array}$ \\
\hline Force In & Front-CS & 0.28 & 0.02 & -0.20 & -4.15 & 4.70 \\
\hline \multirow[t]{5}{*}{ X Dir (Fwd) } & Front-RS & -0.30 & 0.00 & 0.15 & -4.88 & 4.39 \\
\hline & Rear-CS & 0.33 & -0.58 & 0.18 & -3.50 & 2.82 \\
\hline & Rear-RS & -0.31 & 0.56 & -0.12 & -2.62 & 3.23 \\
\hline & Bed & 0.00 & 0.00 & 0.00 & 0.00 & 0.00 \\
\hline & $\begin{array}{l}\text { Sum - All } \\
\text { X Dir Loads }\end{array}$ & 0.00 & 0.00 & 0.00 & -15.15 & 15.15 \\
\hline Force In & Front-CS & -0.18 & 0.26 & -8.97 & 5.37 & 4.04 \\
\hline \multirow[t]{5}{*}{ Y Dir (Lat) } & Front-RS & -0.22 & 0.74 & -9.58 & 4.11 & 6.22 \\
\hline & Rear-CS & 0.15 & -0.25 & -6.21 & 2.99 & 2.77 \\
\hline & Rear-RS & 0.26 & -0.74 & -5.54 & 2.68 & 2.11 \\
\hline & Bed & 0.00 & 0.00 & 0.00 & 0.00 & 0.00 \\
\hline & $\begin{array}{l}\text { Sum - All } \\
\text { Y Dir Loads }\end{array}$ & 0.00 & 0.00 & -30.29 & 15.15 & 15.15 \\
\hline Force In & Front-CS & 5.54 & -6.41 & -3.44 & 1.83 & -6.78 \\
\hline \multirow[t]{5}{*}{ Z Dir (Vert) } & Front-RS & 5.24 & -6.69 & -3.68 & -6.66 & 1.66 \\
\hline & Rear-CS & 1.97 & -4.57 & -2.01 & 0.18 & -0.14 \\
\hline & Rear-RS & 1.66 & -4.78 & -1.37 & -0.86 & -0.13 \\
\hline & Bed & 31.03 & 2.24 & 10.50 & 5.51 & 5.39 \\
\hline & $\begin{array}{l}\text { Sum - All } \\
\text { Z Dir Loads }\end{array}$ & 45.44 & -20.20 & 0.00 & 0.00 & 0.00 \\
\hline Vector Sum & Front-CS & 0.33 & 0.26 & 8.97 & 6.79 & 6.20 \\
\hline Forces $\ln X-Y$ & Front-RS & 0.37 & 0.74 & 9.58 & 6.38 & 7.62 \\
\hline \multirow[t]{2}{*}{ (Fwd-Lat) } & Rear-CS & 0.36 & 0.63 & 6.21 & 4.60 & 3.95 \\
\hline & Rear-RS & 0.40 & 0.93 & 5.54 & 3.75 & 3.86 \\
\hline
\end{tabular}

Table 15. HCCC dowel mount and truck bed support loads from 5 load cases

\section{Loads For Expandable Sections}

As described previously, the HCCC expandables are each supported by 2 support tubes (one forward, one rear) and a top guide attached to the roof; these provide loads in the $\mathrm{Y}$ (forward) and $\mathrm{Z}$ (vertical) directions. The lateral $(\mathrm{X})$ direction load for the expandables is provided by the 2 actuators per expandable (one forward, one rear). The loads from support tubes and top guides in the $\mathrm{Y}$ (forward) and $\mathrm{Z}$ (vertical up) directions observed for the 5 certification load cases are presented in Table 15. To facilitate comparison, the loads in each case are summed and highlighted in green. Using the weight of the curbside and roadside expandables as 1.723 and 1.880 kips, respectively, 
these values clearly indicate that the correct load cases have been applied; for example, the $4.5 \mathrm{~g}$ downward load case leads to total loads of 0 and 7.753 kips in the $\mathrm{Y}$ and $\mathrm{Z}$ directions for the curbside expandable.

\begin{tabular}{|c|c|c|c|c|c|c|}
\hline & & \multicolumn{5}{|c|}{ Total Force (kips) } \\
\hline & & \multicolumn{5}{|c|}{ Tubes and Guides Supporting Expandables } \\
\hline Element & Element & Down, $4.5 \mathrm{~g}$ & Up, $2.0 \mathrm{~g}$ & Forward, $3.0 \mathrm{~g}$ & $\begin{array}{c}\text { Aft, } 1.5 \mathrm{~g} \\
\text { Lat To } C S, 1.5 \mathrm{~g} \\
\end{array}$ & $\begin{array}{c}\text { Aft, } 1.5 \mathrm{~g} \\
\text { Lat To RS, } 1.5 \mathrm{~g}\end{array}$ \\
\hline Force In & Front CS Tube & 0.215 & -1.074 & -3.273 & 1.091 & 2.990 \\
\hline \multirow[t]{3}{*}{ Y Dir (Fwd) } & Rear CS Tube & -0.334 & 1.590 & -2.218 & 2.081 & 1.170 \\
\hline & Top CS Guide & 0.118 & -0.517 & 0.322 & -0.588 & -1.576 \\
\hline & Sum of 3 Loads & -0.001 & -0.001 & -5.169 & 2.584 & 2.584 \\
\hline Force In & Front CS Tube & 4.002 & -2.066 & 1.181 & -0.815 & -1.387 \\
\hline \multirow[t]{3}{*}{ Z Dir (Vert) } & Rear CS Tube & 3.990 & -1.581 & -1.241 & 0.863 & 1.339 \\
\hline & Top CS Guide & -0.239 & 0.201 & 0.060 & -0.048 & 0.048 \\
\hline & Sum of 3 Loads & 7.753 & -3.446 & 0.000 & 0.000 & 0.000 \\
\hline Force In & Front RS Tube & 0.445 & -0.307 & -4.583 & 3.796 & 1.866 \\
\hline \multirow[t]{3}{*}{ Y Dir (Fwd) } & Rear RS Tube & 0.155 & 0.807 & -1.022 & 0.479 & 0.935 \\
\hline & Top RS Guide & -0.601 & -0.499 & -0.035 & -1.455 & 0.018 \\
\hline & Sum of 3 Loads & -0.001 & 0.001 & -5.640 & 2.820 & 2.819 \\
\hline Force In & Front RS Tube & 3.941 & -2.130 & 0.979 & -1.265 & -0.444 \\
\hline \multirow[t]{3}{*}{ Z Dir (Vert) } & Rear RS Tube & 4.559 & -1.652 & -1.015 & 1.197 & 0.534 \\
\hline & Top RS Guide & -0.041 & 0.022 & 0.036 & 0.068 & -0.090 \\
\hline & Sum of 3 Loads & 8.459 & -3.760 & 0.000 & 0.000 & 0.000 \\
\hline
\end{tabular}

Table 16. HCCC expandable support tube and top guide loads from 5 load cases

\begin{tabular}{|l|c|c|c|c|c|}
\cline { 2 - 6 } \multicolumn{1}{c|}{} & \multicolumn{5}{|c|}{ Actuator Load (kips) } \\
\hline & & \multicolumn{5}{|c|}{ Link Elements (2 Force Members) } \\
Element & Down, 4.5 g & Up, 2.0 g & Forward, $3.0 \mathrm{~g}$ & $\begin{array}{c}\text { Aft, } 1.5 \mathrm{~g} \\
\text { Lat To CS, 1.5 g }\end{array}$ & $\begin{array}{c}\text { Aft, } 1.5 \mathrm{~g} \\
\text { Lat To RS, } 1.5 \mathrm{~g}\end{array}$ \\
\hline Curbside, Rear & -0.009 & 0.040 & 0.006 & 1.307 & -1.230 \\
\hline Curbside, Front & 0.009 & -0.040 & -0.006 & 1.277 & -1.354 \\
\hline Curbside, Sum & 0.000 & 0.000 & 0.000 & 2.584 & -2.584 \\
\hline Roadside, Rear & 0.072 & 0.050 & -0.024 & -1.257 & 1.396 \\
\hline Roadside, Front & -0.072 & -0.050 & 0.024 & -1.563 & 1.424 \\
\hline Curbside, Sum & 0.000 & 0.000 & 0.000 & -2.820 & 2.820 \\
\hline
\end{tabular}

Table 17. HCCC actuator loads from 5 load cases 


\section{HCCC FEM ANALYSIS - DYNAMIC SIMULATION}

This section presents a dynamic analysis used to model the HCCC experiencing a sudden stop when transported on a flatbed rail car, or "rail impact." Transient effects are included in the dynamic analysis and accelerations are not constant; the FEM used for dynamic loading is the same as the FEM for static loading.

\section{A. Rail Impact}

The goal of the rail impact test is "collect rail impact shock and vibration data"; this test is done in accordance "in accordance with MIL-STD-810F, Test Method 516.5, Test Procedure VII.” (ATC Rail Impact Facility, 2005 approx.) The results of a rail impact test involving a rigid structure mounted to a high-mobility multipurpose wheeled vehicle (HMMWV) are outlined in a section of a larger document provided by Kentucky Trailer, "2.5 Shock, Rail Impact, Mounted Shelter."; full details of the document such as title, author(s), date of testing, etc. were not provided so the reference is ambiguous. According to the document, environmental data recorders (EDRs) were mounted to the HMMWV, shelter, and the rail car to measure respective accelerations. Figure 61 illustrates the HMMWV mounting to the rail car, and Figure 62 shows the mounting of the EDR inside the shelter. 


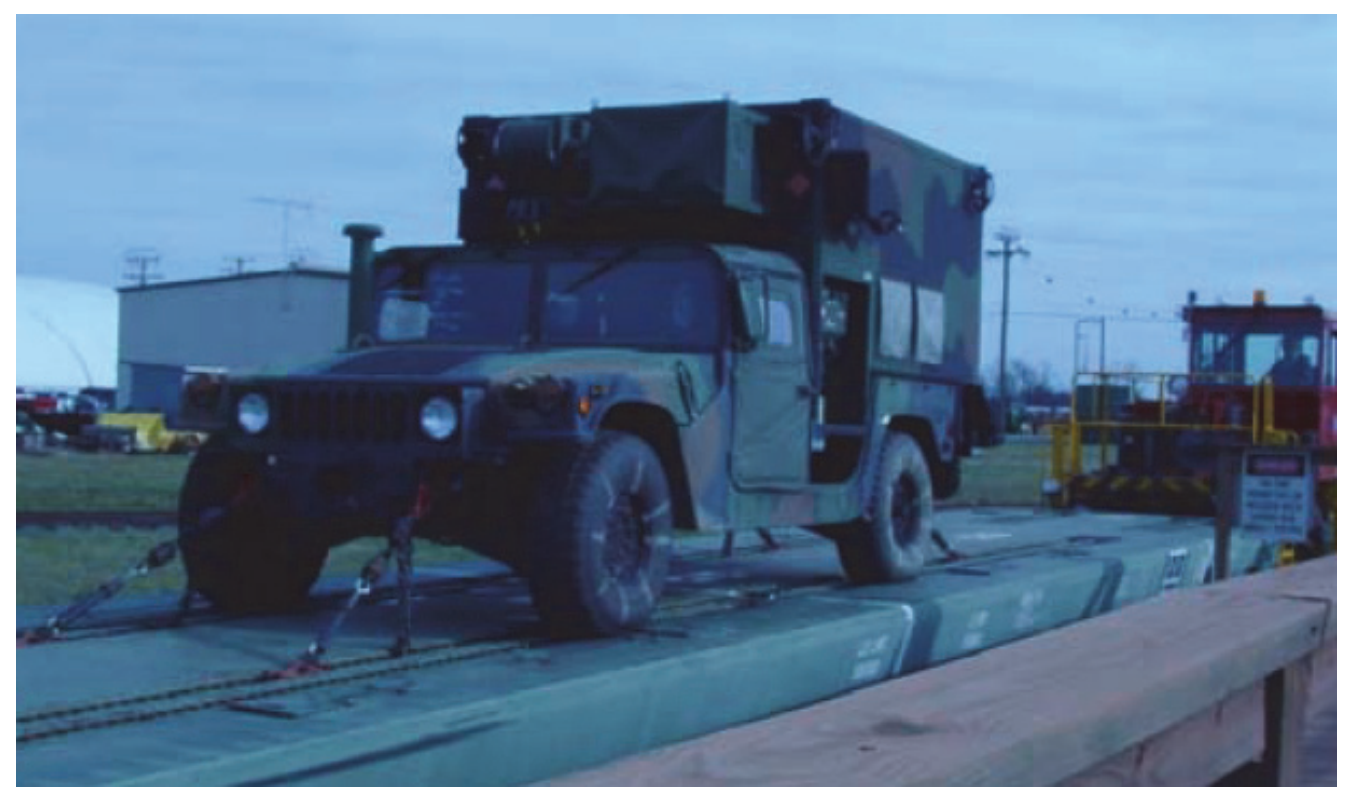

Figure 61. Rail impact test setup with HMMWV and rigid structure (ATC Rail Impact Facility, 2005 approx.)

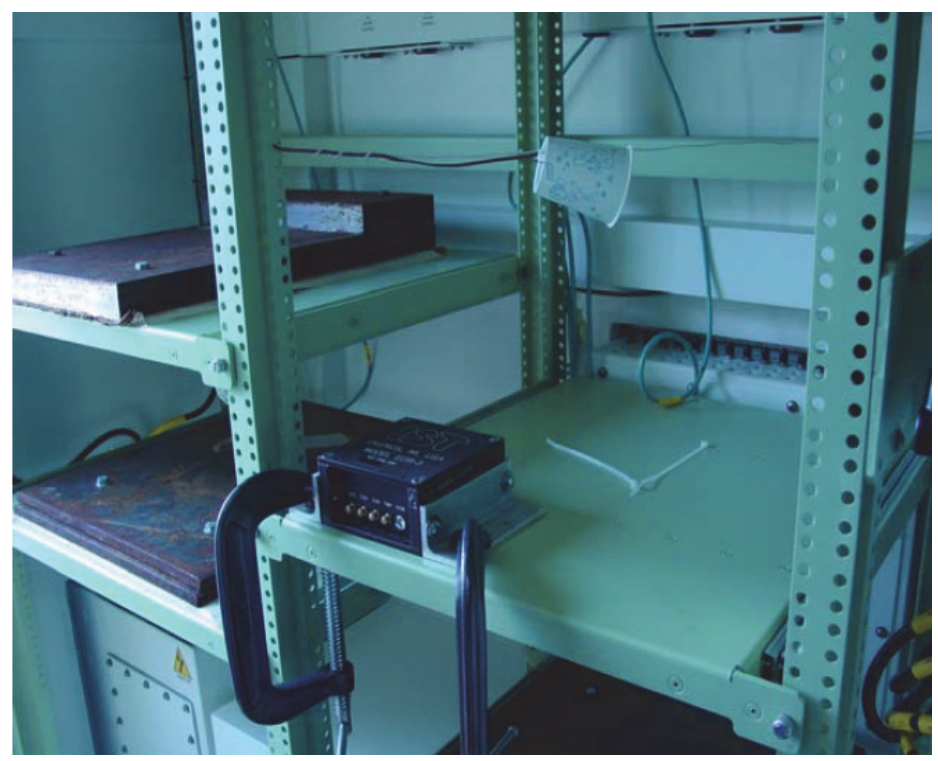

Figure 62. EDR mounting inside the rigid shelter (ATC Rail Impact Facility, 2005 approx.)

Four cases of the rail impact test, of varying initial speeds, were run; those cases are listed in Table 18. For the table, the orientation refers to "the front of the HMMWV 
positioned closest to the point of impact."(ATC Rail Impact Facility, 2005 approx.) The initial speed of the rail car and its resulting accelerations after impact were used to model the driving loads for the HCCC FEM dynamic loading. After discussions with Kentucky Trailer personnel, the reverse $8.3 \mathrm{mph}(8.0 \mathrm{mph}$ nominal $)$ case was chosen for dynamic analysis using the HCCC FEM. In this case, the rail car is traveling in the reverse direction when it impacts another object behind it. The associated EDR data from this case is shown in Figure 63; note that the caption from the original document has been moved above the graph to include its text.

\begin{tabular}{|c|r|r|r|r|l|}
\hline \multirow{2}{*}{$\begin{array}{c}\text { Impact } \\
\text { No. }\end{array}$} & \multicolumn{2}{|c|}{ Nominal Speed } & \multicolumn{2}{|c|}{ Actual Speed } & \\
\cline { 2 - 5 } & $\mathrm{km} / \mathrm{hr}$ & $\mathrm{mph}$ & $\mathrm{km} / \mathrm{hr}$ & $\mathrm{mph}$ & Orientation \\
\hline 1 & 6.4 & 4.0 & 6.6 & 4.1 & Forward \\
\hline 2 & 9.6 & 6.0 & 10.0 & 6.2 & Forward \\
\hline 3 & 12.9 & 8.0 & 13.4 & 8.3 & Forward \\
\hline 4 & 12.9 & 8.0 & 13.4 & 8.3 & Reverse \\
\hline
\end{tabular}

Table 18. Nominal and actual speeds for multiple rail impact tests as listed in Table 2.5-1. (ATC Rail Impact Facility, 2005 approx.) 


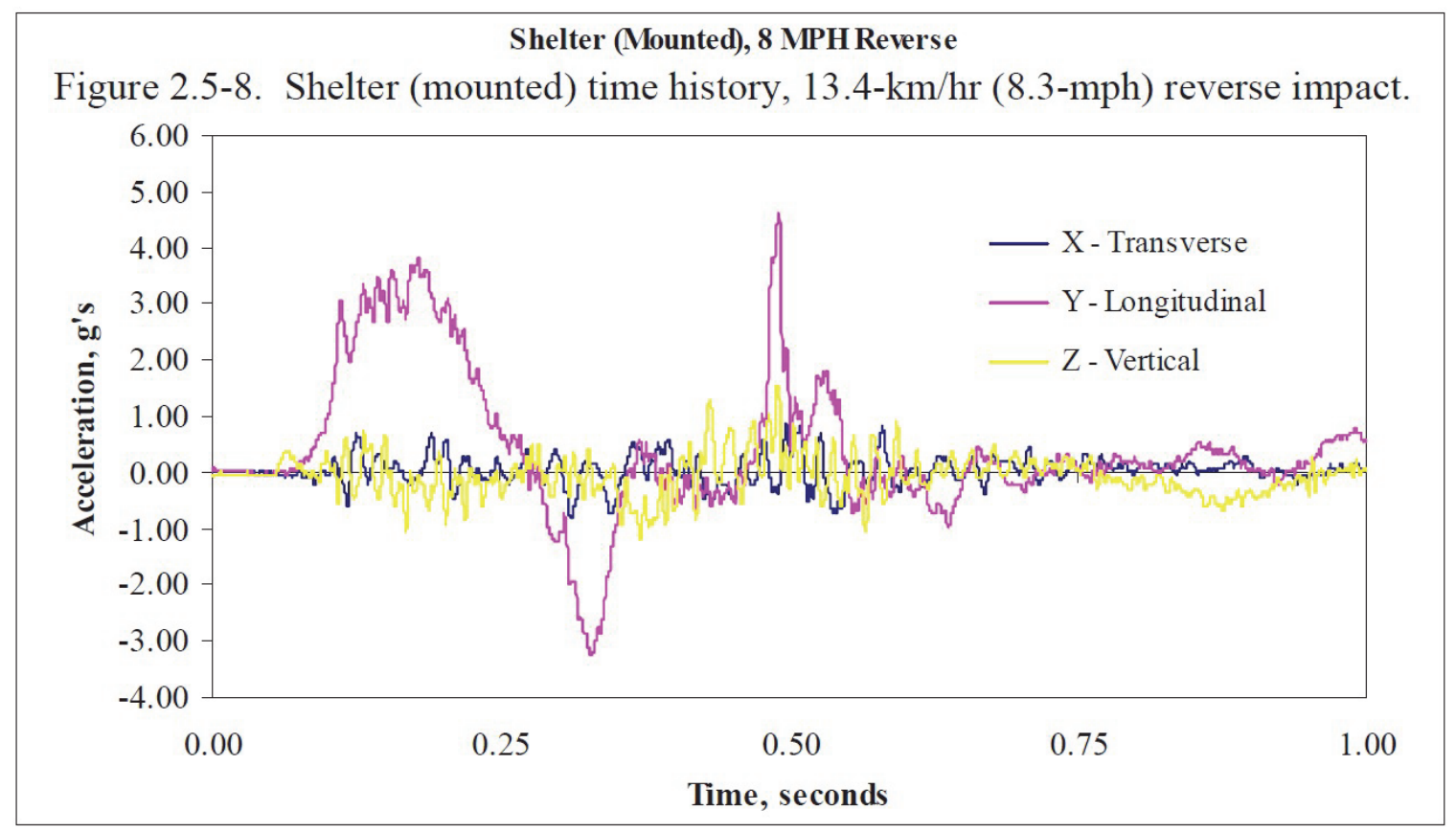

Figure 63. EDR acceleration data from reverse $8.3 \mathrm{mph}$ rail impact test. (ATC Rail Impact Facility, 2005 approx.)

\section{B. Dynamic Loading Details}

Since the acceleration is known from the rail impact test, the HCCC FEM dynamic simulation was performed by providing a specified displacement versus time for the dowel mount nodes. This was done by first smoothing the data above into a series of linear acceleration segments for the data from roughly $0.10 \mathrm{~s}$ (first non-zero accelerations) to $0.45 \mathrm{~s}$ (accelerations become 0 for a period). The time values were offset by approximately $0.10 \mathrm{~s}$ and the resulting curve is shown in Figure 64; the time and acceleration values for each point used to make the linear segments are show. For comparison, an inset also shows a portion of Figure 63 with the time axis shifted such that 0 at the start of non-zero acceleration. The approximation appears to capture the general shape and values of the EDR data. 


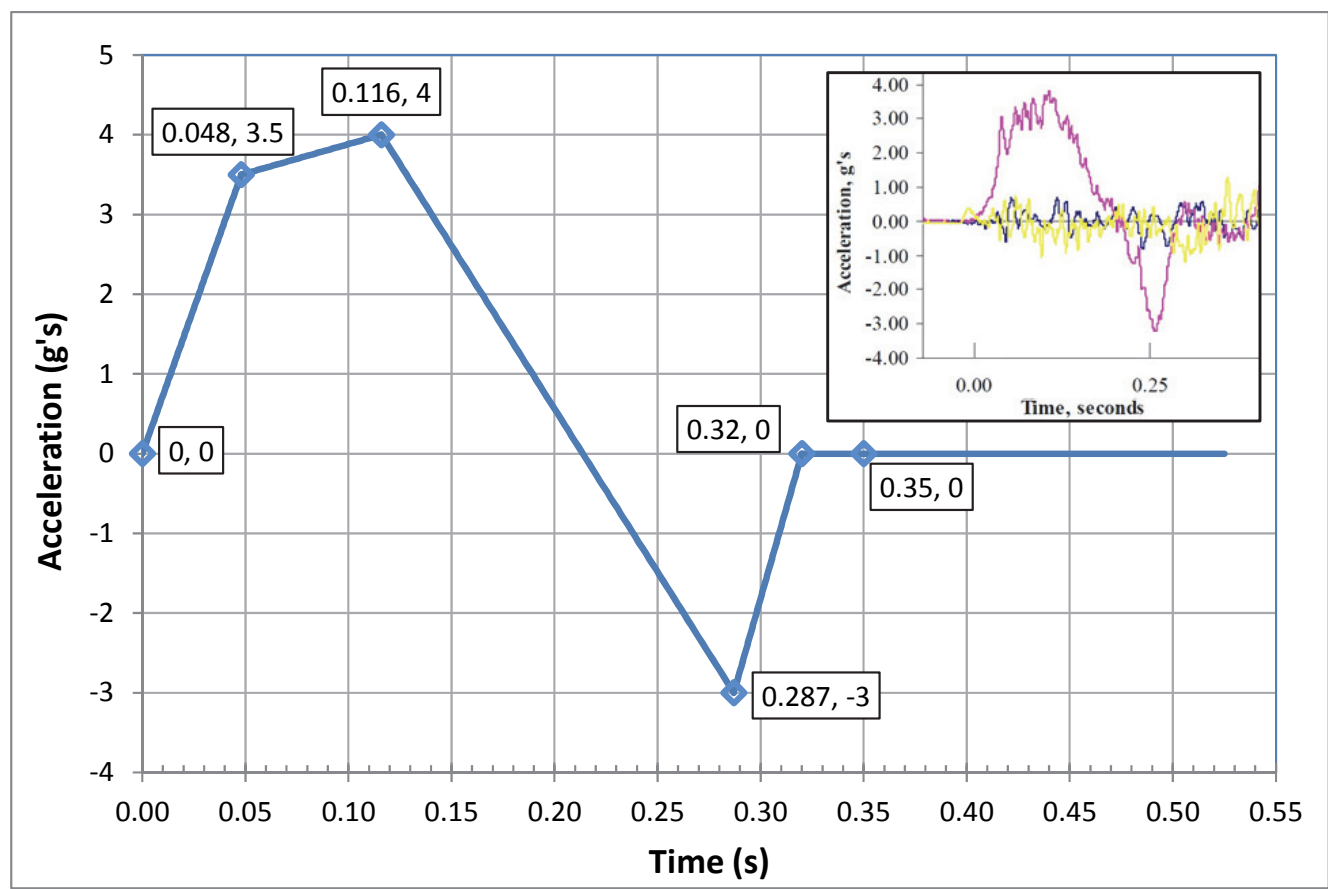

Figure 64. Simulated acceleration for HCCC FEM from reverse $8.3 \mathrm{mph}$ rail impact; inset shows portion of the original data from Figure 63 with time similarly offset.

Once the acceleration versus time is known, it can be converted into in $/ \mathrm{s}^{2}$ and then integrated once to get velocity (in/s) and then again to get displacement (in). This introduces the initial velocity and initial displacement at $t=0$ as constants of integration; the former is assumed to be $-145.527 \mathrm{in} / \mathrm{s}(=-8.3 \mathrm{mph})$ while the latter is assumed to be 0 . The integration was done using a MathCad document created by Dr. Bradshaw and shown in Appendix II. A total of 600 points for time versus displacement were then written to a text file for later use by ANSYS. The resulting curves for velocity and displacement versus time are shown in Figure 65 and Figure 66, respectively. 


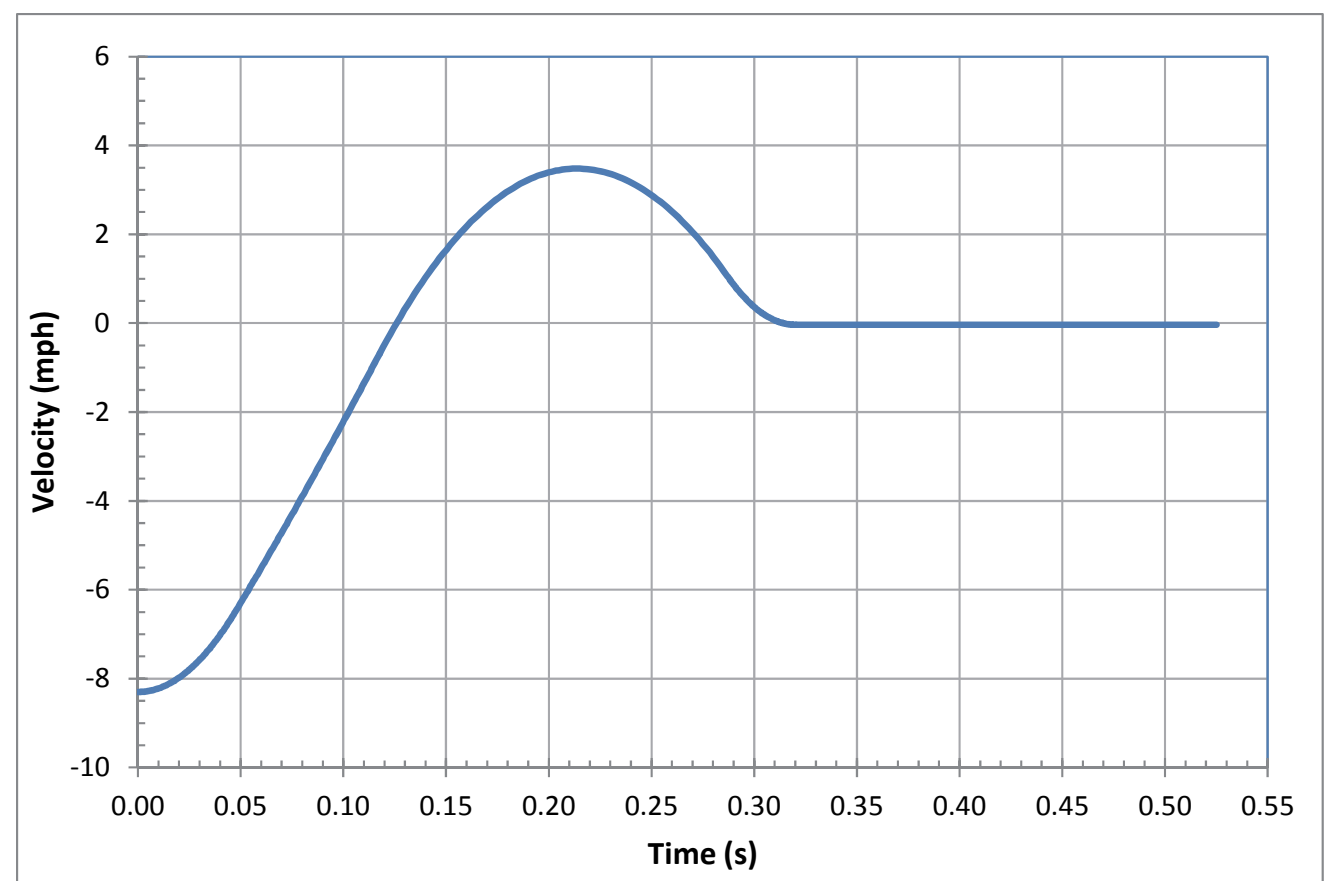

Figure 65. Simulated velocity for HCCC FEM from reverse $8.3 \mathrm{mph}$ rail impact.

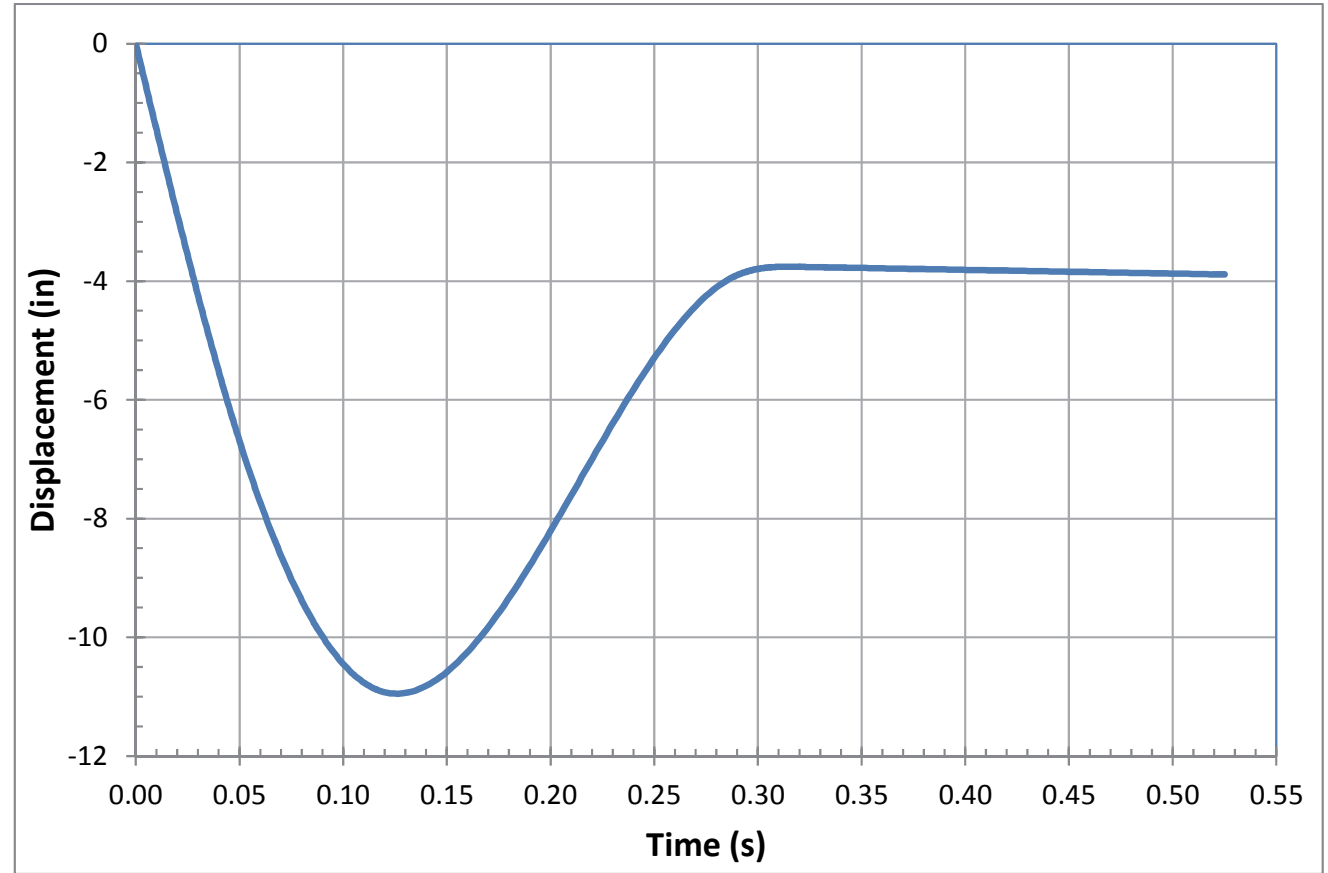

Figure 66. Simulated displacement for HCCC FEM from reverse $8.3 \mathrm{mph}$ rail impact.

The HCCC FEM was run using the "large displacement analysis" solution option. This makes the model nonlinear but allows for correct stress/strain representations as the 
displacements become large relative to element size (as they do in this case); essentially small strain assumptions in a linear solution ("small displacement analysis") no longer apply. The displacements in Figure 66 are applied to the longitudinal (UY) degree of freedom for the dowel mount nodes; the lateral displacement (UX) and vertical displacement (UZ) are assumed to be 0 for all time.

The dynamic analysis includes loads due to acceleration (i.e. $F=m$ a). For a model using units of inches and lbs, the acceleration must be specified using in $/ \mathrm{s}^{2}$ and all mass and density terms known in $\mathrm{lbs}$ or $\mathrm{lb} / \mathrm{in}^{3}$, respectively, must be divided by $386.4 \mathrm{in} / \mathrm{s}^{2}$ (the value of standard $1 \mathrm{~g}$ gravity using in $/ \mathrm{s}^{2}$ units). For example, it takes $1 \mathrm{lbf}$ to accelerate a mass of $1 \mathrm{lbm}$ at $386.4 \mathrm{in} / \mathrm{s}^{2}$ (i.e. $1 \mathrm{~g}$ ); the value of force $\mathrm{F}=\mathrm{m}$ a will be correct if the mass is converted to $1 \mathrm{lb} / 386.4 \mathrm{in} / \mathrm{s}^{2}=0.002588 \mathrm{lb}-\mathrm{s}^{2} /$ in. This conversion was applied to all mass and density terms in the HCCC FEM. The dynamic analysis can also include gravity ( $1 \mathrm{~g}$ in the $\mathrm{Z}$ direction) specified as $386.4 \mathrm{in} / \mathrm{s}^{2}$; however, this was not included in the analysis presented below.

\section{ANSYS Load Steps, Substeps and Solution Issues}

In the $\mathrm{C}-17$ air certification analysis (see Chapter VI), the problem is solved a single "load step" (the set of applied loads at the end of the analysis) with a number of "substeps" (solutions between the start of the analysis and the end of the first load step. For a linear analysis, a single substep is sufficient. However, for nonlinear analyses, a number of substeps are usually required as convergence to a correct solution in a single substep is generally not possible. The HCCC FEM is nonlinear for both static analysis and dynamic analysis due to the contact elements simulating the truck bed support (static 
and dynamic analysis) and large displacement effects (dynamic analysis only). An example showing load steps and substeps from the ANSYS documentation is shown in Figure 67; equilibrium iterations are solutions within a substep until convergence to a correct solution is achieved.

Figure 2.3 Load Steps, Substeps, and Equilibrium Iterations

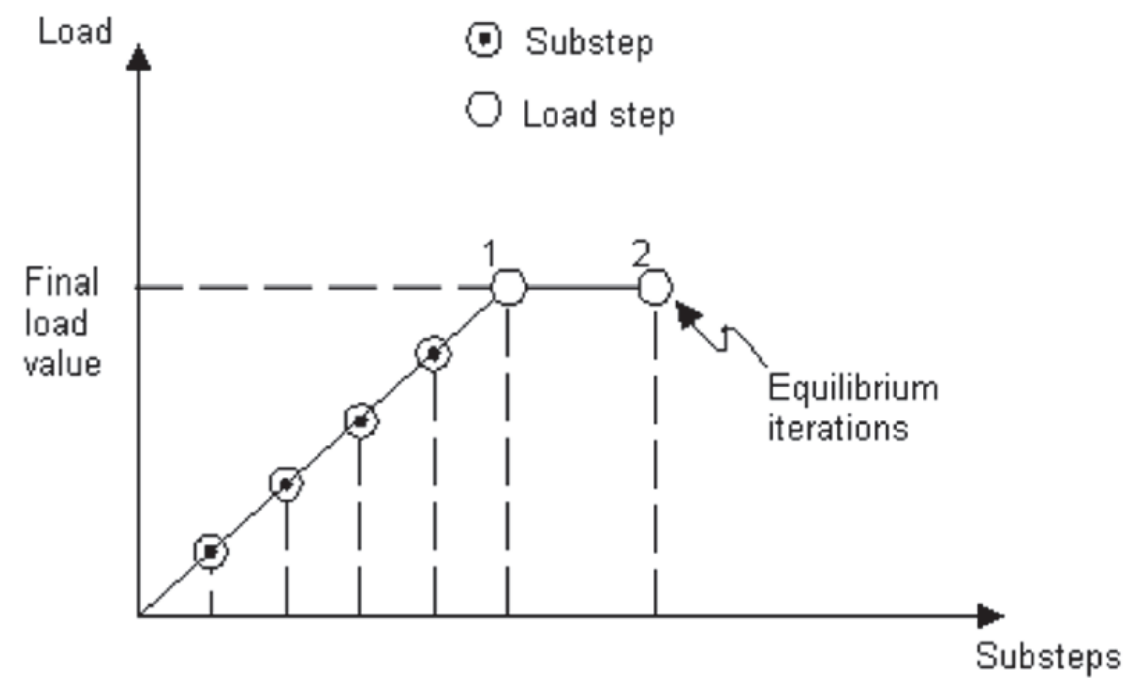

Figure 67. Demonstration of load steps and substeps in ANSYS.(ANSYS, 2008)

In the initial dynamic analysis runs, an approach similar to that for the C-17 analysis was used. The displacement history shown in Figure 66 was broken into a series of segments (load steps) with a number of substeps used between each load step to aid in convergence. In order to enforce a displacement boundary condition (such as UY at the dowel mount nodes), an associated reaction force is determined as part of the solution. In reviewing the dynamic analysis results, it was observed that the approach described above lead to unusual spikes in the reaction force at the dowel mount nodes. These spikes occurred in the first substep of each load step; the reaction forces were much smaller at 
the remaining substeps of each load step.

After considering the solution further, it was observed that the displacement in the load step / substep approach is varies linearly between load steps occurring at two different times (see Figure 67). Therefore, the velocity $v(t)$ in each substep is constant (the first derivative of the displacement $\mathrm{d}(\mathrm{t})$ ) and the acceleration in each substep is 0 (the first derivative of the velocity $\mathrm{v}(\mathrm{t}))$. The only substep for which there is an acceleration is the first substep after a load step concludes. At that moment, the slope of the displacement $\mathrm{d}(\mathrm{t})$ can change before and after the load step; as a result, a change in velocity occurs leading to a non-zero acceleration.

The magnitude of the acceleration that occurs is approximately the change in velocity $\Delta v=v\left(t_{i+1}\right)-v\left(t_{i}\right)$ divided by the time step $\Delta t=t_{i+1}-t_{i}$, where $t_{i+1}$ and $t_{i}$ are the time of the current and previous substep, respectively. The only time that a change in velocity occurs is at the substep following the last load step; hence, an acceleration is observed only in that substep. As the number of substeps in a load step increases, the time step decreases; therefore, increasing the number of substeps increases the magnitude of the force spikes that occur. This is precisely the opposite of a typical analysis, in which more substeps generally leads greater fidelity between the model and the problem that is simulated by the FEM.

In order to correct this, a change was made to the loading of the HCCC FEM for dynamic analysis. The number of desired time points is specified at the outset and the displacement for each of those points is determined using MathCad (see Figure 66). Each of these points (time, displacement) is then applied as an individual load step with the number of substeps held equal to 1. For example, in the results that follow, the 6 
acceleration segments (see Figure 64) are broken into 100 points evenly spaced in time. Therefore, 600 time-displacement points are determined. One additional point is added at the start, corresponding to a time $\left(\mathrm{t}_{1}\right)$ that is a small fraction of the time step. The displacement of this point is set to $v_{0} t_{1}$; this leads to the model having an initial velocity $v_{0}$ at the end of this first load step. Note that during this first step, inertial effects are not included; therefore, the model moves without loads being generated due to $\mathrm{F}=\mathrm{m}$ a. Upon conclusion of the HCCC FEM dynamic analysis, there are 601 load steps each consisting of a single substep.

\section{Model Behavior At Peak Acceleration}

As in the C-17 air certification analysis, each load step leads to a great deal of information that can be characterized by a variety of plots and tables. The C-17 study is only concerned with the results at the end of the single load step; the intermediate substep solutions are used for convergence purposes but are not of interest as results. The dynamic analysis, however, contains useful information at each and every loadstep, corresponding to the dynamic structural response at the associated moment in time. The Create_Output.inp input file can be run at each load step to generate a web page of information for that load step (84 images, 14 data tables). Hence, a great deal of data can be generated.

In order to limit the size of the presentation below, a small number of results are presented below for the load step 200, for which the values are time $t=0.1153 \mathrm{~s}$ and acceleration $\mathrm{a}=3.995 \mathrm{in} / \mathrm{s}^{2}$. This is the load step just prior to that corresponding to peak acceleration ( $4 \mathrm{~g}$ at $\mathrm{t}=0.116 \mathrm{~s})$; it was selected in error after forgetting the first substep 
that sets the initial velocity of the HCCC FEM. Note that the displacement vectors are all approximately the same size, corresponding to their magnitude. This is because the displacement of the dowel mount nodes at this point is $\mathrm{UY}=-10.8688$ in and all displacements below reflect small displacements relative to this value for each node.
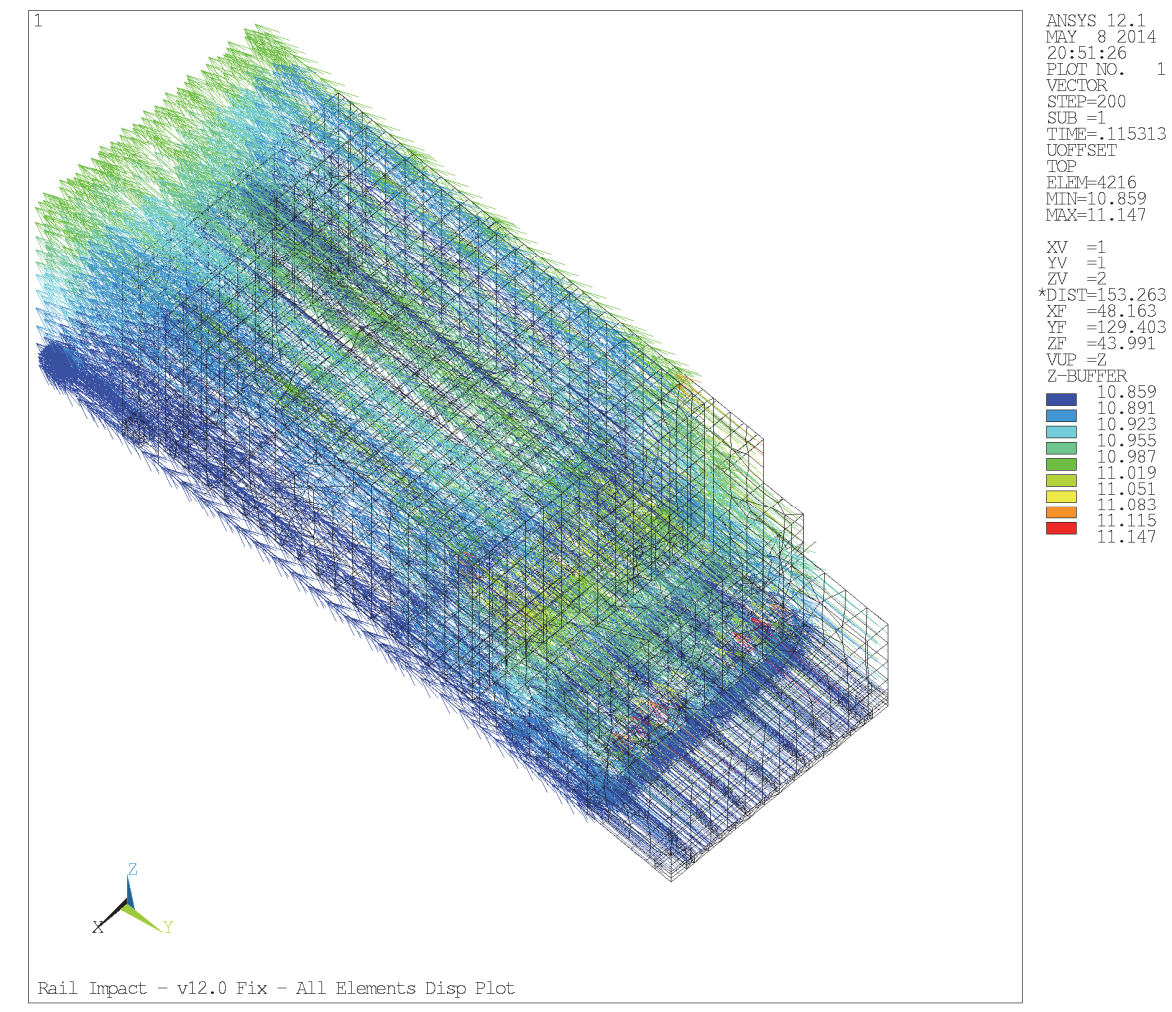

Figure 68. Displacement vector plot at load step $200\left(\mathrm{t}=0.1153 \mathrm{~s}, \mathrm{a}=3.995 \mathrm{in} / \mathrm{s}^{2}\right)$

A better representation of the model displacement at any given moment in time is obtained by subtracting the displacement of the dowel mount nodes; this will give the displacement of the various nodes relative to the nodes where the displacements are specified to drive the simulation. To accomplish this, the ETABLE command is used to store the displacement of each element in three ANSYS element tables (UX, UY, UZ). The displacement of the dowel mount nodes is obtained and subtracted from the three tables above; this leads to three new element tables for the offset (or net) displacement 
for each element. These can be passed to the ANSYS vector plot command as 3 directional values; this leads to the image shown below in Figure 69 for the same data point shown in Figure 68. This view gives a better idea of the relative motion of the structure as well as the magnitude of the relative (or net) displacement. The net displacement values can also be combined together to obtain a net displacement magnitude. This can be used to create a contour plot of the same data as shown in X.

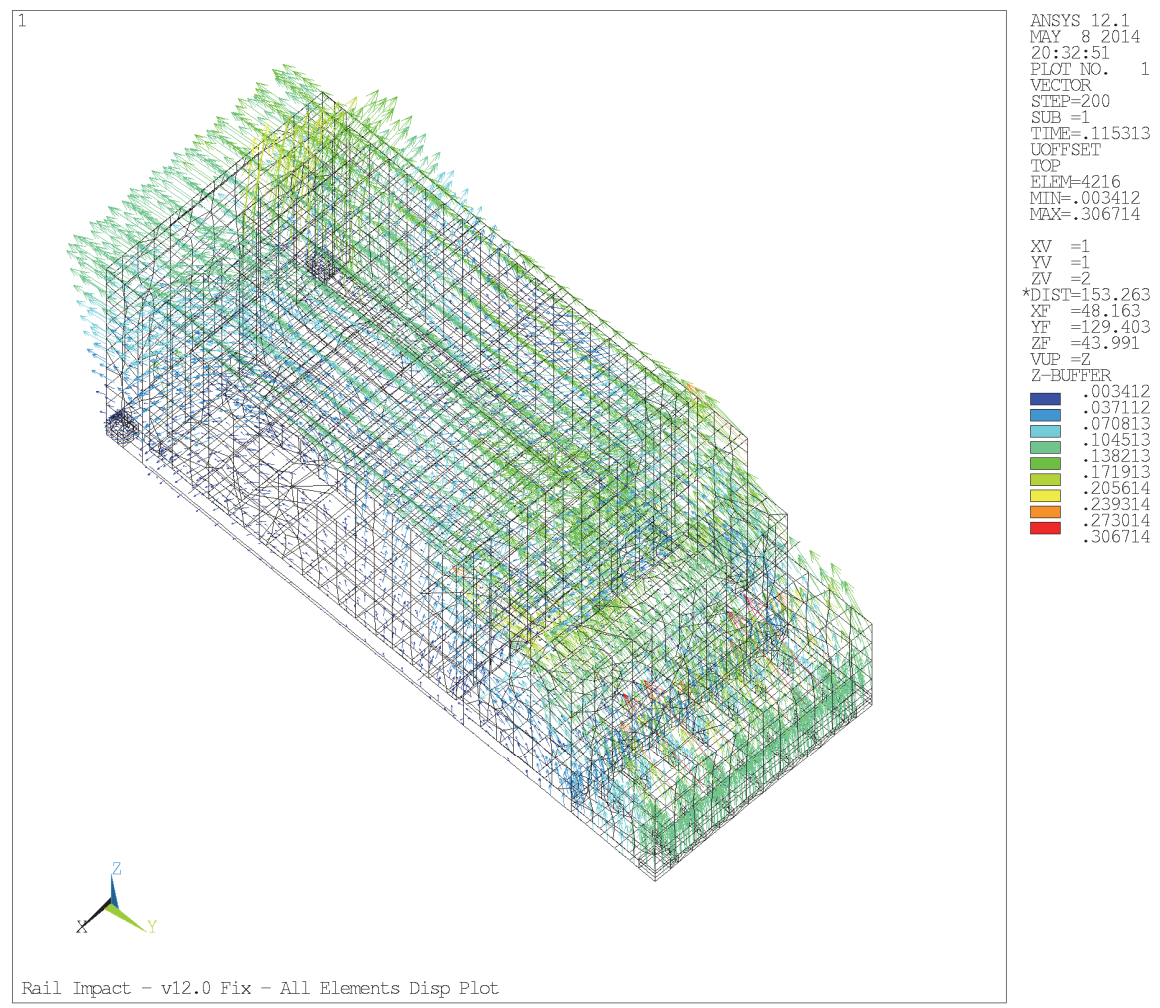

Figure 69. Net displacement vector plot at load step $200\left(\mathrm{t}=0.1153 \mathrm{~s}, \mathrm{a}=3.995 \mathrm{in} / \mathrm{s}^{2}\right)$ 


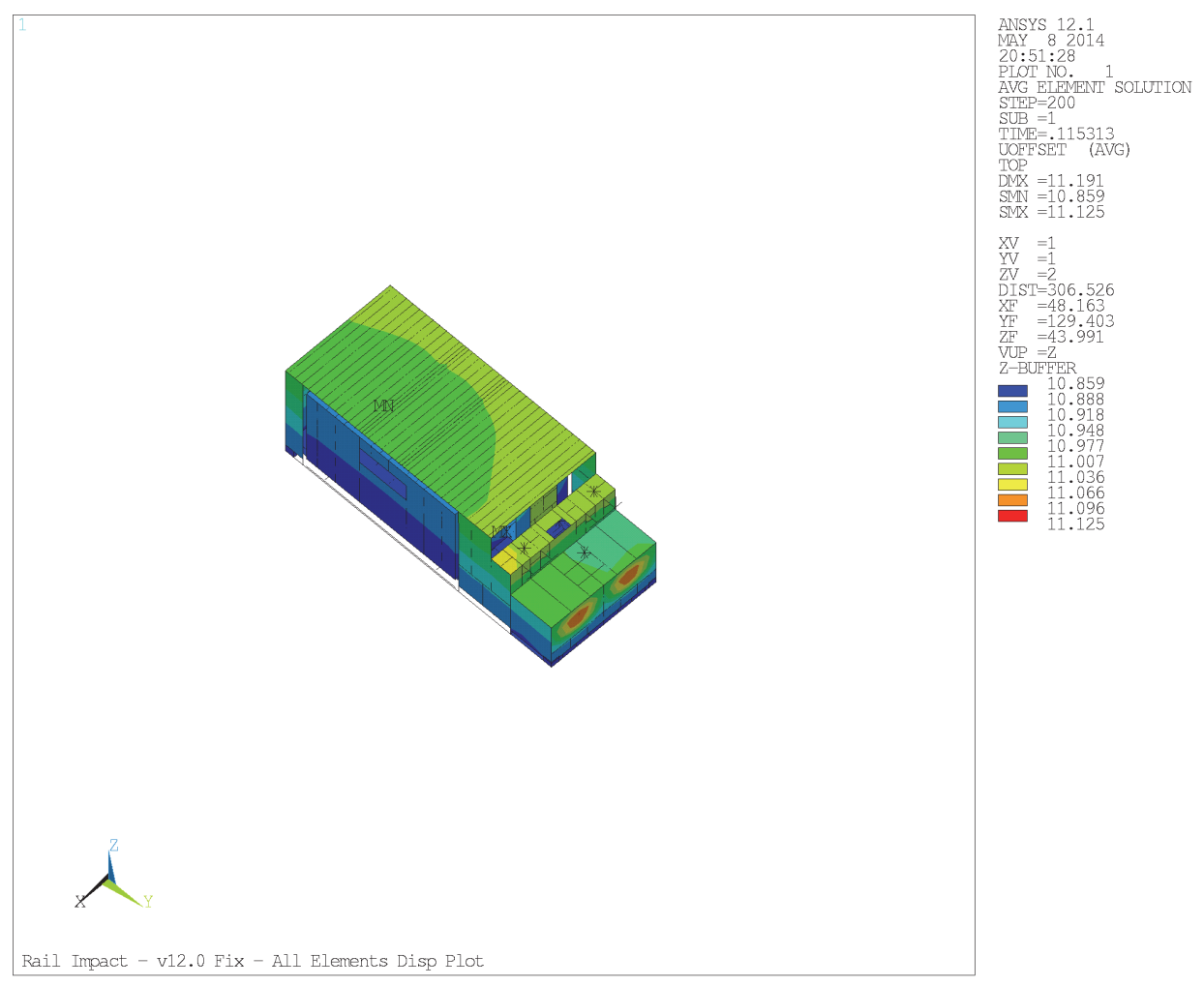

Figure 70. Contour plot of net displacement magnitude at load step 200 $\left(\mathrm{t}=0.1153 \mathrm{~s}, \mathrm{a}=3.995 \mathrm{in} / \mathrm{s}^{2}\right)$

The stress values for each of the structures in the HCCC FEM can also be assessed. For example, the von Mises stress in the beams making up the front frame portion of the main body of the HCCC is shown in Figure 71. Similarly, the von Mises stress in the exterior skin of the curbside expandable is shown in Figure 72. 


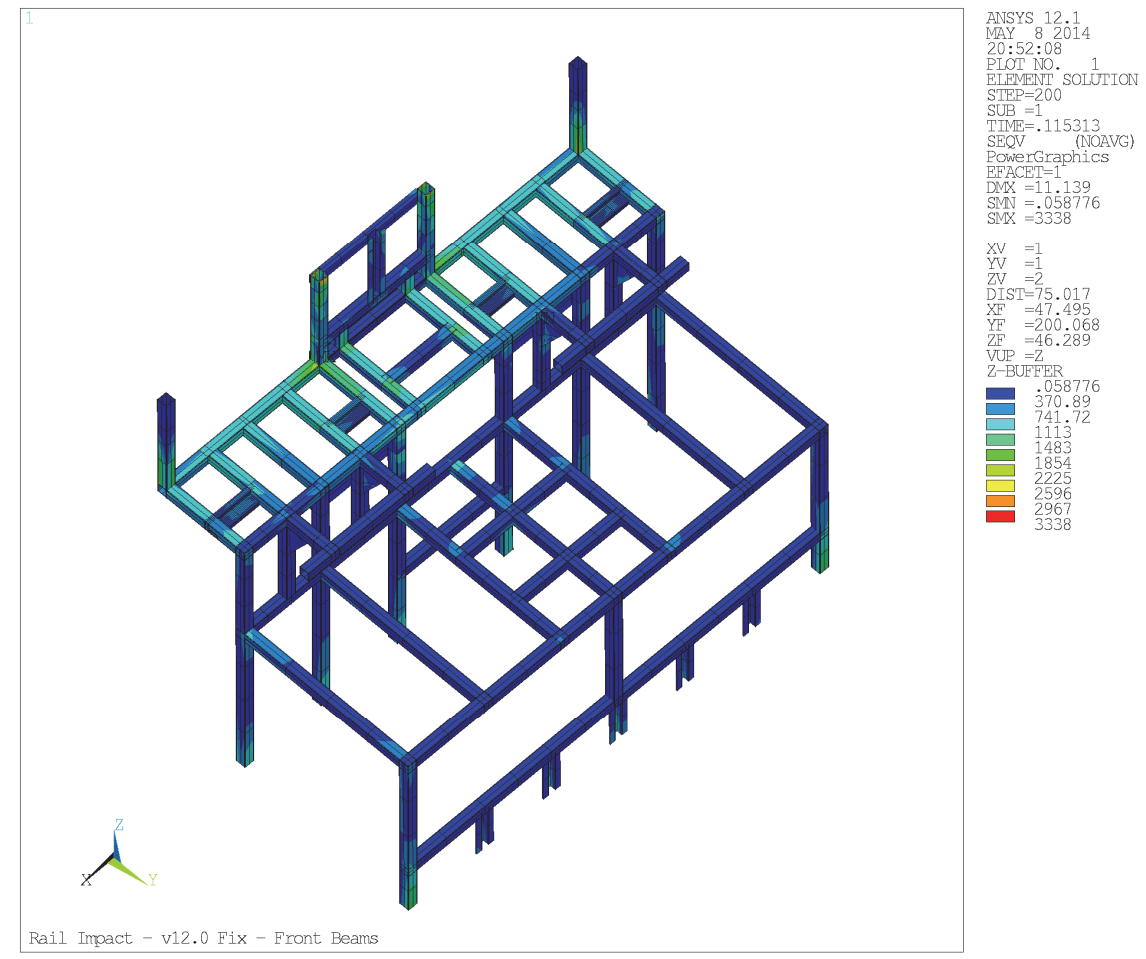

Figure 71. Contour plot of von Mises stress in front frame beams at load step 200 $\left(\mathrm{t}=0.1153 \mathrm{~s}, \mathrm{a}=3.995 \mathrm{in} / \mathrm{s}^{2}\right)$
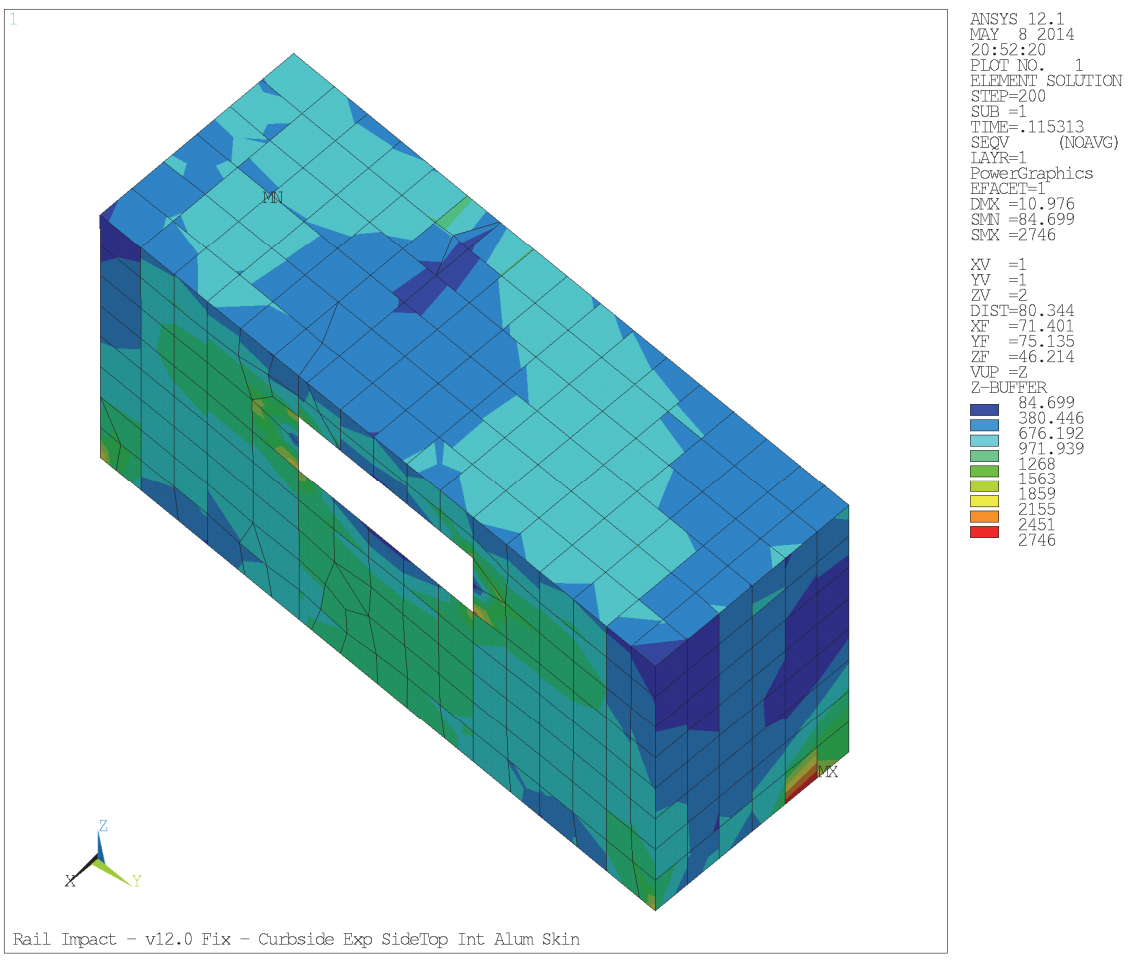

Figure 72. Contour plot of von Mises stress in exterior aluminum skin of curbside expandable at load step $200\left(\mathrm{t}=0.1153 \mathrm{~s}, \mathrm{a}=3.995 \mathrm{in} / \mathrm{s}^{2}\right)$ 
ANSYS can also present data for a single entity, such as the displacement at a particular node, over all time points in the solution using the Time-History Postprocessor. To demonstrate this, the displacement of the four nodes making up the corners of the roof (front and rear, driver side and passenger side) was studied. The net displacement relative to the dowel mount nodes is shown in $\mathrm{X}$ for the $\mathrm{Y}$ direction (direction of travel), $\mathrm{Y}$ for the $\mathrm{X}$ direction (lateral), and $\mathrm{Z}$ for the $\mathrm{Z}$ direction (vertical). The vibratory nature of the system response is clearly evident in these results. The passenger and driver side data shows differences in the $\mathrm{X}$ and $\mathrm{Z}$ directions, presumably due to the differing nature of the expandables for each side. In all cases, the front and rear data for a given side (passenger or driver) appears fairly similar.

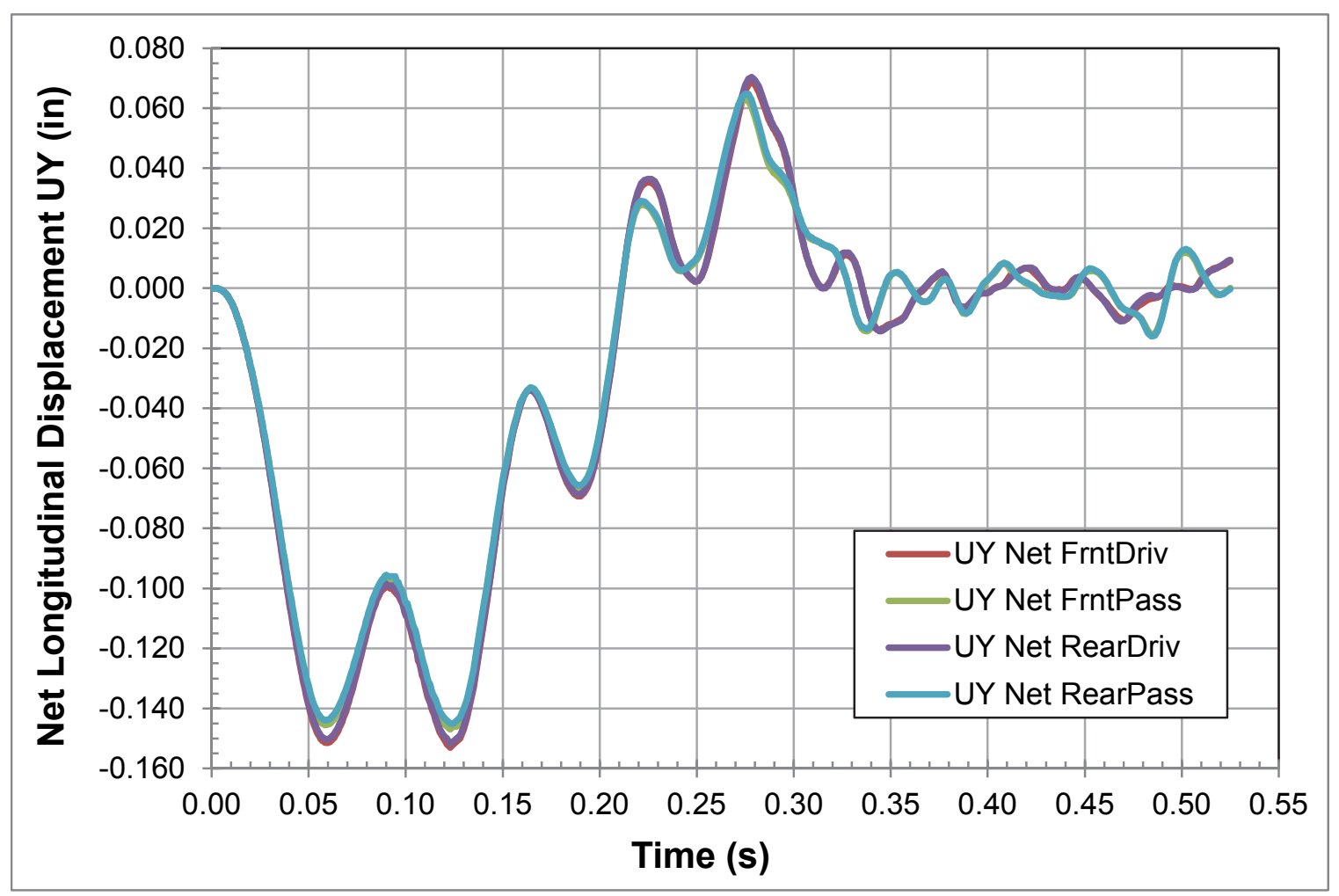

Figure 73. Net displacement of the 4 corner roof nodes over time in Y direction 


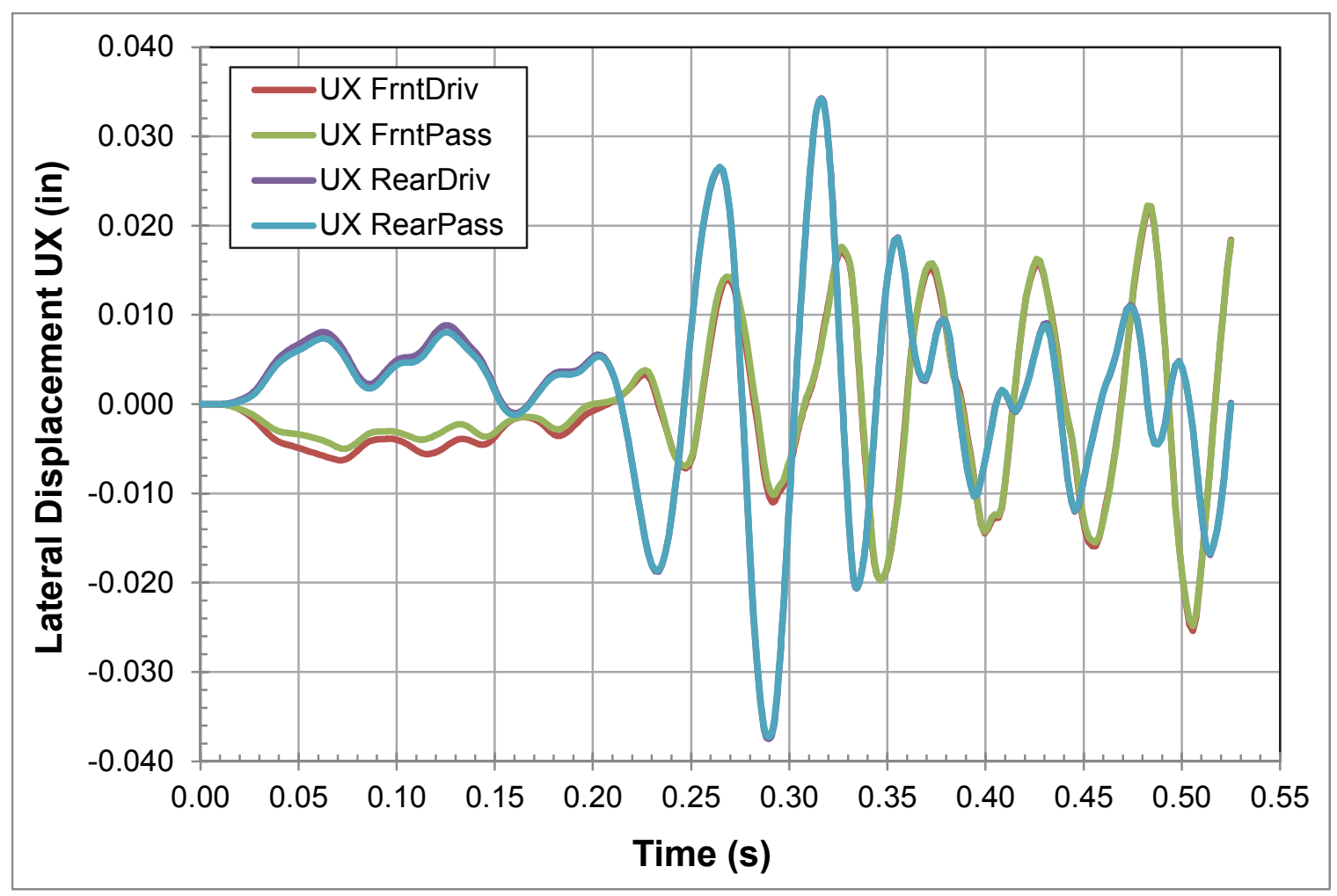

Figure 74. Net displacement of the 4 corner roof nodes over time in $\mathrm{X}$ direction

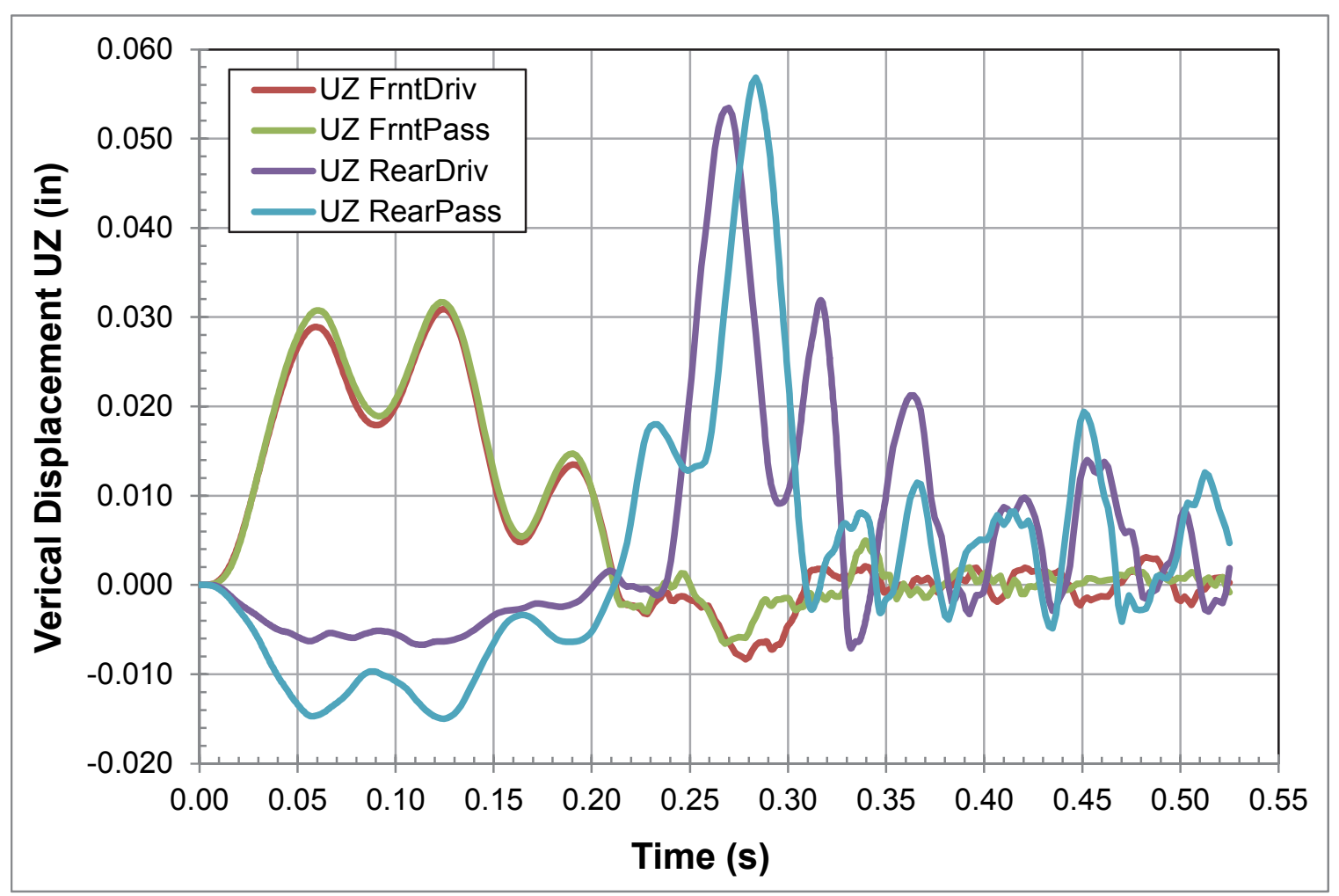

Figure 75. Net displacement of the 4 corner roof nodes over time in $\mathrm{Z}$ direction 


\section{E. Dynamic Loading Max Stresses}

An input file was written to collect detailed results data over the course of the entire rail impact test. In it, the load steps were identified at which each component reached max stresses in the structural beams, aluminum skins, insulating foam, and LitePly layer. The load steps of max stress were then used to generate a report identical to the static loading report but tailored to feature only the max stress plots. Resulting stresses for the aluminum beams, exterior aluminum plates, and Lite-Ply plywood are shown in Table 19, Table 20, and Table 21, respectively. To facilitate review, margins of $0-1,1-$ 2, and $2-3$ are shaded orange, blue, and green, respectively. A negative margin is indicated in red for Lite-Ply in the floor, but when compared to the ultimate strength (5.421 ksi) the margin would be positive, yet still low, at 0.27 . Permanent deformation of the Lite-Ply in the floor is likely, but a complete fracture should not occur.

\begin{tabular}{|l|c|c|c|}
\hline \multicolumn{4}{|c|}{$\begin{array}{c}\text { Maximum von Mises Stress (ksi) and Margin of Safety versus Yield } \\
\text { Aluminum Beam Elements }\end{array}$} \\
\hline Element & VM Stress & $\begin{array}{c}\text { Margin of } \\
\text { Safety }\end{array}$ & $\begin{array}{c}\text { Loadstep of Max } \\
\text { Stress }\end{array}$ \\
\hline Floor, Excl. Supports & 23.2 & 0.724 & 116 \\
\hline Floor, Supports Only & 16.8 & 1.381 & 121 \\
\hline Roof & 6.73 & 4.944 & 206 \\
\hline Sides and Rear & 2.87 & 12.937 & 205 \\
\hline Front & 3.43 & 10.662 & 205 \\
\hline CS Exp & 9.1 & 3.396 & 206 \\
\hline RS Exp & 3.44 & 10.628 & 206 \\
\hline
\end{tabular}

Table 19. Max von Mises stress with corresponding margin of safety and load step for HCCC beams from rail impact case (assumed yield stress of $40 \mathrm{ksi}$ for 6061-T6511 alloy) 


\begin{tabular}{|c|c|c|c|}
\hline \multicolumn{4}{|c|}{$\begin{array}{l}\text { Maximum von Mises Stress (ksi) and Margin of Safety versus Yield } \\
\text { Exterior Aluminum Plates }\end{array}$} \\
\hline Element & $\begin{array}{l}\text { VM } \\
\text { Stress }\end{array}$ & $\begin{array}{l}\text { Margin of } \\
\text { Safety }\end{array}$ & $\begin{array}{c}\text { Loadstep of Max } \\
\text { Stress }\end{array}$ \\
\hline Floor & 11.3 & 0.858 & 121 \\
\hline Roof & 18.4 & 0.141 & 206 \\
\hline Sides and Rear & 6.1 & 2.443 & 205 \\
\hline Front & 4.18 & 4.024 & 205 \\
\hline CS Exp & 5.08 & 3.134 & 206 \\
\hline RS Exp & 3.4 & 5.176 & 207 \\
\hline
\end{tabular}

Table 20. Max von Mises stress with corresponding margin of safety and load step for HCCC exterior aluminum facesheets from rail impact case (assumed yield stress of $21 \mathrm{ksi}$ for 3003-H14 alloy)

\begin{tabular}{|c|c|c|c|}
\hline \multicolumn{4}{|c|}{$\begin{array}{c}\text { Maximum von Mises Stress (ksi) and Margin of Safety versus Yield } \\
\text { Exterior Aluminum Plates }\end{array}$} \\
\hline Element & $\begin{array}{l}\text { VM } \\
\text { Stress }\end{array}$ & $\begin{array}{l}\text { Margin of } \\
\text { Safety }\end{array}$ & $\begin{array}{c}\text { Loadstep of Max } \\
\text { Stress }\end{array}$ \\
\hline Floor & 4.26 & -0.312 & 203 \\
\hline Roof & 1.53 & 0.915 & 206 \\
\hline Sides and Rear & 0.571 & 4.131 & 295 \\
\hline Front & 0.37 & 6.919 & 206 \\
\hline CS Exp & 2.11 & 0.389 & 207 \\
\hline RS Exp & 0.265 & 10.057 & 205 \\
\hline
\end{tabular}

Table 21. Max von Mises stress with corresponding margin of safety and load step for HCCC Lite-Ply from rail impact case (assumed proportional limit stress of $2.931 \mathrm{ksi}$ for yellow poplar plywood) 


\section{CONCLUSION}

The HCCC has been analyzed via a finite element model in ANSYS. This thesis describes the methodology and approach used in the creation, loading, analysis and solution of said model. The results of the model provide a useful approach to assess the viability of the structure under a variety of loading cases; for example, the C-17 certification demonstrated that stresses remained below certain thresholds (such as yield stress) for a variety of conditions.

Since the HCCC FEM using entities such as beam and plate elements, whose properties can be easily changed during analysis, the model is well suited for comparative studies. For example, analyses in which the aluminum facesheets are reduced to save weight (perhaps from 0.050 inches to a lesser value) can be performed easily. This model also provides a platform from which to consider a composite design; specifically, an alternative HCCC could be analyzed in which the expandables are fabricated from fiberglass-polyurethane foam sandwich constrained between aluminum rails. For the HCCC FEM as presented in this thesis, this would involve changing aluminum to a fiberglass laminate and Lite-Ply plywood to polyurethane foam in certain regions of the model along with necessary geometry changes.

For the static analysis of the C-17 air certification study, a total of five inertial (acceleration) cases were considered. The reported requirement is that the HCCC can undergo these load cases without a loss of serviceability. This was interpreted in this thesis as requiring that all von Mises stress in all aluminum components be below the appropriate material yield stress, and that the von Mises stress in the plywood be below proportional limit stresses reported in the literature for a comparable material. The 
margin of safety was calculated for each case; a zero margin means yield/proportional limit stresses are exactly obtained while positive margins mean that the yield/proportional limit stresses are not reached. In all cases, positive margins are observed. This indicates that the load cases considered are not expected to lead to permanent deformation of the structure, which presumably also implies that serviceability of the HCCC will be maintained.

In addition to stress calculations, several values observed during the model solution are presented; these include the model displacements, loads at the dowel mounts attaching the HCCC to the M1085 truck, and the loads between the expandables and the main HCCC body. In all cases, the resulting values are consistent with the load cases under consideration; this provides further verification of the model setup and analysis.

For the dynamic analysis of the rail impact test, one case was considered; this was considered the "worst case" (i.e. saw the largest acceleration in real-world testing) of the possible four test cases. The HCCC can undergo this load case without a loss of serviceability, interpreted in the same manner as the C-17 air certification study. Some re-design of the flooring or underlying structure should be investigated to avoid the negative margin of safety seen in the Lite-Ply in the floor component.

Validation for the analysis presented here could be accomplished by comparing to real-world testing. Real-world results would also assist in refining the FEM for more accurate results. 


\section{APPENDIX I. ANSYS ELEMENTS AND HCCC FEM DETAILS}

The materials in this Appendix will present additional detail for the HCCC FEM. Throughout this thesis, information about ANSYS capabilities and restrictions have been discussed. These have been taken from the applicable sections of the ANSYS software documentation.(ANSYS, 2008)

\section{A. BEAM189 Element Use}

The structural beams were modeled in ANSYS using BEAM189 elements. BEAM189 is a 3 node (one at each end plus a center node) Timoschenko beam element; this element incorporates many advanced deformation capabilities including shear deformation effects, torsional stiffness, and warping capabilities. The element incorporates the ANSYS section tool to describe cross-section behavior; essentially, each cross-section is modeled as a separate finite element model to ascertain the beam stiffness of arbitrarily complex shapes. Another benefit of BEAM189 is that it allows a user to manipulate the node location to exist at any point in space in the plane of the crosssection of the beam. This is especially valuable for the HCCC model as the nodal position is used to coordinate the location of the beams relative to underlying shell elements (representing the aluminum and LitePly wood plates of the HCCC). The nodal offset feature, as this is called, is shown in Figure 76; in this image, a single box tube crosssection with multiple orientations are provided by changing the location of the node belonging to the beam element (located at the intersection of the red lines in this example). 
Another feature of the BEAM189 element is the ability to rotate it about its corresponding line with orientation keypoints; this feature is shown in Figure 77 with the same box tubes in Figure 76 oriented to the same keypoint. In order to accomplish this, each BEAM189 element has an "orientation node" that describes the plane in which the cross-section is oriented. Specifically, the end nodes plus the orientation node describe a plane and the vertical direction of the section lies in this plane. Typically, orientation nodes are placed in such a manner to keep a beam normal to a certain plane and straight along its span. Rather than add orientation nodes individually for each beam element, it was decided early in the HCCC model creation to have a single set of overlying "master orientation keypoints"; these were placed ten million $\left(10^{7}\right)$ inches from the center of the model in each direction in the appropriate directions of interest. This distance is far enough away from the model such that the beam orientation defined using these orientation keypoints appeared vertical, lateral or forward.

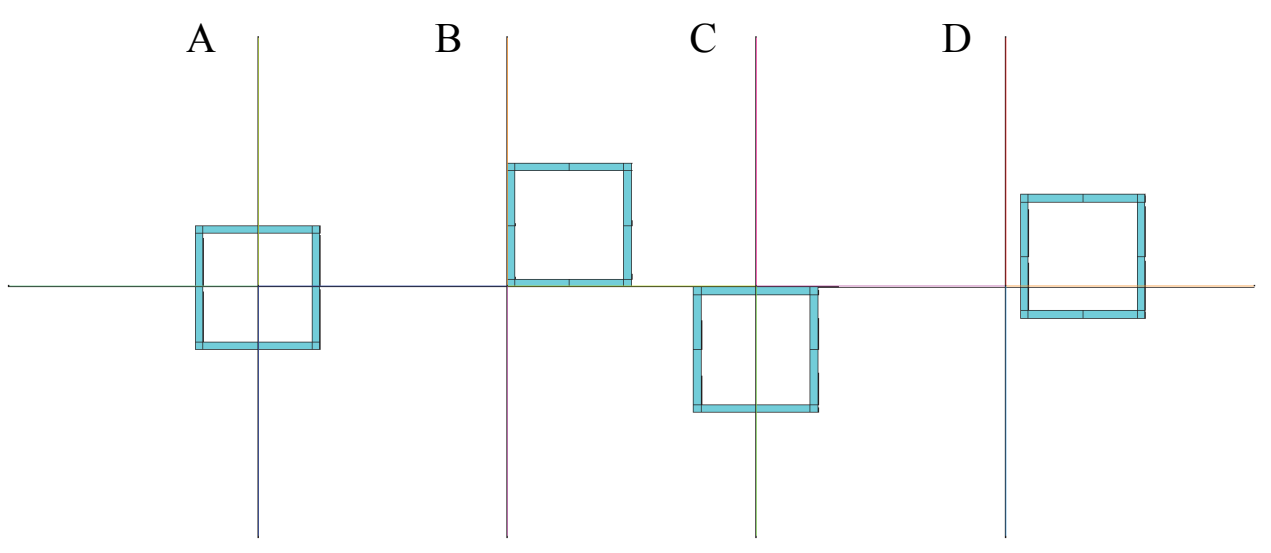

Figure 76. Beam orientation variations based on nodal offset. 


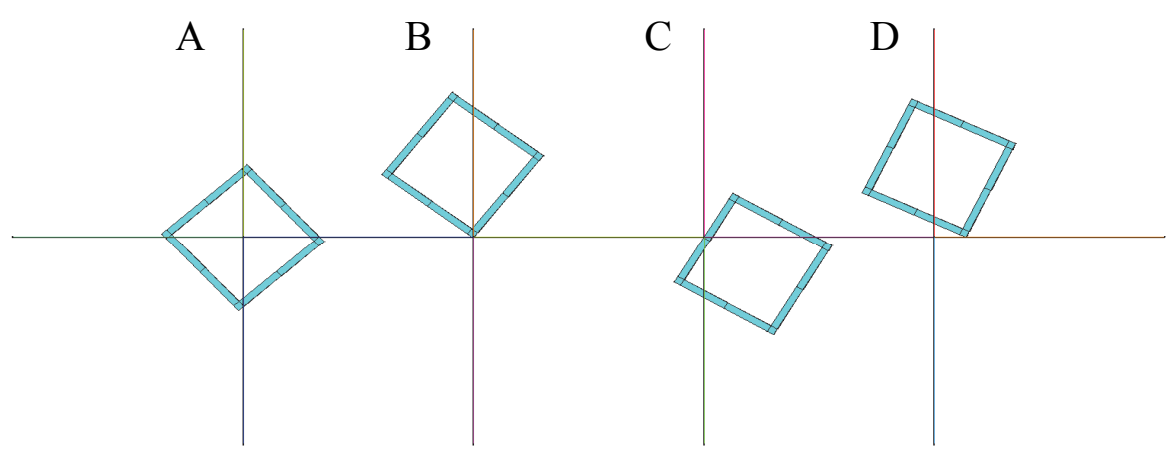

Figure 77. Beam orientation altered with orientation keypoint.

\section{B. SHELL99 Element Use}

The aluminum skins, foam insulation, wood paneling, wood flooring, and gussets were all modeled with shell elements. SHELL99 linear, layered shell elements were used for the majority of shell elements in the model; these elements allow the shell to be described as a series of layers of various materials, thicknesses and orientations (i.e. fiber direction for a fiber-reinforced composite ply). SHELL99 elements were used to simplify modeling of multiple layers of materials stacked on each other (i.e. insulating foam, wood paneling, and aluminum interior skin on most walls). Another feature of the SHELL99 element is the ability to offset the nodes of the shell element to the top, bottom, or midsurface of the plate; this allows for correct orientation of a plate extruding from a respective surface. This is illustrated in Figure 78 with three three-layer SHELL99 elements that have different nodal offsets; in this case, the purple line represents the plane of the shell nodes. It should also be noted that SHELL99 elements are suitable when the shell consists of a single layer; this approach was used for aluminum gussets in the region of the auxiliary power unit (APU) tunnel. 


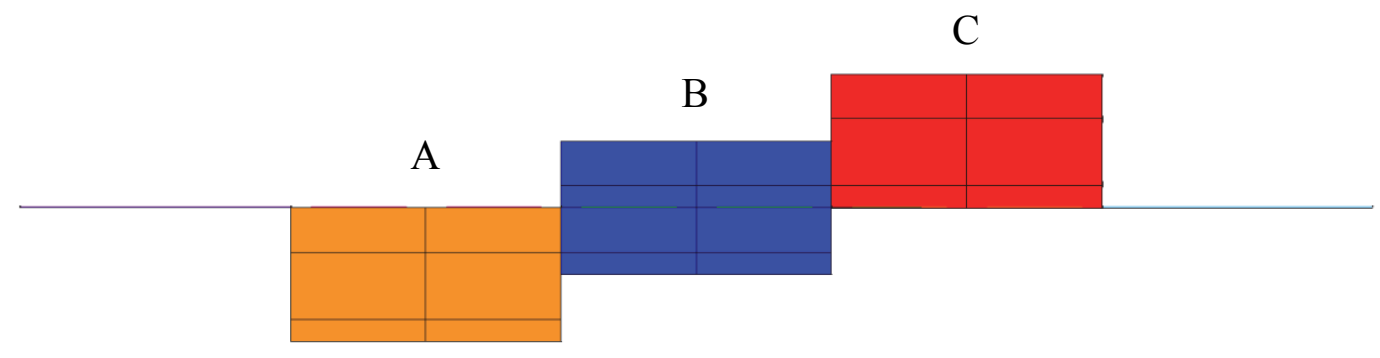

Figure 78. Depiction of SHELL99 elements with nodes offset to top (A), midsurface (B), and bottom (C) of the plate.

\section{MASS21 Element Use}

For several components of the HCCC finite element model, inertial loads are needed but the underlying stiffness of the structure is not modeled. One example of this is the environment control units (ECUs). These are relatively heavy components but their stiffness is not clearly defined. For HCCC load cases involving accelerations, the weight of such components leads to significant loading of the shelter and it must be accounted for. In order to achieve this, MASS21 point mass elements were used. These elements consist of a single REAL constant (mass) and are defined a single node (always located at a keypoint in the HCCC model). It should be noted that MASS21 elements can also incorporate rotational inertia effects; this capability was not used in this project, however.

\section{BEAM189 Cross-Sections}

There are a total of 73 individual cross-sections used to build the HCCC FEM. To demonstrate this, two cross-sections are shown below; the others can be found in “Harbormaster Command and Control Center (HCCC): ANSYS Finite Element Model Aluminum Shelter". In each image, the "Section ID" is shown in the upper left. Note that 
each section plot contains a scale that can be used to determine the size of the section as well as overall section properties such as area, area moments of inertia, etc.

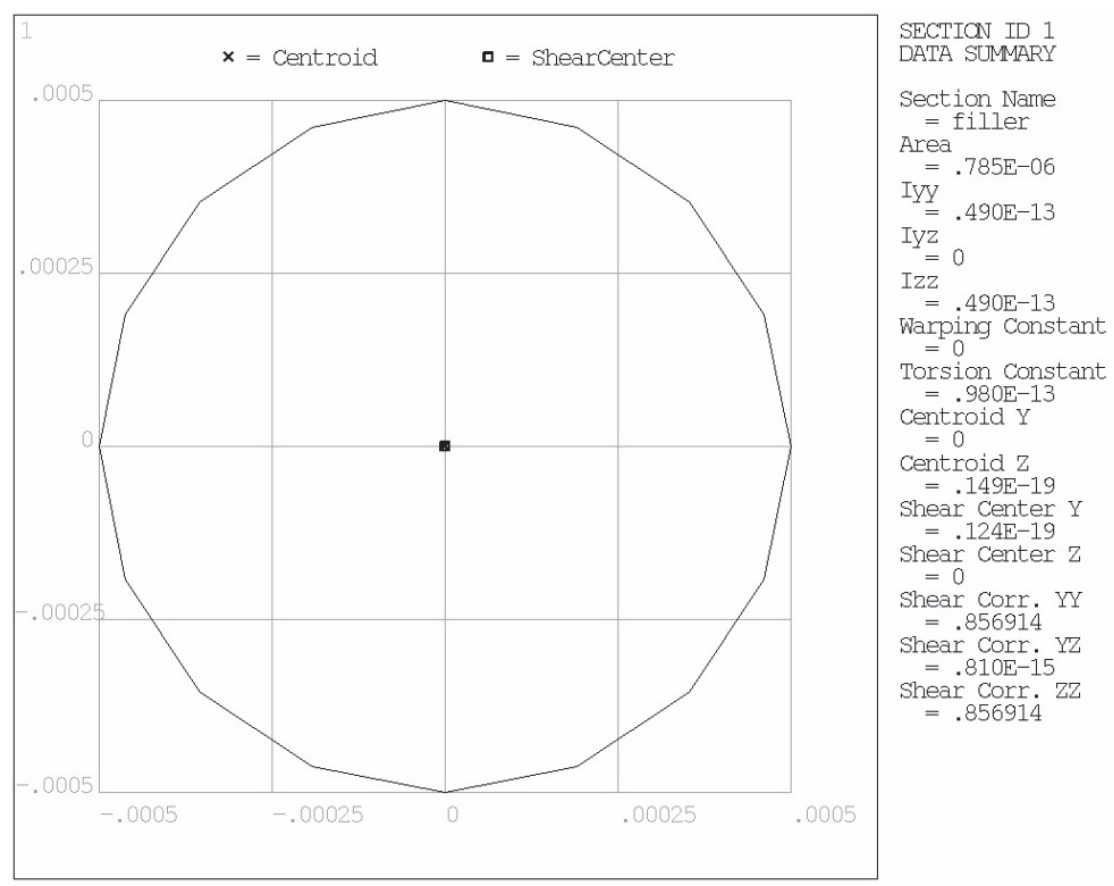

Figure 79. Depiction of beam cross-section 1 from ANSYS "beam section" tool 


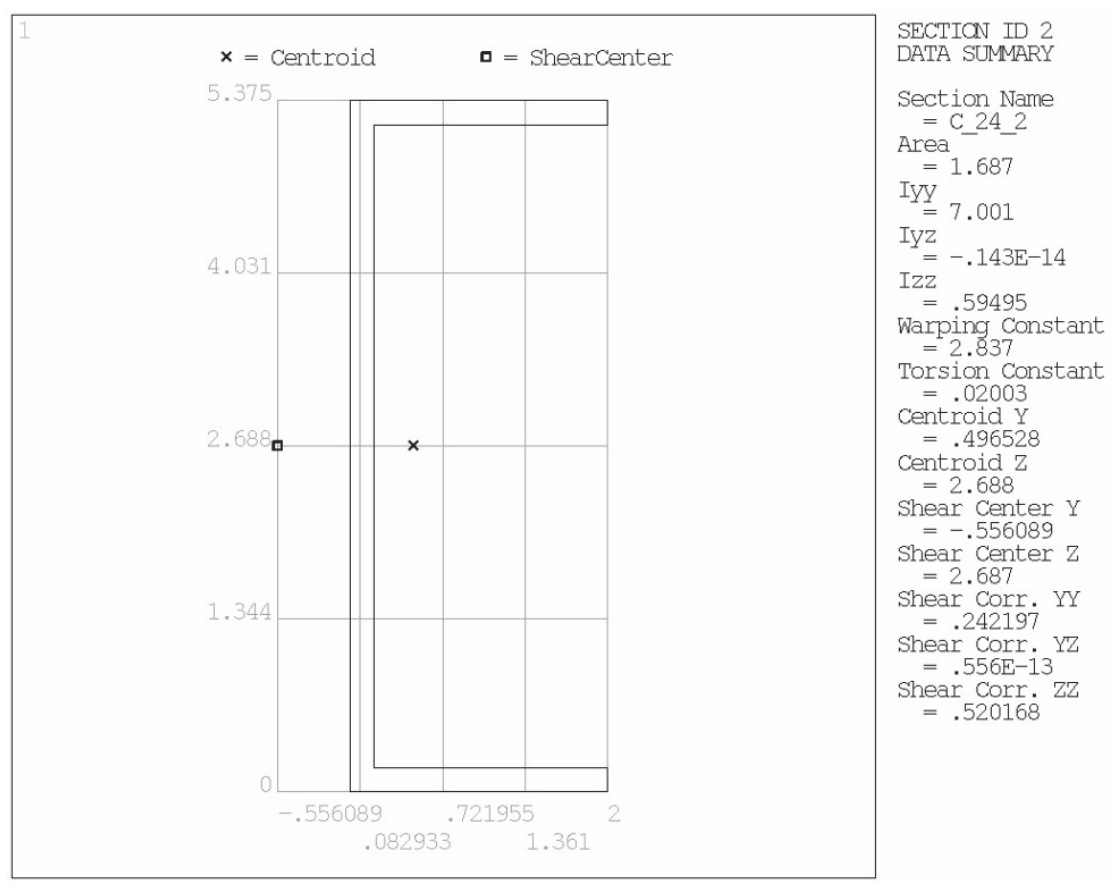

Figure 80. Depiction of beam cross-section 2 from ANSYS “beam section" tool

\section{E. Element Key Options}

While a total of 4 ANSYS elements are used in the HCCC model (BEAM189, SHELL99, LINK8, MASS21), a total of 9 element types are used in the HCCC FEM. These are numbered ET1 - ET10 with ET5 deleted / unused. The reason that the number of element types differs from the 4 is that a single element type (SHELL99 for example) is defined differently for different behaviors. The element "key options" that dictate the behavior of the element. For example, whether the node of a SHELL99 is located on the top, middle or bottom of the shell is set as a key option (referred to as KEYOPT(11) in ANSYS and K11 in the text below). Hence, the total number of element types used in the HCCC model (9) exceeds the number of actual ANSYS elements used (4) because differing behavior is required for different model sections. 
Below, each element type is described in terms of its associated number (ET1, ET2, etc.), ANSYS element (SHELL99, BEAM189, etc.) and key options.

ET1 - BEAM189

\begin{tabular}{|l|l|l|}
\hline Key Option Number & Key Option Title & Option Selected \\
\hline K1 & Warping degrees of freedom & Restrained \\
\hline K2 & Cross section scaling & Func of stretch \\
\hline K4 & Shear stress output & Torsional only \\
\hline K6 & Section force/strain output & At ingr points \\
\hline K7 & Stress/Strain (sect points) & NONE \\
\hline K8 & Stress/Strain (sect nodes) & NONE \\
\hline K9 & Stress/Strain (elmt/sect nds) & NONE \\
\hline K10 & User defined initial stress & No USTRES routn \\
\hline K11 & Section integration & Automatic \\
\hline K12 & Taper section interpretation & Linear \\
\hline
\end{tabular}

ET2 - SHELL99

\begin{tabular}{|l|l|l|}
\hline Key Option Number & Key Option Title & Option Selected \\
\hline K2 & Form of input & Const thk layer \\
\hline K3 & Extra element output & No extra output \\
\hline K4 & Element coord sys defined by & Elem orientation \\
\hline K5 & Strains or stresses output & Stress \& strain \\
\hline K6 & $\begin{array}{l}\text { Extra element output (for layer } \\
\text { input only) }\end{array}$ & No extra output \\
\hline K8 & Storage of layer data & All layers \\
\hline K9 & Eval of strains + stresses & Top \& bot of lay \\
\hline K10 & Material prop matrix output & Exclude \\
\hline K11 & Node offset option & Nodes @ bot face \\
\hline
\end{tabular}

ET3 - SHELL99

\begin{tabular}{|l|l|l|}
\hline Key Option Number & Key Option Title & Option Selected \\
\hline K2 & Form of input & Const thk layer \\
\hline K3 & Extra element output & No extra output \\
\hline K4 & Element coord sys defined by & Elem orientation \\
\hline K5 & Strains or stresses output & Stress \& strain \\
\hline K6 & $\begin{array}{l}\text { Extra element output for layer } \\
\text { input only) }\end{array}$ & No extra output \\
\hline K8 & Storage of layer data & All layers \\
\hline K9 & Eval of strains + stresses & Top \& bot of lay \\
\hline K10 & Material prop matrix output & Exclude \\
\hline K11 & Node offset option & Nodes @ top face \\
\hline
\end{tabular}


ET4 - SHELL99

\begin{tabular}{|l|l|l|}
\hline Key Option Number & Key Option Title & Option Selected \\
\hline K2 & Form of input & Const thk layer \\
\hline K3 & Extra element output & No extra output \\
\hline K4 & Element coord sys defined by & Elem orientation \\
\hline K5 & Strains or stresses output & Stresses only \\
\hline K6 & $\begin{array}{l}\text { Extra element output (for layer } \\
\text { input only) }\end{array}$ & No extra output \\
\hline K8 & Storage of layer data & Bot 1 ${ }^{\text {st }}$ top last \\
\hline K9 & Eval of strains + stresses & Top \& bot of lay \\
\hline K10 & Material prop matrix output & Exclude \\
\hline K11 & Node offset option & Nodes @ midsurf \\
\hline
\end{tabular}

\section{ET5 - REMOVED}

ET6 - CONTAC52

\begin{tabular}{|l|l|l|}
\hline Key Option Number & Key Option Title & Option Selected \\
\hline K1 & Sticking stiff only if MU>0 & Elas coulomb frc \\
\hline K3 & Weak spring across open gap & Do not use spring \\
\hline K4 & Basis for gap size & Real const GAP \\
\hline K7 & Goal for contact time predict & Min time incremt \\
\hline
\end{tabular}

\section{ET7 - LINK8}

This element does not have any options

ET8 - SHELL63

\begin{tabular}{|l|l|l|}
\hline Key Option Number & Key Option Title & Option Selected \\
\hline K1 & Element stiffness & Bnding and membr \\
\hline K2 & Stress stiffening option & Main matrix \\
\hline K3 & Extra displacement shapes & Include \\
\hline K5 & Extra stress output & No extra output \\
\hline K6 & Pressure loading & Reduced loading \\
\hline K7 & Mass matrix & Consistent \\
\hline K8 & Stiffness matrix & Consistent \\
\hline K9 & Element coord sys defined by & Elem orientation \\
\hline K11 & Store mid data on rst file & NO \\
\hline
\end{tabular}


ET9 - MASS21

\begin{tabular}{|l|l|l|}
\hline Key Option Number & Key Option Title & Option Selected \\
\hline K1 & Interpret as constants as & Masses-Inertias \\
\hline K2 & Elem coord system initially & Parall to global \\
\hline K3 & Rotary inertia options & 3-D w/o rot iner \\
\hline
\end{tabular}

ET10 - BEAM189

\begin{tabular}{|l|l|l|}
\hline Key Option Number & Key Option Title & Option Selected \\
\hline K1 & Warping degrees of freedom & \\
\hline K2 & Cross section scaling & \\
\hline K4 & Shear stress output & \\
\hline K6 & Section force/strain output & \\
\hline K8 & Stress/Strain (sect points) & \\
\hline K9 & Stress/Strain (sect nodes) & \\
\hline K10 & Stress/Strain (elmt/sect nds) & \\
\hline K11 & User defined initial stress & \\
\hline K12 & Section integration & \\
\hline
\end{tabular}




\section{F. REAL Constants}

REAL constants in ANSYS are used to provide a variety of information for various element types. A total of 28 REAL constant sets are used in the HCCC model (numbers 1-14 and 16-29). These are detailed below with the associated element type and purpose of the REAL constant in question.

\section{SET 1}

Applies to SHELL99 element

Sets SHELL99 to one layer of aluminum at 0.050 " thickness. This represents exterior aluminum face sheets.

\section{SET 2}

Applies to SHELL99 element

Sets SHELL99 to one layer of aluminum at 1.0625" thickness. This represents the bottom of the Tandemlocs (ISO block corner fittings).

\section{SET 3}

Applies to SHELL99 element Sets SHELL99 to one layer of aluminum at 0.78 " thickness. This represents the sides and top of the Tandemlocs (ISO block corner fittings).

\section{SET 4}

Applies to SHELL99 element Sets SHELL99 to one layer of Lite-Ply (lightweight plywood) at 0.75 " thickness. This represents the floor of the shelter.

\section{SET 5}

Applies to SHELL99 element

Sets SHELL99 to two layers, one of spray in foam at 6.5 " thickness and a second layer of aluminum at 0.050 " thickness. This represents the foam and underside aluminum face sheet underneath the wooden floor in the main shelter, behind the APU tunnel.

\section{SET 6}

Applies to SHELL99 element

Sets SHELL99 to two layers, one of spray in foam at 4.125 " thickness and a second layer of aluminum at 0.050 " thickness. This represents the foam and underside aluminum face sheet underneath the wooden floor in the main shelter, underneath the APU tunnel. 


\section{SET 7}

Applies to SHELL99 element

Sets SHELL99 to three layers, one of spray in foam at 2" thickness, a second of Lite-Ply at 0.375 " thickness, and a third of aluminum at 0.030 " thickness. This represents the foam, plywood, and interior aluminum skin in the roof.

\section{SET 8}

Applies to SHELL99 element

Sets SHELL99 to three layers, one of spray in foam at 2.5" thickness, a second of LitePly at 0.375 " thickness, and a third of aluminum at 0.030 " thickness. This represents the material in the front frame that touches the interior workspace of the HCCC (i.e. behind the equipment racks).

\section{SET 9}

Applies to SHELL99 element

Sets SHELL99 to three layers, one of spray in foam at 3" thickness, a second of Lite-Ply at 0.375 " thickness, and a third of aluminum at 0.030 " thickness. This represents the foam, plywood, and interior aluminum face sheet on the side and rear walls of the main shelter.

\section{SET 10}

Applies to SHELL99 element

Sets SHELL99 to two layers, one of spray in foam at 2" thickness and another of aluminum at 0.050 " thickness. This represents the foam and bottom aluminum face sheet underneath the wooden flooring in the floor section of the roadside expandable.

\section{SET 11}

Applies to SHELL99 element

Sets SHELL99 to three layers, one of spray in foam at 2.5 " thickness, a second of LitePly at 0.375 " thickness, and a third of aluminum at 0.030 " thickness. This represents the foam, plywood, and interior aluminum skin in the roof of the roadside expandable.

\section{SET 12}

Applies to SHELL99 element

Sets SHELL99 to two layers, one of spray in foam at 2" thickness and another of aluminum at 0.050 " thickness. This represents the foam and bottom aluminum face sheet underneath the wooden flooring in the floor section of the curbside expandable.

\section{SET 13}

Applies to SHELL99 element

Sets SHELL99 to three layers, one of spray in foam at 2.5 " thickness, a second of LitePly at 0.375 " thickness, and a third of aluminum at 0.030 " thickness. This represents the foam, plywood, and interior aluminum skin in the roof of the curbside expandable. 


\section{SET 14}

Applies to SHELL99 element

Sets SHELL99 to a single layer of aluminum at 0.25 " thickness. This represents the gussets underneath the ECU supports on the front frame.

SET 16

Applies to CONTAC52 element

(REFERENCE RC VALUES FROM CREATE_FLOOR_CONTACT.INP) EXPLAIN VARIABLES PUT INTO THIS

\section{SET 17}

Applies to LINK8 element

Sets LINK8 to have a cross-sectional area of $4.3258 \mathrm{sq}$ in. This represents the hydraulic cylinders that open and close the expandables; there are four hydraulic cylinders on the shelter. The area is calculated from the outer tube having an OD and ID of 3.875 " and 2.375 " respectively, and the inner tube having an OD and ID of 2.375" and 2.00" respectively. The average area for the tubes was used for the LINK8 element.

\section{SET 18}

Applies to SHELL63 element

Sets SHELL63 to 0.1" thickness and an elastic foundation stiffness of one million (10e6). (DESCRIBE EFS). This represents the truck bed of the M1085.

\section{SET 19}

Applies to SHELL99 element

Sets SHELL99 to a single layer of aluminum at 0.500" thickness. This represents the plate of aluminum that the INMARSAT base sits on.

\section{SET 20}

Applies to SHELL99 element (ET4)

\section{SET 21}

Applies to MASS21 element

Sets MASS21 to $235 \mathrm{lb}$ mass. This mass represents an environmental control unit, ECU; two ECUs are present on the shelter.

\section{SET 22}

Applies to MASS21 element

Sets MASS21 to $450 \mathrm{lb}$ mass. This mass represents an auxiliary power unit, APU; two APUs are present on the shelter.

\section{SET 23}

Applies to MASS21 element

Sets MASS21 to $107 \mathrm{lb}$ mass. This mass represents the INMARSAT communications dome and the support base it sits on; they are $57 \mathrm{lb}$ mass and $50 \mathrm{lb}$ mass, respectively. 


\section{SET 24}

Applies to MASS21 element

Sets MASS21 to $268 \mathrm{lb}$ mass. This mass represents the SIPR rack.

\section{SET 25}

Applies to MASS21 element

Sets MASS21 to $276 \mathrm{lb}$ mass. This mass represents the NIPR rack.

SET 26

Applies to MASS21 element

Sets MASS21 to $233 \mathrm{lb}$ mass. This mass represents the radio rack.

SET 27

Applies to MASS21 element

Sets MASS21 to $50 \mathrm{lb}$ mass. This mass represents the power distribution panel, PDP.

SET 28

Applies to MASS21 element

Sets MASS21 to $130 \mathrm{lb}$ mass. This mass represents the hydraulic pump.

\section{SET 29}

Applies to MASS21 element

Sets MASS21 to $115 \mathrm{lb}$ mass. This mass represents a safe; two safes are present in the shelter.

\section{G. Report Generation}

Once a solution is reached for each analysis case, a respective report is generated using the Create_Output input file created by fellow research assistant Paul Long. Each report is a collection of images and tables and details stresses and displacements of the elements in the FEM. The report breaks the model into its six main regions to make the data easier to visualize. Each section has plots of its displacement magnitude, and it also has von Mises stress plots for each material in that section (aluminum structural beams, aluminum interior and exterior skins, Lite-Ply plywood, and polyurethane foam). Maximum values for both displacement and stress are summarized in tables organized by section, and the stress tables are further broken down by material. Data is also captured in 
tables for resultant loads at the dowel mount locations, expandable actuators, expandable roof guides, and the expandable support rails.

The images are saved in both low and high resolution .PNG files in respective folders. The images and tables are organized in an .HTML web page format, and that is subsequently converted to a .PDF file and formatted for more convenient printing and sharing. 


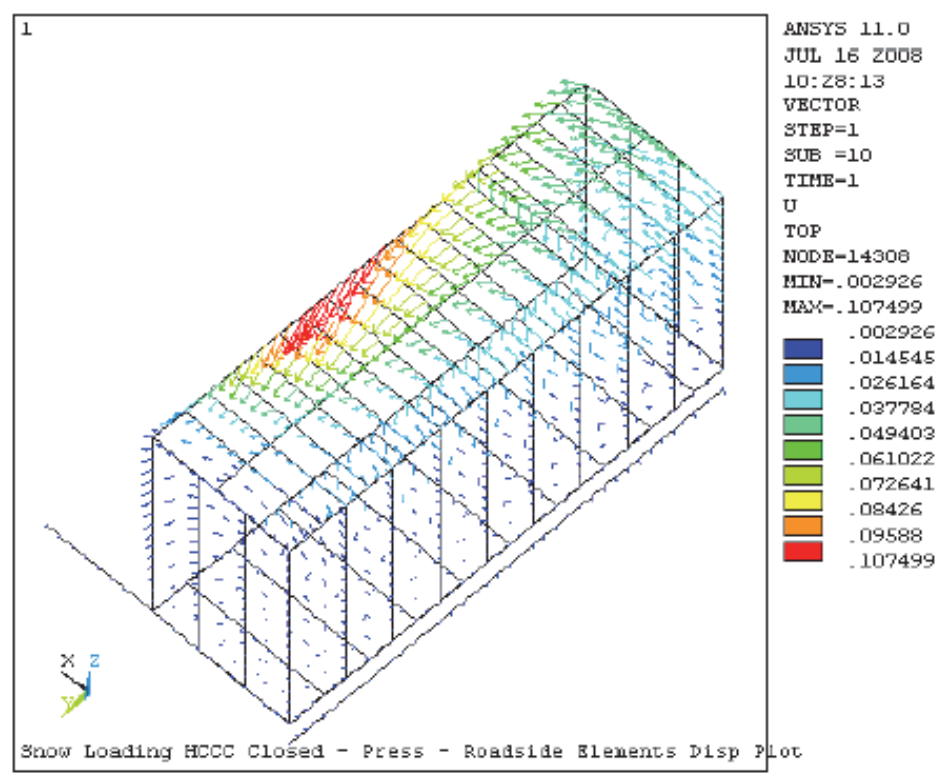

Vector Disp - Roadside Elements

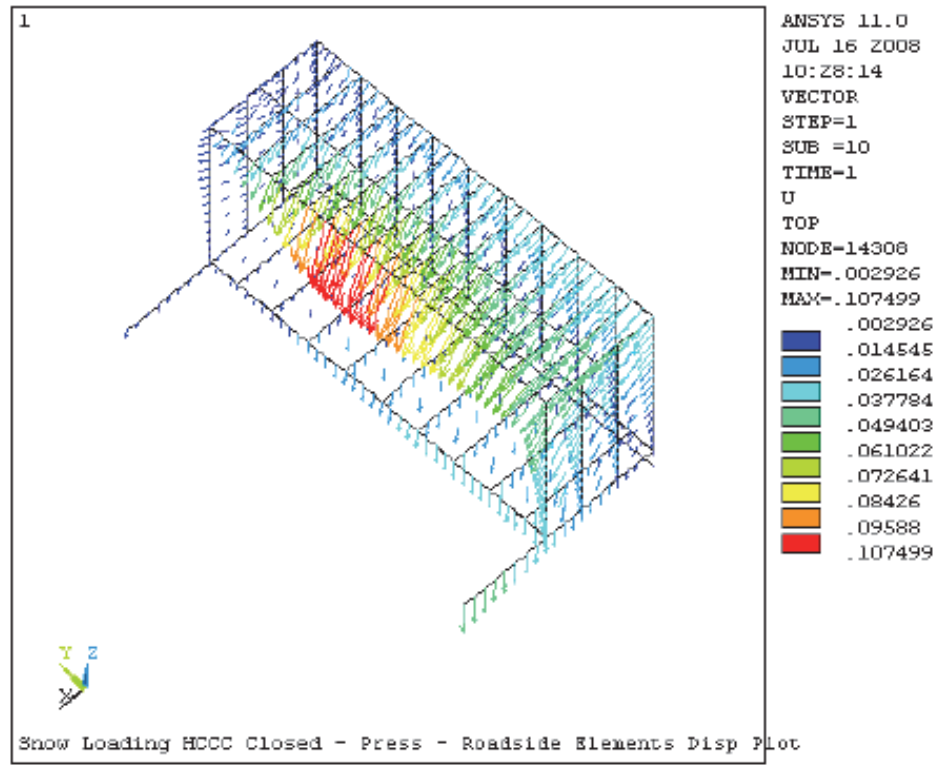

Vector Disp - Roadside Elements

file:/C:Documents and Settings Justin Desktop $\mathrm{HCCC}$ Work Directory Full Weight Case... 7/16/2008

Figure 81. One page from a typical report following an HCCC FEM analysis 


\section{H. Input Files}

A total of 38 input files were used to generate, constrain, analyze, and postprocess analysis for the HCCC FEM. Those files are detailed with their file name, description, and the input file from which they were issued in the following table.

\begin{tabular}{|c|c|c|}
\hline Input File Name & Description & Read From \\
\hline Build HCCC & $\begin{array}{l}\text { Original master input file from which all } \\
\text { analysis is run }\end{array}$ & $\begin{array}{l}\text { AFileTo RunSolve v120 } \\
\text { Fixed (originally, } n / a \text { ) }\end{array}$ \\
\hline $\begin{array}{l}\text { A File To RunSolve v120 } \\
\text { Fixed }\end{array}$ & $\begin{array}{l}\text { Used to correct some issues when } \\
\text { reverting to ANSYS v12.x.x and now } \\
\text { initiates Build_HCCC; it also sets the } \\
\text { number of loadsteps to solve }\end{array}$ & $\mathrm{n} / \mathrm{a}$ \\
\hline Beam Sections & $\begin{array}{l}\text { Creates most beam cross-sections (BEAM } \\
\text { IDs) }\end{array}$ & Build HCCC \\
\hline Floor & $\begin{array}{l}\text { Creates keypoints, lines, areas, } \\
\text { elements, components, coupling }\end{array}$ & Build HCCC \\
\hline APU Gusset Constraint & $\begin{array}{l}\text { Creates the CEs that tie the gusset plates } \\
\text { supporting the APU unit to the }\end{array}$ & Floor \\
\hline Roof & Same as floor, but for items in the roof & Build HCCC \\
\hline Stairs & $\begin{array}{l}\text { Same as floor, but for items in the Front } \\
\text { Frame (that resembles a couple of stairs) }\end{array}$ & Build HCCC \\
\hline Sides And Rear & $\begin{array}{l}\text { Same as the floor but for items in the } \\
\text { upright structure around the sides and } \\
\text { rear of the shelter not including the } \\
\text { front frame or expandables }\end{array}$ & Build HCCC \\
\hline RS Expand & $\begin{array}{l}\text { Same as floor but for items in the } \\
\text { roadside expandable }\end{array}$ & Build HCCC \\
\hline CS Expand & $\begin{array}{l}\text { Same as floor but for items in the } \\
\text { curbside expandable }\end{array}$ & Build HCCC \\
\hline Write Floor CEs & Stores the CEs for use in a later input file & Build HCCC \\
\hline Write Floor CPs & Stores the CPs for use in a later input file & Build HCCC \\
\hline
\end{tabular}

Table 22. Input file descriptions (1 of 3) 


\begin{tabular}{|c|c|c|}
\hline Input File Name & Description & Read From \\
\hline Join Floor Sides & $\begin{array}{l}\text { Joins the elements in the floor and sides } \\
\text { with CEs where they meet. }\end{array}$ & Build HCCC \\
\hline Join Floor Stair & $\begin{array}{l}\text { Joins the elements in the floor and front } \\
\text { frame with CEs where they meet. }\end{array}$ & Build HCCC \\
\hline Join Roof Sides & $\begin{array}{l}\text { Joins the elements in the roof and sides } \\
\text { with CEs where they meet. }\end{array}$ & Build HCCC \\
\hline Join Roof Stair & $\begin{array}{l}\text { Joins the elements in the floor and sides } \\
\text { with CEs where they meet. }\end{array}$ & Build HCCC \\
\hline $\begin{array}{l}\text { Rail Floor Constrain Rear } \\
\text { RS }\end{array}$ & $\begin{array}{l}\text { Constrains the rear slide rail in the RS } \\
\text { expandable to its corresponding slide } \\
\text { tube in the floor using CEs }\end{array}$ & Build HCCC \\
\hline $\begin{array}{l}\text { Rail Floor Constrain Front } \\
\text { RS }\end{array}$ & $\begin{array}{l}\text { Constrains the front slide rail in the RS } \\
\text { expandable to its corresponding slide } \\
\text { tube in the floor using CEs }\end{array}$ & Build HCCC \\
\hline $\begin{array}{l}\text { Rail Floor Constrain Rear } \\
\text { CS }\end{array}$ & $\begin{array}{l}\text { Constrains the rear slide rail in the CS } \\
\text { expandable to its corresponding slide } \\
\text { tube in the floor using CEs }\end{array}$ & Build HCCC \\
\hline $\begin{array}{l}\text { Rail Floor Constrain Front } \\
\text { CS }\end{array}$ & $\begin{array}{l}\text { Constrains the front slide rail in the CS } \\
\text { expandable to its corresponding slide } \\
\text { tube in the floor using CEs }\end{array}$ & Build HCCC \\
\hline Expand Guides & $\begin{array}{l}\text { Creates the hydraulic cylinders that } \\
\text { attach the expandables to the floor. Also } \\
\text { creates the expandable guides that } \\
\text { attaches the expandables to the roof. }\end{array}$ & Build HCCC \\
\hline Find Closest Node & $\begin{array}{l}\text { Finds the closest node on a line to a } \\
\text { selected keypoint or node; these nodes } \\
\text { will be the attachment points for the } \\
\text { hydraulic cylinders }\end{array}$ & Expand Guides \\
\hline Read Floor CEs & $\begin{array}{l}\text { Replaces the CEs that were written } \\
\text { earlier and then deleted due to some } \\
\text { modeling conflicts that arose }\end{array}$ & Build HCCC \\
\hline Read Floor CPs & $\begin{array}{l}\text { Replaces the CPs that were written } \\
\text { earlier and then deleted due to some } \\
\text { modeling conflicts that arose }\end{array}$ & Build HCCC \\
\hline Join Side Beam Floor & $\begin{array}{l}\text { Manually joins a vertical beam in the } \\
\text { rear CS to the floor where there isn't a } \\
\text { shell element to automatically constrain } \\
\text { to with earlier CE input files }\end{array}$ & Build HCCC \\
\hline
\end{tabular}

Table 23. Input file descriptions (2 of 3 ) 


\begin{tabular}{|c|c|c|}
\hline Input File Name & Description & Read From \\
\hline Create Floor Contact & $\begin{array}{l}\text { Creates contact elements between the } \\
\text { floor bottom and the truck support plate }\end{array}$ & Build HCCC \\
\hline Contact Support & $\begin{array}{l}\text { Creates contact elements to show floor } \\
\text { support pressure }\end{array}$ & Build HCCC \\
\hline Attach Masses & $\begin{array}{l}\text { Attaches the heavy items in and on the } \\
\text { shelter as point masses and rigid beams }\end{array}$ & Build HCCC \\
\hline Fix File & $\begin{array}{l}\text { Fixes a few issues that popped up in the } \\
\text { model up to this point (adds some rigid } \\
\text { regions, removes some CEs, and adjusts } \\
\text { the beam offsets for a few beams) }\end{array}$ & Build HCCC \\
\hline Fix Comp & Fixes some component selections & Build HCCC \\
\hline A File To FixCP v120 & $\begin{array}{l}\text { Deletes some CPs that conflicted with } \\
\text { CEs and caused solution issues }\end{array}$ & Build HCCC \\
\hline Loading Contact & $\begin{array}{l}\text { Sets up static analysis (for example, C-17 } \\
\text { loading) }\end{array}$ & Build HCCC \\
\hline Loading Contact Transient & $\begin{array}{l}\text { Original dynamic loading input file that } \\
\text { created } 16 \text { loadsteps with numerous } \\
\text { substeps }\end{array}$ & Build HCCC \\
\hline Write One LS File & $\begin{array}{l}\text { Writes one load step with values } \\
\text { supplied from variables in the partent } \\
\text { input file }\end{array}$ & $\begin{array}{l}\text { Loading Contact } \\
\text { Transient and its } \\
\text { variants }\end{array}$ \\
\hline $\begin{array}{l}\text { Loading Contact Rail } \\
\text { Impact New }\end{array}$ & $\begin{array}{l}\text { Latest dynamic loading input file that } \\
\text { generates } 601 \text { load steps with one load } \\
\text { step each }\end{array}$ & Build HCCC \\
\hline Create Output & $\begin{array}{l}\text { Generates a series of images (both low } \\
\text { and high resolution) and tables and then } \\
\text { compiles them into a webpage for } \\
\text { presentation }\end{array}$ & $\begin{array}{l}\text { AFileTo RunSolve v120 } \\
\text { Fixed (originally, n/a) } \\
\end{array}$ \\
\hline Create PNG Images & $\begin{array}{l}\text { Captures a high resolution image (used } \\
\text { multiple times) }\end{array}$ & Create Output \\
\hline Create Table & $\begin{array}{l}\text { Generates the tables for the output } \\
\text { report }\end{array}$ & $\begin{array}{l}\text { A File To RunSolve v120 } \\
\text { Fixed (originally, n/a) }\end{array}$ \\
\hline
\end{tabular}

Table 24. Input file descriptions (3 of 3) 


\section{APPENDIX II. MATHCAD FILE - DISPLACEMENT POINT GENERATION}

The time-displacement points used in the dynamic analysis are created using a MathCad file written by Dr. Roger Bradshaw. A printout of a version that created the data shown in Figure 64 - Figure 66 is attached below. 
Test - Linear Acceleration Scheme

HCCC ANSYS Transient, Roger Bradshaw, 23 Jul 09 Update 8 May 2014 - Adjust Graphs, Add Additional Output File

Assume that at time $\mathrm{t}=0$ that the $\mathrm{HCCC}$ has 0 displacement, initial velocity $\mathrm{vO}$, and is not accelerating at all. At time $t=0+$, the acceleration jumps to $a 0$ and then linearly ramps to $a 1$ at time 11 , a2 at time t2, ..., an at time tn and remains constant thereafter.

In order to complete a representation of this, a series of ramp values are constructed - these represent the slope of the acceleration curve between the various points. After that, Macaulay functions are used to represent the various integrated terms (must be defined)

This document tests out the approach to make sure that it works as expected. A series of 3 term tests are considered here.

First define the Macaulay function using Heaviside function.

$\mathrm{M}(\mathrm{t}, \mathrm{t} 0, \mathrm{n}):=\Phi(\mathrm{t}-\mathrm{t} 0) \cdot(\mathrm{t}-\mathrm{t} 0)^{\mathrm{n}}$

Lets check that this works using to $=1 / 2$ and time ranging from $0-2$. Looks correct.

$\mathrm{i}:=0 . .200 \quad \mathrm{tv}_{\mathrm{i}}:=0.01 \cdot \mathrm{i}$

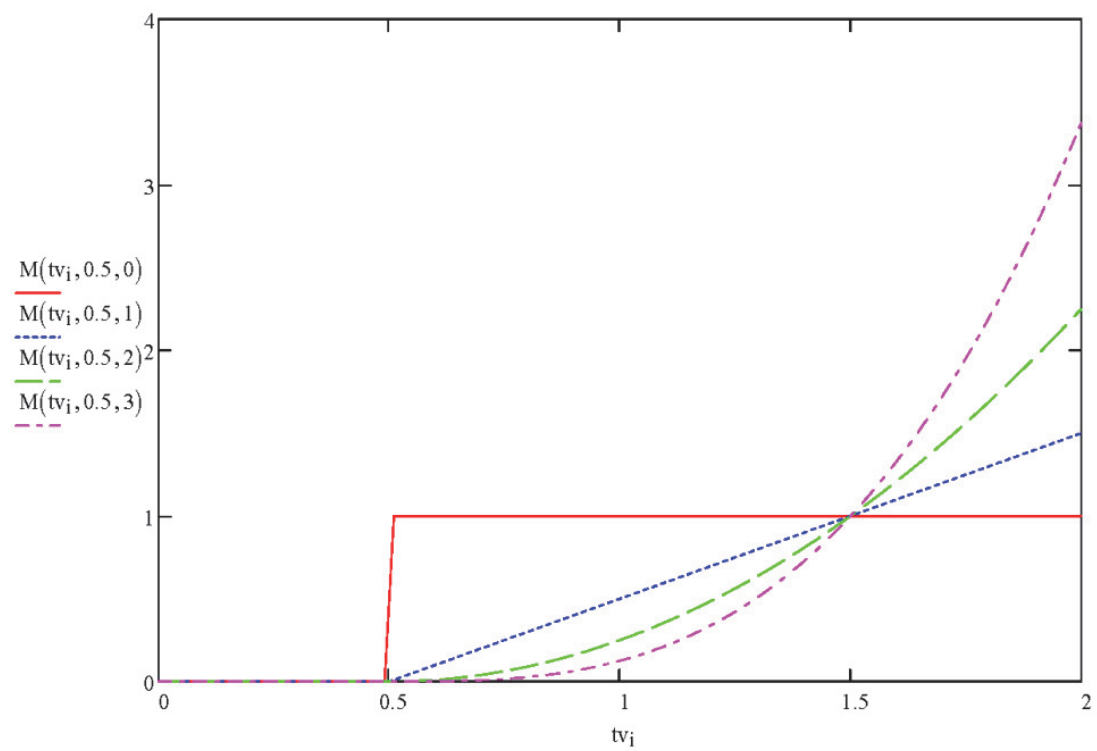

These should should look like a step at 0.5 (red), a line with slope 1 beginning at 0 at to $=0.5$ (blue),

a parabola starting at 0 at to $=0.5$ (green) and a cubic starting at 0 at to $=0.5$ (magenta)

Each function should be equal to 1 at 1.5 (where $t$ - to $=1$ ). All looks correct. 
To use this method, define the time points and the acceleration values and $v 0$. This is the rail impact test results used earlier for the HCCC transient analysis.

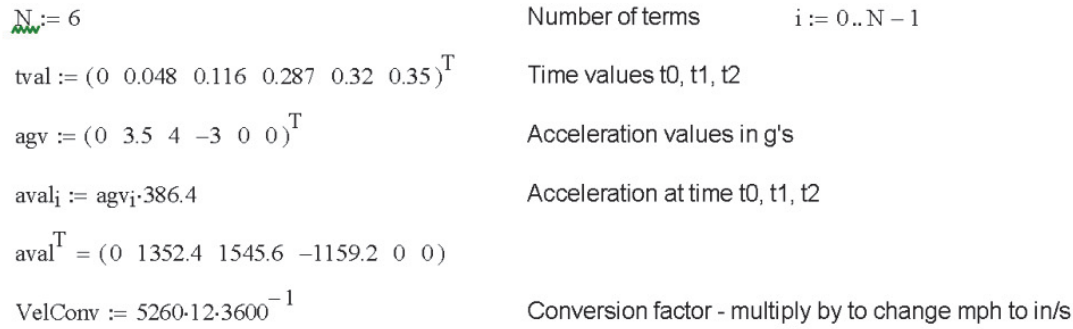

From here forward, the method is automated
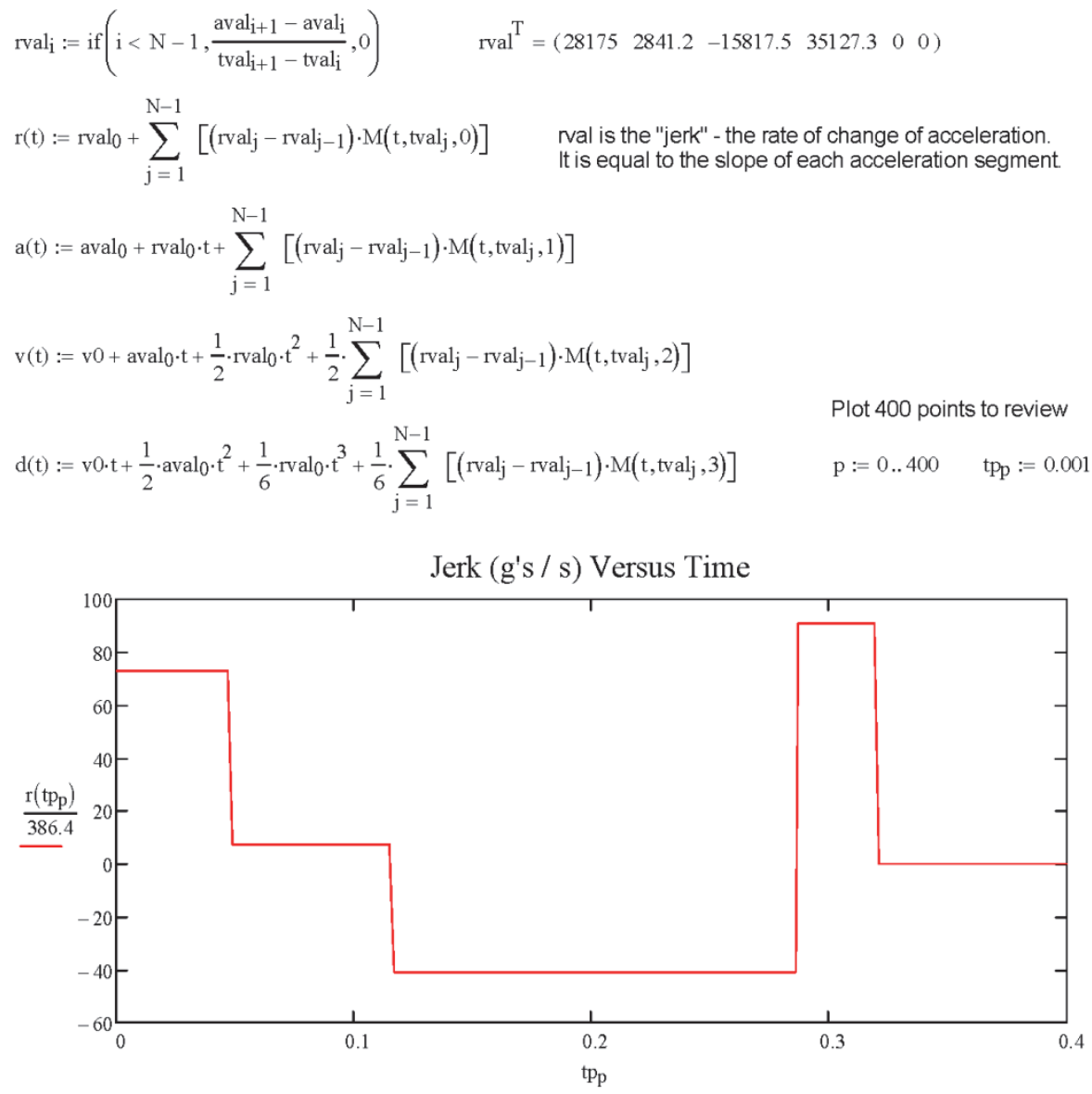

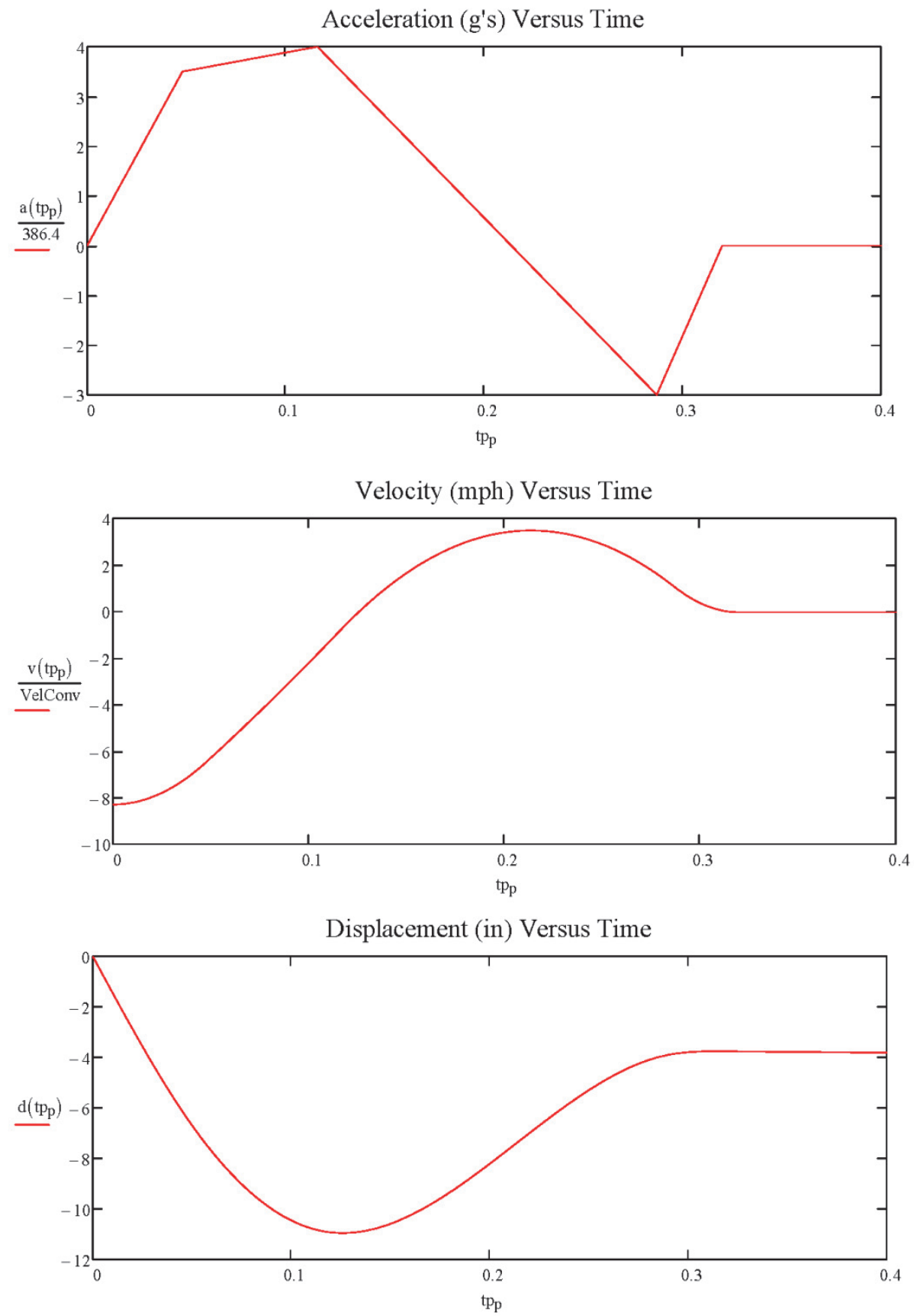
Now create a file with the displacements store in a text file. Assume NP points per segment for analysis.

$\mathrm{NP}:=100 \quad \mathrm{k}:=1$

tval $_{\mathrm{N}}:=\operatorname{tval}_{\mathrm{N}-1} \cdot 1.5$

$\operatorname{tval}_{\mathrm{N}}=0.525$

Updated 7 May 2013 - correct point errors, duplicates every NP points

$\operatorname{tdf}_{0,0}:=0$

$\operatorname{tdf}_{0,1}:=0$

$m:=0$

First segment

$\operatorname{tdf}_{N P} \cdot \mathrm{m}+\mathrm{k}, 0:=\operatorname{tval}_{\mathrm{m}}+\left(\mathrm{tval}_{\mathrm{m}+1}-\mathrm{tval}_{\mathrm{m}}\right) \cdot \frac{\mathrm{k}}{\mathrm{NP}}$

$\operatorname{tdf}_{\mathrm{NP}} \cdot \mathrm{m}+\mathrm{k}, 1:=\mathrm{d}\left(\operatorname{tdf}_{\mathrm{NP}} \cdot \mathrm{m}+\mathrm{k}, 0\right)$

$m:=1 \quad$ Second segment

$\operatorname{tdf}_{N P} \cdot \mathrm{m}+\mathrm{k}, 0:=\operatorname{tval}_{\mathrm{m}}+\left(\mathrm{tval}_{\mathrm{m}+1}-\mathrm{tval}_{\mathrm{m}}\right) \cdot \frac{\mathrm{k}}{\mathrm{NP}}$

$\operatorname{tdf}_{\mathrm{NP}} \cdot \mathrm{m}+\mathrm{k}, 1:=\mathrm{d}\left(\operatorname{tdf}_{\mathrm{NP}} \cdot \mathrm{m}+\mathrm{k}, 0\right)$

$m:=2 \quad$ Third segment

$\operatorname{tdf}_{N P \cdot m+k, 0}:=\operatorname{tval}_{m}+\left(\operatorname{tval}_{m+1}-\operatorname{tval}_{m}\right) \cdot \frac{k}{N P}$

$\operatorname{tdf}_{\mathrm{NP}} \cdot \mathrm{m}+\mathrm{k}, 1:=\mathrm{d}\left(\operatorname{tdf}_{\mathrm{NP}} \cdot \mathrm{m}+\mathrm{k}, 0\right)$

$m:=3 \quad$ Fourth segment

$\operatorname{tdf}_{N P} \cdot m+k, 0:=\operatorname{tval}_{m}+\left(\right.$ tval $_{m+1}-$ tval $\left._{m}\right) \cdot \frac{k}{N P}$

$\operatorname{tdf}_{\mathrm{NP}} \cdot \mathrm{m}+\mathrm{k}, 1:=\mathrm{d}\left(\operatorname{tdf}_{\mathrm{NP}} \cdot \mathrm{m}+\mathrm{k}, 0\right)$

$m:=4 \quad$ Fifth segment

$\operatorname{tdf}_{N P} \cdot \mathrm{m}+\mathrm{k}, 0:=\operatorname{tval}_{\mathrm{m}}+\left(\mathrm{tval}_{\mathrm{m}+1}-\mathrm{tval}_{\mathrm{m}}\right) \cdot \frac{\mathrm{k}}{\mathrm{NP}}$

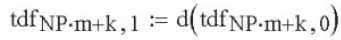

$m:=5 \quad$ Sixth segment

$\operatorname{tdf}_{\mathrm{NP} \cdot \mathrm{m}+\mathrm{k}, 0}:=\mathrm{tval}_{\mathrm{m}}+\left(\mathrm{tval}_{\mathrm{m}+1}-\mathrm{tval}_{\mathrm{m}}\right) \cdot \frac{\mathrm{k}}{\mathrm{NP}}$

$\operatorname{tdf}_{\mathrm{NP}} \cdot \mathrm{m}+\mathrm{k}, 1:=\mathrm{d}\left(\operatorname{tdf}_{\mathrm{NP}} \cdot \mathrm{m}+\mathrm{k}, 0\right)$

$\operatorname{tdf}_{1,0}:=\operatorname{tval}_{1} \cdot 10^{-3} \quad \operatorname{tdf}_{1,1}:=\operatorname{tdf}_{1,0} \cdot \mathrm{v0}$

$\operatorname{tdf}_{1,0}=4.8 \times 10^{-5}$

$\operatorname{tdf}_{1,1}=-6.985 \times 10^{-3}$ tdf is a pairwise set of time and displacement

first point is obvious, second point sets initial velocity subsequent points are the data of interest 
Displacement (in) Versus Time - Use In ANSYS Run

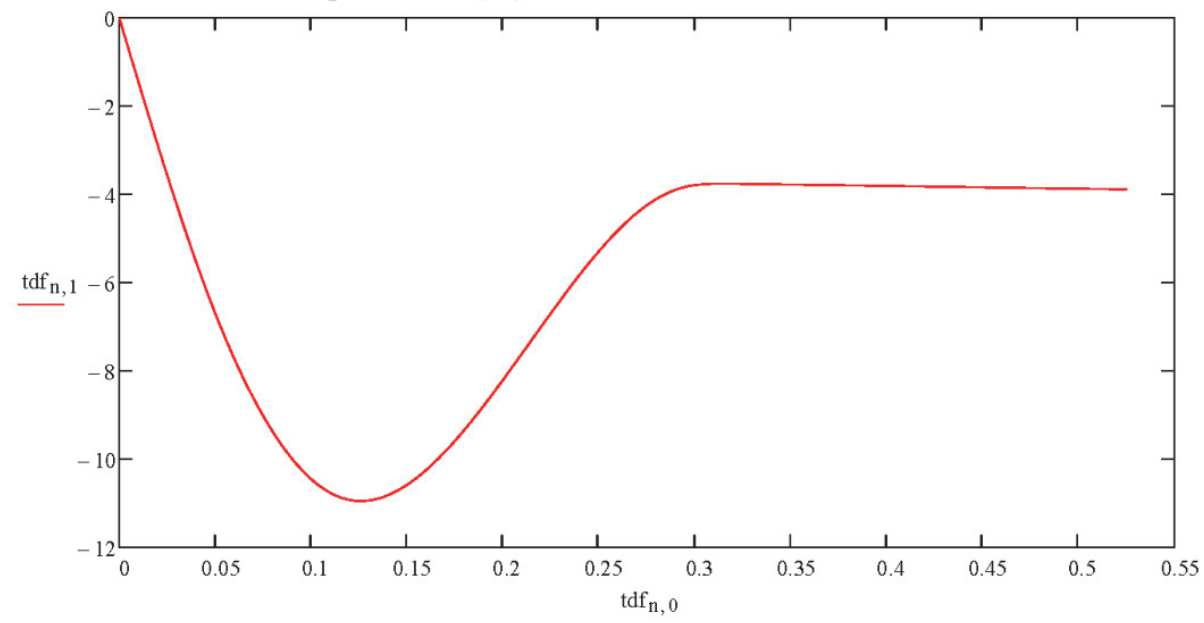

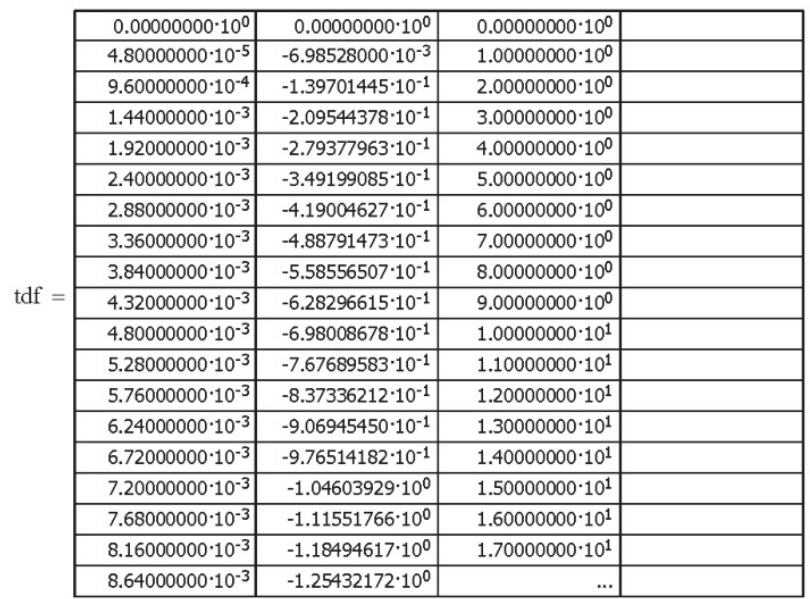

out := WRITEPRN ("HCCC_transient.prn" ,tdf)

Write text file with time, displacement, point number $(0-600)$

Now create a 2nd file with displacement, velocity (in/s), acceleration (in/s2), velocity (mph), acceleration (g's)

$\mathrm{k}:=0 . .600$

$$
\begin{array}{ll}
\operatorname{tdf}_{\mathrm{k}, 2}:=\mathrm{v}\left(\operatorname{tdf}_{\mathrm{k}, 0}\right) & \operatorname{tdf}_{\mathrm{k}, 3}:=\mathrm{a}\left(\operatorname{tdf}_{\mathrm{k}, 0}\right) \\
\operatorname{tdf}_{\mathrm{k}, 4}:=\mathrm{v}\left(\operatorname{tdf}_{\mathrm{k}, 0)}\right) \cdot \mathrm{VelConv}^{-1} & \operatorname{tdf}_{\mathrm{k}, 5}:=\mathrm{a}\left(\operatorname{tdf}_{\mathrm{k}, 0}\right) \cdot
\end{array}
$$$$
\operatorname{tdf}_{\mathrm{k}, 5}:=\mathrm{a}\left(\operatorname{tdf}_{\mathrm{k}, 0}\right) \cdot 386.4^{-1} \quad \operatorname{tdf}_{\mathrm{k}, 6}:=\mathrm{k}
$$

out : = WRITEPRN $($ "HCCC_transient_all.prn" ,tdf $)$

Write text file with time, displacement, velocity (in/s), acceleration (in/s $\mathrm{s}^{2}$ ), velocity ( $\mathrm{mph}$ ), acceleration ( $\mathrm{g}$ 's), point number $(0-600)$ 


\section{LIST OF REFERENCES}

ANSYS (2008) "ANSYS Mechanical APDL - Help Documents (v. 11.0)."

R.D. Bradshaw and J.W. Borden (uncredited) (2009). Fiberglass Panel Materials Research Report: Harbormaster Command and Control Center (HCCC) [Report to Kentucky Trailer, 17 July 2009], University of Louisville.

R.D. Bradshaw and J.K. McCoy (uncredited) (2008). Dowel Mount Analysis For Rail Impact Test: Harbormaster Command and Control Center (HCCC) [Report to Kentucky Trailer, 9 May 2008], University of Louisville.

R.D. Bradshaw and G.P. Prater Jr. (2006). A Whitepaper On University Of Louisville Participation In A Project To Develop A C-130 Deployable Command Post For The U.S. Army (report on 13 Feb 2006 to US Army CERDEC / Kentucky Trailer Corp.).

R.D. Bradshaw and G.P. Prater Jr. (2007). Structural Analysis and Design Optimization of the Harbormaster Command and Control Center (HCCC) [Proposal to Kentucky Trailer Corporation, 11 Jan 2007].

R.D. Bradshaw and J.D. Watson (uncredited) (2008). C17 Certification Analysis: Harbormaster Command and Control Center (HCCC) [Report to Kentucky Trailer, 26 July 2008], University of Louisville.

Department of Defense (1985). Designing for Internal Aerial Delivery in Fixed Wing Aircraft. MIL-STD-1791. Washington, D.C.

ATC Rail Impact Facility (2005 approx.). 2.5 Shock, Rail Impact, Mounted Shelter [Section from larger document about rail impact testing of HMMWV (highmobility multipurpose wheeled vehicle) performed at ATC Rail Impact Facility at Aberdeen Proving Ground (APG), Maryland; provided by Kentucky Trailer].

Forest Products Laboratory. (1964). "Bending Strength of Plywood (U.S. Forest Service Research Note FPL-059)." Retrieved June 8, 2008, from http://www.fpl.fs.fed.us/documnts/fplrn/fplrn059a.pdf http://tinyurl.com/lbzpkt6).

J.E. Mandt and R.D. Bradshaw (2008). Composite Materials Research Report: Harbormaster Command and Control Center (HCCC) [Report to Kentucky Trailer, 29 April 2008], University of Louisville.

Matweb. (2006, June 8, 2008). "Metal Alloy Elemental Composition Search." Retrieved June 8, 2008, from http://matweb.com/search/CompositionSearch.aspx (or http://tinyurl.com/m97d3ko). 
R. Ramsdale. (2006, July 24, 2006). "Reference Tables - Aluminum Temper Designations (Engineer's Handbook)." Retrieved June 8, 2008, from http://www.engineershandbook.com/Tables/alumtemper.htm $\quad$ (or http://tinyurl.com/lfdr5ls).

J.D. Watson and R.D. Bradshaw (2009). Harbormaster Command and Control Center (HCCC): ANSYS Finite Element Model - Aluminum Shelter [Report to Kentucky Trailer, 8 May 2009], University of Louisville. 


\title{
VITA
}

\author{
Name: Justin Daniel Watson \\ Address: $\quad 11$ Cassotta Lane \\ Suffield, CT 06078 \\ DOB: $\quad$ Henderson, Kentucky - December 6, 1983 \\ Education: B.S., Mechanical Engineering \\ University of Louisville \\ 2002-2006
}

